FLÁVIO BOMFIM MARIANA

ANÁLISE NUMÉRICA DA INFLUÊNCIA DE CONFIGURAÇÕES DE ABERTURAS DA FACHADA E DO MOBILIÁRIO NA VENTILAÇÃO NATURAL EM AMBIENTES DE ESCRITÓRIOS

SÃO PAULO

2013 
FLÁVIO BOMFIM MARIANA

\section{ANÁLISE NUMÉRICA DA INFLUÊNCIA DE CONFIGURAÇÕES DE ABERTURAS DA FACHADA E DO MOBILIÁRIO NA VENTILAÇÃO} NATURAL EM AMBIENTES DE ESCRITÓRIOS

Dissertação de Mestrado apresentada à Escola Politécnica da Universidade de São Paulo para obtenção do título de Mestre em Engenharia

Área de Concentração:

Engenharia Mecânica

Orientador:

Prof. Dr. Arlindo Tribess

SÃO PAULO 
Este exemplar foi revisado e alterado em relação à versão original, sob responsabilidade única do autor e com anuência de seu orientador.

São Paulo, 17 de junho de 2013

Assinatura do Autor

Assinatura do Orientador

\section{FICHA CATALOGRÁFICA}

Mariana, Flávio Bomfim

Análise numérica da influência de configurações de aberturas da fachada e do mobiliário na ventilação natural em ambientes de escritórios. Flávio Bomfim Mariana - ed. rev. - São Paulo, 2013.

196p.

Dissertação (Mestrado) - Escola Politécnica da Universidade de São Paulo. Departamento de Engenharia Mecânica.

1. Ventilação natural 2. CFD 3. Conforto térmico 4. Ambientes de escritórios I. Universidade de São Paulo. Escola Politécnica. Departamento de Engenharia Mecânica II. t 
Aos meus pais Richard e Regina, aos meus irmãos Fernando e Marcelo, e à Michelle. 


\section{AGRADECIMENTOS}

Agradeço aos meus pais, que foram, são e serão sempre exemplo de vida para mim. Sem seu carinho, ensinamentos e apoio incondicional certamente este momento não teria ocorrido. Aos meus irmãos Fernando e Marcelo, que mesmo de longe ensinam valiosas lições sobre a vida.

Ao meu orientador professor Dr. Arlindo Tribess, por acreditar no meu potencial desde o início do trabalho e por sua disponibilidade para orientar, questionar, tirar dúvidas, criar dúvidas e discutir também os aspectos sociais e comportamentais que permeiam a vida.

À professora Dra. Brenda Chaves Coelho Leite e à professora Dra. Denise Helena Silva Duarte, pelas importantes contribuições para o desenvolvimento do trabalho. Ao professor Dr. Alberto Hernandez Neto e ao professor Dr. Fábio Saltara, meus orientadores na graduação.

Ao engenheiro M.Sc. Tales Adriano Ferreira, pelos ensinamentos no uso dos programas de CFD. Obrigado pelas discussões e conselhos, especialmente quando as simulações "davam pau", sua contribuição foi fundamental para este trabalho.

À arquiteta M.Sc. Thais Aya Hassan Inatomi, pela sugestão de desenvolver trabalho no tema da dissertação e pela ajuda no início desta longa caminhada. Ao engenheiro Dr. Sandro Tavares Conceição pelas dicas de modelagem do problema.

Ao meu supervisor na Volkswagen do Brasil, o engenheiro M.Sc. Leandro Vieira da Silva Macedo, por incentivar o desenvolvimento de seus funcionários. Seu apoio foi muito importante para a realização deste trabalho. À minha antiga gerente, a engenheira Juliana Gonçalves Vieira Malho, por também incentivar o desenvolvimento dos seus funcionários.

À minha noiva Michelle, por compartilhar comigo todos os caminhos da vida. Seu carinho, amor, paciência e incentivo deram-me muita força nos momentos mais difíceis deste trabalho.

A todos os amigos e colegas que da sua forma me ajudaram neste projeto.

Por fim, a Deus, pela força para enfrentar os desafios da vida e oportunidade de desfrutá-la. 
Eu não sei como eu posso parecer ao mundo, mas para mim, eu pareço ser apenas como uma criança brincando na beira do mar, divertindo-me e encontrando um seixo mais liso ou uma concha mais bonita do que o ordinário, enquanto o grande oceano da verdade permanece todo indescoberto diante de mim.

Issac Newton 


\section{RESUMO}

\section{MARIANA, F. B. Análise numérica da influência de configurações de aberturas da}

fachada e do mobiliário na ventilação natural em ambientes de escritórios. 2013. 196p. Dissertação (Mestrado em Engenharia Mecânica de Energia e Fluidos) - Escola Politécnica, Universidade de São Paulo, 2013.

Com a disseminação do conceito de desenvolvimento sustentável tem sido verificado um aumento no interesse por sistemas de baixo ou nenhum consumo de energia. Uma forma de diminuir o consumo e propiciar condições de qualidade do ar e conforto térmico é utilizar a ventilação natural. No presente trabalho analisa-se a influência de diferentes tipos de janelas e mobiliário sobre as condições de ventilação natural em ambientes de escritório utilizando simulação numérica. O modelo é composto por um edifício de cinco pavimentos, sendo analisadas as condições térmicas do pavimento mais alto. A mudança do mobiliário apresentou tendência de piora das condições de conforto com o aumento das partições, sendo significativa com partições de $1,50 \mathrm{~m}$ de altura e as demais condições menos propícias para a ventilação natural. Não foi observada mudança significativa entre as partições de $0,90 \mathrm{~m}$ e 1,10m, sendo preferível então a última pela melhor privacidade dos ocupantes. A modificação do layout não resultou em mudanças significativas de temperatura do ar no ambiente ocupado, salvo na configuração que reuniu as piores condições de ventilação. Já a geometria das janelas apresentou resultados significativamente diferentes, pois a janela maxim-ar permitiu a entrada de um volume maior de ar e o distribuiu melhor dentro dos ambientes de escritório simulados, em comparação com a janela de correr vertical. Verificou-se que a escolha adequada das janelas influencia o ambiente térmico de maneira semelhante à redução da iluminação e dos equipamentos que dissipam calor. Concluiu-se que com a implantação adequada da edificação, escolha correta das aberturas, da configuração do mobiliário e das cargas térmicas internas é possível utilizar sistemas de ventilação natural em ambientes de escritórios com bons resultados. Por fim, é importante destacar que a aplicação da dinâmica dos fluidos computacional (CFD) para ventilação natural é complexa, pois este fenômeno é naturalmente instável, com necessidade de bastante cuidado na definição dos modelos para representar o problema e no processo de simulação numérica.

Palavras-chave: Ventilação natural. CFD. Conforto térmico. Ambientes de escritórios. 


\begin{abstract}
MARIANA, F. B. Numerical analysis of the influence of façade openings and furniture configurations on natural ventilation in office environments. 2013. 196p. M. Sc. Thesis Escola Politécnica, Universidade de São Paulo, 2013.

Among the spread of the sustainability concept it has been found a rising interest on low or zero energy consumption systems. One approach to reduce energy consumption and also provide acceptable levels of indoor air quality and thermal comfort is using natural ventilation. On the present report it is analyzed the influence of different types of windows and furniture on natural ventilation conditions of office environments using numerical simulation. The model is a five storey building, being the thermal conditions evaluated in the highest floor. Furniture change presented a worsen tendency of the comfort conditions as the partitions height increased. This worsen was significant when $1.50 \mathrm{~m}$ height partitions were combined with other features less propitious for natural ventilation. No significant change was found between the $0.90 \mathrm{~m}$ and $1.10 \mathrm{~m}$ height partitions, being the last preferable due to occupants privacy enhance. Layout modification did not result on significant changes of occupied zone air temperature, except on the set up that gathered the worse ventilation conditions. However, the different window geometries presented results significantly different, since the maxim-air window allowed the entrance of more wind and has distributed it better inside the simulated office environments. Therefore, thermal comfort conditions became better than in comparison with the vertical sliding windows. It was verified that the adequate choice of windows influences the thermal environment in a similar way to the reduction of lighting and equipments that dissipate heat. It was concluded that with the proper building implementation, correct choice of openings, furniture configuration and internal heat gains it is possible to use natural ventilation in office environments with good results. Finally, it is noteworthy the complexity in applying the computational fluid dynamics (CFD) for natural ventilation, since it is an inherently unstable phenomenon, requiring considerable care in defining the models to represent the problem and in the numerical simulation process.
\end{abstract}

Keywords: Natural ventilation. CFD. Thermal comfort. Office environments. 


\section{LISTA DE FIGURAS}

Figura 2.1.1: Representação do fluxo de ar devido ao gradiente de temperatura (Adaptado de

CIBSE, 2005) 40

Figura 2.1.2: Fluxo de ar em função da posição da linha de pressão neutra (Adaptado de CIBSE, 2005)

Figura 2.1.3: Variação de altura da NPL em decorrência de altura e geometria das aberturas (YARKE, 2005).

Figura 2.1.4: Aplicação do efeito chaminé em um projeto de edificação com três pavimentos (CIBSE, 2005).

Figura 2.1.5: Estratégias para mudança da altura da linha de pressão neutra (ALLARD; GHIAUS, 2005).

Figura 2.1.6: Pressão de empuxo e NPL para edificação com zonas verticais desconectadas (adaptado de AWBI, 2003).

Figura 2.1.7: Esteira formada ao redor de edificação por incidência de ventos (FADIGAS, 2010).

Figura 2.1.8: Perfis de velocidades da camada limite atmosférica em diferentes tipos de terrenos

(adaptado de YARKE, 2005) 45

Figura 2.1.9: Distribuição esquemática de pressão ao redor de um edifício (adaptado de YARKE, 2005). 45

Figura 2.1.10: Fluxos padrão ao redor de uma edificação retangular (adaptado de ASHRAE, 2009). 46

Figura 2.1.11: Fluxos padrão em superfícies e dimensões da edificação (adaptado de WILSON, 1979).

Figura 2.1.12: Coeficientes de pressão médios para fachadas de edifícios altos (adaptado de AKINS, PETERKA, CEMAK, 1979). 48 
Figura 2.2.1: Representação da área de abertura efetiva para janela tipo maxim-ar (MARCONDES, 2010).

Figura 2.2.2: Tipos de aberturas (adaptado de ROULET, 2004).

Figura 2.2.3: Influência da abertura de janela basculante superior e inferior sobre o escoamento - totalmente aberta (a) e parcialmente fechada (b) (ALLARD, 1998).

Figura 2.2.4: Aplicações da janela pivotante horizontal em ventilação unilateral e cruzada (adaptado de AWBI, 2003). .54

Figura 2.2.5: Chaminé solar (AWBI, 2003). 55

Figura 2.4.1: Ambiente com ventilação unilateral e aberturas duplas (KENDRICK; MARTIN; BOOTH, 1998). 60

Figura 2.4.2: Profundidade do ambiente em função do pé-direito para ventilação unilateral com abertura simples (CIBSE, 2005).

Figura 2.4.3: Profundidade do ambiente em função do pé-direito para ventilação unilateral com abertura dupla (adaptado de CIBSE, 2005).

Figura 2.4.4: Ambiente com ventilação cruzada (KENDRICK; MARTIN; BOOTH, 1998). .62 Figura 2.4.5: Profundidade do ambiente em função do pé-direito para ventilação cruzada (CIBSE, 2005).

Figura 2.4.6: Diferença do caminho do ar dentro de um ambiente ventilado unilateralmente com efeito mais próximo ao da ventilação cruzada (Adaptado de YARKE, 2005). .64

Figura 3.1.1: Formulação da equação da continuidade para elemento bidimensional .............66

Figura 3.2.1: Típica medição de velocidade em ponto de um escoamento turbulento.............71

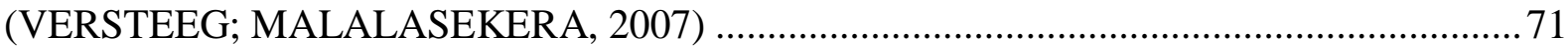

Figura 3.3.1: Dormitório analisado por Alloca, Chen e Glicksman (2003). ...........................80

Figura 3.3.2: Modelo da edificação utilizada por Evola e Popov (adaptado de EVOLA; POPOV, 2006)

Figura 3.3.3: Perfil de velocidades no plano a 90cm do piso (FIGUEIREDO, 2007). 82

Figura 3.3.4: Perfil de temperatura no interior do edifício analisado por Figueiredo (2007). .82

Figura 4.1.1: Planta utilizada por Gratia, Bruyère e De Herde (2004). 84 
Figura 4.1.2: Vista externa das janelas dos escritórios analisados por Gratia, Bruyère e De Herde (2004).

Figura 4.1.3: Vista das partições e aberturas internas utilizadas por Gratia, Bruyère e De

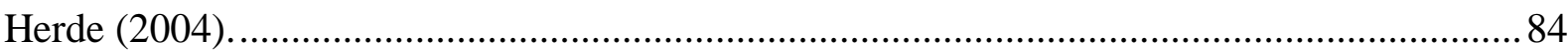

Figura 4.1.4: Corte do escritório simulado por Gratia, Bruyère e De Herde (2004)...............85

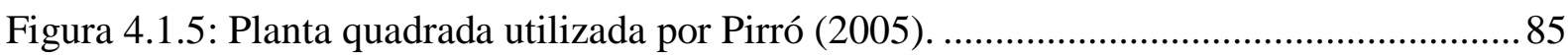

Figura 4.1.6: Perspectiva do modelo de edificação utilizado por Benedetto (2007) ................86

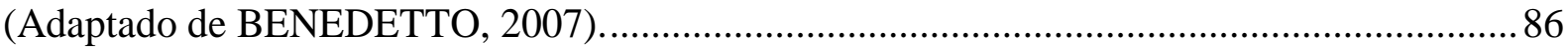

Figura 4.1.7: Planta baixa do modelo M2 utilizado por Benedetto (2007) ............................ 86

Figura 4.1.8: Planta baixa do modelo M3 utilizado por Benedetto (2007) ............................ 87

Figura 4.1.9: Cortes esquemáticos dos modelos M2 (a) e M3 (b) utilizados por Benedetto (2007).

Figura 4.1.10: Planta quadrada utilizada por Figueiredo (2007) (Adaptado de FIGUEIREDO, 2007) 88

Figura 4.1.11: Corte do modelo utilizado por Figueiredo (2007) (Adaptado de FIGUEIREDO,

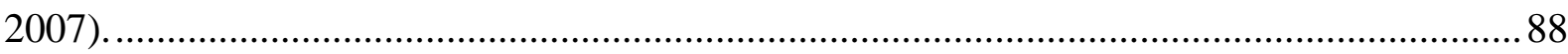

Figura 4.1.12: Perspectiva do pavimento tipo utilizado por Figueiredo (2007).....................89

Figura 4.1.13: Planta retangular utilizada por Marcondes (2010).......................................90

Figura 4.1.14: Planta quadrada utilizada por Marcondes (2010). ........................................90

Figura 4.1.15: Planta retangular utilizada nas simulações...................................................91

Figura 4.1.16: Vista em perspectiva da edificação utilizada nas análises numéricas...............91

Figura 4.1.17: Dimensões principais das aberturas e seu posicionamento na fachada. ...........92

Figura 4.2.1: Domínio utilizado nas simulações de Evola e Popov (2006).............................93

Figura 4.2.2: Domínio de base retangular utilizado por Cóstola (2006)................................93

Figura 4.2.3: Domínio utilizado por Figueiredo (2007). ....................................................94

Figura 4.2.4: Representação do domínio utilizado no trabalho.............................................94

Figura 4.3.1: Malha utilizada para escoamento ao redor de um cilindro. ..............................96 
Figura 4.3.2: Comparação dos resultados com diferentes critérios de convergência.

Figura 4.3.3: Ilustração qualitativa da influência dos parâmetros de subrelaxação na solução numérica em regime permanente de um fenômeno naturalmente transiente.

Figura 4.4.1: Frequência de ocorrência de direção e velocidade do vento ao longo do ano de referência, com dados coletados na cidade de São Paulo, SP, de 2003 a2005 (BENEDETTO, 2007).

Figura 4.4.2: Frequência de ocorrência do vento em São Paulo por estação do ano obtida do programa SOL-AR, do LabEEE da UFSC, com dados coletados de 1951 a 1970. 101

Figura 4.4.3: Sobreposição do perfil real e médio de velocidades do vento 102 (Adaptado de MANWELL; MCGOWAN; ROGERS, 2009). 102

Figura 4.4.4: Distribuição das lâmpadas no ambiente de escritório. 104

Figura 4.4.5: Lâmpadas (em vermelho) que permaneceram acesas na modificação da densidade de potência de iluminação. 105

Figura 4.4.5: Domínio efetivamente utilizado no trabalho. 106

Figura 4.5.1: Geometrias analisadas de janelas (adaptado de CIBSE, 2005). 107

Figura 4.5.2: Modelagem das janelas maxim-ar. 108

Figura 4.5.3: Dimensões do modelo utilizado da janela maxim-ar. 109

Figura 4.5.4: Modelagem das janelas de correr vertical.

Figura 4.5.5: Dimensões do modelo utilizado da janela de correr vertical. 109

Figura 4.5.5: Estação de trabalho com partições de 1,50m.

Figura 4.5.6: Superfícies de trabalho em "L" dispostas em formato "C". 111

Figura 4.5.7: Layout quadrado utilizado nas simulações. 112

Figura 4.5.8: Layout em linha utilizado nas simulações. 112

Figura 4.6.1: Faixas de temperaturas operativas aceitáveis para conforto em ambientes ventilados naturalmente (adaptado de ASHRAE, 2010). 114

Figura 4.6.2: Pontos de medição da temperatura do ar ao redor de um ocupante. 115

Figura 4.6.3: Ocupantes insatisfeitos versus diferença vertical de temperatura (adaptado de ASHRAE, 2010). 116 
Figura 4.6.4: Equações para ventilação do ambiente por ação da pressão do vento (adaptado de BSI, 1991).

Figura 4.6.5: Equações para ventilação do ambiente por ação gradiente de temperaturas (adaptado de BSI, 1991).

Figura 4.6.6: Equações para ventilação do ambiente por ação combinada da pressão do vento e gradiente de temperaturas (adaptado de BSI, 1991).

Figura 4.6.7: Perfil de temperaturas do ar em um plano vertical no domínio do escritório...118 Figura 4.6.8: Perfil de velocidades do ar em um plano horizontal no domínio do escritório. 119 Figura 4.6.8: Perfil de velocidades em um plano horizontal no domínio do escritório 120

Figura 5.1.1: Malhas volumétricas com taxa de crescimento 1,3 (a), 1,6 (b) e 1,9 (c) utilizada nos escritórios.

Figura 5.3.1: Plano vertical $\mathrm{y}=-12,65 \mathrm{~m}$ colorido por velocidade com os respectivos vetores para o layout quadrado com partições de $0,90 \mathrm{~m}$, janelas de correr vertical e velocidade máxima do ar de $2 \mathrm{~m} / \mathrm{s}$

Figura 5.3.2: Plano vertical $\mathrm{y}=-12,65 \mathrm{~m}$ colorido por velocidade com os respectivos vetores para o layout quadrado com partições de $1,50 \mathrm{~m}$, janelas de correr vertical e velocidade máxima do ar de $2 \mathrm{~m} / \mathrm{s}$ 128

Figura 5.3.3: Plano horizontal $\mathrm{z}=1,10 \mathrm{~m}$ colorido por temperatura para o layout quadrado com partições de $0,90 \mathrm{~m}$, janelas de correr vertical e velocidade máxima do ar de $2 \mathrm{~m} / \mathrm{s}$. 128

Figura 5.3.4: Plano horizontal $\mathrm{z}=1,10 \mathrm{~m}$ colorido por temperatura para o layout quadrado com partições de $1,50 \mathrm{~m}$, janelas de correr vertical e velocidade máxima do ar de $2 \mathrm{~m} / \mathrm{s}$.

Figura 5.3.5: Plano vertical $\mathrm{y}=-13,20 \mathrm{~m}$ colorido por velocidade com os respectivos vetores para o layout quadrado com partições de $0,90 \mathrm{~m}$, janelas de correr vertical e velocidade máxima do ar de $2 \mathrm{~m} / \mathrm{s}$

Figura 5.3.6: Plano vertical $\mathrm{y}=-13,20 \mathrm{~m}$ colorido por velocidade com os respectivos vetores para o layout quadrado com partições de $1,50 \mathrm{~m}$, janelas de correr vertical e velocidade máxima do ar de $2 \mathrm{~m} / \mathrm{s}$

Figura 5.3.7: Plano horizontal $\mathrm{z}=1,10 \mathrm{~m}$ colorido por temperatura para o layout em linha com partições de $0,90 \mathrm{~m}$, janelas de correr vertical e velocidade máxima do ar de $2 \mathrm{~m} / \mathrm{s}$. 
Figura 5.3.8: Plano horizontal $\mathrm{z}=1,10 \mathrm{~m}$ colorido por temperatura para o layout em linha com partições de $1,50 \mathrm{~m}$, janelas de correr vertical e velocidade máxima do ar de $2 \mathrm{~m} / \mathrm{s}$.

Figura 5.4.1: Plano vertical $\mathrm{y}=-06,00 \mathrm{~m}$ colorido por temperatura para o layout quadrado com partições de $1,50 \mathrm{~m}$, janelas de correr vertical e velocidade máxima do ar de $2 \mathrm{~m} / \mathrm{s}$.

Figura 5.4.2: Plano vertical $\mathrm{y}=-05,90 \mathrm{~m}$ colorido por temperatura para o layout em linha com partições de $1,50 \mathrm{~m}$, janelas de correr vertical e velocidade máxima do ar de $2 \mathrm{~m} / \mathrm{s}$. 135

Figura 5.4.3: Plano vertical $\mathrm{x}=06,90 \mathrm{~m}$ colorido por temperatura para o layout quadrado com partições de $1,50 \mathrm{~m}$, janelas de correr vertical e velocidade máxima do ar de $2 \mathrm{~m} / \mathrm{s}$.

Figura 5.4.4: Plano vertical $\mathrm{x}=05,15 \mathrm{~m}$ colorido por temperatura para o layout em linha com partições de $1,50 \mathrm{~m}$, janelas de correr vertical e velocidade máxima do ar de $2 \mathrm{~m} / \mathrm{s}$. 136

Figura 5.4.5: Plano vertical $\mathrm{x}=02,30 \mathrm{~m}$ colorido por temperatura para o layout quadrado com partições de 1,50m, janelas de correr vertical e velocidade máxima do ar de $2 \mathrm{~m} / \mathrm{s}$.

Figura 5.4.6: Plano vertical $\mathrm{x}=01,80 \mathrm{~m}$ colorido por temperatura para o layout em linha com partições de $1,50 \mathrm{~m}$, janelas de correr vertical e velocidade máxima do ar de $2 \mathrm{~m} / \mathrm{s}$.

Figura 5.4.7: Plano vertical $\mathrm{y}=-12,65 \mathrm{~m}$ colorido por velocidade com os respectivos vetores para o layout quadrado com partições de $1,50 \mathrm{~m}$, janelas de correr vertical e velocidade máxima do ar de $2 \mathrm{~m} / \mathrm{s}$ 138

Figura 5.4.8: Plano vertical $\mathrm{y}=-13,20 \mathrm{~m}$ colorido por velocidade com os respectivos vetores para o layout em linha com partições de $1,50 \mathrm{~m}$, janelas de correr vertical e velocidade máxima do ar de $2 \mathrm{~m} / \mathrm{s}$

Figura 5.4.9: Plano vertical $\mathrm{y}=-13,20 \mathrm{~m}$ colorido por velocidade com os respectivos vetores para o layout quadrado com partições de $1,50 \mathrm{~m}$, janelas maxim-ar e velocidade máxima do ar de $4 \mathrm{~m} / \mathrm{s}$

Figura 5.4.10: Plano vertical $\mathrm{y}=-13,20 \mathrm{~m}$ colorido por velocidade com os respectivos vetores para o layout em linha com partições de 1,50m, janelas maxim-ar e velocidade máxima do ar de $4 \mathrm{~m} / \mathrm{s}$

Figura 5.4.11: Plano vertical $\mathrm{x}=06,90 \mathrm{~m}$ colorido por temperatura para o layout quadrado com partições de 1,50m, janelas maxim-ar e velocidade máxima do ar de $4 \mathrm{~m} / \mathrm{s}$.

Figura 5.4.12: Plano vertical $\mathrm{x}=05,15 \mathrm{~m}$ colorido por temperatura para o layout em linha com partições de 1,50m, janelas maxim-ar e velocidade máxima do ar de $4 \mathrm{~m} / \mathrm{s}$. 140 
Figura 5.5.1: Plano vertical $y=-03,20 \mathrm{~m}$ colorido por temperatura com vetores de velocidade para o layout quadrado com partições de $1,50 \mathrm{~m}$, janelas maxim-ar e velocidade máxima do ar de $2 \mathrm{~m} / \mathrm{s}$

Figura 5.5.2: Plano vertical y $=-03,20 \mathrm{~m}$ colorido por temperatura com vetores de velocidade para o layout quadrado com partições de $1,50 \mathrm{~m}$, janelas de correr vertical e velocidade máxima do ar de $2 \mathrm{~m} / \mathrm{s}$ 143

Figura 5.5.3: Plano vertical $\mathrm{x}=06,90 \mathrm{~m}$ colorido por temperatura com vetores de velocidade para o layout quadrado com partições de $1,50 \mathrm{~m}$, janelas maxim-ar e velocidade máxima do ar de $2 \mathrm{~m} / \mathrm{s}$

Figura 5.5.4: Plano vertical $\mathrm{x}=06,90 \mathrm{~m}$ colorido por temperatura com vetores de velocidade para o layout quadrado com partições de $1,50 \mathrm{~m}$, janelas de correr vertical e velocidade máxima do ar de $2 \mathrm{~m} / \mathrm{s}$

Figura 5.5.5: Plano vertical y $=-02,50 \mathrm{~m}$ colorido por temperatura com vetores de velocidade para o layout em linha com partições de 1,10m, janelas maxim-ar e velocidade máxima do ar de $4 \mathrm{~m} / \mathrm{s}$ 146

Figura 5.5.6: Plano vertical $\mathrm{y}=-02,50 \mathrm{~m}$ colorido por temperatura com vetores de velocidade para o layout em linha com partições de $1,10 \mathrm{~m}$, janelas de correr vertical e velocidade máxima do ar de $4 \mathrm{~m} / \mathrm{s}$

Figura 5.5.7: Plano vertical $\mathrm{x}=05,15 \mathrm{~m}$ colorido por temperatura com vetores de velocidade para o layout em linha com partições de $1,10 \mathrm{~m}$, janelas maxim-ar e velocidade máxima do ar de $4 \mathrm{~m} / \mathrm{s}$

Figura 5.5.8: Plano vertical $\mathrm{x}=05,15 \mathrm{~m}$ colorido por temperatura com vetores de velocidade para o layout em linha com partições de $1,10 \mathrm{~m}$, janelas de correr vertical e velocidade máxima do ar de $4 \mathrm{~m} / \mathrm{s}$

Figura 5.5.9: Plano vertical $\mathrm{y}=-02,50 \mathrm{~m}$ colorido por velocidade com os respectivos vetores para o layout quadrado com partições de $1,50 \mathrm{~m}$, janelas maxim-ar e velocidade máxima do ar de $2 \mathrm{~m} / \mathrm{s}$

Figura 5.5.10: Plano vertical $\mathrm{y}=-02,50 \mathrm{~m}$ colorido por velocidade com os respectivos vetores para o layout quadrado com partições de $1,50 \mathrm{~m}$, janelas de correr vertical e velocidade máxima do ar de $2 \mathrm{~m} / \mathrm{s}$ 
Figura 5.5.9: Plano vertical $\mathrm{y}=-02,50 \mathrm{~m}$ colorido por velocidade com os respectivos vetores para o layout quadrado com partições de $1,50 \mathrm{~m}$, janelas maxim-ar e velocidade máxima do ar de $2 \mathrm{~m} / \mathrm{s}$

Figura 5.5.10: Plano vertical y $=-02,50 \mathrm{~m}$ colorido por velocidade com os respectivos vetores para o layout quadrado com partições de $1,50 \mathrm{~m}$, janelas de correr vertical e velocidade máxima do ar de $2 \mathrm{~m} / \mathrm{s}$

Figura 5.6.1: Plano vertical $\mathrm{y}=-03,20 \mathrm{~m}$ colorido por temperatura com vetores de velocidade para o layout quadrado com partições de $1,50 \mathrm{~m}$, janelas de correr vertical e velocidade máxima do ar de $2 \mathrm{~m} / \mathrm{s}$

Figura 5.6.2: Plano vertical $\mathrm{y}=-03,20 \mathrm{~m}$ colorido por temperatura com vetores de velocidade para o layout quadrado com partições de $1,50 \mathrm{~m}$, janelas de correr vertical e velocidade máxima do ar de $4 \mathrm{~m} / \mathrm{s}$

Figura 5.6.3: Plano vertical $\mathrm{x}=02,30 \mathrm{~m}$ colorido por temperatura com vetores de velocidade para o layout quadrado com partições de $1,50 \mathrm{~m}$, janelas de correr vertical e velocidade máxima do ar de $2 \mathrm{~m} / \mathrm{s}$ 151

Figura 5.6.4: Plano vertical $\mathrm{x}=02,30 \mathrm{~m}$ colorido por temperatura com vetores de velocidade para o layout quadrado com partições de $1,50 \mathrm{~m}$, janelas de correr vertical e velocidade máxima do ar de $4 \mathrm{~m} / \mathrm{s}$ 152

Figura 5.6.5: Plano vertical $\mathrm{y}=-02,50 \mathrm{~m}$ colorido por temperatura para o layout em linha com partições de 1,50m, janelas maxim-ar e velocidade máxima do ar de $2 \mathrm{~m} / \mathrm{s}$.

Figura 5.6.6: Plano vertical $\mathrm{y}=-02,50 \mathrm{~m}$ colorido por temperatura para o layout em linha com partições de 1,50m, janelas maxim-ar e velocidade máxima do ar de $4 \mathrm{~m} / \mathrm{s}$.

Figura 5.6.7: Plano vertical $\mathrm{y}=-02,50 \mathrm{~m}$ colorido por velocidade com os respectivos vetores para o layout em linha com partições de 1,50m, janelas maxim-ar e velocidade máxima do ar de $2 \mathrm{~m} / \mathrm{s}$

Figura 5.6.8: Plano vertical $\mathrm{y}=-02,50 \mathrm{~m}$ colorido por velocidade com os respectivos vetores para o layout em linha com partições de $1,50 \mathrm{~m}$, janelas maxim-ar e velocidade máxima do ar de $4 \mathrm{~m} / \mathrm{s}$

Figura 5.6.9: Convergência da vazão de ar para a configuração com layout em linha, altura das partições de $1,10 \mathrm{~m}$, janelas maxim-ar e velocidade máxima do vento de $1 \mathrm{~m} / \mathrm{s}$. 155 
Figura 5.6.10: Convergência da temperatura para a configuração com layout em linha, altura das partições de $1,10 \mathrm{~m}$, janelas maxim-ar e velocidade máxima do vento de $1 \mathrm{~m} / \mathrm{s}$. 156

Figura 5.6.11: Convergência da vazão de ar para a configuração com layout em linha, altura das partições de $1,10 \mathrm{~m}$, janelas maxim-ar e velocidade máxima do vento de $2 \mathrm{~m} / \mathrm{s}$.

Figura 5.6.12: Convergência da temperatura para a configuração com layout em linha, altura das partições de $1,10 \mathrm{~m}$, janelas maxim-ar e velocidade máxima do vento de $2 \mathrm{~m} / \mathrm{s}$.

Figura 5.7.1: Plano horizontal $\mathrm{z}=1,10 \mathrm{~m}$ colorido por temperatura com vetores de velocidade para o layout em linha com partições de $1,10 \mathrm{~m}$, janelas maxim-ar, velocidade máxima do ar de $2 \mathrm{~m} / \mathrm{s}$ e carga térmica completa.

Figura 5.7.2: Plano horizontal $\mathrm{z}=1,10 \mathrm{~m}$ colorido por temperatura com vetores de velocidade para o layout em linha com partições de $1,10 \mathrm{~m}$, janelas maxim-ar, velocidade máxima do ar de $2 \mathrm{~m} / \mathrm{s}$ e carga térmica com maior redução.

Figura 5.7.3: Plano vertical $\mathrm{y}=-9,30 \mathrm{~m}$ colorido por temperatura com vetores de velocidade para o layout em linha com partições de $1,10 \mathrm{~m}$, janelas maxim-ar, velocidade máxima do ar de $2 \mathrm{~m} / \mathrm{s}$ e carga térmica completa.

Figura 5.7.4: Plano vertical $\mathrm{y}=-9,30 \mathrm{~m}$ colorido por temperatura com vetores de velocidade para o layout em linha com partições de $1,10 \mathrm{~m}$, janelas maxim-ar, velocidade máxima do ar de $2 \mathrm{~m} / \mathrm{s}$ e carga térmica com maior redução.

Figura 5.7.5: Plano vertical $\mathrm{y}=-2,50 \mathrm{~m}$ colorido por temperatura com vetores de velocidade para o layout em linha com partições de $1,10 \mathrm{~m}$, janelas maxim-ar, velocidade máxima do ar de $2 \mathrm{~m} / \mathrm{s}$, carga térmica completa e temperatura do ar exterior de $299,0 \mathrm{~K}$.

Figura 5.7.6: Plano vertical $\mathrm{y}=-2,50 \mathrm{~m}$ colorido por temperatura com vetores de velocidade para o layout em linha com partições de $1,10 \mathrm{~m}$, janelas maxim-ar, velocidade máxima do ar de $2 \mathrm{~m} / \mathrm{s}$, carga térmica completa e temperatura do ar exterior de $300,5 \mathrm{~K}$. 164

Figura 5.7.7: Plano vertical $\mathrm{y}=-2,50 \mathrm{~m}$ colorido por temperatura com vetores de velocidade para o layout em linha com partições de $1,10 \mathrm{~m}$, janelas maxim-ar, velocidade máxima do ar de $2 \mathrm{~m} / \mathrm{s}$, carga com maior redução e temperatura do ar exterior de $299,0 \mathrm{~K}$.

Figura 5.7.8: Plano vertical $\mathrm{y}=-9,30 \mathrm{~m}$ colorido por temperatura com vetores de velocidade para o layout em linha com partições de $1,10 \mathrm{~m}$, janelas maxim-ar, velocidade máxima do ar de $2 \mathrm{~m} / \mathrm{s}$ e carga térmica com maior redução. 
Figura 5.8.1: Ocupantes coloridos identificando condições de conforto térmico para o layout quadrado com partições de $1,50 \mathrm{~m}$, janelas de correr vertical e velocidade máxima do ar de $2 \mathrm{~m} / \mathrm{s}$.

Figura 5.8.2: Ocupantes coloridos identificando condições de conforto térmico para o layout em linha com partições de $0,90 \mathrm{~m}$, janelas maxim-ar e velocidade máxima do ar de $2 \mathrm{~m} / \mathrm{s}$... 168 Figura 5.8.3: Ocupantes coloridos identificando condições de conforto térmico para a configuração analisada com carga térmica máxima e temperatura do ar externo de $300,5 \mathrm{~K} .170$ Figura 5.8.4: Ocupantes coloridos identificando condições de conforto térmico para a configuração analisada com carga térmica mínima e temperatura do ar externo de 300,5K. 170 Figura 6.1.1: Detalhe do plano vertical $\mathrm{y}=-12,65 \mathrm{~m}$ colorido por velocidade com os respectivos vetores para o layout quadrado com partições de $1,10 \mathrm{~m}$, janelas de correr vertical e velocidade máxima do ar de $2 \mathrm{~m} / \mathrm{s}$

Figura 6.1.2: Plano vertical $\mathrm{y}=-13,20 \mathrm{~m}$ colorido por temperatura com os vetores de velocidade para o layout quadrado com partições de $1,50 \mathrm{~m}$, janelas de correr vertical e velocidade máxima do ar de $2 \mathrm{~m} / \mathrm{s}$.

Figura 6.1.3: Plano vertical $\mathrm{y}=-13,20 \mathrm{~m}$ colorido por temperatura com os vetores de velocidade para o layout em linha com partições de $1,50 \mathrm{~m}$, janelas de correr vertical e velocidade máxima do ar de $2 \mathrm{~m} / \mathrm{s}$. 


\section{LISTA DE TABELAS}

Tabela 4.3.1: Critérios de convergência adotados para a simulação numérica 97

Tabela 4.3.2: Parâmetros de subrelaxação utilizados 99

Tabela 4.4.1: Frequência de ocorrência de direção e velocidade do vento ao longo do ano de referência, SP (BENEDETTO, 2007)

Tabela 4.4.2: Média das temperaturas máximas e mínimas para a cidade de São Paulo, SP, de 2003 a 2005 (adaptado de BENEDETTO, 2007).

Tabela 4.4.3: Valores aproximados de comprimento de rugosidade para diversos tipos de terrenos (Adaptado de MANWELL; MCGOWAN; ROGERS, 2009).

Tabela 4.4.4: Elementos geradores de carga térmica utilizados neste trabalho. 104

Tabela 4.5.1: Alturas de divisórias segundo sua classificação (ABNT, 2003). 110

Tabela 5.1.1: Parâmetros quantitativos analisados para análise de independência de malha.123

Tabela 5.2.1: Dados utilizados para o cálculo analítica da vazão de ar dos escritórios com janelas de correr vertical.

Tabela 5.2.2: Comparação da vazão de ar calculada analiticamente e numericamente para os escritórios com janelas de correr vertical.

Tabela 5.3.1: Temperatura média do ar para velocidade do ar exterior máxima de $2 \mathrm{~m} / \mathrm{s} . \ldots . .125$

Tabela 5.3.2: Temperatura média do ar para velocidade do ar exterior máxima de $4 \mathrm{~m} / \mathrm{s} \ldots \ldots .125$

Tabela 5.3.3: Estratificação de temperatura entre pés e cabeça para velocidade do ar exterior máxima de $2 \mathrm{~m} / \mathrm{s}$.

Tabela 5.3.4: Estratificação de temperatura entre pés e cabeça para velocidade do ar exterior máxima de $4 \mathrm{~m} / \mathrm{s}$. 126

Tabela 5.3.5: Temperaturas médias, mínimas e máximas do ar nos três planos de medição para o layout quadrado com janelas de correr vertical e velocidade máxima do ar de $2 \mathrm{~m} / \mathrm{s} .127$ Tabela 5.3.6: Temperaturas médias, mínimas e máximas do ar nos três planos de medição para o layout em linha com janelas de correr vertical e velocidade máxima do ar de $2 \mathrm{~m} / \mathrm{s}$. . 129

Tabela 5.3.7: Vazão mássica de ar através das janelas para velocidade do ar de $2 \mathrm{~m} / \mathrm{s}$. 
Tabela 5.3.8: Vazão mássica de ar através das janelas para velocidade do ar de 4m/s

Tabela 5.4.1: Temperaturas médias, mínimas e máximas do ar nos três planos de medição para as configurações com janelas de correr vertical, alturas das partições de $1,50 \mathrm{~m}$ e velocidade máxima do ar de $2 \mathrm{~m} / \mathrm{s}$.

Tabela 5.4.2: Temperaturas médias, mínimas e máximas do ar nos três planos de medição para a terceira fileira dos escritórios com janelas de correr vertical, alturas das partições de 1,50m e velocidade máxima do ar de $2 \mathrm{~m} / \mathrm{s}$.

Tabela 5.4.3: Temperaturas médias, mínimas e máximas do ar nos três planos de medição para a primeira fileira dos escritórios com janelas de correr vertical, alturas das partições de $1,50 \mathrm{~m}$ e velocidade máxima do ar de $2 \mathrm{~m} / \mathrm{s}$.

Tabela 5.4.4: Temperaturas médias, mínimas e máximas do ar nos três planos de medição para a terceira fileira dos escritórios com janelas maxim-ar, alturas das partições de 1,50m e velocidade máxima do ar de $4 \mathrm{~m} / \mathrm{s}$.

Tabela 5.4.5: Temperaturas médias, mínimas e máximas do ar nos três planos de medição para as configurações com janelas maxim-ar, alturas das partições de 1,50m e velocidade máxima do ar de $4 \mathrm{~m} / \mathrm{s}$

Tabela 5.5.1: Temperaturas médias, mínimas e máximas do ar nos três planos de medição para as configurações com layout quadrado, alturas das partições de 1,50m e velocidade máxima do ar de $2 \mathrm{~m} / \mathrm{s}$

Tabela 5.5.2: Temperaturas médias em cada fileira das estações de trabalho para as configurações com layout quadrado, alturas das partições de $1,50 \mathrm{~m}$ e velocidade máxima do ar de $2 \mathrm{~m} / \mathrm{s}$

Tabela 5.6.1: Temperaturas médias em cada fileira das estações de trabalho para as configurações com layout quadrado, alturas das partições de $1,50 \mathrm{~m}$ e janelas de correr vertical.

Tabela 5.6.2: Temperaturas médias em cada fileira das estações de trabalho para as configurações com layout em linha, alturas das partições de $1,50 \mathrm{~m}$ e janelas maxim-ar. .....152

Tabela 5.7.1: Temperatura média do ar para a variação dos elementos geradores de carga térmica na configuração analisada 
Tabela 5.7.2: Temperatura do ar nos três planos de medição para a variação dos elementos geradores de carga térmica na configuração analisada.

Tabela 5.7.3: Temperatura do ar em cada fileira para a variação dos elementos geradores de carga térmica na configuração analisada.

Tabela 5.7.4: Vazão de ar para a variação dos elementos geradores de carga térmica na configuração analisada.

Tabela 5.7.5: Temperatura média do ar com temperatura externa aumentada em 1,5K para a variação dos elementos geradores de carga térmica na configuração analisada.

Tabela 5.7.6: Temperatura do ar nos três planos de medição com temperatura externa aumentada em $1,5 \mathrm{~K}$ para a variação dos elementos geradores de carga térmica na configuração analisada.

Tabela 5.7.7: Temperatura do ar em cada fileira para a variação dos elementos geradores de carga térmica na configuração analisada.

Tabela 5.7.8: Vazão de ar para a variação dos elementos geradores de carga térmica na configuração analisada.

Tabela 5.8.1: Percentual de estações de trabalho dentro das condições de conforto para 80\% dos ocupantes para velocidade do ar exterior máxima de $2 \mathrm{~m} / \mathrm{s}$ 166

Tabela 5.8.2: Percentual de estações de trabalho dentro das condições de conforto para $80 \%$ dos ocupantes para velocidade do ar exterior máxima de $4 \mathrm{~m} / \mathrm{s}$. 166

Tabela 5.8.3: Percentual de estações de trabalho dentro das condições de conforto para 90\% dos ocupantes para velocidade do ar exterior máxima de $4 \mathrm{~m} / \mathrm{s}$.

Tabela 5.8.4: Estações de trabalho dentro das condições de conforto para 90\% dos ocupantes para a variação dos elementos geradores de carga térmica na configuração analisada com temperatura externa de $299,0 \mathrm{~K}$.

Tabela 5.8.5: Estações de trabalho dentro das condições de conforto para 80\% dos ocupantes para a variação dos elementos geradores de carga térmica na configuração analisada com temperatura externa de $300,5 \mathrm{~K}$. 


\section{LISTA DE SIGLAS}

ABNT

ADPI

ASHRAE

CFD

CIBSE

COST

DES

DOE

IAG

ISO

IWEC

LABAUT

LabEEE

LES

NBR

NPL

RANS

RNG

SWERA

UDF

UFSC

USP
Associação Brasileira de Normas Técnicas

Air Diffusion Performance Index

American Society of Heating, Refrigerating and Air-

Conditioning Engineers, Inc.

Computational Fluid Dynamics (Dinâmica dos Fluidos

Computacional)

Chartered Institution of Building Services Engineering London

European Cooperation in the Field of Scientific and Technical

Research

Detached Eddy Simulation

United States Department of Energy

Instituto de Astronomia, Geofísica e Ciências Atmosféricas

International Organization for Standardization

International Weather for Energy Calculations

Laboratório de Conforto Ambiental e Eficiência Energética da Faculdade de Arquitetura e Urbanismo da USP

Laboratório de Eficiência Energética em Edificações do

Departamento de Engenharia Civil da USFC

Large Eddy Simulation

Norma Brasileira

Neutral Pressure Line (Linha de Pressão Neutra)

Reynolds Averaged Navier-Stokes

Renormalization Group

Solar and Wind Energy Resource Assessment

User Defined Function (Função Definida pelo Usuário)

Universidade Federal de Santa Catarina

Universidade de São Paulo 


\section{LISTA DE SÍMBOLOS}

\section{Símbolos latinos}

\begin{tabular}{|c|c|}
\hline A & Área $\left[\mathrm{m}^{2}\right]$ \\
\hline $\mathrm{C}_{\mathrm{d}}$ & Coeficiente de descarga [-] \\
\hline $\mathrm{C}_{\mathrm{p}}$ & Coeficiente de pressão [-] \\
\hline $\mathrm{c}_{\mathrm{p}}$ & Calor específico à pressão constante $[\mathrm{J} /(\mathrm{kg} \cdot \mathrm{K})]$ \\
\hline $\mathrm{C}_{\mathrm{V}}$ & Coeficiente de vazão [-] \\
\hline $\mathrm{D}$ & Comprimento característico [m] \\
\hline $\mathrm{E}$ & Energia $[\mathrm{J}]$ \\
\hline $\mathrm{g}$ & Aceleração local da gravidade $\left[\mathrm{m} / \mathrm{s}^{2}\right]$ \\
\hline $\mathrm{H}$ & Altura da edificação [m] \\
\hline \multirow[t]{2}{*}{$\mathrm{h}$} & Altura $[\mathrm{m}]$ \\
\hline & Diferença de altura $[\mathrm{m}]$ \\
\hline I & Intensidade de radiação $\left[\mathrm{W} / \mathrm{m}^{2}\right]$ \\
\hline \multirow[t]{2}{*}{$\mathrm{k}$} & Energia cinética turbulenta $[\mathrm{J}]$ \\
\hline & Condutividade térmica $[\mathrm{W} /(\mathrm{m} \cdot \mathrm{K})]$ \\
\hline M & Número de Mach [-] \\
\hline $\mathrm{m}$ & Massa $[\mathrm{kg}]$ \\
\hline $\mathrm{n}$ & Índice de refração [-] \\
\hline $\operatorname{Re}$ & Número de Reynolds [-] \\
\hline $\mathrm{p}$ & Pressão $[\mathrm{Pa}]$ \\
\hline $\operatorname{Pr}$ & Número de Prandtl [-] \\
\hline \multirow[t]{2}{*}{ Q } & Vazão volumétrica $\left[\mathrm{m}^{3} / \mathrm{s}\right]$ \\
\hline & Quantidade de calor $[\mathrm{J}]$ \\
\hline $\mathrm{q}$ & Taxa de transferência de calor $[\mathrm{W}]$ \\
\hline q"' & Taxa de geração de calor por unidade de volume $\left[\mathrm{W} / \mathrm{m}^{3}\right]$ \\
\hline $\mathrm{r}$ & Vetor posição [m] \\
\hline s & Vetor direção da radiação [m] \\
\hline $\mathrm{S}$ & Velocidade do som $[\mathrm{m} / \mathrm{s}]$ \\
\hline $\mathrm{S}_{\mathrm{ij}}$ & Tensor taxa de deformação $\left[\mathrm{s}^{-1}\right]$ \\
\hline $\mathrm{t}$ & Tempo $[\mathrm{s}]$ \\
\hline
\end{tabular}


$\mathrm{u}, \mathrm{v}, \mathrm{w}$

U

$u^{\prime}$

$\mathrm{u}_{\mathrm{i}}$

V

W

$\mathrm{x}, \mathrm{y}, \mathrm{z}$

$\mathrm{X}_{\mathrm{i}}$

\section{Símbolos gregos}

$\alpha$

$\varepsilon$

$\Phi$

$\kappa$

$\lambda$

$\mu$

$\mu_{\mathrm{t}}$

v

$\rho$

$\sigma$

$\sigma_{\mathrm{S}}$

$\tau_{\mathrm{ij}}$

$\Omega$

$\Omega_{\mathrm{ij}}$

\section{Índices}

ar

d

$\operatorname{din}$

e

i

Temperatura [K]

Componentes do vetor velocidades nas direções $\mathrm{x}, \mathrm{y}, \mathrm{z}[\mathrm{m} / \mathrm{s}]$

Velocidade média $[\mathrm{m} / \mathrm{s}]$

Flutuação da velocidade média $[\mathrm{m} / \mathrm{s}]$

Velocidade na direção i $[\mathrm{m} / \mathrm{s}]$

Velocidade do fluido $[\mathrm{m} / \mathrm{s}]$

Trabalho [J]

Coordenadas cartesianas [m]

Coordenada cartesiana na direção i [m]

Coeficiente de absortância $\left[\mathrm{m}^{-1}\right]$

Taxa de dissipação da energia cinética turbulenta [J/s]

Função dissipação viscosa $\left[\mathrm{W} / \mathrm{m}^{3}\right]$

Função de fase da dispersão [-]

Constante de von Kármán [-]

Segundo coeficiente de viscosidade $\left[\mathrm{N} \cdot \mathrm{s} / \mathrm{m}^{2}\right]$

Viscosidade dinâmica $\left[\mathrm{N} \cdot \mathrm{s} / \mathrm{m}^{2}\right]$

Viscosidade turbulenta $\left[\mathrm{N} \cdot \mathrm{s} / \mathrm{m}^{2}\right]$

Viscosidade cinemática $\left[\mathrm{m}^{2} / \mathrm{s}\right]$

Massa específica $\left[\mathrm{kg} / \mathrm{m}^{3}\right]$

Constante de Stefan-Boltzmann $\left[\mathrm{W} /\left(\mathrm{m}^{2} \cdot \mathrm{K}^{4}\right)\right]$

Coeficiente de dispersão $\left[\mathrm{m}^{-1}\right]$

Tensor das tensões $\left[\mathrm{N} / \mathrm{m}^{2}\right]$

Ângulo sólido [-]

Tensor taxa de rotação $\left[\mathrm{s}^{-1}\right]$

$\operatorname{Ar}$

Descarga

Dinâmico

Empuxo

Interno 


$\begin{array}{ll}\text { id } & \text { Ideal } \\ \text { o } & \text { Externo; Condição de referência } \\ \text { op } & \text { Operativa } \\ \mathrm{r} & \text { Rugosidade } \\ & \text { Radiante } \\ \mathrm{W} & \text { Vento }\end{array}$

\section{Operadores matemáticos}

$\begin{array}{ll}\partial & \text { Derivada parcial } \\ \delta_{\mathrm{ij}} & \text { Delta de Kronecker } \\ \varepsilon_{\mathrm{ijk}} & \text { Produto cruzado tensorial } \\ \Delta & \text { Variação } \\ \operatorname{acos} & \text { Arco cosseno } \\ \cos & \text { Cosseno } \\ \operatorname{div} & \text { Divergente } \\ \text { grad } & \text { Gradiente } \\ \ln & \text { Logaritmo natural } \\ \tanh & \text { Tangente hiperbólica } \\ - & \text { Média } \\ \rightarrow & \text { Vetor } \\ \| & \text { Módulo }\end{array}$




\section{SUMÁRIO}

\section{LISTA DE FIGURAS}

LISTA DE TABELAS

LISTA DE SIGLAS

LISTA DE SÍMBOLOS

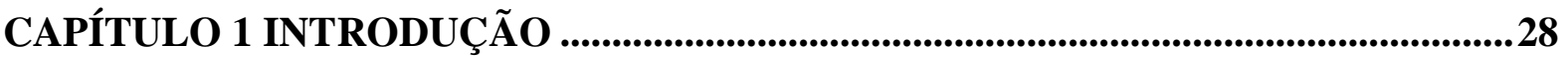

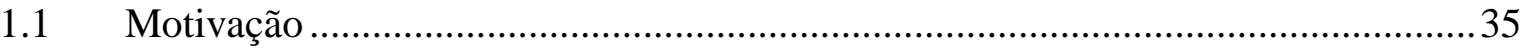

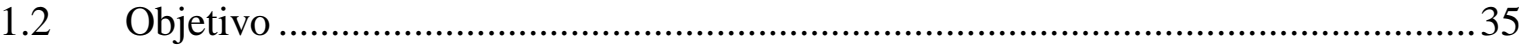

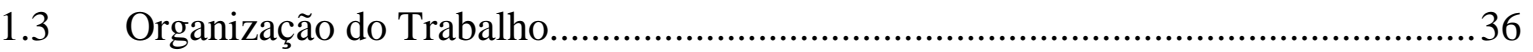

CAPÍTULO 2 VENTILAÇÃ̃ NATURAL ..............................................................................37

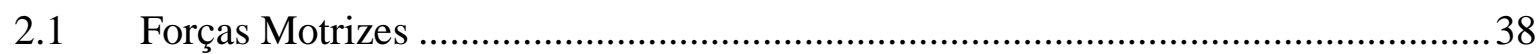

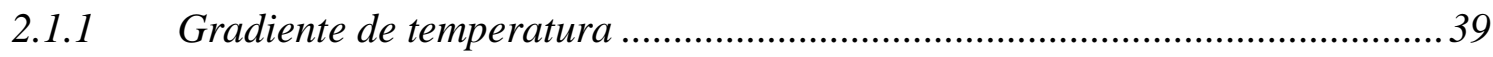

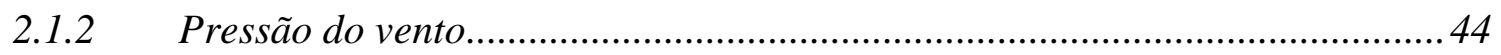

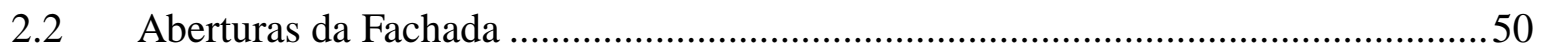

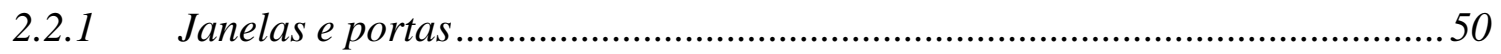

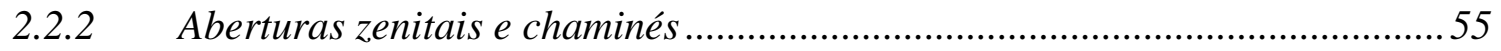

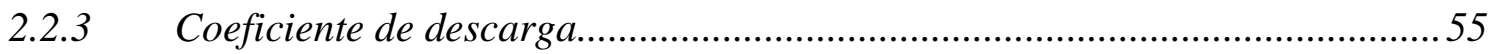

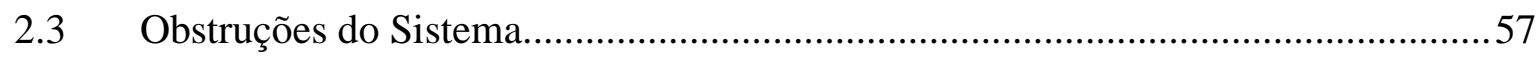

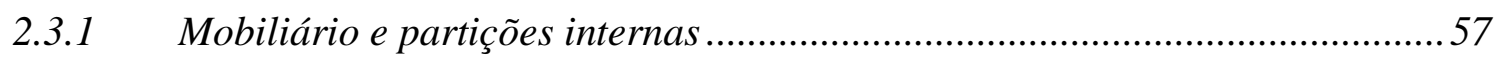

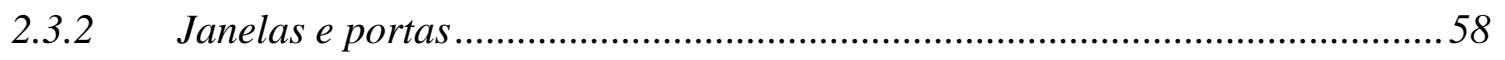

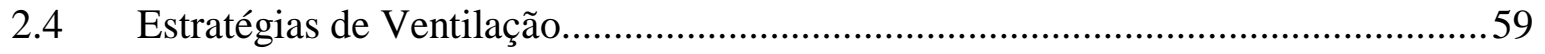

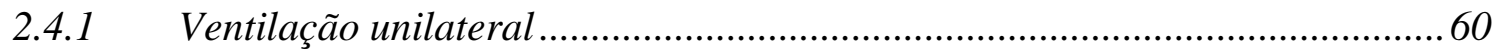

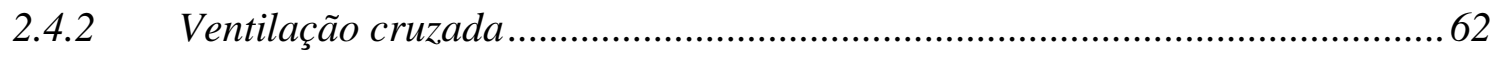

CAPÍTULO 3 FUNDAMENTAÇÃO TEÓRICA DA SIMULAÇÃO NUMÉRICA.......65

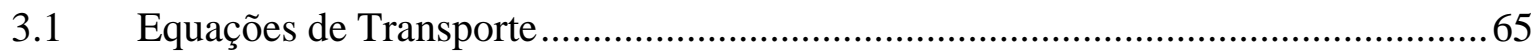

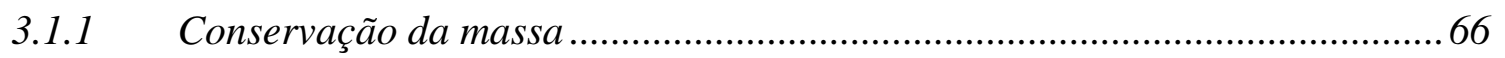

3.1.2 Conservação da quantidade de movimento .................................................67 


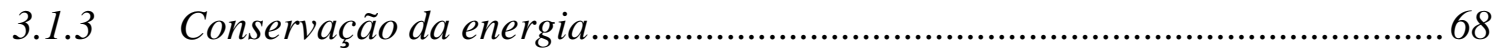

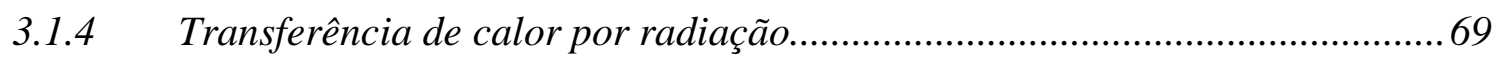

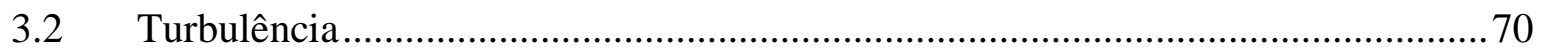

3.2.1 Decomposição de Reynolds e hipótese de Boussinesq ................................... 71

3.2.2 Modelos de turbulência utilizados no estudo de ventilação de ambientes...... 73

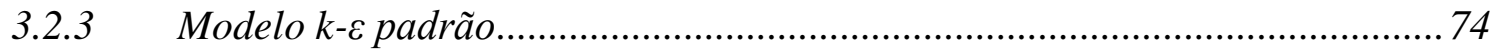

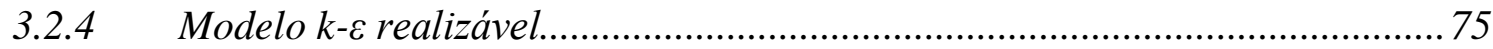

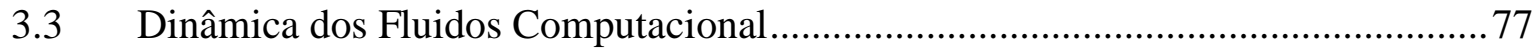

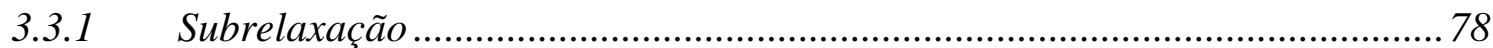

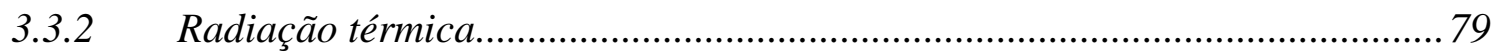

3.3.3 CFD aplicado à ventilação natural............................................................... 80

CAPÍTULO 4 SIMULAÇÃO NUMÉRICA DA VENTILAÇÃO NATURAL EM

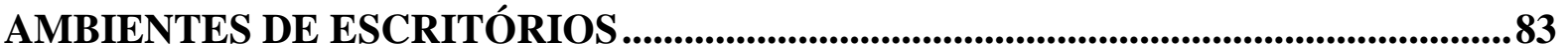

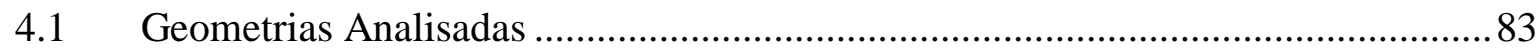

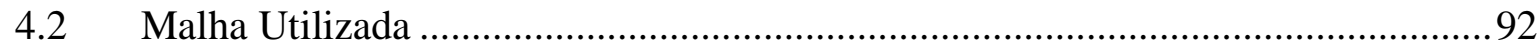

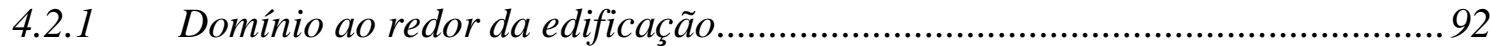

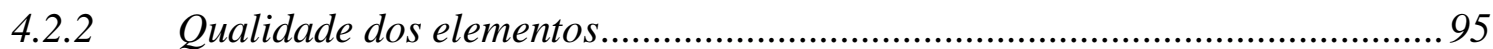

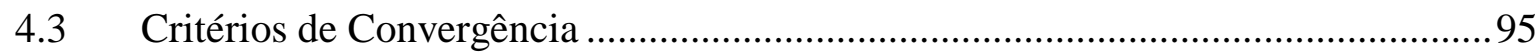

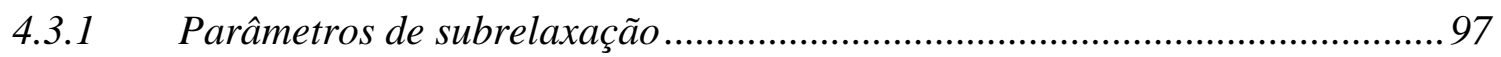

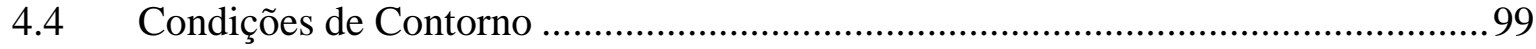

4.4.1 Condições climáticas da cidade de São Paulo ................................................ 99

4.4.2 Perfil de velocidades do vento................................................................... 102

4.4.3 Elementos geradores de carga térmica ......................................................... 104

4.4.4 Condições de contorno do modelo numérico ................................................. 105

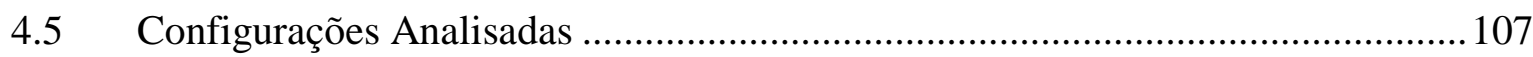

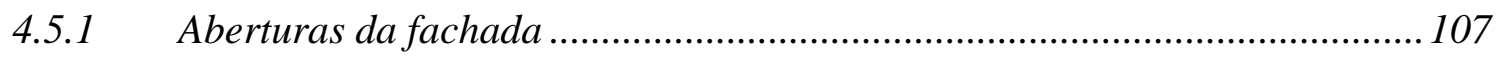

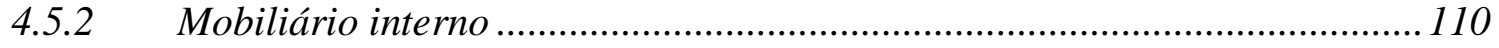

4.6 Parâmetros de Análise da Eficiência da Ventilação Natural ................................. 112

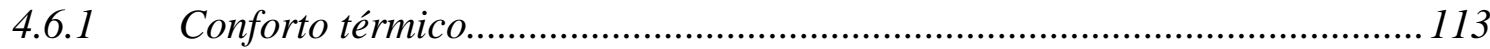

4.6.2 Estratificação da temperatura do ar ......................................................... 116

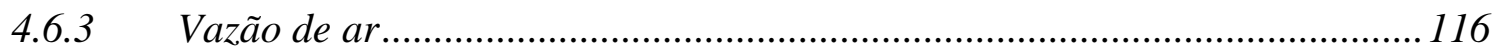

4.6.4 Análise qualitativa do escoamento do ar no ambiente.................................... 118 


\section{CAPÍTULO 5 RESULTAdOS E ANÁLISE DA EFICIÊNCIA DA VENTILAÇÃO}

NATURAL NOS AMBIENTES .............................................................................................121

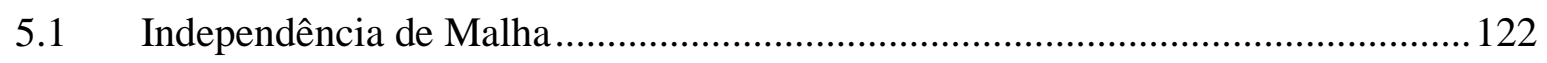

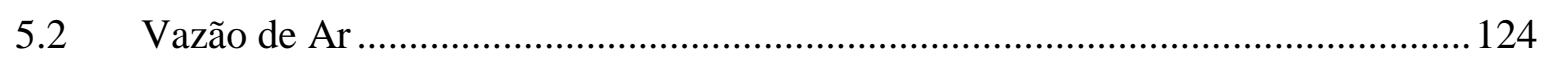

5.3 Variação da Altura das Partições ...................................................................... 125

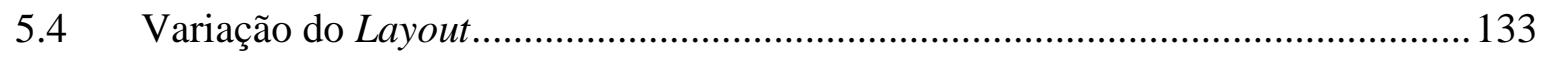

5.5 Variação da Geometria das Aberturas ................................................................... 142

5.6 Variação da Velocidade do Vento ....................................................................... 150

5.7 Variação de Outros Elementos na Simulação....................................................... 157

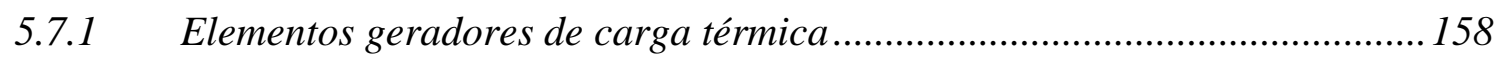

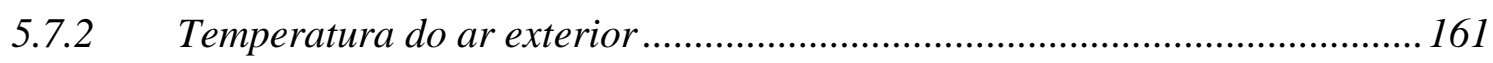

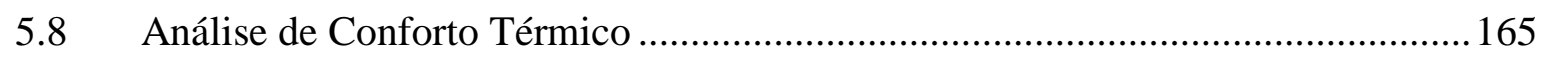

CAPÍTULO 6 CONSIDERAÇÕES FINAIS E CONCLUSÕES ....................................171

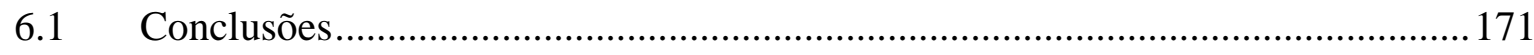

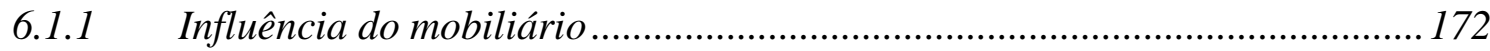

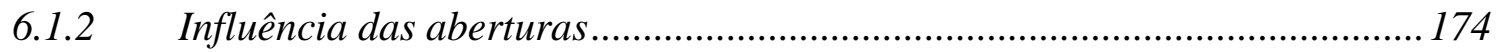

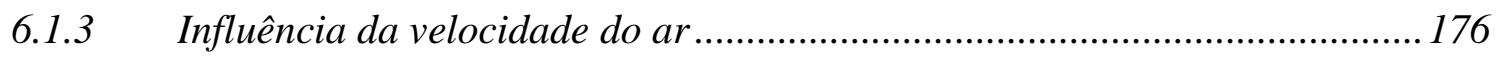

6.1.4 Influência dos elementos geradores de carga térmica ..................................177

6.1.5 Influência da temperatura do ar............................................................. 178

6.1.6 Influência sobre as condições de conforto térmico ....................................... 178

6.2 Principais Dificuldades Encontradas na Simulação ............................................... 179

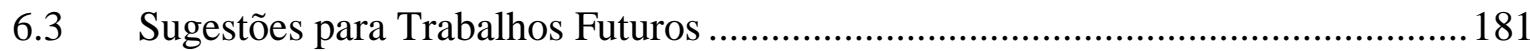

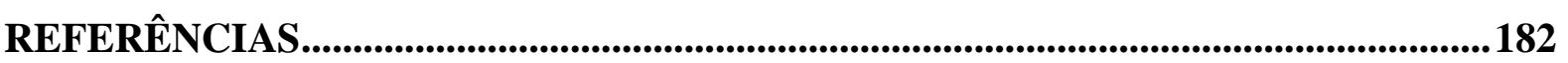

APÊNDICE A - RESUMO DOS RESULTADOS OBTIDOS ...........................................189

APÊNDICE B - SCRIPT PARA O CÁLCULO DAS SIMULAÇÕES............................. 193 


\section{CAPÍTULO 1 INTRODUÇÃO}

A ventilação de ambientes com renovação de ar externo deve prover nível apropriado de qualidade do ar interior, removendo e diluindo os contaminantes destes ambientes (ASHRAE, 2007a; ABNT, 2008c), e propiciando condições de conforto térmico (ASHRAE, 2010; ISO, 2005; ABNT, 2008b).

Em geral, a análise do processo de ventilação divide-se em duas etapas, sendo uma relativa à troca de ar entre o ambiente interno e o meio externo e a outra relativa ao movimento do ar dentro do próprio ambiente (CIBSE, 2005). Estes processos podem ser controlados por meio da utilização de sistemas projetados para este fim, os sistemas de ventilação, formados por conjuntos de equipamentos e recursos utilizados para a movimentação do ar em ambientes ocupados, englobando desde a captação do ar em outros ambientes até a exaustão deste do ambiente ocupado, passando pelos processos de tratamento do ar no controle da temperatura, umidade e nível de contaminantes (filtração) e a distribuição do ar tratado.

A complexidade do sistema de ventilação varia de acordo com a aplicação desejada, que vai desde grandes sistemas de ar condicionado, com o uso de resfriadores de líquido, sistemas de vazão variável com insuflamento pelo piso e recuperação de calor, até a utilização de aberturas adequadas na fachada, com o uso das condições naturais de ventilação propiciadas pelas condições ambientais externas, passando pelos sistemas híbridos de ventilação.

Em edificações de uso comercial, o uso de sistemas de ar condicionado tem sido cada vez maior. Estes sistemas, contudo, são responsáveis por parcela significativa do consumo de energia das edificações. Segundo dados do Procel Edifica (LEDUC, 2008), estes sistemas respondem por 34\% deste consumo. O Balanço Energético Nacional de 2010 (BRASIL, 2010) indica que $23,7 \%$ de toda a eletricidade consumida no Brasil tenham fins comerciais e públicos.

Por outro lado, no caso da ventilação natural não ocorre consumo de energia, pois o sistema de ventilação consiste em sistemas que permitem a utilização dos recursos eólicos para ventilar os ambientes internos, auxiliando na dispersão dos poluentes presentes, assim como na obtenção das condições de conforto térmico dos ocupantes, caso as condições 
externas sejam adequadas. Todo o processo de tomada de ar externo, insuflamento e exaustão é realizado sem o auxílio de equipamentos mecânicos, como ventiladores por exemplo. Contudo, em muitas situações, em função das cargas internas e das condições climáticas, o uso da ventilação natural não é apropriado (CIBSE, 2005).

Neste caso, uma das formas de diminuir o consumo de energia e propiciar condições de qualidade do ar e conforto térmico seria a utilização de sistemas híbridos, que busca unir as melhores características do sistema de climatização mecânico com o de ventilação natural. Este conceito está relacionado com a possibilidade de operação do sistema de ventilação natural o máximo de tempo possível, passando para o uso de sistemas mecânicos (ventilação mecânica ou o uso de ar condicionado) quando as condições operacionais exigirem seu funcionamento (CIBSE, 2005).

Sistemas híbridos, também conhecidos por sistemas mistos, de maneira geral podem ser operados de três formas: simultaneamente ao sistema de ventilação natural, alternadamente ao sistema de ventilação natural e em zonas separadas. Neste último, as zonas da edificação são separadas, de forma que em algumas são utilizadas o modo mecânico e em outras o modo de ventilação natural.

O modo simultâneo de operação consiste em uma mesma zona ter suas variáveis ambientais de conforto influenciadas naturalmente e mecanicamente, como ocorre por exemplo em um ambiente com entrada de ar por janelas operáveis e resfriamento interno utilizando vigas frias. Já no modo alternado, o funcionamento do sistema mecânico fica condicionado à parada do sistema natural, como por exemplo o funcionamento de um sistema de climatização após o fechamento das janelas.

Para a correta utilização de sistemas híbridos é necessário que seja realizado, inicialmente, estudo pormenorizado de viabilidade de utilização da ventilação natural, suas potencialidades e limites. Um exemplo deste tipo de análise pode ser encontrado em Brandão et al (2008), onde foi avaliada a possibilidade de uso da ventilação natural no edifício CENPES II da Petrobrás. É nesta linha de estudos que se insere o presente trabalho.

Ademais, com a disseminação do conceito de desenvolvimento sustentável tem sido verificado um aumento significativo no interesse por sistemas de baixo ou nenhum consumo de energia. Função disto, estudos de viabilidade de utilização da ventilação natural e de ventilação híbrida tem crescido em importância.

Na revisão bibliográfica verificou-se a existência de um significativo número de trabalhos que analisam a ventilação natural em situações muito específicas, quase como estudos de caso. Usualmente, analisa-se a situação inicial da edificação e os impactos na 
ventilação de uma determinada proposta, sendo utilizados métodos analíticos, numéricos ou experimentais, de acordo com o estudo.

As análises de variáveis, quando existem, normalmente se limitam a ambientes hipotéticos, como por exemplo edificações com apenas uma ou duas aberturas ou construções sem divisões internas, muito distantes dos encontrados em situações do cotidiano. Os ambientes mais realísticos analisados nos trabalhos ainda se dividem em residenciais, comerciais e industriais, sendo este último retirado da pesquisa por possuir características muito diferentes da proposta nesta dissertação, conforme objetivos descritos no item 1.2.

A seguir são apresentados alguns trabalhos que tratam do uso da ventilação natural e da análise de variáveis que interferem na ventilação natural, e que foram utilizados como referência para o desenvolvimento do presente trabalho.

Heiselberg et al. (1999) estudaram experimentalmente a caracterização de três tipos diferentes de janelas, considerando diferenciais de temperatura e diferentes estratégias de ventilação. Foi demonstrado que a capacidade de ventilação, qualidade do ar e conforto térmico pode ser melhorado de acordo com a combinação das aberturas estudadas.

Fracastoro e Perino (1999) analisaram efeitos transientes de aberturas de janelas nos edifícios utilizando dinâmica dos fluidos computacional (CFD). Nesta pesquisa, foi considerada como força motriz o efeito chaminé, sendo desprezada a influência da pressão do vento. Os autores analisaram as janelas modificando o seu tamanho, as condições de contorno e os métodos de cálculo, concluindo que a aplicação da ferramenta de CFD deve ser aplicada cuidadosamente por especialistas, com opções de cálculo adequadas.

Li e Delsante (2001) analisaram com ferramentas matemáticas analíticas a interação entre a ventilação induzida pelo gradiente de temperatura e pela ação do vento sobre um edifício com duas aberturas e composto por um único ambiente interno. A geometria das aberturas foi variada de forma que as duas forças motrizes pudessem ter seus efeitos amplificados ou contrapostos. O modelo analítico desenvolvido representou bem as condições de ventilação, embora o modelo possua simplificações significativas.

Alloca, Chen e Glicksman (2003) realizaram uma comparação entre três métodos de avaliação da ventilação natural: analítica, numérica e experimental. A geometria analisada foi um dormitório típico, inicialmente sem considerar o meio externo e, posteriormente, incluindo-o no domínio de cálculo. Foram empregadas duas janelas no ambiente simulado com ventilação por efeito chaminé e por efeito combinado com o vento, a fim de verificar se os modelos numéricos desenvolvidos possuíam boa aderência com os demais métodos. Para ventilação por efeito chaminé, o modelo de CFD, que incluía o ambiente exterior, apresentou 
bons resultados, enquanto que na ocorrência de ventilação híbrida o método numérico subestimou a ventilação dos ambientes.

Gratia, Bruyère e De Herde (2004) analisaram com o programa computacional TAS a aplicabilidade da ventilação natural em um edifício de escritório com planta estreita, considerada mais apropriada para este sistema, na cidade de Bruxelas. O estudo abordou a variação de diversos elementos, como condição de incidência do vento sobre a construção, existência ou não de proteções solares e de vento e ventilação noturna. Nas condições climáticas analisadas, a ventilação natural se mostrou bem eficiente, reduzindo a carga térmica em até $40 \%$, sendo recomendadas ações diferentes para ventilação unilateral ou cruzada, como posicionamento e abertura das janelas.

Prata (2005) avaliou as condições de distribuição dos ventos sobre o meio urbano devido à altura das edificações no entorno na cidade de Santos. Para tal, foram utilizados ensaios experimentais e simulações utilizando CFD, sendo empregadas também medições in loco para validação de propriedades como velocidade e direção do vento. Em todas as análises efetuadas, a autora pode concluir que a altura das edificações efetivamente influencia a distribuição dos ventos no meio urbano, especialmente em regiões à jusante da edificação.

Cóstola (2006) formulou um procedimento para avaliar a possibilidade de utilização da ventilação natural, sendo determinadas experimental e numericamente grandezas como coeficientes de pressão e coeficientes de descarga, parâmetros amplamente utilizados nos projetos de ambientes naturalmente ventilados, além da vazão de ar nos ambientes. $\mathrm{O}$ autor conclui do seu procedimento que existem diversas ferramentas disponíveis para auxiliar a predição da ventilação natural nos edifícios, sendo recomendado cuidado no emprego destas tanto pelo pesquisador quanto pelo arquiteto.

Figueiredo (2007) analisou as tendências da arquitetura na cidade de São Paulo para os edifícios de escritórios concebidos visando conforto térmico e eficiência no consumo energético. Em um primeiro momento, foram avaliadas temperaturas médias para todo o ano para um edifício de escritório ventilado naturalmente, utilizando o programa Energy Plus. Foram efetuadas também análises de CFD com o programa $C F X$ visando estimar se ocorreriam efeitos locais nos ambientes ventilados naturalmente, como correntes de ar e grandes gradientes de temperatura, que poderiam causar situações de desconforto; condição verificada apenas para uma pequena parcela do ambiente de escritório analisado, devido à velocidade do ar.

Benedetto (2007) realizou estudo de viabilidade de algumas soluções arquitetônicas que possibilitavam o uso de ventilação natural em escritórios localizados no Rio de Janeiro e 
em São Paulo. Para esta análise, a autora utilizou o programa TAS para avaliar o desempenho térmico e energético das alternativas, verificando que nas situações climáticas mais favoráveis a ventilação natural é suficiente para prover conforto térmico a $90 \%$ dos usuários em $86,5 \%$ do período de ocupação. No restante do período, a autora cita que seriam necessários outros recursos além dos naturais, sem especificar exatamente quais seriam.

Costa (2009) analisou a ventilação natural em um edifício residencial na cidade de Aracaju, variando a localização das janelas e portas em relação à planta baixa do apartamento, abertura ou não destas portas, modelagem das janelas através da inclusão ou não de esquadrias, e até a variação da planta arquitetônica. O fechamento das portas prejudicou significativamente o fluxo de ar dentro dos ambientes, situação parcialmente revertida com a existência de aberturas acima das portas. As demais modificações não resultaram em grandes mudanças na movimentação do ar no apartamento.

Motezuki (2009) e Prata (1998) propõem em suas dissertações um simulador numérico computacional, baseados no estudo de Givoni (1976), para analisar a ventilação em ambientes residenciais, dadas algumas condições geográficas, climáticas e geométricas. Motezuki (2009) cita como motivação para desenvolver um método baseado no método de Givoni (1976) a dificuldade de executar simulações de CFD, campo que requer conhecimentos altamente especializados e experiência prática para se obter bons resultados.

Yang et al (2010) analisaram como o ângulo de abertura de portas e janelas influencia o coeficiente de descarga e o coeficiente de perda de carga destes elementos utilizando CFD. Para validação de suas simulações, houve ainda a construção de modelos em túnel de vento e medições de vazão para comparação com os resultados computacionais. Como conclusão, há a recomendação de se utilizar um ângulo de abertura de pelo menos $30^{\circ}$ para minimizar a diminuição na ventilação dos ambientes.

Marcondes (2010), em sua tese de doutorado, apresenta uma série de edifícios de escritórios construídos na década de 1990 e início da década de 2000, situados no Brasil e na Europa, que possuíam características consideradas "verdes", ou seja, ligados a algum aspecto da sustentabilidade. É dada ênfase nas estratégias passivas arquitetônicas para redução da carga térmica e, consequentemente, também da energia necessária para a climatização dos ambientes, visando ampliar a utilização de ventilação natural nestas edificações.

Cheung e Liu (2011) analisaram a interferência de edificações no entorno sobre a taxa de ventilação cruzada em apartamentos hipotéticos sem divisórias internas, para cada pavimento. Vários arranjos de construções foram comparados com um edifício de referência, localizado em um domínio sem a presença de elementos externos como edificações vizinhas, 
sendo modificada a posição (alinhadas ou não) e o distanciamento entre elas, bem como o ângulo de incidência do vento. Os autores concluíram que a influência de edifícios nas proximidades pode ser desde nula até significativa na ventilação dos ambientes.

Bady et al (2011) investigaram experimentalmente a pressão nas superfícies de edificações cúbicas em áreas residenciais densamente urbanizadas do Japão. Os autores analisaram quatro variações da geometria da edificação e seis ângulos de incidência do vento, verificando que estes ângulos e o posicionamento das edificações influenciam significativamente a ventilação natural dos ambientes. A presença de aberturas entre edificações adjacentes possibilitou "introduzir mais vento" nas áreas urbanas, e este elemento é um fator a ser considerado por projetistas, de acordo com os autores.

Ahmed e Wongpanyathaworn (2012) apresentaram um estudo de caso sobre o uso da ventilação natural em uma edificação na Austrália. Foram analisadas diversas configurações das aberturas, considerando localização e tamanho, a fim de determinar o projeto mais eficiente economicamente. Com a otimização das aberturas, foi possível reduzir em $61 \%$ o consumo de energia elétrica da edificação, em comparação com fachadas compostas por vidros fixos.

Tecle et al (2013) analisaram experimentalmente a queda de pressão em uma residência naturalmente ventilada em função da quantidade e posição das aberturas nas fachadas da construção. Os autores verificaram que a queda de pressão era maior com a diminuição da razão entre as áreas das aberturas de entrada sobre as de saída. Ainda, verificou-se que aberturas entre fachadas opostas causam também maior queda de pressão do ar em fachadas adjacentes, considerando iguais condições das aberturas.

O efeito das divisões internas dos ambientes, assim como a análise da influência do mobiliário, sobre as condições de ventilação natural é bem menos comum na literatura, sendo encontradas principalmente referências qualitativas sobre o assunto. Por exemplo, Etheridge e Sandberg (1996) citam que o mobiliário influi resistindo ao escoamento, mudando o volume do ambiente ventilado e desviando a corrente principal. Sua presença pode até defletir jatos de ar, causando correntes na zona ocupada.

Kendrick, Martin e Booth (1998) apenas apontam como recomendações gerais de que o mobiliário deve ser mantido baixo na maior parte possível do ambiente ventilado e o posicionamento de estantes, armários e outros mobiliários altos deve ocorrer no perímetro do ambiente, entre as janelas, minimizando a interferência sobre o movimento do ar.

Clements-Croome (2003) cita que ferramentas de CFD podem ser utilizadas para ventilação natural, e até apresenta uma imagem do perfil de temperaturas em uma edificação, 
porém é possível somente tirar conclusões qualitativas destas. CIBSE (2005) destaca que no uso da ventilação cruzada de ambientes devem ser evitadas partições altas e portas. Caso estas sejam inevitáveis, grelhas de transferência devem ser instaladas nas partições, permitindo o fluxo de ar.

Costa (2009) variou o posicionamento de portas nos ambientes simulados, além de analisar a influência da inclusão de aberturas sobre as portas, o que deixaria sempre uma área livre para a movimentação do ar entre os ambientes interiores. Ainda, a variação da planta arquitetônica também visava compreender o impacto que estes elementos interiores possuem sobre a ventilação natural e se estas mudanças seriam significativas para a ventilação do apartamento analisado.

Tecle et al (2013) também analisaram experimentalmente os efeitos das partições internas sobre a queda de pressão do ar em uma edificação residencial. Os autores concluíram que sob condições de ventilação cruzada as partições internas mudam significativamente a distribuição da pressão interna, com as quedas de pressão variando muito em função da localização do ambiente em relação às aberturas de entrada e saída do ar.

Dados quantitativos sobre a influência do mobiliário foram encontrados somente no trabalho de Bojic, Yik e Lo (2002), porém este analisava um ambiente de dormitório climatizado por um equipamento de ar condicionado do tipo janela. Foi avaliado o índice de desempenho da difusão do ar (ADPI), que pondera a ocorrência ou não de correntes de ar na zona ocupada, para três posições diferentes do ar condicionado na parede, sendo todo o restante do mobiliário mantido constante nas simulações.

$\mathrm{Na}$ análise dos trabalhos da literatura verificou-se que existe uma lacuna na análise da ventilação natural de ambientes de escritório utilizando ferramentas de CFD. Esta ferramenta numérica é amplamente utilizada em casos mais simples, como na análise dos ventos ao redor de uma edificação, ou considerando muitas vezes edificações formadas apenas pela fachada externa, com um único espaço interior totalmente livre. Ainda, muitas vezes são analisadas situações específicas onde a variação de tipos de janelas, por exemplo, caso ocorra, se limita a dois ou três casos.

Considerando o mobiliário, a literatura demonstra ainda mais a falta de pesquisas, limitando-se a análises qualitativas desta influência, e análises quantitativas limitadas apenas a edifícios residenciais. Apesar da existência de fatores adversos nestes casos, como a flexibilidade de layout, um aprofundamento no estudo destas variáveis pode determinar qual seu nível de influência sobre a ventilação natural, comparativamente aos sistemas de fachada, ressaltando ou não sua importância no desenvolvimento de projetos de ventilação natural. 
Função disto, no presente trabalho foi avaliada a influência de diferentes sistemas de fachada e mobiliário interno sobre as condições de ventilação natural em ambientes de escritório. Foram variadas a geometria e localização das janelas, assim como de mobiliário e partições internas, a fim de encontrar a condição que propicia a melhor ventilação, de forma a maximizar o uso dos recursos naturais, em vez dos sistemas mecânicos de climatização.

O ambiente analisado foi um escritório comercial típico, com estações de trabalho distribuídas em um layout estilo aberto e janelas operáveis. As variações de mobiliário e janelas são descritas no capítulo 4, dedicado à simulação, que contém detalhes dos modelos computacionais utilizados.

\subsection{MOTIVAÇÃO}

Como motivação para o desenvolvimento deste estudo tem-se a busca pela redução no consumo de energia de edifícios, evitando assim o uso desnecessário de recursos energéticos naturais e/ou de fontes não renováveis de energia. Aumentar o uso da ventilação natural nos ambientes tradicionalmente climatizados, sem comprometer o conforto de seus ocupantes, auxiliará na utilização mais racional dos recursos energéticos.

O estudo dos principais componentes ligados à ventilação natural, analisando comparativamente alguns parâmetros, pode auxiliar no aumento do uso das tecnologias passivas, fornecendo uma indicação de quais condições devem ser buscadas, tendo em mente a redução do uso dos sistemas ativos, consumidores de energia.

\subsection{OBJETIVO}

O objetivo desta dissertação consiste na avaliação da influência de diferentes configurações de aberturas da fachada e do mobiliário sobre as condições de ventilação natural em ambientes de escritórios na cidade de São Paulo, utilizando CFD. Foram analisados diferentes tipos de janelas e de altura e disposição do mobiliário, com o objetivo de se verificar quais situações propiciam melhores condições de ventilação dos ambientes, de forma a maximizar o uso dos recursos naturais no lugar dos sistemas mecânicos de climatização. 


\subsection{ORGANIZAÇÃO DO TRABALHO}

No capítulo 2 são apresentados os principais conceitos relacionados com a ventilação natural, com descrição das forças motrizes do vento, dos principais componentes deste sistema de ventilação, das obstruções que reduzem sua eficiência e das estratégias utilizadas para a ventilação dos ambientes.

A fundamentação teórica necessária para a simulação numérica dos fenômenos analisados está descrita no capítulo 3, sendo contemplados o equacionamento do transporte de massa, quantidade de movimento e energia, os modelos de turbulência utilizados e conceitos de dinâmica dos fluidos computacional (CFD), além de características e exemplos da aplicação desta ferramenta em ambientes ventilados naturalmente.

Em seguida, no capítulo 4, são enumeradas as condições necessárias para criação dos modelos computacionais e sua solução numérica, dentre eles as informações para a geração de malhas e condições de simulação, além das condições e parâmetros avaliados na simulação numérica da ventilação natural em ambientes de escritórios.

No capítulo 5 são apresentados os resultados obtidos das simulações numéricas, considerando a influência das condições analisadas sobre os parâmetros avaliados.

Por fim, no capítulo 6, são apresentadas as discussões em torno dos resultados obtidos, detalhando quais são as condições que proporcionam melhora na ventilação dos ambientes. Ainda, sugestões de estudos futuros são listadas, de forma a auxiliar no uso e desenvolvimento de sistemas de ventilação natural. 


\section{CAPÍTULO 2 VENTILAÇÃO NATURAL}

Dentre os sistemas de ventilação, a ventilação natural consiste no uso de equipamentos e estratégias especificamente passivos, ou seja, sem a utilização de elementos que consomem energia. Ventilação natural é a ventilação promovida por efeitos térmicos, de vento ou de infiltração através de portas, janelas, ou outras aberturas intencionais da edificação (ASHRAE, 2007a). O projeto adequado deste sistema, aplicado a climas amenos, permite o controle de condições ambientais interiores, como temperatura e velocidade do ar.

Conforme apresentado pela equação de Navier-Stokes na seção de fundamentação teórica da simulação numérica, item 3.1.2, a movimentação do fluido é causada essencialmente por três termos fonte: ação gravitacional, gradiente de pressão e efeitos viscosos. Entretanto, este último pode ser negligenciado em alguns tipos de escoamentos, permitindo obter uma aproximação de primeira ordem para estes casos se os efeitos viscosos forem ignorados (MUNSON; YOUNG; OKIISHI, 2004).

Diversos elementos estão diretamente ligados com a ventilação de ambientes interiores, como a diferença de pressão do ar entre os ambientes internos e externos, a resistência ao escoamento do ar oferecida pelas aberturas e obstruções internas, além de uma série de implicações relativas à incidência do vento e forma do edifício (FROTA; SCHIFFER, 2003).

Como a ventilação natural depende mais intensamente das condições ambientais externas do que a ventilação mecânica, sua capacidade de controlar parâmetros de conforto térmico torna-se menor. Desta forma, torna-se necessária a limitação de alguns fatores inerentes ao ambiente.

O manual de aplicação de ventilação natural da CIBSE (2005) cita como regra geral da viabilidade da ventilação natural a limitação da carga térmica total (carga interna somada à solar) do ambiente em 30 a 40W/m². Também é recomendada a utilização de plantas estreitas, preferencialmente com menos de $15 \mathrm{~m}$ de largura, e a permissão aos ocupantes de se adaptar às mudanças climáticas.

O projeto do sistema de ventilação natural deve considerar três questões básicas:

a) Padrão de fluxo de ar: qual será o comportamento de ventilação no ambiente desejado, da sua entrada à saída. Este será afetado por fatores internos e 
externos, como distribuição do vento ao redor da edificação, elementos utilizados como entrada e saída do ar, resistências internas e restrições de acústica e qualidade do ar;

b) Forças motrizes: fonte do movimento de ar no ambiente ventilado. Podem ter origem na pressão do vento ou no gradiente de temperatura;

c) Tamanho e localização das aberturas: seu dimensionamento deve possuir capacidade de prover fluxos de ar calculados para manter as condições estabelecidas de qualidade do ar, temperatura e umidade, durante o período de ocupação do ambiente.

O manual de eficiência energética da CIBSE (2004) apresenta uma referência hierárquica de preferência das estratégias de ventilação, sendo preferível na seguinte ordem: ventilação natural; ventilação mecânica; ventilação híbrida; climatização sem controle de umidade; e climatização com controle de umidade.

A ventilação natural é citada por este manual como o modo com menor consumo de energia, custos de investimento, operação e manutenção, além de complexidade mais baixa. Sua aplicação é realizada através de infiltrações e/ou pela permissão de escoamentos de ar entrando e saindo da edificação por meio de aberturas (SANTAMOURIS; ASIMAKOPOULOS, 1996). A vazão de ar necessária para remoção da carga térmica de determinado ambiente, descrita por ASHRAE (2009), é apresentada na equação 2.0.1.

$$
Q=\frac{q}{c_{p} \cdot \rho \cdot\left(T_{i}-T_{o}\right)}
$$

onde Q é a vazão volumétrica $\left[\mathrm{m}^{3} / \mathrm{s}\right]$, q é taxa de transferência de calor $[\mathrm{W}], \mathrm{c}_{\mathrm{P}}$ é o calor específico à pressão constante $[\mathrm{J} /(\mathrm{kg} \cdot \mathrm{K})], \rho$ é a massa específica do ar $\left[\mathrm{kg} / \mathrm{m}^{3}\right], \mathrm{T}_{\mathrm{i}}$ é a temperatura do ar do ambiente interno $[\mathrm{K}], \mathrm{T}_{\mathrm{o}}$ é a temperatura do ar do ambiente externo $[\mathrm{K}]$.

\subsection{FORÇAS MOTRIZES}

Em todos os casos de ventilação natural, as forças motrizes do movimento do ar são atribuídas a diferenças de pressão criadas através das diversas aberturas na estrutura da 
edificação (YARKE, 2005). As características de ventilação, como intensidade e direção, dependerão fortemente das propriedades das forças motrizes, assim como das resistências à passagem do fluido. Um bom projeto de ventilação natural deve levar em consideração todos estes fatores (CIBSE, 2005).

Essencialmente, existem duas forças motrizes: pressão do vento e gradiente de temperatura. Dependendo das condições, ambas atuarão ao mesmo tempo, porém suas origens são completamente distintas, e existem equipamentos e estratégias que podem se adequar melhor a cada uma delas, como é descrito ao longo deste capítulo.

As discussões sobre estas forças tomam como hipótese condições de regime permanente, utilizadas nas análises nesta dissertação. O fenômeno da ventilação natural compreende características transitórias, porém a variação no tempo torna demasiadamente complexa a análise, especialmente utilizando CFD, sendo que para a análise comparativa das melhores alternativas a abordagem em regime permanente mostra-se suficiente.

\subsubsection{Gradiente de temperatura}

O ar é um fluido compressível, embora o escoamento atmosférico possa ser abordado como incompressível, de modo que sua massa específica varia com o estado termodinâmico que se encontra. Mais especificamente, sob temperaturas diferentes, o ar apresentará também densidades distintas, sendo esta causa de diferenciais de pressão e, consequentemente, movimentação do fluido.

A ventilação por gradiente de temperatura também é conhecida como ventilação por efeito chaminé ou convecção natural, e a diferença de pressão deste fenômeno é resultante da diferença de temperatura do ar entre o ambiente interno e externo. Para aberturas localizadas em diferentes alturas, a diferença de pressão será decorrente do gradiente vertical de densidade e calculado de acordo com a equação 2.1.1 (AWBI, 2003):

$$
p_{e}=-\rho_{o} g h\left(1-\frac{T_{o}}{T_{i}}\right)
$$

onde $\mathrm{p}_{\mathrm{e}}$ é a pressão devida ao empuxo [Pa], $\rho_{\mathrm{o}}$ é a massa específica do ambiente externo $\left[\mathrm{kg} / \mathrm{m}^{3}\right]$, g é a aceleração local da gravidade $\left[\mathrm{m} / \mathrm{s}^{2}\right]$, h é a diferença de altura $[\mathrm{m}], \mathrm{T}_{\mathrm{o}}$ é a temperatura do ar do ambiente externo $[\mathrm{K}], \mathrm{T}_{\mathrm{i}}$ é a temperatura do ar do ambiente interno $[\mathrm{K}]$. 
Em CIBSE (2005) é descrito o fenômeno considerando duas colunas de ar, inicialmente separadas, sendo uma com temperatura maior. Se estas duas colunas de densidades diferentes fossem conectadas, o ar mais frio e denso escoaria para baixo, empurrando o ar mais quente para o alto. Esta dinâmica se repete para o caso das edificações, onde usualmente o ar interior é mais quente do que o exterior, permitindo a entrada do fluxo através das aberturas inferiores, e exaurindo o ar quente interno por aberturas superiores. A figura 2.1.1 ilustra esse comportamento simplificado.

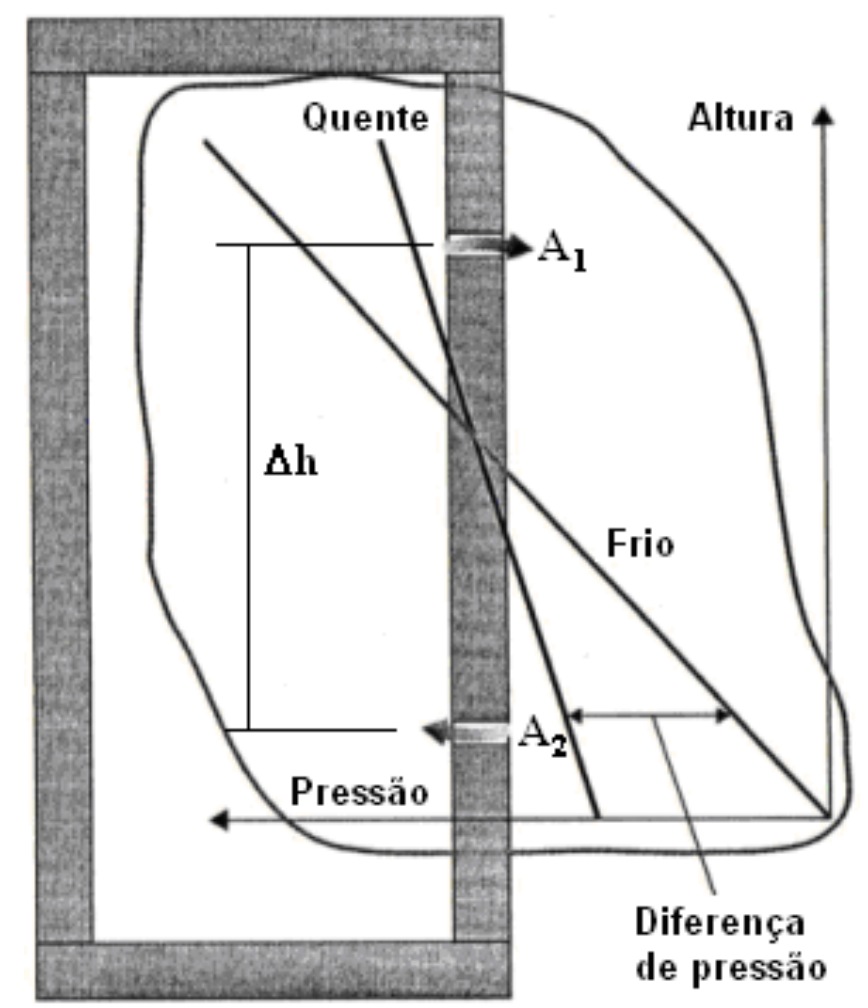

Figura 2.1.1: Representação do fluxo de ar devido ao gradiente de temperatura (Adaptado de CIBSE, 2005).

Este modo de ventilação pode ocorrer em qualquer abertura, desde que haja diferença de temperatura. Entretanto, a pressão de empuxo é usualmente pequena, necessitando de grandes aberturas para garantir taxas de ventilação grandes o suficiente (ALLARD; GHIAUS, 2005). Este diferencial de pressão é proporcional à diferença de temperatura e distância vertical da linha de pressão neutra (NPL - Neutral Pressure Line), de forma que para aumentar a vazão de ar é necessário aumentar a diferença destas propriedades. 


\subsubsection{Linha de pressão neutra}

A linha de pressão neutra é um conceito importante relacionado com a ventilação por gradiente de temperatura. Essencialmente, ela é definida como a altura onde as pressões interna e externa se equilibram, ou seja, acima dela o ar quente interior deixará o ambiente, enquanto que abaixo dela o ar frio externo entrará nele, como mostra a figura 2.1.2.

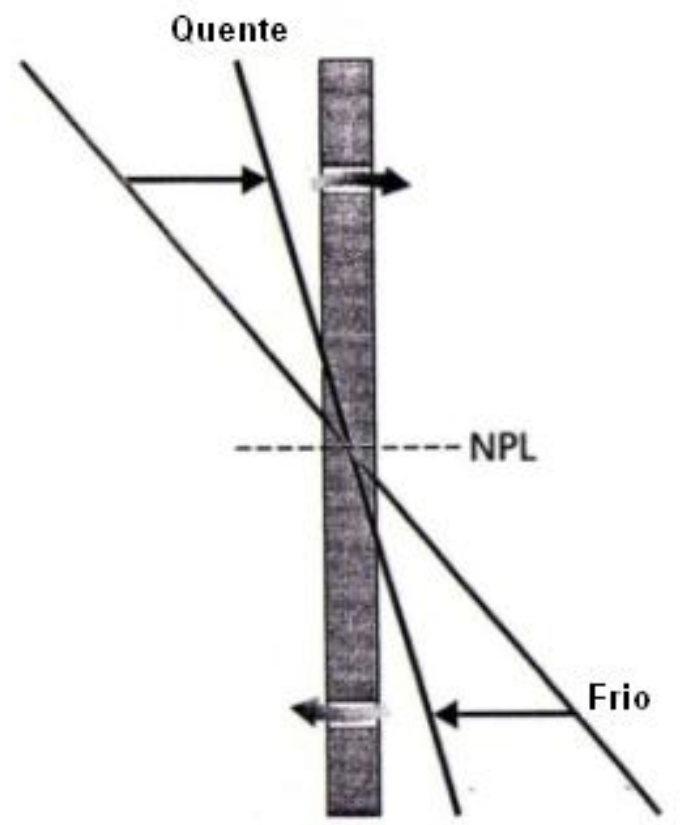

Figura 2.1.2: Fluxo de ar em função da posição da linha de pressão neutra (Adaptado de CIBSE, 2005).

O posicionamento da linha de pressão neutra dependerá das áreas das aberturas entre os ambientes e de suas geometrias, e pode variar conforme o exemplo da figura 2.1.3. Caso todos os elementos sejam uniformes, a linha se encontrará na altura média da edificação; se houver um aumento das aberturas superiores, a linha se deslocará para cima.
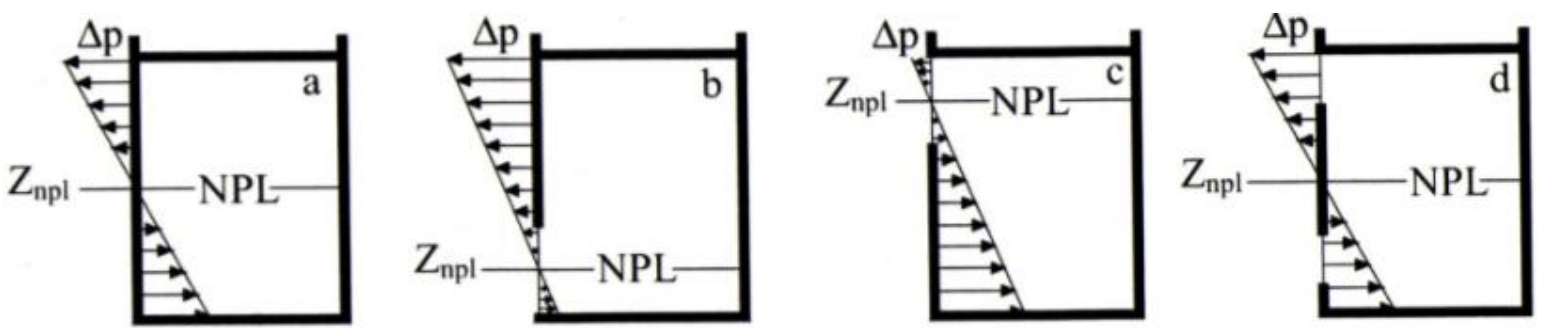

Figura 2.1.3: Variação de altura da NPL em decorrência de altura e geometria das aberturas (YARKE, 2005). 
Estimar a altura da NPL é uma tarefa complexa. Caso apenas uma abertura exista, ou ela represente mais que $90 \%$ da área total das fachadas, esta linha estará no centro da abertura, tornando a ventilação do ambiente um escoamento essencialmente bidirecional. Os elementos internos da edificação, como paredes e divisórias interiores, shafts de elevadores, dutos, etc. tornam esta análise ainda mais complexa. Poucas informações sobre dados de NPL são disponíveis. Para edifícios altos a NPL varia entre 0,3 e 0,7 da altura total da edificação.

A figura 2.1.4 apresenta o impacto do aumento de aberturas no alto de uma edificação de três andares, sendo possível verificar que na condição dada, o ar exterior, mais frio, entrará por todos os pavimentos ocupados, sendo exaurido por uma abertura no alto. No exemplo ilustrado, possui grande importância manter a NPL acima do último pavimento ocupado, caso contrário o ar quente dos demais pavimentos sairá pelo andar mais alto, comprometendo as condições de conforto térmico da população local (CIBSE, 2005).

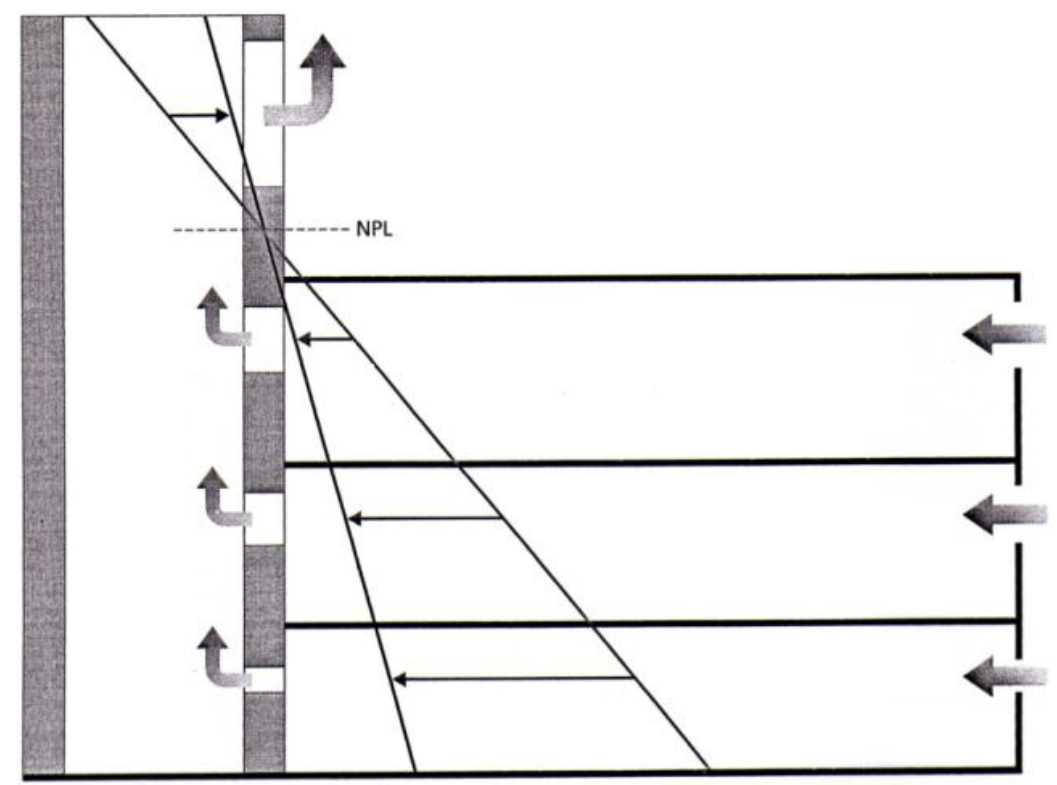

Figura 2.1.4: Aplicação do efeito chaminé em um projeto de edificação com três pavimentos (CIBSE, 2005).

As combinações de aberturas mudam também o padrão do escoamento no interior do edifício, além da altura da NPL. A figura 2.1.5(a) mostra a condição indesejável de saída de ar quente pelo pavimento superior, enquanto que as demais mostram soluções possíveis de serem adotadas, como isolamento do andar mais alto (figura 2.1.5(b)), posicionamento da abertura de saída em uma altura maior, fechando entradas próximas ao solo (figura 2.1.5(c)) ou mesmo aumentando a área da saída do (figura 2.1.5(d)). 


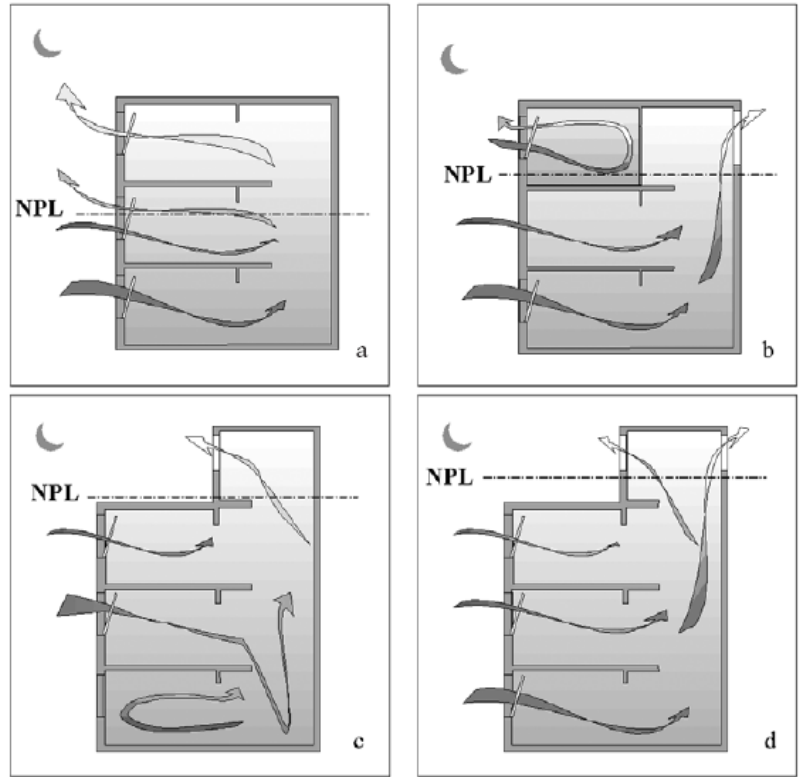

Figura 2.1.5: Estratégias para mudança da altura da linha de pressão neutra (ALLARD; GHIAUS, 2005).

Verifica-se que na figura 2.1.5(b) o pavimento superior, por estar desconectado do restante do ambiente, não possui a mesma NPL da edificação. Caso os diversos andarem possuam independência entre si, existirá uma linha de pressão neutra para cada um deles, como mostra a figura 2.1.6.

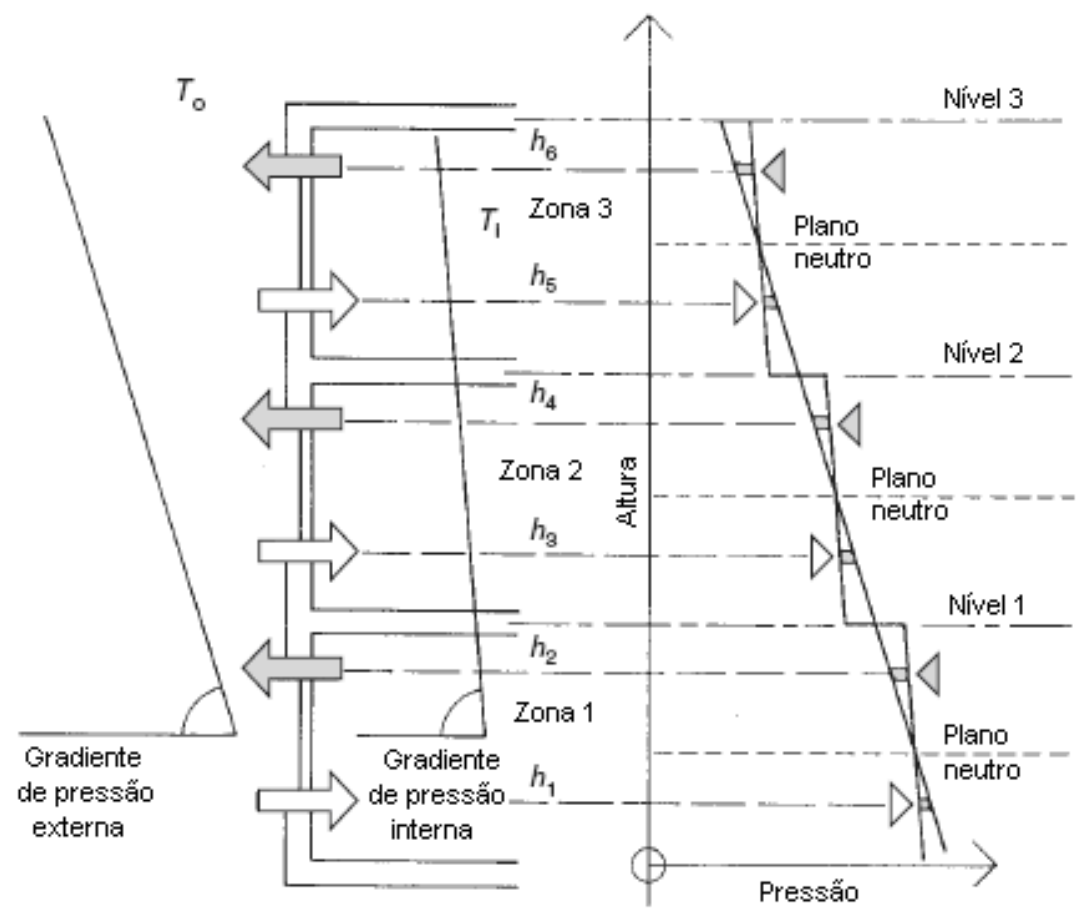

Figura 2.1.6: Pressão de empuxo e NPL para edificação com zonas verticais desconectadas (adaptado de AWBI, 2003). 
As análises apresentadas anteriormente levam em consideração a hipótese de que a temperatura do ambiente interno é aproximadamente constante, mantendo a variação de pressão com a altura uma função linear. Este fato, porém, não é sempre justificável - em edificações industriais pode haver significativa estratificação térmica, decorrente de maquinário e processos geradores de calor (ETHERIDGE; SANDBERG, 1996). Contudo, como a presente dissertação tem por objetivo analisar ambientes de escritórios, e não industriais, este não necessita ser mais profundamente descrito.

\subsubsection{Pressão do vento}

O vento consiste na movimentação de ar em relação a um ponto fixo sobre o terreno, e é desta maneira como é medido habitualmente nas estações meteorológicas do mundo (YARKE, 2005). O movimento do ar devido à pressão do vento, denominado de convecção forçada, é um fenômeno presente em sistemas de ventilação natural ${ }^{1}$ ou forçada. Em sistemas de ventilação natural, a origem da diferença de pressão são os ventos externos à edificação, enquanto que em sistemas de ventilação forçada a origem da diferença de pressão é um ventilador, que demanda consumo de energia para a sua operação.

O escoamento de ar ao redor das edificações pode exercer influência significativa na distribuição de pressões nas fachadas, e estas diferenças podem resultar de elementos como a forma da edificação, sua orientação, demais construções localizadas nas proximidades e perfil geográfico do local. A figura 2.1.7 ilustra a esteira formada ao redor de uma construção, enquanto que a figura 2.1.8 ilustra a influência do terreno sobre o comportamento da camada limite atmosférica.

De maneira geral, a fachada localizada a montante do escoamento possui pressão positiva, enquanto que as fachadas a jusante possuem pressão negativa, conforme ilustra a figura 2.1.9.

\footnotetext{
${ }^{1}$ É importante ressaltar que na ventilação natural, além dos efeitos da pressão do vento, responsável pela convecção forçada do ar no interior do ambiente, e dos efeitos de gradientes de temperatura entre o ar interior e o ar exterior, responsáveis pela convecção natural do ar por efeito chaminé (conforme visto no item 2.1.1), também pode ocorrer movimentação significativa do ar no interior do ambiente devido à convecção natural decorrente da existência de gradientes de temperatura entre o ar interior e superfícies aquecidas (pessoas, equipamentos, lâmpadas etc), na formação de plumas térmicas, conforme será visto na análise dos resultados no Capítulo 5.
} 


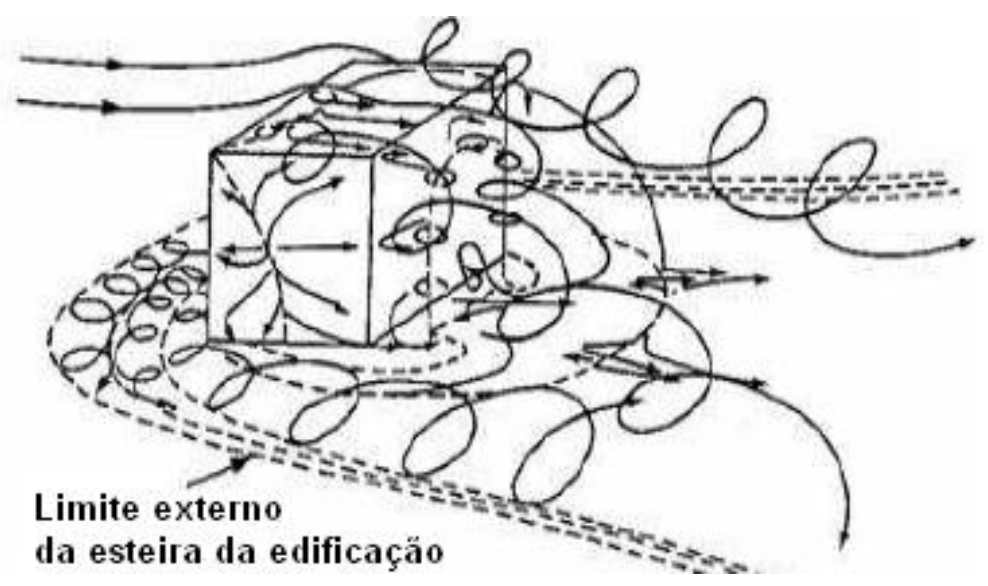

Figura 2.1.7: Esteira formada ao redor de edificação por incidência de ventos (FADIGAS, 2010).

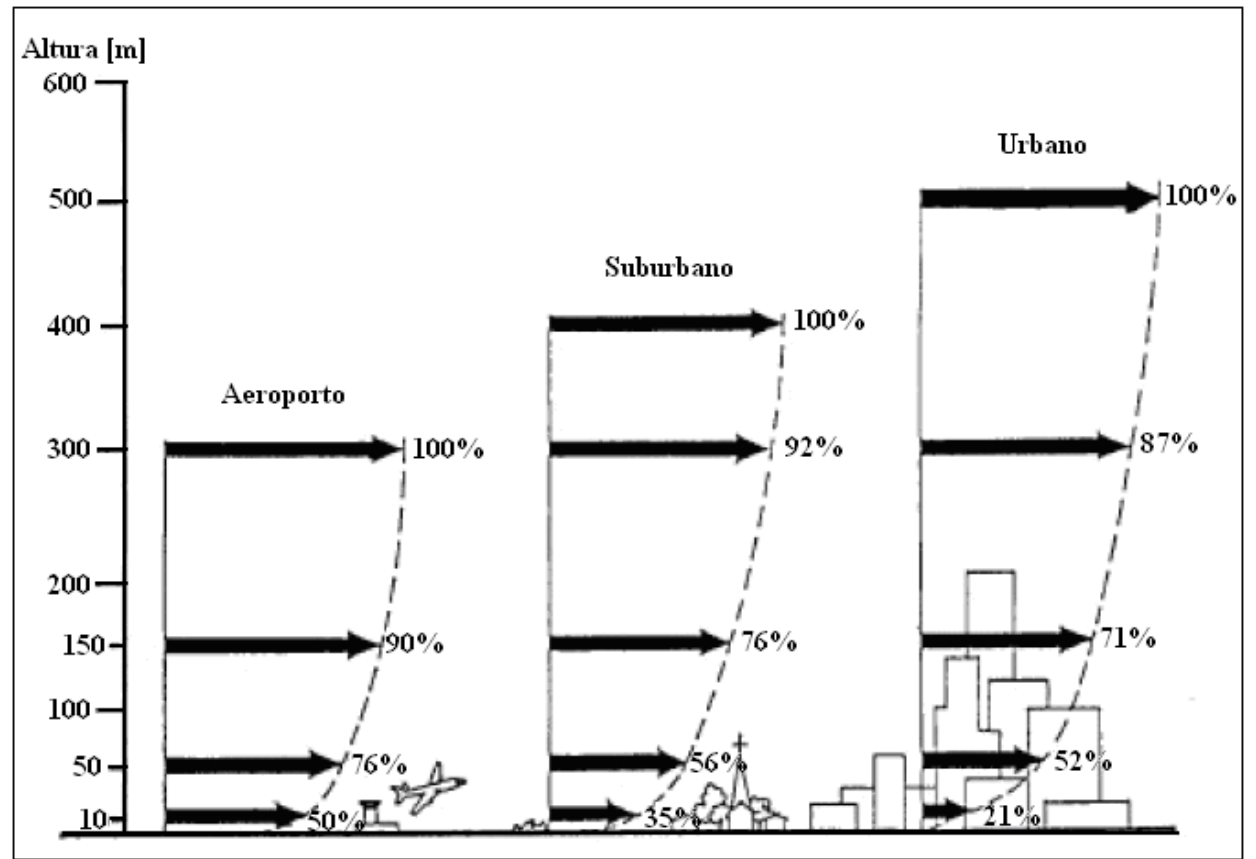

Figura 2.1.8: Perfis de velocidades da camada limite atmosférica em diferentes tipos de terrenos (adaptado de YARKE, 2005).
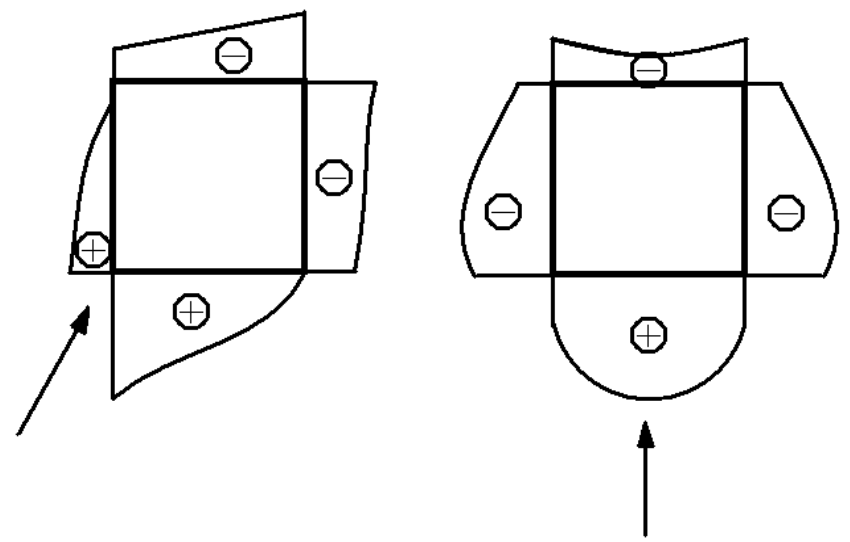

Figura 2.1.9: Distribuição esquemática de pressão ao redor de um edifício (adaptado de YARKE, 2005). 
Desta forma, um bom projeto de ventilação natural deve levar em consideração as condições externas do local específico de implantação, pois o fluxo de ar no ambiente ventilado terá influência também da geometria das aberturas e obstruções internas, assim como dos elementos externos apontados anteriormente. As aberturas podem guiar o ar dentro de padrões específicos e regular sua velocidade (BOUTET, 1987).

Tomando como base um edifício retangular, a velocidade média do vento que se aproxima é maior conforme aumenta a altura analisada. Tanto o perfil de velocidade quando a turbulência do escoamento possuem forte influência sobre o escoamento padrão e distribuição de pressões sobre as fachadas.

Como ilustra a figura 2.1.10, logo na fachada de incidência, é formada uma área de estagnação, sendo que as demais fachadas ficam sob a ação da separação do escoamento, gerando área de recirculação que causará a distribuição de pressão negativa descrita anteriormente.

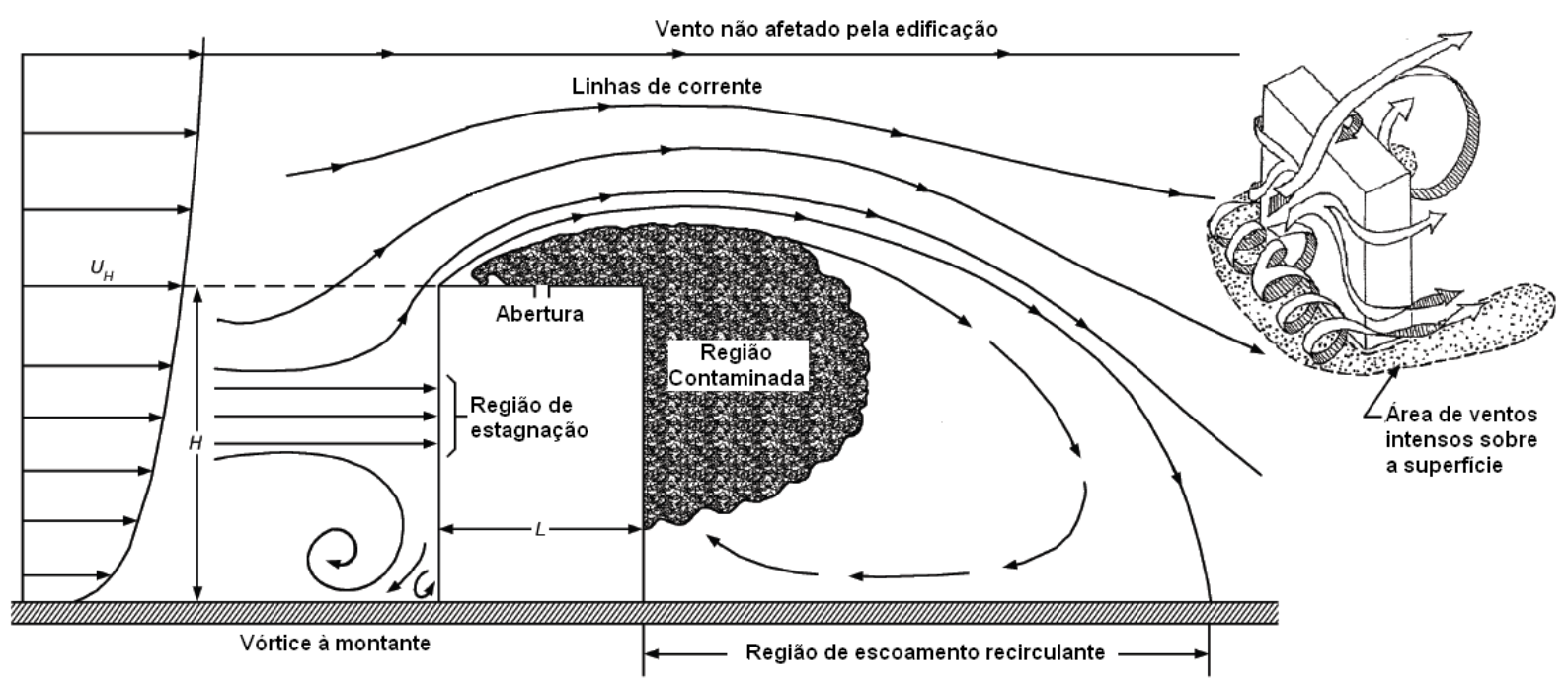

Figura 2.1.10: Fluxos padrão ao redor de uma edificação retangular (adaptado de ASHRAE, 2009).

A própria cobertura das edificações sofrerá fenômeno semelhante, decorrente das mesmas causas. À montante do edifício, na região próxima do solo, poderá ocorrer a formação de um vórtice que pode causar altas velocidades. Esse vórtice será propagado pelos lados do edifício, com um formato semelhante a "U", e causa suspensão de poeira e detritos que podem contaminar tomadas de ar próximas do solo.

A taxa de ventilação causada pela ação do vento é influenciada principalmente pela velocidade média do ar e pela direção predominante, assim como pelas flutuações turbulentas, diárias e sazonais. Uma equação para relacionar a vazão de ar em determinada abertura com 
sua área, em função da velocidade do vento e a eficiência das aberturas, pode ser encontrada em ASHRAE (2009) e é apresentada na equação 2.2.2.

$$
\mathrm{Q}=\mathrm{C}_{\mathrm{V}} \mathrm{AV}
$$

onde $\mathrm{Q}$ é a vazão volumétrica $\left[\mathrm{m}^{3} / \mathrm{s}\right], \mathrm{C}_{\mathrm{V}}$ é o coeficiente de vazão [-], A é a área de abertura $\left[\mathrm{m}^{2}\right], \mathrm{V}$ é a velocidade do fluido $[\mathrm{m} / \mathrm{s}]$.

Conforme apresentado anteriormente, a orientação da edificação também influencia significativamente o escoamento ao seu redor, modificando o campo de pressões nas fachadas. As dimensões das fachadas podem fazer com que haja um recolamento do fluxo separado na fachada de incidência do vento, ou mesmo causar o surgimento de vórtices nas arestas da construção, como ilustra a figura 2.1.11.
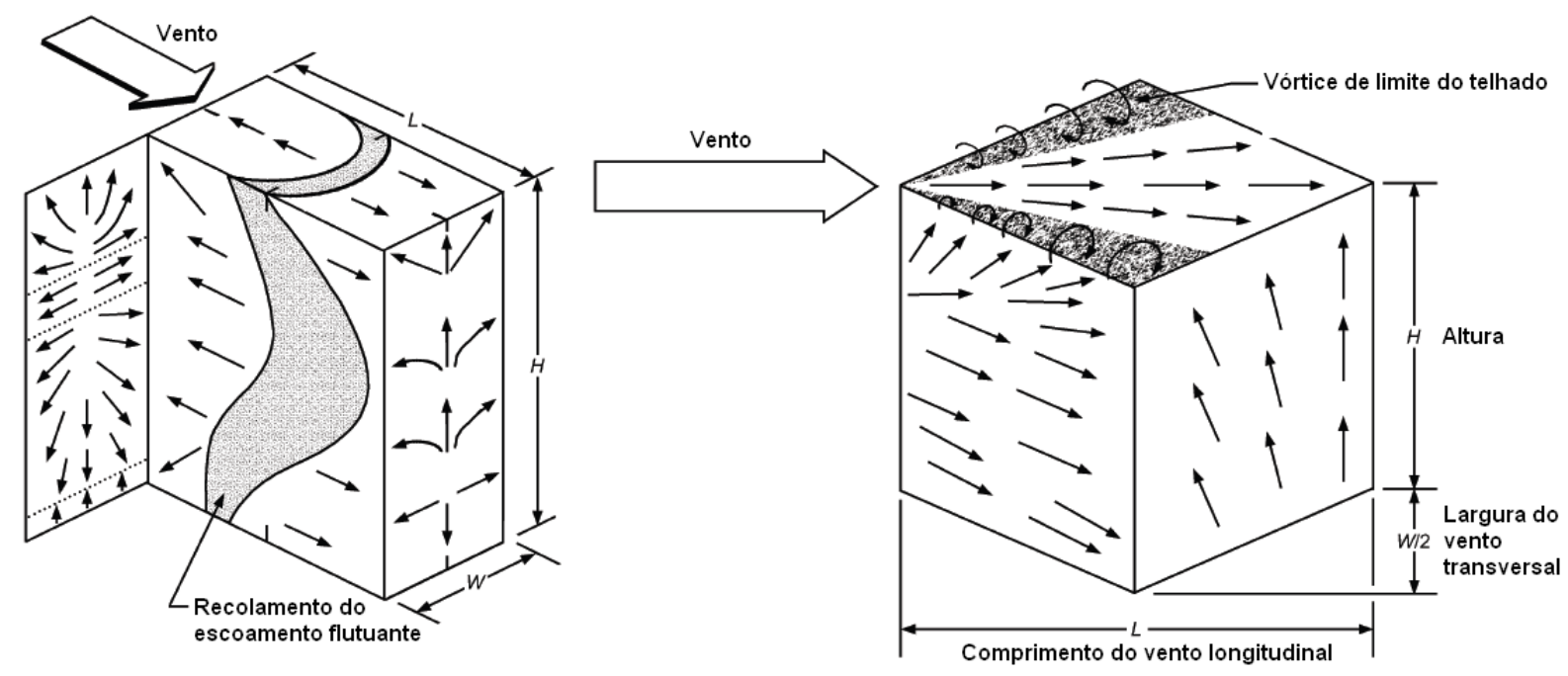

Figura 2.1.11: Fluxos padrão em superfícies e dimensões da edificação (adaptado de WILSON, 1979).

\subsubsection{Coeficiente de pressão}

A movimentação do fluxo de ar ao redor da edificação dará origem a uma distribuição de pressões sobre sua fachada, sendo que estas serão proporcionais à pressão dinâmica da corrente livre, conforme equação 2.2.3. A constante que define esta proporcionalidade é chamada de coeficiente de pressão, $\mathrm{C}_{\mathrm{P}}$, e seu valor depende das características do escoamento nas proximidades de um obstáculo, assim como o próprio obstáculo (ALLARD; GHIAUS, 2005). 


$$
\mathrm{p}_{\mathrm{W}}=\mathrm{C}_{\mathrm{P}} \cdot \mathrm{p}_{\mathrm{din}}=\mathrm{C}_{\mathrm{P}} \cdot\left(0,5 \cdot \rho_{\mathrm{o}} \cdot \mathrm{V}_{\mathrm{o}}^{2}\right)
$$

onde $\mathrm{p}_{\mathrm{W}}$ é a pressão do vento [Pa], $\mathrm{C}_{\mathrm{P}}$ é o coeficiente de pressão [-], $\mathrm{p}_{\text {din }}$ é a pressão dinâmica do vento $[\mathrm{Pa}], \rho_{\mathrm{o}}$ é a massa específica do ambiente externo $\left[\mathrm{kg} / \mathrm{m}^{3}\right]$ e $\mathrm{V}_{\mathrm{o}}$ é a velocidade do vento $[\mathrm{m} / \mathrm{s}]$.

Entretanto, o fluxo de ar sobre as fachadas não é constante, devido às características transitórias do escoamento, assim como sua turbulência, de forma que valores médios de pressão são utilizados para cálculos. Em geral, fachadas localizadas a montante possuirão coeficientes de pressão positivos e aquelas a jusante valores negativos. Características geométricas e do escoamento influenciarão sobre o sinal deste parâmetro nas fachadas laterais, assim como a topografia local e vegetação existente no entorno da edificação.

Caso a edificação possua uma forma retangular, é possível utilizar dados de testes experimentais já realizados em túneis de vento, sendo necessárias correções para a densidade do ar local, bem como negligenciados os efeitos decorrentes de irregularidades do terreno e seu entorno neste caso. A figura 2.1.12 apresenta coeficientes de pressão médios para edifícios altos, enquanto que a figura 2.1.13 contém os valores para edifícios baixos. Yarke (2005) apresenta diversas tabelas, em função da relação de altura e largura da edificação, assim como ângulo de incidência dos ventos, para se obter valores dos coeficientes.

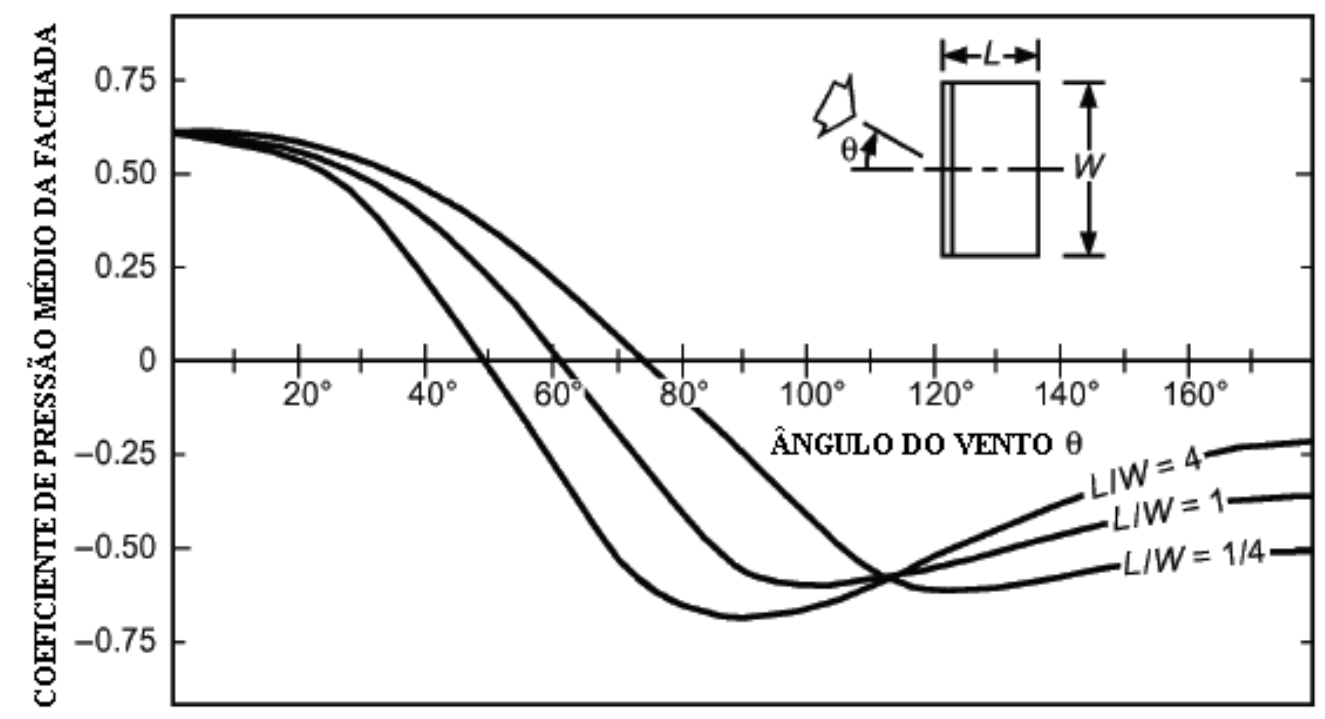

Figura 2.1.12: Coeficientes de pressão médios para fachadas de edifícios altos (adaptado de AKINS, PETERKA, CEMAK, 1979). 
Coeficientes de pressão podem ser obtidos também com simulações numéricas, como as utilizadas no presente trabalho. Esta ferramenta permite obter o valor médio da pressão em qualquer superfície modelada, como por exemplo as fachadas da edificação, e visualizar a distribuição da pressão sobre as superfícies, conforme ilustra a figura 2.1.14.
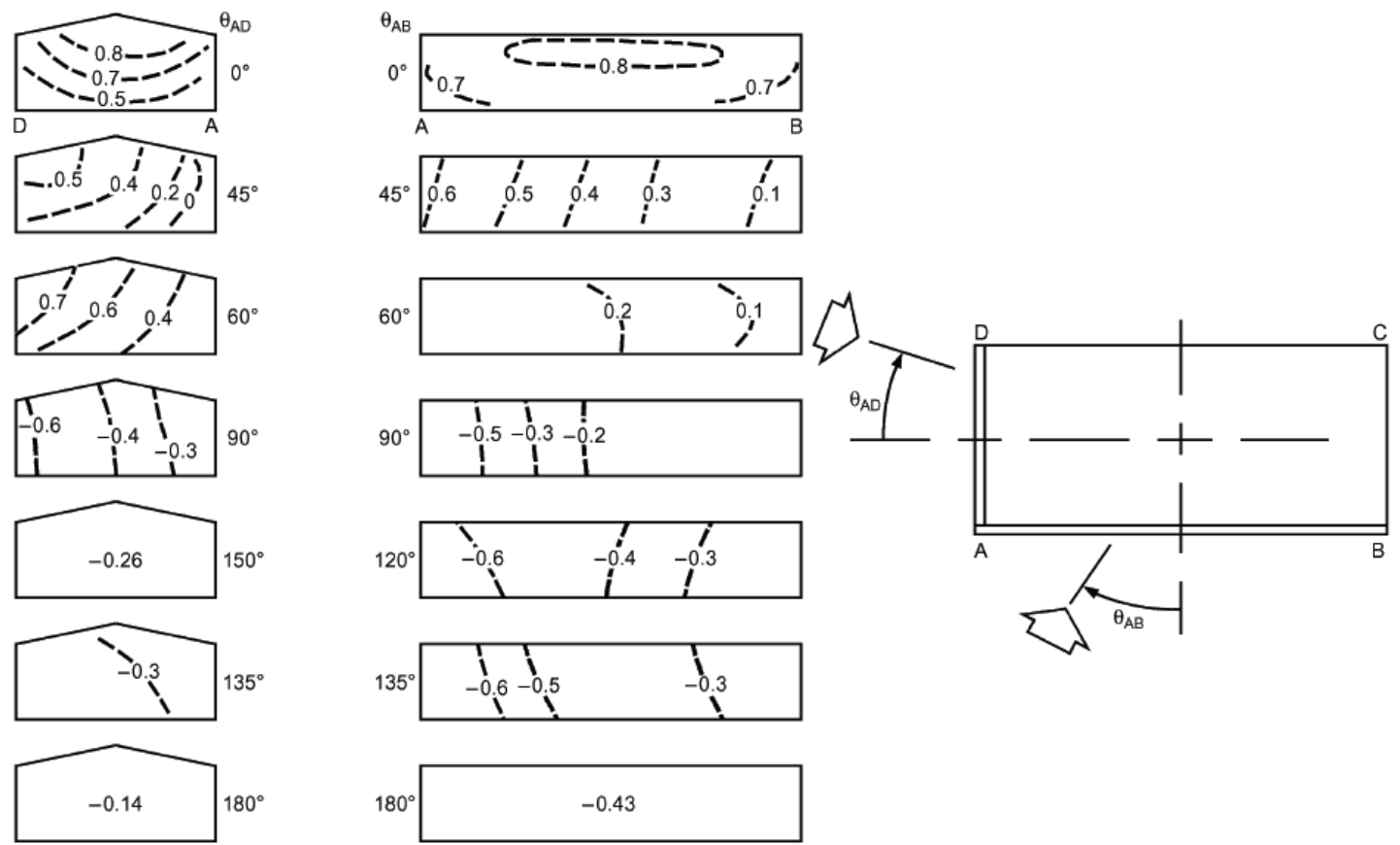

Figura 2.1.13: Coeficientes de pressão médios para fachadas de edifícios baixos (LINDDAMENT, 1986).

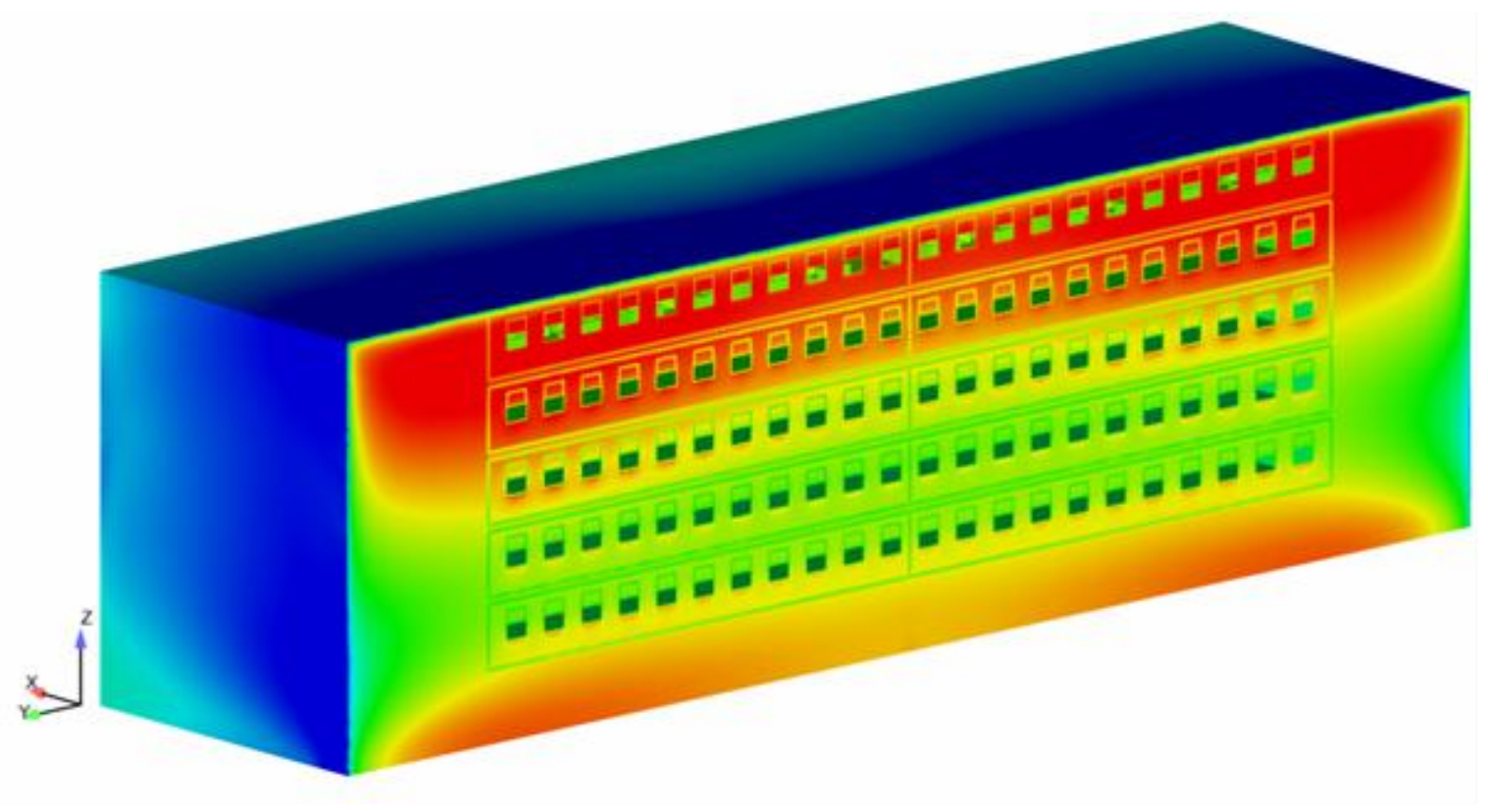

Figura 2.1.14: Distribuição de pressão sobre a fachada em um modelo numérico. 
O uso dos coeficientes médios, no entanto, negligencia as variações de pressão em uma mesma fachada, podendo levar a erros no cálculo da vazão de ar. Cóstola et al (2010) efetuou uma análise para verificar as incertezas decorrentes da utilização destes coeficientes médios, em comparação com coeficientes locais.

Em edifícios com pequenas variações de $C_{P}$ nas fachadas a montante e jusante, concluiu-se que o uso dos coeficientes médios pode levar a cálculos de vazões $77 \%$ menor a $400 \%$ maior, sendo que se o gradiente de pressão entre as fachadas for grande estes valores são reduzidos para $48 \%$ e $42 \%$, respectivamente. Cóstola et al (2010) ressaltam que estes valores foram obtidos para análises de edificações isoladas do entorno considerando apenas a ventilação por ação do vento. Embora os modelos utilizados sejam simples, é provável que o emprego de coeficientes locais leve a projetos de ventilação natural mais precisos.

Normalmente, o coeficiente de pressão é obtido de medições de pressão em túneis de vento utilizando modelos em escala reduzida dos edifícios ou dos componentes das edificações ou mesmo medições de pressão em construções reais (AWBI, 2003). Os valores do coeficiente de pressão são utilizados não somente para cálculos de vazão em sistemas de ventilação natural, mas também para infiltrações em edifícios climatizados.

\subsection{ABERTURAS DA FACHADA}

Existem diversos tipos de aberturas da fachada utilizadas para ventilação natural, sendo que o mais comumente utilizado é a janela, para a qual a principal força motriz é o vento, embora o gradiente de temperatura tenha um efeito não-negligenciável (ALLARD; GHIAUS, 2005).

Os elementos utilizados para abertura podem ser divididos em aberturas grandes e pequenas, como apresentado por Awbi (2003), ou pelos tipos de elementos, como descrito por CIBSE (2005) e Allard (1998), sendo esta última a metodologia utilizada nesta dissertação.

\subsubsection{Janelas e portas}

Janelas operáveis são comumente usadas em sistemas de ventilação natural, e podem variar significativamente suas características, como geometria e fluxo de ar, por exemplo. 
Estas podem disponibilizar grandes quantidades de ar, visando à retirada de poluentes ou carga térmica, porém possuem baixa capacidade de manter um fluxo de ar baixo, porém contínuo e controlado (ALLARD; GHIAUS, 2005).

São apontadas por CIBSE (2005) e Kendrick, Martin e Booth (1998) diversas características que devem ser levadas em consideração durante a escolha dos tipos de janelas utilizadas para a ventilação natural. Os principais aspectos - capacidade de ventilação, controlabilidade e conforto, segurança e selagem - encontram-se descritos nos parágrafos subsequentes.

A capacidade de ventilação consiste em um item primordial, visto que no projeto de um sistema de ventilação natural são determinados fluxos de ar necessários, e as aberturas devem possuir capacidade de prover o determinado fluxo. O coeficiente de descarga, $C_{d}$, é um parâmetro utilizado na quantificação do volume de ar que a abertura permite entrar no ambiente e se encontra descrito no tópico 2.2.3.

O percentual de abertura efetivo é outro fator relacionado diretamente com a capacidade de ventilação, e varia diretamente com a configuração da janela. Este valor pode variar desde $30 \%$ para janelas do tipo maxim-ar e basculante alta + basculante central (MARCONDES, 2010) até 90\% para janelas pivotantes, articuladas e deslizantes (YARKE, 2005).

Um exemplo de determinação do percentual de abertura efetivo de uma janela se encontra na figura 2.2.1, onde é apresentado um corte e uma vista frontal da janela tipo maxim-ar. Note que a abertura efetiva deve ser contabilizada para tanto a parte superior como inferior da abertura, e que obstruções no parapeito podem reduzir a eficiência do dispositivo.

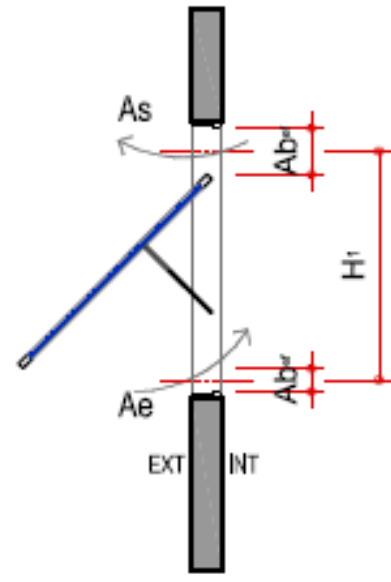

CORTE

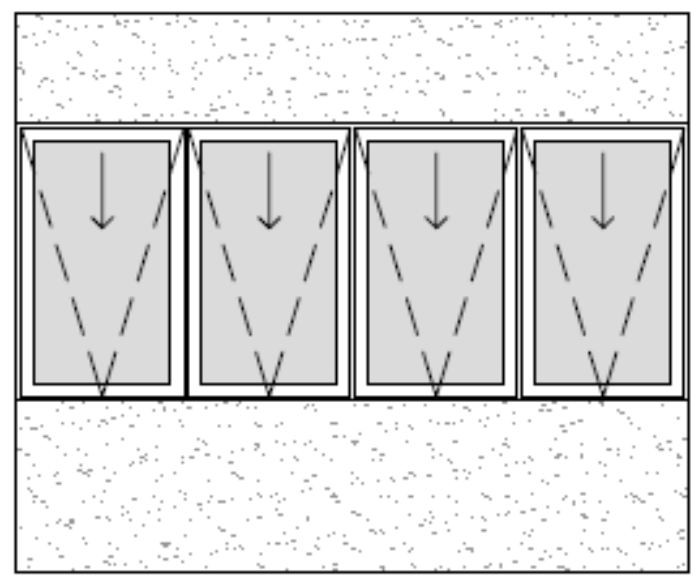

ELEVAÇÃO EXTERNA

Figura 2.2.1: Representação da área de abertura efetiva para janela tipo maxim-ar (MARCONDES, 2010). 
Controlabilidade das janelas é outro fator de grande impacto nos sistemas de ventilação natural. Caso janelas sejam demasiadamente grandes ou pesadas, pode haver dificuldades para os ocupantes controlarem a abertura destes elementos de acordo com suas necessidades. Geralmente, esta possibilidade proporciona ao usuário uma sensação de satisfação e conforto (CIBSE, 2005), fazendo com que os seus ocupantes sintam-se confortáveis com temperaturas do ar mais altas do que a população de ambientes climatizados (ROETZEL, et al., 2010).

Para manter o fluxo ar em um nível adequado, tendo em mente o conforto, a controlabilidade deve permitir também um controle fino, ou seja, que exista a possibilidade de regular as aberturas além de posições pré-fixadas, como totalmente aberta, fechada ou intermediárias. Visando ampliar o conforto, é possível ainda combinar a controlabilidade de algumas janelas pelos ocupantes com o controle automático de outras aberturas.

Considerando a automatização do processo de controle das janelas, o manual de automação de sistemas prediais da CIBSE (2000) cita que caso as aberturas sejam grandes, estas demandam alguma forma de controle modular, ao passo que, caso sejam pequenas, é possível utilizar uma estratégia de abertura e fechamento completos. Este é especialmente válido se uma série de aberturas for operada de forma sequencial.

Uma das maiores preocupações para um ocupante de uma edificação é a segurança contra entradas não autorizadas (ALLARD, 1998). Considerando que as aberturas criam um meio de ligação direto do ambiente interno com o meio exterior, é necessário adotar medidas para garantir segurança, tais como limitar a abertura máxima das janelas ou instalar dispositivos suplementares para a segurança. Usualmente, o problema da segurança está mais relacionado com o pavimento térreo ou primeiros andares (CIBSE, 2005).

Existem outros aspectos que devem ser considerados no projeto de sistemas de ventilação natural, como o cuidado para a selagem, de forma que a ventilação não seja prejudicada por intempéries como a chuva. O projeto de locais como salas de espera, salas de fotocópias e áreas de tratamento que podem ser ocupadas apenas de forma intermitente deve particularmente considerar este assunto (KENDRICK; MARTIN; BOOTH, 1998).

Geometrias muito distintas podem ser encontradas em janelas, conforme ilustra a figura 2.2.2. Embora existam aberturas que possam receber classificações diferentes, como basculantes laterais e inferiores ao mesmo tempo, elas são essencialmente divididas em três classes: 
a) Aberturas simples: são as janelas de correr, simples, duplas, verticais e/ou horizontais.

b) Aberturas verticais: são as basculantes laterais e pivotantes verticais, onde o eixo de rotação para operação é vertical.

c) Aberturas horizontais: são as basculantes superiores e inferiores, pivotantes horizontais e maxim-ar, onde o eixo de rotação para operação é horizontal.

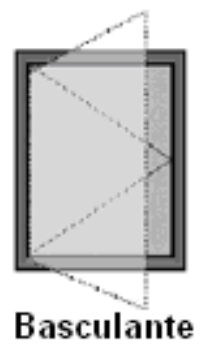

lateral

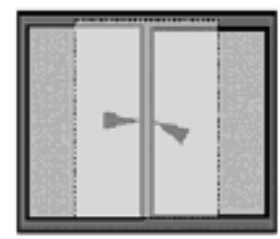

De correr horizontal

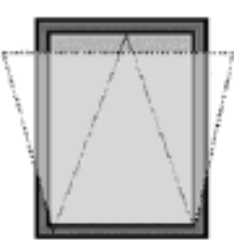

Basculante inferior

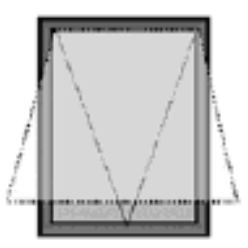

Basculante superior

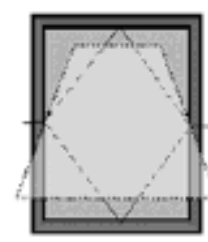

Pivotante horizontal

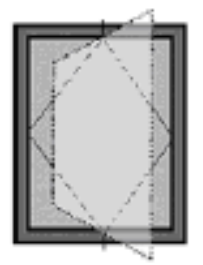

Pivotante vertical

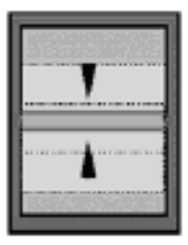

De correr vertical

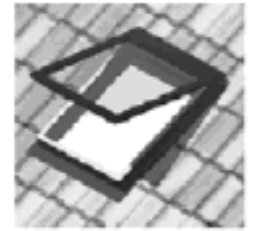

Abertura zenital

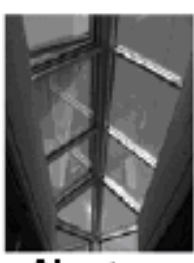

Abertura zenital

Figura 2.2.2: Tipos de aberturas (adaptado de ROULET, 2004).

Janelas de aberturas simples geralmente não afetam o padrão do escoamento, exceto pela região próxima da janela, onde ocorre aumento da velocidade do ar (ALLARD, 1998), e o fluxo interno usualmente segue a direção do externo. Sua área de abertura efetiva é de no máximo $50 \%$, e é considerada segura para casos de altas velocidades do vento. Como desvantagens, Kendrick, Martin e Booth (1998) apontam que este tipo de abertura não é adequado para ventilação noturna e proteção contra chuvas, além de poder causar correntes de ar na altura do plano de trabalho.

As aberturas verticais exercem uma influência variada sobre o padrão e velocidade do vento, e a ventilação do ambiente é fortemente condicionada às condições externas (CIBSE, 2005). Elas podem causar a entrada de correntes de ar e tornar difícil o controle mais preciso no período de inverno, além de não ser segura em ocorrência de rajadas de vento, podendo ocorrer até autorrotação nas pivotantes. O uso de persianas é impossível no caso destas últimas, assim como as basculantes para o interior do ambiente ventilado. A utilização de 
fachadas duplas ou de aberturas para um átrio central da edificação são alternativas viáveis em edificações altas para evitar este tipo de condições ambientais indesejáveis.

Já as aberturas horizontais influenciam o padrão de escoamento interno do ar principalmente na direção vertical, conforme apresentado na figura 2.2.3. As pivotantes possuem grande capacidade de ventilação, sendo bem utilizada tanto em casos de ventilação unilateral, onde o ar entra pela abertura inferior e sai pela superior, assim como ventilação cruzada, com o ar entrando por ambas as áreas, como mostra a figura 2.2.4.

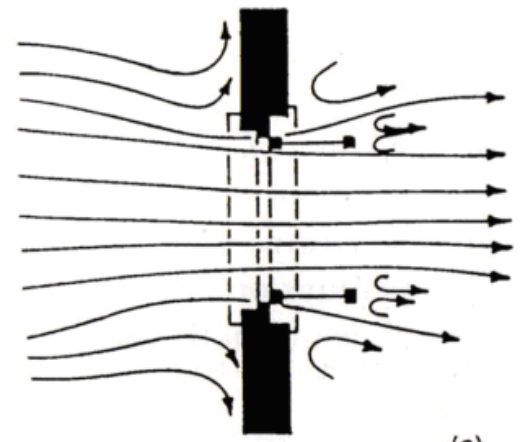

(a)

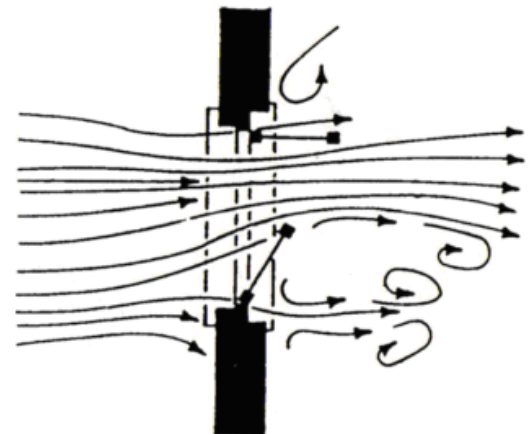

(b)

Figura 2.2.3: Influência da abertura de janela basculante superior e inferior sobre o escoamento - totalmente aberta (a) e parcialmente fechada (b) (ALLARD, 1998).

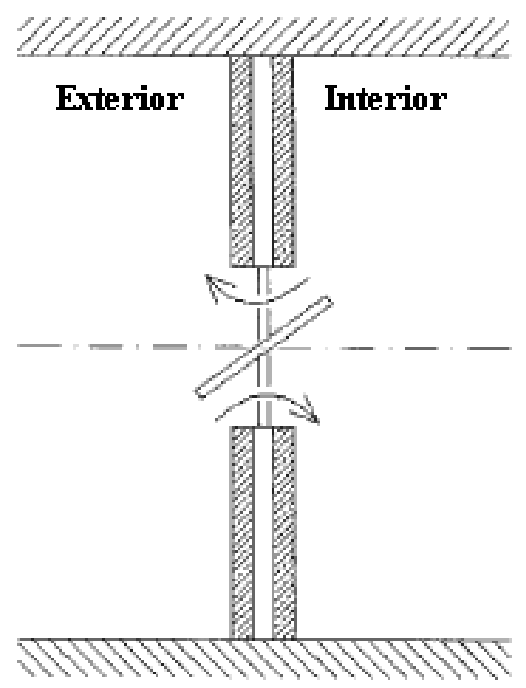

Lado único

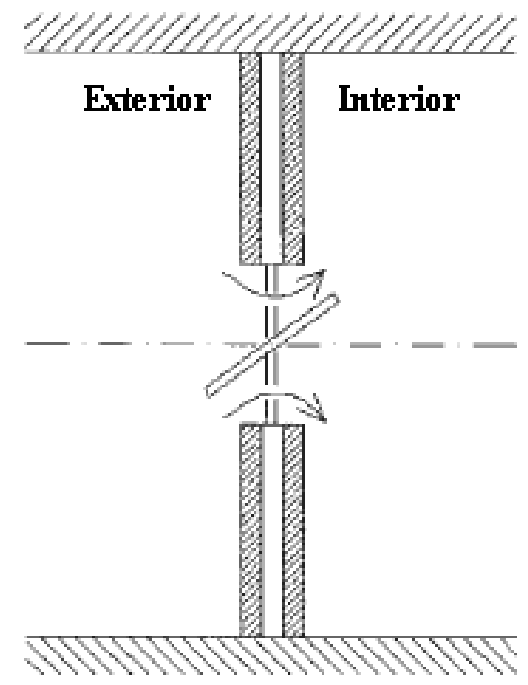

Cruxada

Figura 2.2.4: Aplicações da janela pivotante horizontal em ventilação unilateral e cruzada (adaptado de AWBI, 2003).

A janela basculante possui uma larga gama de opções de dispositivos atuadores (CIBSE, 2005), e a superior é mais indicada para os casos de ventilação de ambientes ocupados, enquanto que a inferior para proporcionar ventilação noturna e na proximidade do 
teto. Este tipo é menos propenso a causar correntes de ar durante o inverno, porém possui menor capacidade de ventilação nos dias quentes do verão. Sua proteção contra chuvas pode ser boa no caso da basculante superior, porém pode refletir ruído mais facilmente para o interior do ambiente.

\subsubsection{Aberturas zenitais e chaminés}

Uma das vantagens da abertura zenital é a possibilidade de elevação da NPL, melhorando assim as condições de ventilação por efeito chaminé (ALLARD; GHIAUS, 2005). A figura 2.1.5 ilustra como a existência de aberturas nas partes altas da edificação pode impactar no escoamento das demais aberturas, permitindo até que o ar entre na edificação pelas aberturas dos ambientes ventilados e saindo pelas aberturas zenitais, por exemplo.

As chaminés fazem uso do efeito chaminé, onde o ar em seu interior é aquecido pela energia solar, forçando o fluxo para cima. Essa chaminé é então conectada em sua base com o interior da edificação e em seu topo com o meio externo, criando uma forma de exaustão natural, como ilustra a figura 2.2.5.

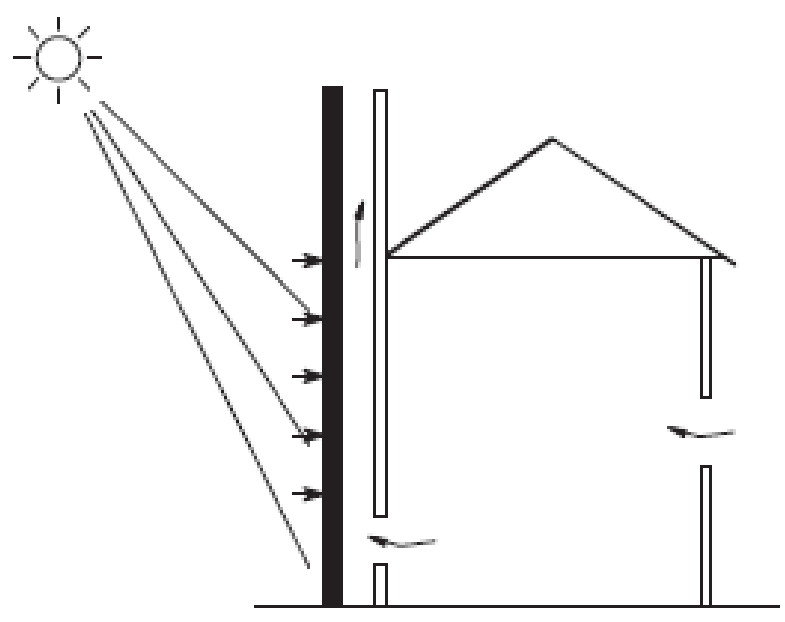

Figura 2.2.5: Chaminé solar (AWBI, 2003).

\subsubsection{Coeficiente de descarga}

O coeficiente de descarga é um parâmetro adimensional utilizado para avaliar o fluxo de ar que passa através de uma determinada abertura, sendo geralmente aplicado a janelas nos sistemas de ventilação natural. Este coeficiente é função principalmente da geometria da 
abertura, e relaciona a vazão por esta com a diferença de pressão, área da abertura e massa específica do fluido em movimento, como ilustra a equação 2.2.1.

$$
C_{d}=\frac{Q}{A \sqrt{\frac{2 \Delta p}{\rho}}}
$$

onde $\mathrm{C}_{\mathrm{d}}$ é o coeficiente de descarga [-], Q é a vazão volumétrica [m³/s], A é a área efetiva de abertura $\left[\mathrm{m}^{2}\right], \Delta$ p é a variação de pressão $[\mathrm{Pa}], \rho$ é a massa específica do ar $\left[\mathrm{kg} / \mathrm{m}^{3}\right]$.

A relação apontada na equação 2.2.1 é baseada na equação de Bernoulli, sendo esta utilizada em escoamentos incompressíveis, irrotacionais e em regime permanente. $\mathrm{O}$ coeficiente de descarga depende apenas do diferencial de pressão em escoamentos laminares, ou seja, a vazão dependerá apenas da pressão. Já em escoamentos turbulentos, com altos valores de Reynolds (ver equação 2.2.2), essa hipótese também será válida, desde que se mantenha fixo o número de Reynolds (ASHRAE, 2009).

$$
\operatorname{Re}=\frac{\rho \cdot V \cdot D}{\mu}
$$

onde Re é o número de Reynolds [-], $\rho$ é a massa específica do $\operatorname{ar}\left[\mathrm{kg} / \mathrm{m}^{3}\right]$, V é a velocidade do fluido $[\mathrm{m} / \mathrm{s}$ ], D é a dimensão característica do escoamento [m], $\mu$ é a viscosidade dinâmica $\left[\mathrm{N} \cdot \mathrm{s} / \mathrm{m}^{2}\right]$.

Uma versão mais geral da equação 2.2.1 também pode ser utilizada. Nela, a vazão pela abertura é descrita somente em função do diferencial de pressão e de dois coeficientes, $c$ e $n$, como apresentado pela equação 2.2.3. Estas constantes vão depender de condições do escoamento, como velocidade e pressão, assim como das características geométricas da abertura analisada.

$$
\mathrm{Q}=\mathrm{c} \cdot(\Delta \mathrm{p})^{\mathrm{n}}
$$

onde Q é a vazão volumétrica $\left[\mathrm{m}^{3} / \mathrm{s}\right], \Delta$ p é a variação de pressão [Pa], n é a potência que relaciona a variação de pressão com a vazão [-], c é o coeficiente que relaciona a variação de pressão com a vazão $\left[\left(\mathrm{m}^{(3+\mathrm{n}) \cdot \mathrm{s}}{ }^{(\mathrm{n}-1)}\right) / \mathrm{kg}^{\mathrm{n}}\right]$. 
O coeficiente $n$ contém a relação que existe entre a diferença de pressão entre dois pontos e a velocidade do escoamento entre eles, sendo o valor 0,5 da equação 2.2.1 consequência da equação de Bernoulli. Já o coeficiente $c$ representa os fatores que influenciam a vazão de ar com uma mesma diferença de pressão, como por exemplo, a área de abertura das janelas ou a massa específica do ar.

A bibliografia apresenta diversos valores de coeficiente de descarga. Uma abertura com arestas retas possui um $\mathrm{C}_{\mathrm{d}}$ que varia de 0,61 (KENDRICK; MARTIN; BOOTH, 1998; AWBI, 2003) a 0,63 (ASHRAE, 2009). Grandes aberturas internas possuem valores próximos da unidade, enquanto que pequenas aberturas valores de 0,65 . Um valor médio proposto é de 0,78 (ALLARD; GHIAUS, 2005). Outros valores dos coeficientes para aberturas são apresentados em Santamouris e Asimakopoulos (1996) e ASHRAE (2009).

\subsection{OBSTRUÇÕES DO SISTEMA}

Essencialmente, qualquer elemento que se encontre no caminho do fluxo de ar pode ser caracterizado como uma obstrução do sistema, já que a perda de carga será aumentada. Portas, janelas, partições internas, mobiliário, etc. são elementos que não só resistem ao escoamento, como também podem modificar o padrão de ventilação (CIBSE, 2005).

Uma discussão sobre os principais componentes de obstrução dos sistemas se encontra nos itens subsequentes.

\subsubsection{Mobiliário e partições internas}

O mobiliário e as partições internas mudam a geometria do ambiente ventilado e, consequentemente, mudam as características do escoamento de ar dentro deste ambiente. As partições, embora auxiliem no conforto acústico e na privacidade dos ocupantes, devem ser mantidas baixas, preferencialmente com até 1,2 $\mathrm{m}$ de altura (KENDRICK; MARTIN; BOOTH, 1998). CIBSE (2005) recomenda que, quando empregadas divisórias altas, grelhas de transferência sejam instaladas, permitindo troca de ar entre os ambientes ventilados naturalmente. 
De forma semelhante, também deve haver cuidado com o posicionamento do mobiliário no layout. Este pode afetar o campo de velocidades de várias maneiras (ETHERIDGE; SANDBERG, 1996), sendo apontadas três maneiras: resistindo ao escoamento; mudando o volume do ambiente ventilado; e desviando a corrente principal.

Kendrick, Martin e Booth (1998) apontam que o mobiliário deve ser mantido baixo na maior parte possível do ambiente ventilado, sendo recomendado o posicionamento de estantes, armários e outros mobiliários altos perpendicularmente às paredes do perímetro do ambiente, entre as janelas.

Clements-Croome (2003) apresenta um exemplo qualitativo de influência do mobiliário em uma edificação de quatro pavimentos e átrio central com estantes altas posicionadas no primeiro pavimento, próximo ao átrio. Foi verificado que existe um aumento da temperatura no primeiro pavimento, próximo às estantes, em comparação com o restante do ambiente.

Estas prateleiras poderiam então ser posicionadas entre as janelas, a fim de minimizar a influência sobre o fluxo de ar. Caso esta recomendação não seja exequível, elas deveriam ser posicionadas de forma a minimizar a resistência ao fluxo de ar, perpendicularmente às janelas (KENDRICK, C.; MARTIN, A.; BOOTH, W, 1998).

As variações no fluxo interno de ar causadas pelo mobiliário podem causar não só o aumento de temperaturas indicado em Clements-Croome (2003), mas também aumentar demasiadamente a velocidade do ar. Jatos defletidos por obstáculos e mobiliário na zona ocupada são uma fonte comum de problemas de corrente de ar (ETHERIDGE; SANDBERG, 1996).

Bojic, Yik e Lo (2002) analisaram via CFD o impacto do posicionamento de um ar condicionado de janela sobre o fluxo de ar em um ambiente de dormitório, sendo incluso neste modelo mobiliário e um ocupante. Segundo os autores, a melhor condição de conforto térmico foi obtida quando o equipamento de climatização se encontrava na distância máxima dos armários, ou seja, quando o fluxo de ar sofria mínima obstrução do mobiliário.

\subsubsection{Janelas e portas}

Apesar de serem utilizadas como aberturas, as janelas também podem ser caracterizadas como uma fonte de resistência para o escoamento do fluido, uma vez que diferentes níveis de abertura permitem a passagem de volumes distintos de ar. De forma 
semelhante, as portas também variam o comportamento do escoamento de acordo com sua abertura.

Diversos estudos foram realizados para examinar as características de resistência destas aberturas (YANG et al, 2010). Uma análise de como o coeficiente de descarga destes elementos varia de acordo com o ângulo de abertura de portas e janelas foi feita por Yang et al (2010), onde simulações utilizando CFD foram realizadas. Ainda, um túnel de vento em escala foi construído para validação das análises computacionais.

Quando o ângulo de abertura da porta ou janela é inferior a $30^{\circ}$, o coeficiente de perda varia abruptamente, mantendo-se aproximadamente constante para ângulos acima deste valor (YANG et al, 2010). Desta forma, seria interessante manter as aberturas com no mínimo a angulação indicada, visando redução da perda do potencial de ventilação natural.

\subsection{ESTRATÉGIAS DE VENTILAÇÃo}

De acordo com as características arquitetônicas externas e internas da edificação, é possível combinar os elementos apresentados anteriormente, eventualmente incluindo mais equipamentos ou procedimentos de operação, para desenvolver uma estratégia de ventilação natural. CIBSE (2005) cita seis estratégias que podem ser aplicadas:
a) Ventilação unilateral
b) Ventilação cruzada
c) Ventilação por efeito chaminé
d) Ventilação por fachada dupla
e) Estratégias assistidas mecanicamente
f) Ventilação noturna

No contexto desta dissertação, onde é avaliada a influência de diferentes sistemas de fachada e mobiliário interno sobre as condições de ventilação natural de ambientes de escritório, não cabe a análise de estratégias assistidas mecanicamente, pois seria necessária a inclusão de elementos mecânicos de ventilação, tais como ventiladores e dutos específicos para este fim.

Embora a utilização da ventilação noturna possa auxiliar na implantação de sistemas de ventilação natural, esta se caracteriza por ser uma estratégia diferente de operação dos 
mesmos componentes utilizados durante o período ocupado. Sua utilização otimiza o uso de condições climáticas favoráveis, porém da mesma maneira foge do contexto desta dissertação.

O modo de ventilação por efeito chaminé ocorre devido à diferença de densidade do ar, originando um fluxo convectivo no ambiente. De maneira semelhante, a fachada dupla também age desta forma, criando uma chaminé solar em toda a fachada da edificação. Contudo, como estes modos requerem mudanças mais significativas na arquitetura exterior do edifício, em comparação com a ventilação unilateral e a cruzada, apenas as duas últimas foram abordadas no trabalho, visando à análise comparativa da melhor alternativa.

\subsubsection{Ventilação unilateral}

A ventilação unilateral consiste em um ambiente onde existe apenas uma única parede com uma ou mais aberturas, sendo esta(s) utilizada(s) tanto para a entrada como para a saída do fluxo de ar, conforme ilustrado pela figura 2.4.1. Um exemplo de local onde esta estratégia pode ser adotada é uma sala fechada, com partições internas e portas até o teto, onde existe uma janela em uma das paredes.

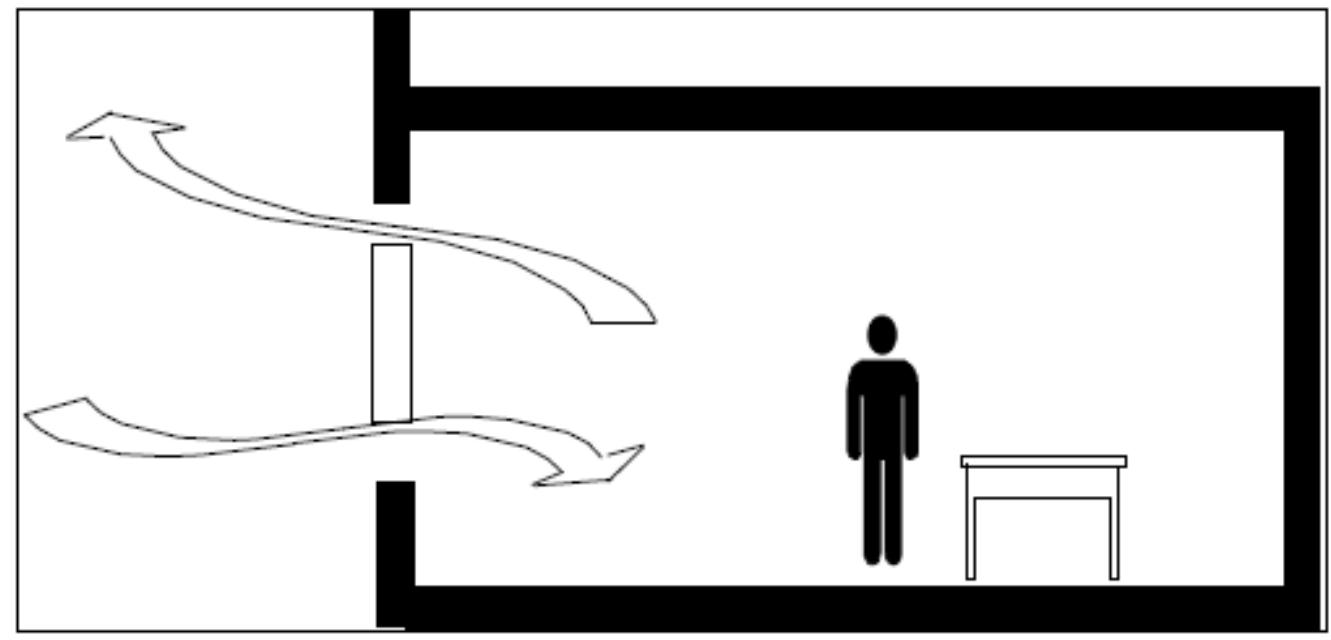

Figura 2.4.1: Ambiente com ventilação unilateral e aberturas duplas (KENDRICK; MARTIN; BOOTH, 1998).

Esta forma é usualmente a mais simples para ventilar uma edificação (AWBI, 2003). Nos EUA, limitações de forma das edificações, normas de combate a incêndio e privacidade limitam a utilização de ventilação cruzada, porém estas condições são diferentes em outros locais, como na Europa por exemplo. 
Alloca, Chen e Glicksman (2003) citam que a ventilação unilateral é mais aceitável pelos ocupantes do ambiente do que a cruzada, apesar de sua eficiência ser mais baixa. Allard e Ghiaus (2005), por sua vez, sugerem que a ventilação unilateral pode ser usada quando é necessária a ventilação de ambientes individuais.

Em geral, nesta estratégia podem ser utilizadas aberturas simples ou duplas. Considerando a abertura simples, no verão a principal força motriz da ventilação natural será a turbulência do vento (CIBSE, 2005), ocorrendo isto particularmente para o caso de aberturas pequenas (AWBI, 2003). CIBSE (2005) apresenta uma limitação geral de profundidade do ambiente de duas vezes a altura do seu pé-direito, conforme ilustra a figura 2.4.2.

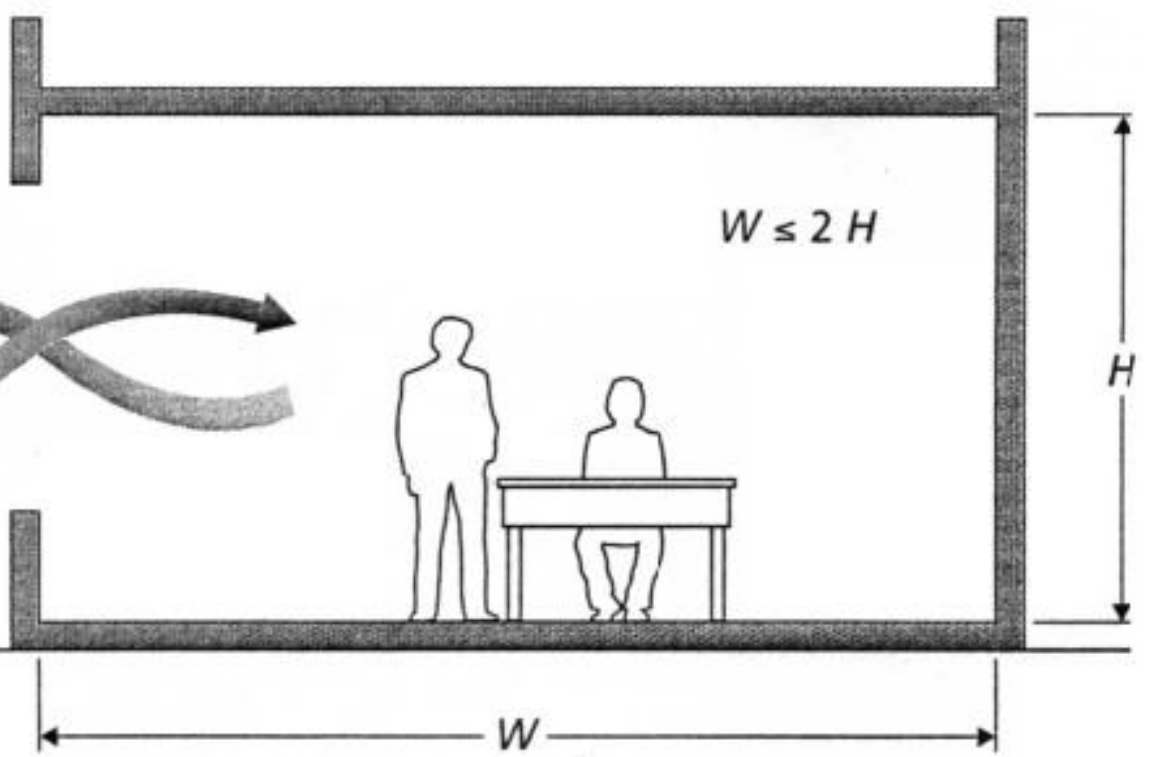

Figura 2.4.2: Profundidade do ambiente em função do pé-direito para ventilação unilateral com abertura simples (CIBSE, 2005).

As aberturas duplas, ou mesmo múltiplas, permitem também a utilização das forças de empuxo para a ventilação do ambiente, ocorrendo entrada de ar frio pela abertura inferior e saída de ar aquecido pela abertura superior, fenômeno ilustrado pela figura 2.4.1.

Neste caso, como são utilizadas ambas as forças de empuxo e do vento, é possível ventilar uma profundidade maior do ambiente: aproximadamente 2,5 vezes a altura do pédireito (CIBSE, 2005; KENDRICK; MARTIN; BOOTH, 1998; AWBI, 2003), como indica a figura 2.4.3. 


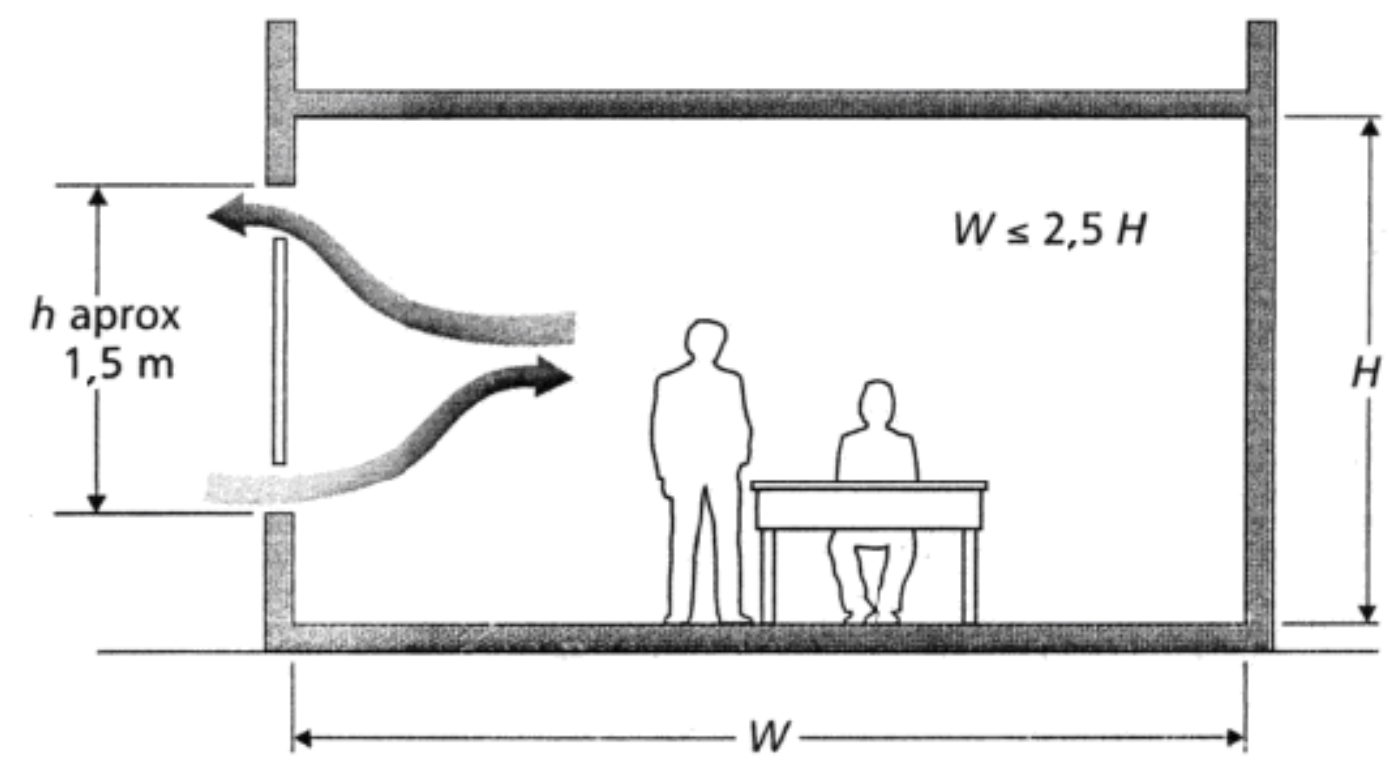

Figura 2.4.3: Profundidade do ambiente em função do pé-direito para ventilação unilateral com abertura dupla (adaptado de CIBSE, 2005).

\subsubsection{Ventilação cruzada}

A ventilação cruzada consiste em um ambiente onde mais de uma parede possui abertura para o meio externo, de forma que ocorre a entrada de ar por uma fachada e sua saída por outra, conforme ilustra a figura 2.4.4. O escoamento neste caso ocorre principalmente pela pressão do vento, e efeitos de empuxo se tornam importantes somente se existe grande diferença de altura entre as aberturas de entrada e saída (AWBI, 2003).

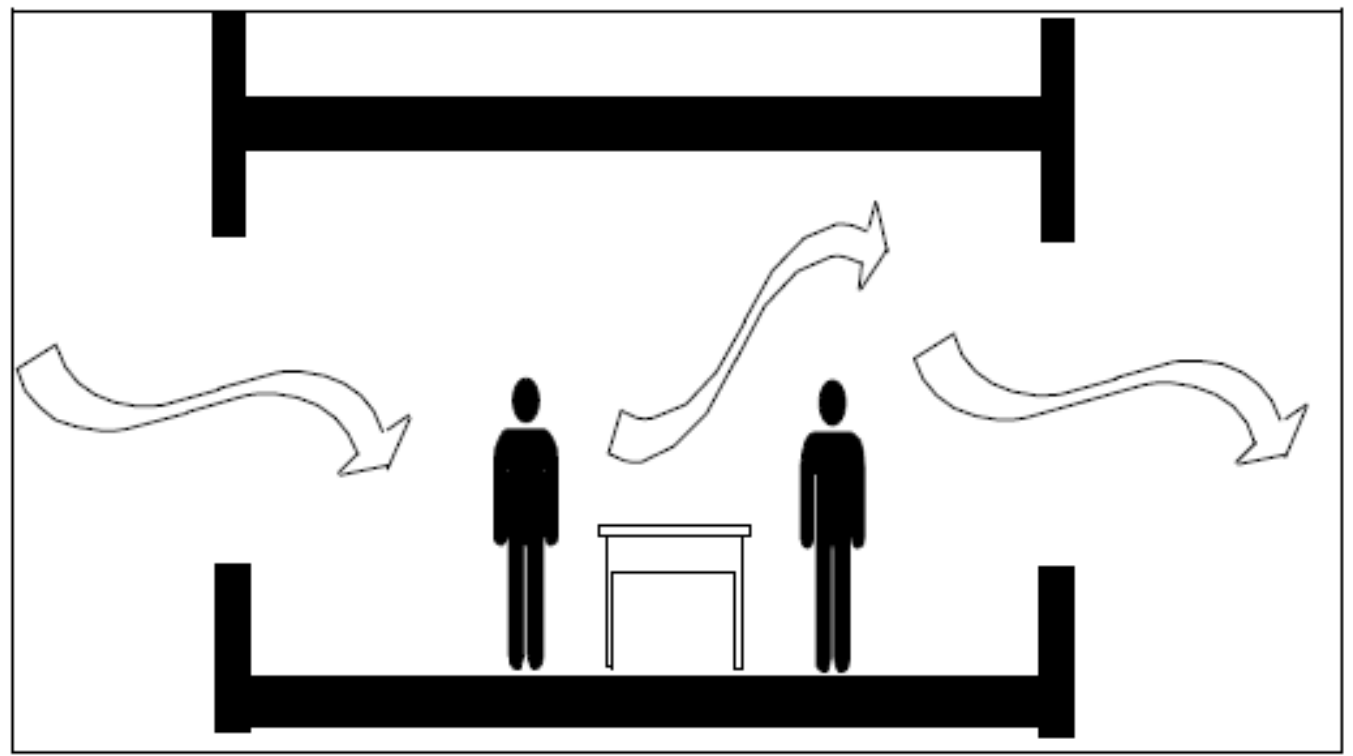

Figura 2.4.4: Ambiente com ventilação cruzada (KENDRICK; MARTIN; BOOTH, 1998). 
O posicionamento das aberturas deve ocorrer de forma que algumas delas estejam posicionadas a montante do escoamento do vento, enquanto que outras devem estar à jusante (ALLARD; GHIAUS, 2005; AWBI, 2003; CIBSE, 1999). Esta medida visa à manutenção de um bom gradiente de pressão entre as aberturas de entrada e saída, melhorando o aproveitamento das condições encontradas.

Os ambientes com ventilação cruzada podem, como regra geral, ventilar profundidades de até cinco vezes a altura do pé-direito (AWBI, 2003; CIBSE, 2005; KENDRICK; MARTIN; BOOTH, 1998), como ilustra a figura 2.4.5. Assim como para a ventilação unilateral, se trata de uma recomendação geral, que pode sofrer ajustes de acordo com outras características do ambiente analisado, como obstruções internas e condições do vento.

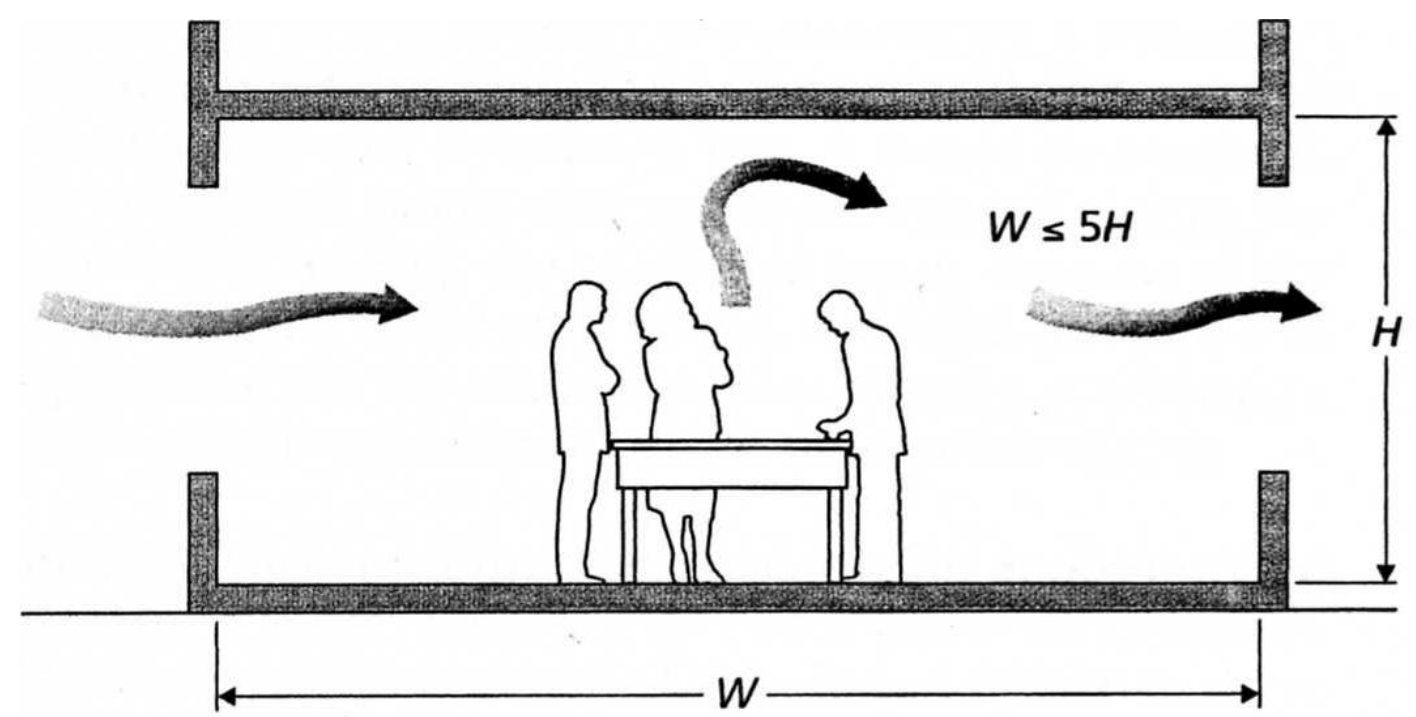

Figura 2.4.5: Profundidade do ambiente em função do pé-direito para ventilação cruzada (CIBSE, 2005).

Como a ventilação cruzada permite a entrada de um fluxo maior de ar em comparação com a unilateral, é desejável que se tente obter esta condição mesmo que haja apenas uma parede disponível para instalação de janelas. Isto pode ser obtido utilizando duas aberturas localizadas lado a lado na mesma fachada, possibilitando assim um caminho para a corrente de ar dentro do ambiente, sem utilizar a mesma abertura para entrada e saída.

A figura 2.4.6 mostra um corte indicando a diferença do caminho do ar para um ambiente com ventilação unilateral, porém com uma ou duas aberturas. Desta maneira se obtém um dos principais efeitos da ventilação cruzada, mesmo tendo a disponibilidade de uma só fachada para ventilação. 

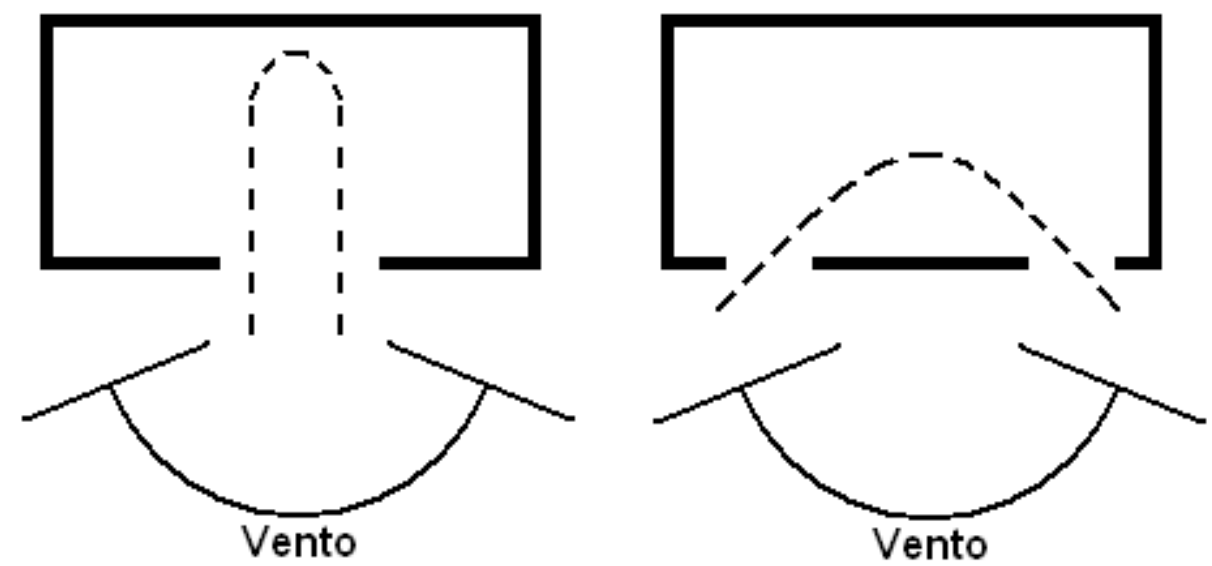

Figura 2.4.6: Diferença do caminho do ar dentro de um ambiente ventilado unilateralmente com efeito mais próximo ao da ventilação cruzada (Adaptado de YARKE, 2005). 


\section{CAPÍTULO 3 FUNDAMENTAÇÃO TEÓRICA DA SIMULAÇÃO NUMÉRICA}

Este capítulo tem como objetivo apresentar os conceitos teóricos e equacionamentos utilizados para o desenvolvimento das simulações numéricas. Para as análises de ventilação natural desenvolvidas é necessário conhecer as propriedades da movimentação do fluido, incluindo a turbulência, e aspectos da análise computacional relacionados com a dinâmica desse fluido.

\subsection{EQUAÇÕES DE TRANSPORTE}

O movimento dos fluidos é descrito por uma série de equações não lineares conhecidas há mais de 100 anos (WHITE, 1991). Embora existam soluções analíticas apenas para alguns casos particulares, onde diversas simplificações são feitas, derivadas de primeira e segunda ordem em variáveis no tempo e espaço são a principal causa da falta de soluções analíticas gerais destas.

As equações fundamentais que devem ser resolvidas, dentro do escopo desta dissertação, são as seguintes:
a) Conservação da massa
b) Conservação da quantidade de movimento
c) Conservação da energia
d) Transferência de calor por radiação

Estas equações apresentam como variáveis desconhecidas o campo de velocidades vetorial, o campo de pressões e o campo de temperaturas. Conforme descrito nos itens 3.1.1 a 3.1.4, outras propriedades termodinâmicas são utilizadas nas formulações, porém todas estas podem ser definidas tendo-se conhecimento de duas propriedades independentes.

É possível ainda listar dentre as equações básicas da dinâmica dos fluidos a conservação das espécies e leis de reações químicas. Contudo, nos escoamentos abordados 
não são avaliados fenômenos como a dispersão de poluentes e contaminantes, que utilizam a primeira equação, e também não fenômenos de combustão, sendo a análise de reações igualmente negligenciada.

\subsubsection{Conservação da massa}

A equação de conservação da massa tem sua origem na definição de um sistema, no qual a massa necessariamente não varia. Para obtê-la é possível utilizar uma partícula elementar de fluido e desenvolver um equacionamento da variação da massa, igualando-o a zero, como ilustra a figura 3.1.1 para um caso bidimensional, ou mesmo partir da definição utilizando notação euleriana, como na equação 3.1.1.

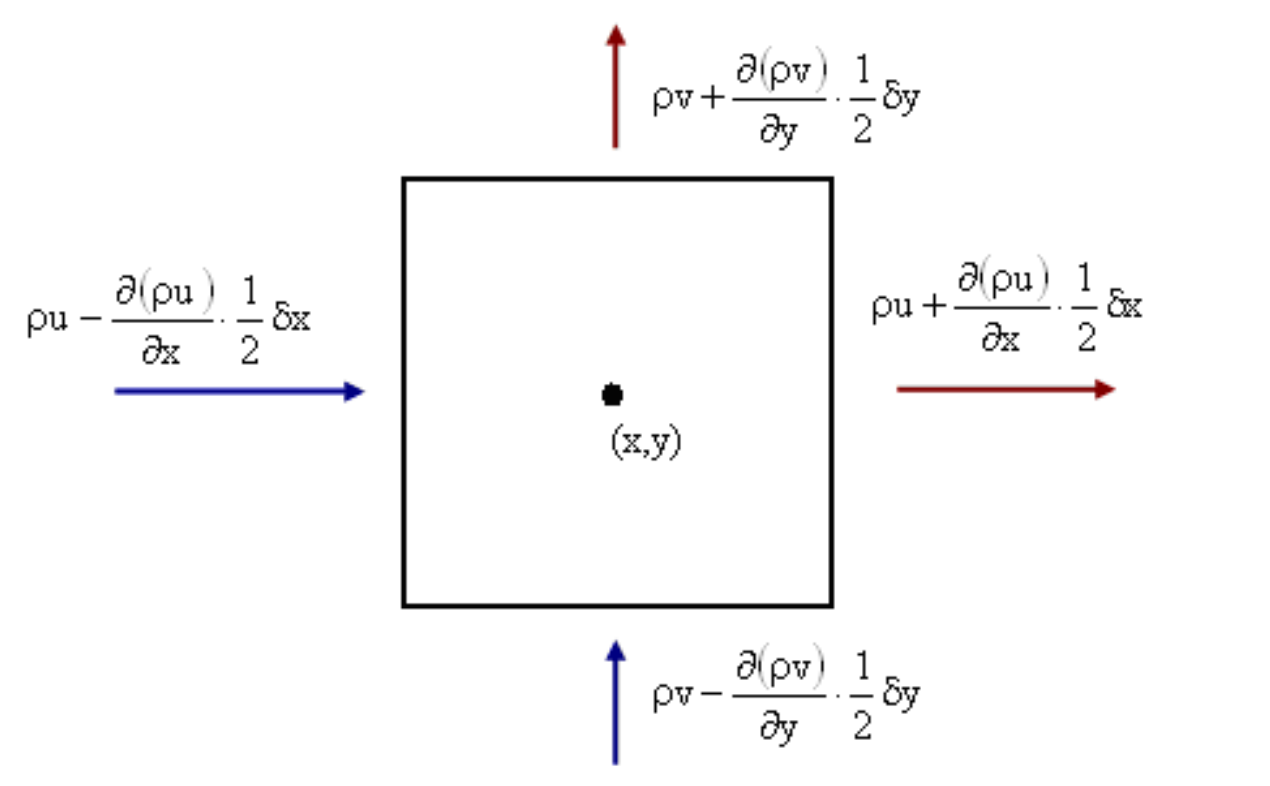

Figura 3.1.1: Formulação da equação da continuidade para elemento bidimensional

$$
\frac{\mathrm{Dm}}{\mathrm{Dt}}=\frac{\partial \rho}{\partial \mathrm{t}}+\operatorname{div}(\rho \overrightarrow{\mathrm{V}})=0
$$

onde $\mathrm{m}$ é a massa do fluido $[\mathrm{kg}], \mathrm{t}$ é o tempo [s], $\rho$ é a massa específica $\left[\mathrm{kg} / \mathrm{m}^{3}\right], \mathrm{V}$ é a velocidade do fluido $[\mathrm{m} / \mathrm{s}]$.

Em regime permanente, o primeiro termo da equação se anula, mantendo apenas o segundo. Nos escoamentos ditos "incompressíveis", como a movimentação do ar em ambientes interiores, a divergência do campo de velocidades é nula e o número de Mach, 
definido na equação 3.1.2, é pequeno, de forma que se obtém uma forma simplificada da equação de conservação da massa (Eq. 3.1.3).

$$
\begin{gathered}
M=\frac{V}{S} \\
\operatorname{div}(\vec{V})=0
\end{gathered}
$$

onde $\mathrm{M}$ é o número de Mach [-], $\mathrm{V}$ é a velocidade do fluido [m/s], $\mathrm{S}$ é a velocidade do som $[\mathrm{m} / \mathrm{s}]$.

\subsubsection{Conservação da quantidade de movimento}

A $2^{\mathrm{a}}$ Lei de Newton dá origem à equação de conservação da quantidade de movimento igualando a taxa de variação da quantidade de movimento da partícula fluida às forças que agem sobre esta, conforme equação 3.1.4:

$$
\rho \frac{\mathrm{DV}}{\mathrm{Dt}}=\rho \overrightarrow{\mathrm{g}}+\operatorname{div}\left(\tau_{\mathrm{ij}}\right)
$$

onde $\rho$ é a massa específica $\left[\mathrm{kg} / \mathrm{m}^{3}\right], \mathrm{V}$ é a velocidade do fluido $[\mathrm{m} / \mathrm{s}]$, t é o tempo $[\mathrm{s}], \mathrm{g}$ é a aceleração local da gravidade $\left[\mathrm{m} / \mathrm{s}^{2}\right], \tau_{\mathrm{ij}}$ é o tensor das tensões $\left[\mathrm{N} / \mathrm{m}^{2}\right]$.

As forças que agem sobre a partícula fluida podem ser divididas em forças de campo e de contato, sendo a primeira equivalente à gravidade, salvo a existência de fluidos magnéticos. O segundo termo contém termos de pressão e de viscosidade, que podem ser descritos conforme a equação 3.1.5.

$$
\tau_{\mathrm{ij}}=-\mathrm{p} \delta_{\mathrm{ij}}+\mu\left(\frac{\partial \mathrm{u}_{\mathrm{i}}}{\partial \mathrm{x}_{\mathrm{j}}}+\frac{\partial \mathrm{u}_{\mathrm{j}}}{\partial \mathrm{x}_{\mathrm{i}}}\right)+\delta_{\mathrm{ij}} \lambda \operatorname{div} \overrightarrow{\mathrm{V}}
$$

onde $\tau_{\mathrm{ij}}$ é o tensor das tensões [N/m²], p é a pressão [Pa], $\mu$ é a viscosidade dinâmica $\left[\mathrm{N}{ }^{`} \mathrm{~s} / \mathrm{m}^{2}\right]$, u é a velocidade do fluido $[\mathrm{m} / \mathrm{s}]$, x é a coordenada $[\mathrm{m}], \lambda$ é o segundo coeficiente de viscosidade $\left[\mathrm{N} \cdot \mathrm{s} / \mathrm{m}^{2}\right]$ e $\mathrm{V}$ é o vetor de velocidade $[\mathrm{m} / \mathrm{s}]$. 
Utilizando a hipótese de Stokes, igualando a pressão termodinâmica à pressão mecânica (WHITE, 1991), obtém-se então a forma generalista da equação da conservação da quantidade de movimento, também conhecida como equação de Navier-Stokes (equação 3.1.6). A hipótese de escoamento ou fluido incompressível permite eliminar o termo função do segundo coeficiente de viscosidade, $\lambda$.

$$
\rho \frac{\mathrm{DV}}{\mathrm{Dt}}=\rho \overrightarrow{\mathrm{g}}-\operatorname{grad}(\mathrm{p})+\operatorname{div}\left(\mu \cdot \operatorname{grad}(\overrightarrow{\mathrm{V}})+\delta_{\mathrm{ij}} \lambda \operatorname{div}(\overrightarrow{\mathrm{V}})\right)
$$

onde $\rho$ é a massa específica $\left[\mathrm{kg} / \mathrm{m}^{3}\right], \mathrm{V}$ é a velocidade do fluido $[\mathrm{m} / \mathrm{s}], \mathrm{t}$ é o tempo [s], $\mathrm{g}$ é a aceleração local da gravidade $\left[\mathrm{m} / \mathrm{s}^{2}\right]$, p é a pressão $[\mathrm{Pa}], \mu$ é a viscosidade dinâmica $\left[\mathrm{N}^{*} \mathrm{~s} / \mathrm{m}^{2}\right] \mathrm{e}$ $\lambda$ é o segundo coeficiente de viscosidade $\left[\mathrm{N} \cdot \mathrm{s} / \mathrm{m}^{2}\right]$.

\subsubsection{Conservação da energia}

A equação da conservação da energia é obtida a partir da primeira lei da termodinâmica, ou seja, a taxa de variação da energia interna é igual à taxa líquida de transferência de calor difusiva, ao trabalho líquido realizado sobre o volume de controle e o fluxo convectivo líquido de energia, conforme equação 3.1.7. Com alguma manipulação algébrica obtém-se a equação 3.1.8, uma forma mais comum da equação de conservação da energia para escoamentos incompressíveis.

$$
\begin{gathered}
\left.\frac{\Delta \mathrm{E}}{\Delta \mathrm{t}}\right|_{\mathrm{VC}}=\dot{\mathrm{Q}}-\dot{\mathrm{W}}+\dot{\mathrm{E}}_{\mathrm{e}}-\dot{\mathrm{E}}_{\mathrm{s}} \\
\rho c_{\mathrm{p}} \frac{\mathrm{DT}}{\mathrm{Dt}}=\operatorname{div}(\mathrm{k} \cdot \operatorname{grad}(\mathrm{T}))+\mathrm{q}^{\prime \prime \prime}+\Phi
\end{gathered}
$$

onde E é a energia [J], Q é o calor [J], W é o trabalho [J], $\rho$ é a massa específica $\left[\mathrm{kg} / \mathrm{m}^{3}\right], \mathrm{c}_{\mathrm{p}}$ é o calor específico à pressão constante $[\mathrm{J} /(\mathrm{kg} \cdot \mathrm{K})]$, T é a temperatura $[\mathrm{K}], \mathrm{t}$ é o tempo $[\mathrm{s}]$, $\mathrm{k}$ é a condutividade térmica $[\mathrm{W} /(\mathrm{m} \cdot \mathrm{K})]$, q"' é taxa de geração de calor por volume $\left[\mathrm{W} / \mathrm{m}^{3}\right]$ e $\Phi$ é a função dissipação viscosa $\left[\mathrm{W} / \mathrm{m}^{3}\right]$. 
A função de dissipação $\Phi$ é definida conforme a equação 3.1.9, onde para escoamentos incompressíveis o último termo se anula, eliminando a influência do segundo termo de viscosidade e tornando esta função estritamente quadrática. Em outras palavras, a dissipação viscosa da quantidade de movimento sempre leva a um aumento da energia do fluido, em acordo com a segunda lei da termodinâmica.

$$
\begin{gathered}
\Phi=\mu\left\{2\left[\left(\frac{\partial \mathrm{u}}{\partial \mathrm{x}}\right)^{2}+\left(\frac{\partial \mathrm{v}}{\partial \mathrm{y}}\right)^{2}+\left(\frac{\partial \mathrm{w}}{\partial \mathrm{z}}\right)^{2}\right]+\left(\frac{\partial \mathrm{u}}{\partial \mathrm{y}}+\frac{\partial \mathrm{v}}{\partial \mathrm{x}}\right)^{2}+\right. \\
\left.+\left(\frac{\partial \mathrm{u}}{\partial \mathrm{z}}+\frac{\partial \mathrm{w}}{\partial \mathrm{x}}\right)^{2}+\left(\frac{\partial \mathrm{w}}{\partial \mathrm{y}}+\frac{\partial \mathrm{v}}{\partial \mathrm{z}}\right)^{2}\right\}+\lambda(\operatorname{div} \overrightarrow{\mathrm{u}})^{2}
\end{gathered}
$$

onde $\Phi$ é a função dissipação viscosa $\left[\mathrm{W} / \mathrm{m}^{3}\right], \mu$ é a viscosidade dinâmica $\left[\mathrm{N} \cdot \mathrm{s} / \mathrm{m}^{2}\right], \mathrm{u}, \mathrm{v}$ e w são as componentes do vetor velocidade nas direções $\mathrm{x}$, y e $\mathrm{z}[\mathrm{m} / \mathrm{s}]$, $\mathrm{x}$, y e $\mathrm{z}$ são as coordenadas cartesianas $[\mathrm{m}]$ e $\lambda$ é o segundo coeficiente de viscosidade $\left[\mathrm{N} \cdot \mathrm{s} / \mathrm{m}^{2}\right]$.

\subsubsection{Transferência de calor por radiação}

Embora as equações anteriores descrevam bem diversos problemas de engenharia, existem várias situações específicas onde as taxas de transferência de calor por radiação não podem ser negligenciadas. Versteeg e Malalasekera (2007) citam três exemplos proeminentes destas situações, sendo uma delas a ventilação natural em edificações.

Apesar das temperaturas serem baixas nessas situações, condição que reduz a importância da radiação, as velocidades também são muito baixas, de forma que a troca de calor por convecção possui a mesma ordem de grandeza. Mostra-se necessária então a adoção de um equacionamento que acople a transferência de calor por convecção e radiação.

O acoplamento entre a radiação térmica e o CFD pode ocorrer de duas maneiras: afetando diretamente o fluido ou afetando apenas as condições de contorno. Esta última é a verificada em casos de ventilação natural, pois com as temperaturas baixas o fluido não participa diretamente da troca por radiação (meio não participante), esta se dá apenas entre as paredes.

O aumento ou diminuição da temperatura das paredes irá então afetar a camada de fluido adjacente, que por sua vez transmitirá a energia térmica por convecção para o restante 
do fluido. O equacionamento geral da transferência de calor por radiação é apresentado na equação 3.1.10 e detalhado no item 3.3.2.

$$
\nabla \cdot(\mathrm{I}(\overrightarrow{\mathrm{r}}, \overrightarrow{\mathrm{s}}) \overrightarrow{\mathrm{s}})+\left(\alpha+\sigma_{\mathrm{S}}\right) \mathrm{I}(\overrightarrow{\mathrm{r}}, \overrightarrow{\mathrm{s}})=\alpha \cdot \mathrm{n}^{2} \frac{\sigma \mathrm{T}^{4}}{\pi}+\frac{\sigma_{\mathrm{S}}}{4 \pi} \int_{0}^{4 \pi} \mathrm{I}\left(\overrightarrow{\mathrm{r}}, \overrightarrow{\mathrm{s}}^{\prime}\right) \Phi\left(\overrightarrow{\mathrm{s}}, \overrightarrow{\mathrm{s}}^{\prime}\right) \mathrm{d} \Omega^{\prime}
$$

onde I é a intensidade de radiação $\left[\mathrm{W} / \mathrm{m}^{2}\right]$, $\mathrm{r}$ é o vetor posição do elemento $[\mathrm{m}]$, s é o vetor de direção da radiação incidente $[\mathrm{m}], \alpha$ é o coeficiente de absortância $\left[\mathrm{m}^{-1}\right], \sigma_{\mathrm{S}}$ é o coeficiente de dispersão $\left[\mathrm{m}^{-1}\right]$, n é o índice de refração [-], $\sigma$ é a constante de Stefan-Boltzmann $\left[\mathrm{W} /\left(\mathrm{m}^{2} \cdot \mathrm{K}^{4}\right)\right]$, T é a temperatura $[\mathrm{K}]$, s' é o vetor de direção da radiação dispersada [m], massa do fluido [kg], $\Phi$ é a função de fase da dispersão [-], $\Omega$ ’ é o ângulo sólido da radiação emitida [-].

\subsection{TURBULÊNCIA}

A turbulência é um fenômeno presente no dia a dia, sendo que a maioria dos escoamentos na natureza e de aplicação de engenharia são turbulentos (TENNEKES; LUMLEY, 1972). Fenômenos como ventos intensos, fluxo de água de uma cachoeira ou mesmo a fumaça de uma chaminé são exemplos de escoamentos turbulentos facilmente observados (POPE, 2000).

A definição exata de turbulência é algo muito difícil de fazer, apesar da facilidade de ter alguma ideia sobre o seu significado (TENNEKES; LUMLEY, 1972), sendo mais simples apontar as características mais importantes deste fenômeno. Segundo Pope (2000), o elemento fundamental dos escoamentos turbulentos é que o campo de velocidades varia significativamente e irregularmente tanto no espaço como no tempo, como ilustra a figura 3.2.1. Tennekes e Lumley (1972) citam outras características importantes da turbulência, como difusividade, presença de grandes números de Reynolds, flutuações de vórtices em três dimensões, dissipação e continuidade. 


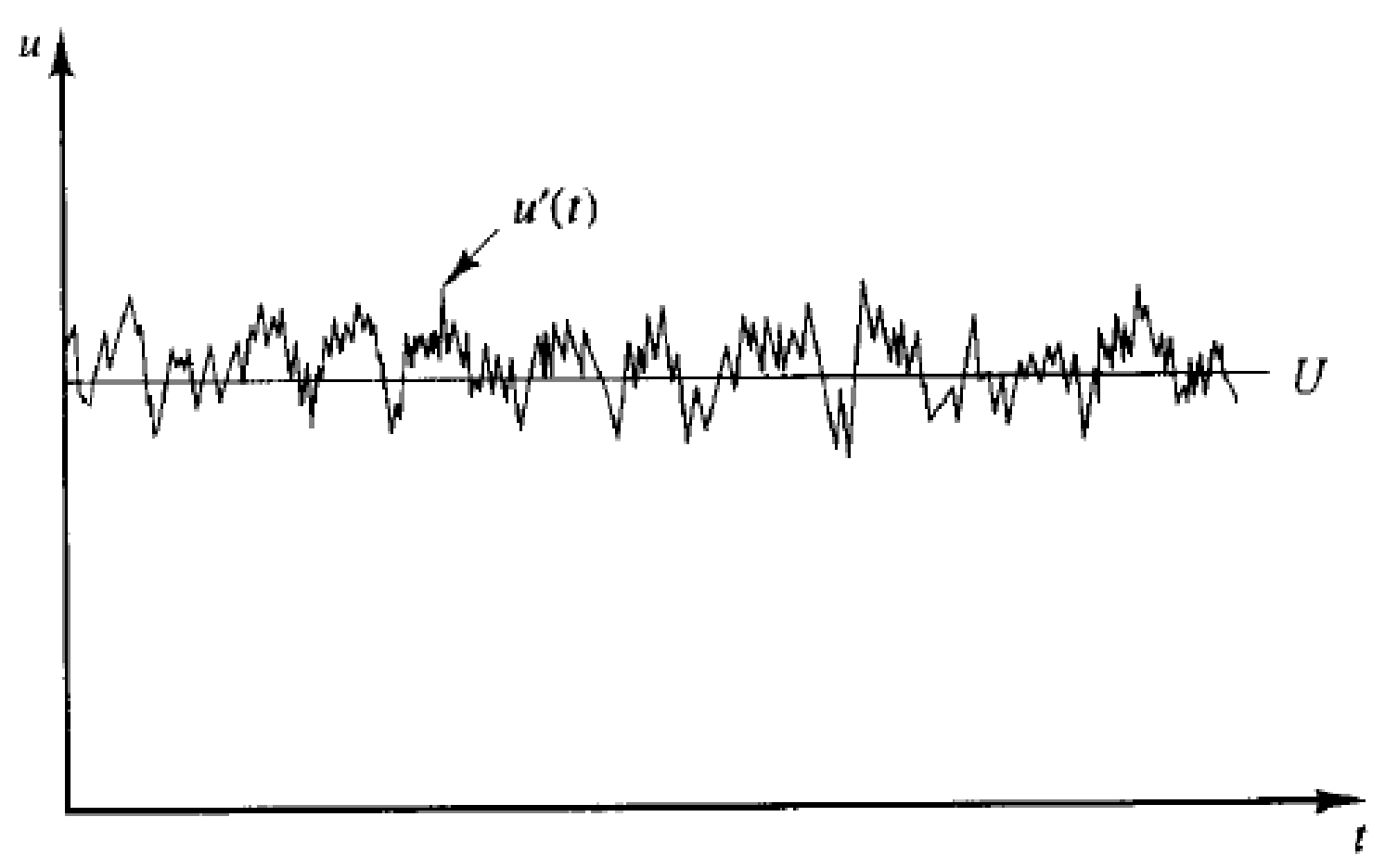

Figura 3.2.1: Típica medição de velocidade em ponto de um escoamento turbulento

(VERSTEEG; MALALASEKERA, 2007)

\subsubsection{Decomposição de Reynolds e hipótese de Boussinesq}

Uma característica que pode ser observada na figura 3.2.1 é que, apesar da velocidade do escoamento variar significativamente no tempo, essa flutuação ocorre ao redor de um valor médio. Desta forma, é possível decompor a velocidade u em duas parcelas, uma média U e uma flutuação u', conforme a equação 3.2.1. Desta mesma forma, é possível caracterizar todas as grandezas envolvidas no escoamento, como velocidade, pressão e temperatura, por variáveis médias e suas respectivas flutuações.

$$
\mathrm{u}(\mathrm{t})=\mathrm{U}+\mathrm{u}^{\prime}(\mathrm{t})
$$

onde u é a velocidade em uma determinada direção $[\mathrm{m} / \mathrm{s}]$, U é a velocidade média nesta direção $[\mathrm{m} / \mathrm{s}]$, u' é a flutuação da velocidade $[\mathrm{m} / \mathrm{s}]$.

Aplicando a decomposição de Reynolds nas equações que governam o movimento do fluido em escoamentos incompressíveis (equações 3.1.3, 3.1.6, 3.1.8 e 3.1.9), é possível 
reescrevê-las na forma das equações 3.2.2 a 3.2.5. Note-se que a equação 3.2.2 é idêntica à 3.1.3, ou seja, a continuidade é satisfeita também para o escoamento médio.

$$
\begin{gathered}
\operatorname{div}(\overline{\vec{V}})=0 \\
\rho \frac{D \overline{\vec{V}}}{D t}=\rho \vec{g}-\operatorname{grad}(\bar{p})+\operatorname{div}\left(\mu \cdot \operatorname{grad}(\overline{\vec{V}})-\rho \overline{u_{i}^{\prime} u_{j}^{\prime}}\right) \\
\rho c_{p} \frac{D \bar{T}}{D t}=\operatorname{div}\left(k \cdot \operatorname{grad}(\bar{T})-\rho c_{p} \overline{u_{i}^{\prime} T^{\prime}}\right)+\overline{q^{\prime \prime \prime}}+\bar{\Phi} \\
\bar{\Phi}=\frac{\mu}{2\left(\frac{\partial \overline{u_{i}}}{\partial x_{j}}+\frac{\partial u_{i}^{\prime}}{\partial x_{j}}+\frac{\partial \overline{u_{j}}}{\partial x_{i}}+\frac{\partial u_{j}^{\prime}}{\partial x_{i}}\right)^{2}}
\end{gathered}
$$

onde $\mathrm{V}$ é o vetor velocidade do fluido [m/s], $\rho$ é a massa específica do fluido $\left[\mathrm{kg} / \mathrm{m}^{3}\right]$, $\mathrm{t}$ é o tempo [s], g é a aceleração local da gravidade $\left[\mathrm{m} / \mathrm{s}^{2}\right]$, p é a pressão $[\mathrm{Pa}], \mu$ é a viscosidade dinâmica $\left[\mathrm{N}^{\prime} \mathrm{s} / \mathrm{m}^{2}\right]$, u' é a flutuação da velocidade $[\mathrm{m} / \mathrm{s}], \mathrm{c}_{\mathrm{p}}$ é o calor específico à velocidade constante $[\mathrm{J} /(\mathrm{kg} \cdot \mathrm{K})]$, T é a temperatura $[\mathrm{K}]$, $\mathrm{k}$ é a condutividade térmica $[\mathrm{W} /(\mathrm{m} \cdot \mathrm{K})]$, q"' é taxa de geração de calor por unidade de volume [W/m³], x é a coordenada cartesiana $[\mathrm{m}]$.

As equações 3.2.3 a 3.2.5 apresentam médias de produtos de flutuações, que não podem ser ignoradas. $\mathrm{O}$ tensor $-\rho \overline{\mathrm{u}_{\mathrm{i}} \mathrm{u}_{\mathrm{j}}^{\prime}}$, chamado de Tensor das Tensões de Reynolds, introduz novas variáveis às equações de transporte de quantidade de movimento do fluido, de forma que são necessárias mais equações para o fechamento do sistema.

Para resolver este problema foram desenvolvidos modelos de turbulência, os quais introduzem novas equações para resolução do sistema de equações. O modelo das tensões de Reynolds (RSM), por exemplo, utiliza mais seis equações para modelar os seis termos do tensor das tensões de Reynolds. Outros modelos, entretanto, utilizam uma abordagem mais simples, baseados na hipótese de Boussinesq.

Boussinesq propôs uma relação entre as tensões de Reynolds e duas novas propriedades, a viscosidade turbulenta e a energia cinética turbulenta, conforme equação 3.2.6. Esta formulação é utilizada por diversos modelos de turbulência, como o SpallartAllmaras, $\mathrm{k}-\varepsilon, \mathrm{k}-\omega \mathrm{e}$ variantes destes. 


$$
-\rho \overline{u_{i}^{\prime} u_{j}^{\prime}}=\mu_{t}\left(\frac{\partial u_{i}}{\partial x_{j}}+\frac{\partial u_{j}}{\partial x_{i}}\right)-\frac{2}{3}\left(\rho k+\mu_{t} \frac{\partial u_{i}}{\partial x_{i}}\right) \delta_{i j}
$$

onde $\rho$ é a massa específica do fluido $\left[\mathrm{kg} / \mathrm{m}^{3}\right]$, u' é a flutuação da velocidade $[\mathrm{m} / \mathrm{s}], \mu_{\mathrm{t}}$ é a viscosidade turbulenta $\left[\mathrm{N}^{\top} \mathrm{s} / \mathrm{m}^{2}\right]$, u é a velocidade $[\mathrm{m} / \mathrm{s}]$, x é a coordenada cartesiana $[\mathrm{m}], \mathrm{k}$ é a energia cinética turbulenta $[\mathrm{J}]$.

\subsubsection{Modelos de turbulência utilizados no estudo de ventilação de ambientes}

Para resolver as equações de conservação de um escoamento turbulento, necessita-se escolher um modelo de turbulência. Cada modelo, entretanto, possui vantagens e desvantagens sobre os outros, sendo necessário analisar quais modelos possuem melhor aplicação à ventilação natural.

O modelo $\mathrm{k}-\varepsilon$, amplamente utilizado na literatura, foi por diversas vezes adotado em modelos computacionais de escoamentos internos e confrontado com medições experimentais. Chen e Jiang (1992) analisaram diversos destes trabalhos, onde este modelo de turbulência apresentou resultados próximos aos dos valores experimentais. Os autores apontam que o modelo adere bem aos resultados experimentais. Chen e Jiang (1992) ressaltam alguns cuidados que devem ser tomados, como diferentes usuários obterem resultados diferentes com o mesmo programa, e que as soluções são muito sensíveis às condições de contorno.

Mais recentemente, Evola e Popov (2006) realizaram simulações utilizando dois modelos de turbulência, o k- $\varepsilon$ padrão e o RNG. Seus resultados apontaram que o modelo RNG apresentou boa aderência com os dados experimentais, especialmente para as simulações de ventilação unilateral. A principal deficiência do modelo k- $\varepsilon$ consistia na dificuldade de descrever o escoamento próximo de superfícies, especialmente onde efeitos de amortecimento são relevantes.

Zhai et al (2007) fizeram uma análise dos modelos de turbulência utilizados na simulação de ambientes interiores, considerando desde os modelos de zero equações até mesmo DES (Detached Eddy Simulation) ou LES (Large Eddy Simulation). Sobre os modelos $\mathrm{k}-\varepsilon$, é apontado que a variante RNG aparece mais frequentemente na literatura em comparação com o k-E padrão e o realizável. A revisão bibliográfica realizada por estes autores apontou que o modelo RNG é ligeiramente mais utilizado do que o padrão. 
Uma comparação entre oito modelos de turbulência, dentre os mais utilizados na literatura, foi feita por Zhang et al (2007) por meio da simulação de quatro casos exemplo: convecção natural, convecção forçada em um ambiente particionado, convecção mista e convecção natural intensa. O modelo LES apresentou os melhores resultados, porém a simulação de geometrias complexas pode tornar o tempo de simulação proibitivo.

Dentre os modelos RANS (Reynolds Averaged Navier-Stokes), que possuem tempo muito menor de cálculo, o modelo de turbulência k- $\varepsilon$ RNG se destacou sobre os demais, por resultar no melhor desempenho geral.

Da revisão bibliográfica, conclui-se que os modelos $k-\varepsilon$ de turbulência foram amplamente empregados nas simulações numéricas e comparados com resultados experimentais, obtendo-se resultados satisfatórios. Dentre estes modelos, notou-se uma preferência pelo k- $\varepsilon$ RNG. Entretanto, optou-se por empregar no presente trabalho o modelo k-E realizável, pois este modelo apresentou resultados mais adequados de convergência, aumentando a confiabilidade da simulação numérica. Este modelo possui uma formulação ligeiramente diferente do modelo padrão, conforme descrito nos itens a seguir.

\subsubsection{Modelo k- $\varepsilon$ padrão}

O modelo k- $\varepsilon$ padrão é considerado um modelo de duas equações, pois apresenta formulações para duas grandezas dos escoamentos turbulentos, a energia cinética turbulenta $\mathrm{k}$ e sua dissipação viscosa $\varepsilon$. Este modelo foi proposto pela primeira vez por Launder e Spalding (1974), baseado no trabalho de Jones e Launder (1972), e é citado como um dos mais utilizados nas aplicações de engenharia (ANSYS FLUENT, 2010; POPE, 2000; WILCOX, 1994). Sua ampla utilização se deve à sua robustez e economia no tempo computacional, como se verifica a partir dos trabalhos apresentados no item 3.2.1.

As formulações que modelam $\mathrm{k}$ e $\varepsilon$ são apresentadas nas equações 3.2.7 e 3.2.8, respectivamente. Estas grandezas são relacionadas com a viscosidade turbulenta conforme a equação 3.2.9, sendo esta última aplicada nas equações de Navier-Stokes utilizando a hipótese de Boussinesq. $\mathrm{O}$ termo $\mathrm{G}_{\mathrm{b}}$ encontra-se na equação 3.2.10 e está relacionado com os efeitos de empuxo, importantes na ventilação natural Os valores das constantes foram obtidos de dados experimentais de Launder e Spalding (1972) e se encontram na equação 3.2.11. 


$$
\begin{gathered}
\frac{\partial(\rho \mathrm{k})}{\partial \mathrm{t}}+\operatorname{div}(\rho \mathrm{k} \overrightarrow{\mathrm{V}})=\operatorname{div}\left[\frac{\mu_{\mathrm{t}}}{\sigma_{\mathrm{k}}} \operatorname{grad}(\mathrm{k})\right]+2 \mu_{\mathrm{t}} \mathrm{S}_{\mathrm{ij}} \mathrm{S}_{\mathrm{ij}}+\mathrm{G}_{\mathrm{b}}-\rho \varepsilon \\
\frac{\partial(\rho \varepsilon)}{\partial \mathrm{t}}+\operatorname{div}(\rho \varepsilon \overrightarrow{\mathrm{V}})=\operatorname{div}\left[\frac{\mu_{\mathrm{t}}}{\sigma_{\varepsilon}} \operatorname{grad}(\varepsilon)\right]+\mathrm{C}_{1 \varepsilon} \frac{\varepsilon}{\mathrm{k}}\left(2 \mu_{\mathrm{t}} \mathrm{S}_{\mathrm{ij}} \mathrm{S}_{\mathrm{ij}}+\tanh \left|\frac{\mathrm{v}}{\mathrm{u}}\right| \mathrm{G}_{\mathrm{b}}\right)-\mathrm{C}_{2 \varepsilon} \rho \frac{\varepsilon^{2}}{\mathrm{k}} \\
\mathrm{G}_{\mathrm{b}}=-\frac{1}{\rho}\left(\frac{\partial \rho}{\partial \mathrm{T}}\right)_{\mathrm{p}} \mathrm{g}_{\mathrm{t}} \frac{\mu_{\mathrm{t}}}{\operatorname{Pr}_{\mathrm{t}}} \operatorname{grad}(\mathrm{T}) \\
\mathrm{C}_{\mu} \frac{\mathrm{k}^{2}}{\varepsilon} \quad 0,09 \quad \mathrm{~S}_{\mathrm{ij}}=\frac{1}{2}\left(\frac{\partial \mathrm{u}_{\mathrm{j}}}{\partial \mathrm{x}_{\mathrm{i}}}+\frac{\partial \mathrm{u}_{\mathrm{i}}}{\partial \mathrm{x}_{\mathrm{j}}}\right) \\
\sigma_{\mathrm{k}}=1,00 \quad \sigma_{\varepsilon}=1,30 \quad \mathrm{C}_{1 \varepsilon}=1,44 \quad \mathrm{C}_{2 \varepsilon}=1,92
\end{gathered}
$$

onde $\rho$ é a massa específica do fluido $\left[\mathrm{kg} / \mathrm{m}^{3}\right]$, $\mathrm{k}$ é a energia cinética turbulenta $[\mathrm{J}]$, $\mathrm{t}$ é o tempo [s], V é o vetor velocidade do fluido $[\mathrm{m} / \mathrm{s}], \mu_{\mathrm{t}}$ é a viscosidade turbulenta $\left[\mathrm{N} \cdot \mathrm{s} / \mathrm{m}^{2}\right], \mathrm{S}_{\mathrm{ij}}$ é o tensor taxa de deformação $\left[\mathrm{s}^{-1}\right], \varepsilon$ é taxa de dissipação da energia cinética turbulenta $[\mathrm{J} / \mathrm{s}]$, u e v são componentes da velocidade do fluido $[\mathrm{m} / \mathrm{s}]$, T é a temperatura $[\mathrm{K}]$, p é a pressão $[\mathrm{Pa}], \operatorname{Pr}_{\mathrm{t}}$ é o número de Prandtl turbulento [-].

Uma das hipóteses do modelo k- $\varepsilon$ é que a turbulência está plenamente desenvolvida, ou seja, seus efeitos são muitos mais significativos do que os efeitos viscosos, predominantes em escoamentos com baixos valores de Reynolds. Entretanto, na proximidade das paredes a diminuição da velocidade torna estes efeitos importantes, de forma que para manter a validade do modelo foram criadas funções de parede, obtidas a partir de análises empíricas. Uma discussão interessante sobre estas funções se encontra em Versteeg e Malalasekera (2007), no capítulo de modelagem da turbulência.

\subsubsection{Modelo k- $\varepsilon$ realizável}

O modelo k- $\varepsilon$ realizável foi desenvolvido por Shih et al (1995) e foi validado pelos autores para uma ampla gama de escoamentos (SHIH et al, 1995). O termo realizável significa que certas restrições matemáticas das Tensões de Reynolds, consistentes com a física da turbulência, são satisfeitas (ANSYS FLUENT, 2010). Este modelo possui duas 
formulações diferentes do modelo k-£ padrão, uma para a viscosidade turbulenta e outra para a equação de transporte da dissipação viscosa $\varepsilon$.

As formulações e definições de constantes utilizadas na formulação deste modelo encontram-se nas equações 3.2.12 a 3.2.19. Ao contrário do modelo padrão, o parâmetro $\mathrm{C}_{\mu}$ não é mais constante na formulação realizável, e deve ser calculado utilizando estas equações apresentadas.

$$
\begin{aligned}
& \frac{\partial}{\partial t}(\rho \mathrm{k})+\operatorname{div}(\rho \mathrm{k} \overrightarrow{\mathrm{V}})=\operatorname{div}\left[\mu \frac{\mu_{\mathrm{t}}}{\sigma_{\mathrm{k}}} \operatorname{grad}(\mathrm{k})\right]+2 \mu_{\mathrm{t}} \mathrm{S}_{\mathrm{ij}} \mathrm{S}_{\mathrm{ij}}+\mathrm{G}_{\mathrm{b}}-\rho \varepsilon \\
& \frac{\partial(\rho \varepsilon)}{\partial \mathrm{t}}+\operatorname{div}(\rho \varepsilon \overrightarrow{\mathrm{V}})=\operatorname{div}\left[\frac{\mu_{\mathrm{t}}}{\sigma_{\varepsilon}} \operatorname{grad}(\varepsilon)\right]+\rho \mathrm{C}_{1} \sqrt{2 \mathrm{~S}_{\mathrm{ij}} \mathrm{S}_{\mathrm{ij}}} \varepsilon-\rho \mathrm{C}_{2} \frac{\varepsilon^{2}}{\mathrm{k}+\sqrt{v \varepsilon}}+\mathrm{C}_{1 \varepsilon} \frac{\varepsilon}{\mathrm{k}} \tanh \left|\frac{\mathrm{v}}{\mathrm{u}}\right| \mathrm{G}_{\mathrm{b}} \\
& \mu_{\mathrm{t}}=\rho \mathrm{C}_{\mu} \frac{\mathrm{k}^{2}}{\varepsilon} \\
& \mathrm{G}_{\mathrm{b}}=-\frac{1}{\rho}\left(\frac{\partial \rho}{\partial \mathrm{T}}\right)_{\mathrm{p}} \overrightarrow{\mathrm{g}} \frac{\mu_{\mathrm{t}}}{\operatorname{Pr}_{\mathrm{t}}} \operatorname{grad}(\mathrm{T}) \\
& \mathrm{C}_{1}=\max \left[0,43 ; \frac{\eta}{\eta+5}\right] \quad \eta=\frac{\mathrm{k}}{\varepsilon} \sqrt{2 \mathrm{~S}_{\mathrm{ij}} \mathrm{S}_{\mathrm{ij}}} \\
& \mathrm{C}_{\mu}=\frac{1}{\mathrm{~A}_{0}+\mathrm{A}_{\mathrm{S}} \frac{\mathrm{kU^{* }}}{\varepsilon}} \mathrm{U}^{*}=\sqrt{\mathrm{S}_{\mathrm{ij}} \mathrm{S}_{\mathrm{ij}}+\tilde{\Omega}_{\mathrm{ij}} \tilde{\Omega}_{\mathrm{ij}}} \quad \tilde{\Omega}_{\mathrm{ij}}=\Omega_{\mathrm{ij}}-2 \varepsilon_{\mathrm{ijk}} \omega_{\mathrm{k}} \quad \Omega_{\mathrm{ij}}=\bar{\Omega}_{\mathrm{ij}}-\varepsilon_{\mathrm{ijk}} \omega_{\mathrm{k}} \\
& \mathrm{A}_{0}=4,04 \quad \mathrm{~A}_{\mathrm{S}}=\sqrt{6 \cos \phi} \quad \phi=\mathrm{a} \cos (\mathrm{W} \sqrt{6}) \quad \mathrm{W}=\frac{\mathrm{S}_{\mathrm{ij}} \mathrm{S}_{\mathrm{jk}} \mathrm{S}_{\mathrm{ki}}}{\left(\sqrt{\mathrm{S}_{\mathrm{ij}} \mathrm{S}_{\mathrm{ij}}}\right)^{3}} \quad \Omega_{\mathrm{ij}}=\frac{1}{2}\left(\frac{\partial \mathrm{u}_{\mathrm{j}}}{\partial \mathrm{x}_{\mathrm{i}}}-\frac{\partial \mathrm{u}_{\mathrm{i}}}{\partial \mathrm{x}_{\mathrm{j}}}\right) \\
& \sigma_{\mathrm{k}}=1,0 \quad \sigma_{\varepsilon}=1,2 \quad \mathrm{C}_{1 \varepsilon}=1,44 \quad \mathrm{C}_{2}=1,9
\end{aligned}
$$

onde $\rho$ é a massa específica do fluido $\left[\mathrm{kg} / \mathrm{m}^{3}\right]$, $\mathrm{k}$ é a energia cinética turbulenta $[\mathrm{J}]$, $\mathrm{t}$ é o tempo [s], V é o vetor velocidade do fluido $[\mathrm{m} / \mathrm{s}], \mu$ é a viscosidade dinâmica $\left[\mathrm{N} s / \mathrm{m}^{2}\right], \mu_{\mathrm{t}}$ é a viscosidade turbulenta $\left[\mathrm{N} \cdot \mathrm{s} / \mathrm{m}^{2}\right], \mathrm{S}_{\mathrm{ij}}$ é o tensor taxa de deformação $\left[\mathrm{s}^{-1}\right]$, $\varepsilon$ é taxa de dissipação da energia cinética turbulenta $[\mathrm{J} / \mathrm{s}], v$ é a viscosidade cinemática $\left[\mathrm{m}^{2} / \mathrm{s}\right]$, u e $\mathrm{v}$ são 
componentes da velocidade do fluido $[\mathrm{m} / \mathrm{s}]$, T é a temperatura $[\mathrm{K}]$, p é a pressão [Pa], $\operatorname{Pr}_{\mathrm{t}}$ é o número de Prandtl turbulento [-], $\Omega_{\mathrm{ij}}$ é o tensor taxa de rotação [s $\left.{ }^{-1}\right]$.

Nas equações 3.2.12 e 3.2.13 é possível adicionar um termo de geração da propriedade transportada ( $\mathrm{k}$ e $\varepsilon$ respectivamente). Este termo fonte, entretanto, não foi utilizado neste trabalho, pois estas propriedades são originadas apenas pelo desenvolvimento do escoamento médio e formação da turbulência decorrente.

\subsection{DINÂMICA DOS FLUIDOS COMPUTACIONAL}

A dinâmica dos fluidos computacional (CFD) está presente na classe de métodos numéricos de solução de problemas, sendo possível também utilizar métodos analíticos ou experimentais. Para se obter uma solução numérica, o domínio de interesse deve ser subdividido utilizando um método de discretização que aproxima as equações diferenciais por um sistema de equações algébricas, as quais podem então ser resolvidas em computadores (FERZIGER; PERIĆ, 2002).

A discretização utilizada pelo programa ANSYS FLUENT (2010) é a do Método dos Volumes Finitos, que consiste em utilizar a formulação integral das equações de conservação sobre os volumes elementares, obtendo assim equações de balanço para os volumes que compõem o domínio de cálculo (MALISKA, 2004).

Versteeg e Malalasekera (2007) citam que os programas comerciais de CFD incluem interfaces sofisticadas para facilitar o acesso do usuário às ferramentas numéricas, sendo que estes programas são divididos em três principais etapas:

a) Pré-processamento: etapa que possui maior influência do usuário dos programas, onde a maior parte do tempo de uma simulação é empregada. Este momento pode ser subdividido em outros quatro passos do processo: definição da geometria a ser analisada, incluindo as simplificações necessárias; geração da malha volumétrica, onde serão resolvidas as equações de conservação; escolha dos fenômenos físicos e equações que influenciam na análise; e descrição das propriedades das condições de contorno e materiais.

b) Processamento: nesta etapa, o solver resolverá numericamente as equações de conservação escolhidas pelo usuário. A partir de uma condição inicial dada, 
um processo iterativo calcula, utilizando equações discretizadas, as variáveis relevantes do escoamento.

c) Pós-processamento: etapa onde o usuário avaliará o resultado da simulação. Nesta etapa são analisados problemas que podem ter ocorrido por inconsistências da geometria, baixo nível de refinamento da malha em regiões de grandes gradientes, ou ainda erros na determinação de condições de contorno (FERREIRA, 2011).

Algumas limitações e possibilidades do CFD são listadas por Ferziger e Perić (2002), como por exemplo que este método é sempre uma aproximação, pois as equações podem conter aproximações e idealizações, sem contar que para fenômenos complexos como a turbulência são utilizados modelos. Dentre as possibilidades, os autores ressaltam a capacidade de estudar diversas condições de contorno, sendo capaz de resolver com boa precisão as equações de Navier-Stokes, o que é difícil de ser obtido por outros métodos em situações de interesse da engenharia, como em sistemas de ventilação.

\subsubsection{Subrelaxação}

Em uma simulação de CFD, assim como em outras abordagens numéricas, estima-se um valor inicial para todas as propriedades relevantes na análise, chamado também de inicialização. A partir das condições de contorno, os valores vão sendo atualizados a cada iteração, até que a variação destas grandezas se torna menor do que um determinado valor, para o qual se diz que houve convergência.

A equação 3.3.1 ilustra de maneira simplificada este processo, onde o valor de uma propriedade $\mathrm{x}$ na iteração $\mathrm{k}$ é a soma de seu valor na iteração k-1, acrescida de uma correção calculada pelo programa computacional. Entretanto, existe um coeficiente que modifica este avanço numérico da simulação, chamado parâmetro de subrelaxação $(\alpha)$, conforme indicado na equação 3.3.2.

$$
\begin{gathered}
x^{(k)}=x^{(k-1)}+\Delta x^{(k-1)} \\
x^{(k)}=x^{(k-1)}+\alpha \cdot \Delta x^{(k-1)}
\end{gathered}
$$


onde x é o valor de uma propriedade qualquer, $\mathrm{k}$ é a iteração presente, $\alpha$ é o parâmetro de subrelaxação.

O parâmetro de subrelaxação controla a velocidade com que a solução caminha no processo iterativo, pois permite que o valor da variável na iteração seguinte seja a soma do valor na iteração anterior acrescida apenas de uma parte da correção calculada. Por exemplo, no programa comercial ANSYS Fluent, o valor padrão do coeficiente de subrelaxação para a pressão é de apenas 0,3 , ou seja, o valor na iteração seguinte será a pressão da iteração anterior acrescida apenas de $30 \%$ da diferença calculada inicialmente pelo programa.

Como descrito adiante na seção 4.3.1, este parâmetro é de fundamental importância para a simulação da ventilação natural, pois ele pode possibilitar ou não a convergência das equações apresentadas nas seções 3.1 e 3.2, de acordo com as condições de contorno e estratégias de simulação adotadas.

\subsubsection{Radiação térmica}

O modelo de radiação utilizado no presente trabalho foi o das Ordenadas Discretas (Discrete Ordinates - DO). Neste método, a equação de transferência de calor por radiação (equação 3.1.10) é resolvida para um conjunto de $n$ direções dentro do total de $4 \pi$ para ângulos sólidos (VERSTEEG; MALALASEKERA, 2007).

A quantidade de direções pode ser escolhida, sendo que uma maior quantidade permite um aumento na precisão da troca de calor por radiação, mas tendo também uma necessidade maior de recursos computacionais para o cálculo. Usualmente, para economizar estes recursos, é realizada uma iteração da troca de calor por radiação a cada dez iterações das demais equações de transporte.

A equação de troca de calor por radiação discretizada permanece igual à apresentada na equação 3.1.10, sendo que o programa computacional calcula uma equação de transporte para cada uma das direções definidas (ANSYS FLUENT, 2010). Desta forma, no lugar de uma equação vetorial de transporte haverá tantas equações escalares de transporte quantas as direções definidas pelo usuário do programa. Esta é a razão pela qual não se deve usar uma quantidade excessiva de direções para se calcular a transferência de calor por radiação. 


\subsubsection{CFD aplicado à ventilação natural}

Ferramentas de CFD já foram empregadas em diversas pesquisas sobre ventilação natural, sendo analisados o escoamento ao redor de edificações, coeficientes de pressão sobre as fachadas e distribuição de velocidades dentro do ambiente.

A distribuição de velocidades foi estudada por Alloca, Chen e Glicksman (2003) em dormitório típico, apresentado na figura 3.3.1, inicialmente sem considerar o meio externo e, posteriormente, incluindo-o no domínio de cálculo. Os autores concluíram que o CFD apresenta resultados bons, porém deve existir um cuidado grande com a modelagem das condições de contorno e com o domínio, que podem ter impacto significativo nas condições de ventilação calculadas.

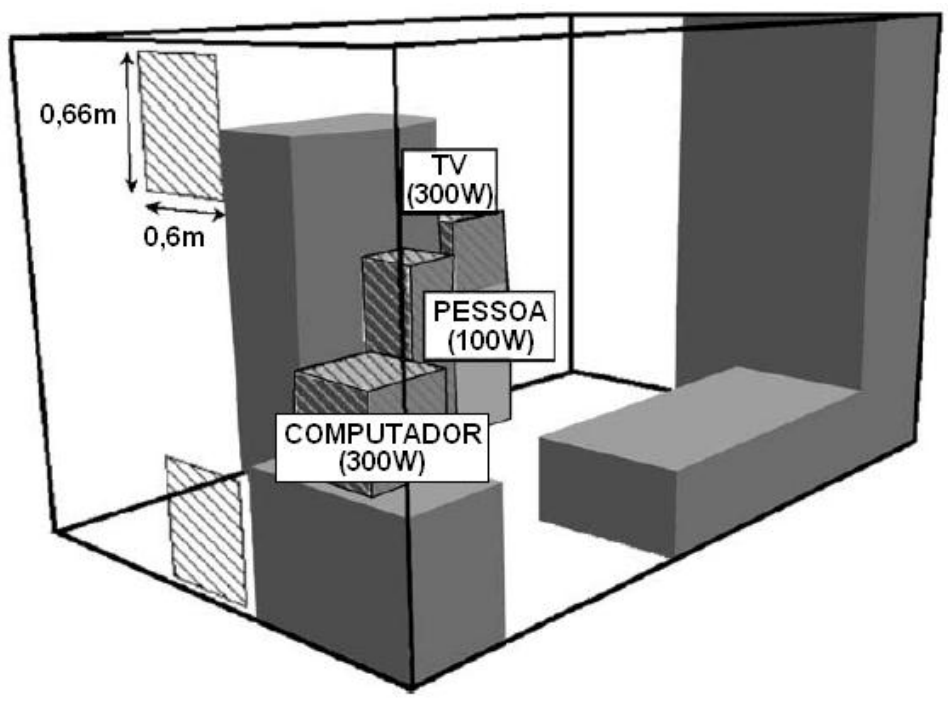

Figura 3.3.1: Dormitório analisado por Alloca, Chen e Glicksman (2003).

Nesse trabalho, por exemplo, inicialmente foi utilizado como domínio apenas o dormitório para analisar a ventilação por efeito chaminé, sendo posteriormente incluído parte do ambiente externo. Este novo domínio ampliado trouxe o erro do cálculo para apenas 10\%, em contraposição ao erro anterior de $41 \%$ obtido pelos mesmos autores, comparando os resultados das simulações numéricas com equações semianalíticas.

Evola e Popov (2006) analisaram o escoamento ao redor e dentro de uma edificação com formato cúbico, sendo estudados três modelos: o primeiro, apresentado na figura 3.3.2, contém uma abertura na fachada a montante do escoamento; o segundo possui a mesma abertura na fachada a jusante; e o último, que apresenta aberturas em ambas as fachadas. 


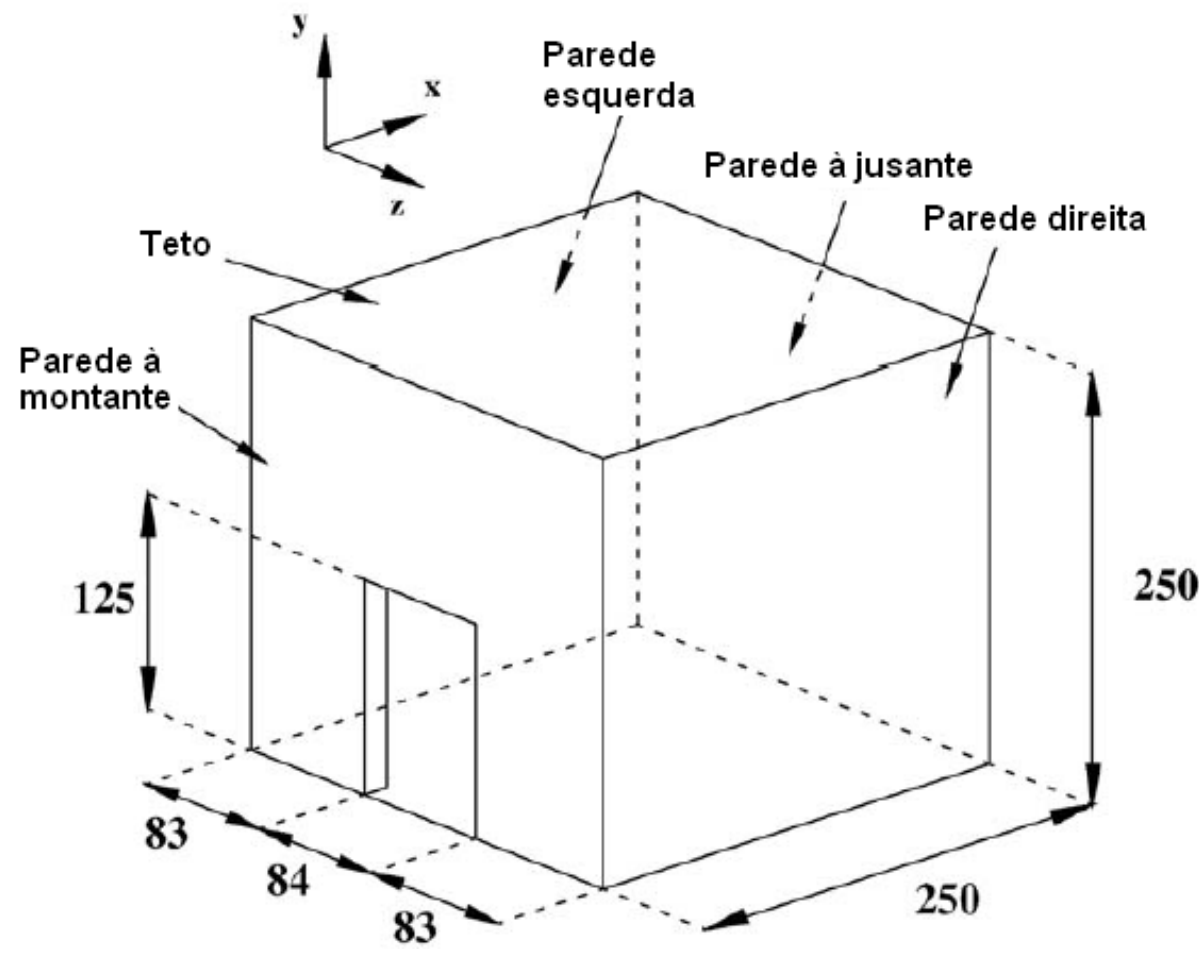

Figura 3.3.2: Modelo da edificação utilizada por Evola e Popov (adaptado de EVOLA; POPOV, 2006).

O maior propósito do estudo de Evola e Popov (2006) foi a investigação da confiabilidade dos modelos RANS de turbulência para aplicações de ventilação natural, como descrito anteriormente no item 3.2.2. Considerando as geometrias analisadas, a ventilação cruzada apresentou os maiores índices de ventilação, sendo que para a ventilação unilateral a abertura localizada na fachada a jusante do escoamento proporcionou resultados melhores do que a fachada a montante com abertura.

Figueiredo (2007) utilizou o CFD para estimar características locais da ventilação dos ambientes sobre o conforto térmico dos ocupantes. Para avaliar efeitos de corrente de ar, a autora utilizou a distribuição de velocidades sobre planos paralelos e perpendiculares ao piso, conforme ilustrado pela figura 3.3.3. De maneira semelhante, a estratificação de temperatura foi analisada em diversos planos sobre o domínio, utilizando as mesmas ferramentas gráficas, como exemplificado na figura 3.3.4.

Das imagens analisadas, Figueiredo (2007) aponta algumas características possíveis de se obter apenas com CFD, como o direcionamento do escoamento de ar para o forro devido ao ângulo de abertura das janelas, zonas de estagnação próximas do piso e distantes das janelas de entrada e saída do fluxo de ar. 


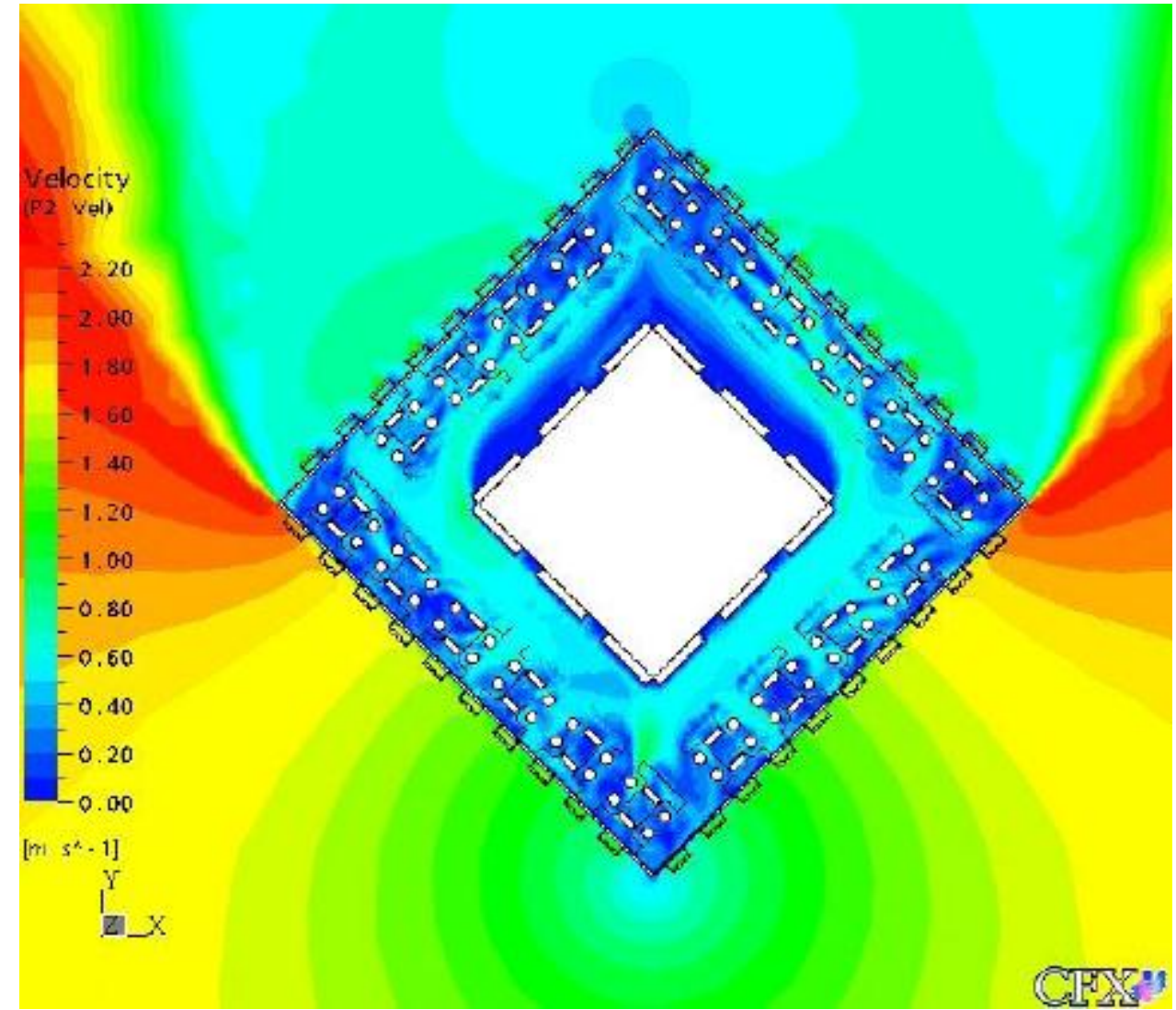

Figura 3.3.3: Perfil de velocidades no plano a 90cm do piso (FIGUEIREDO, 2007).
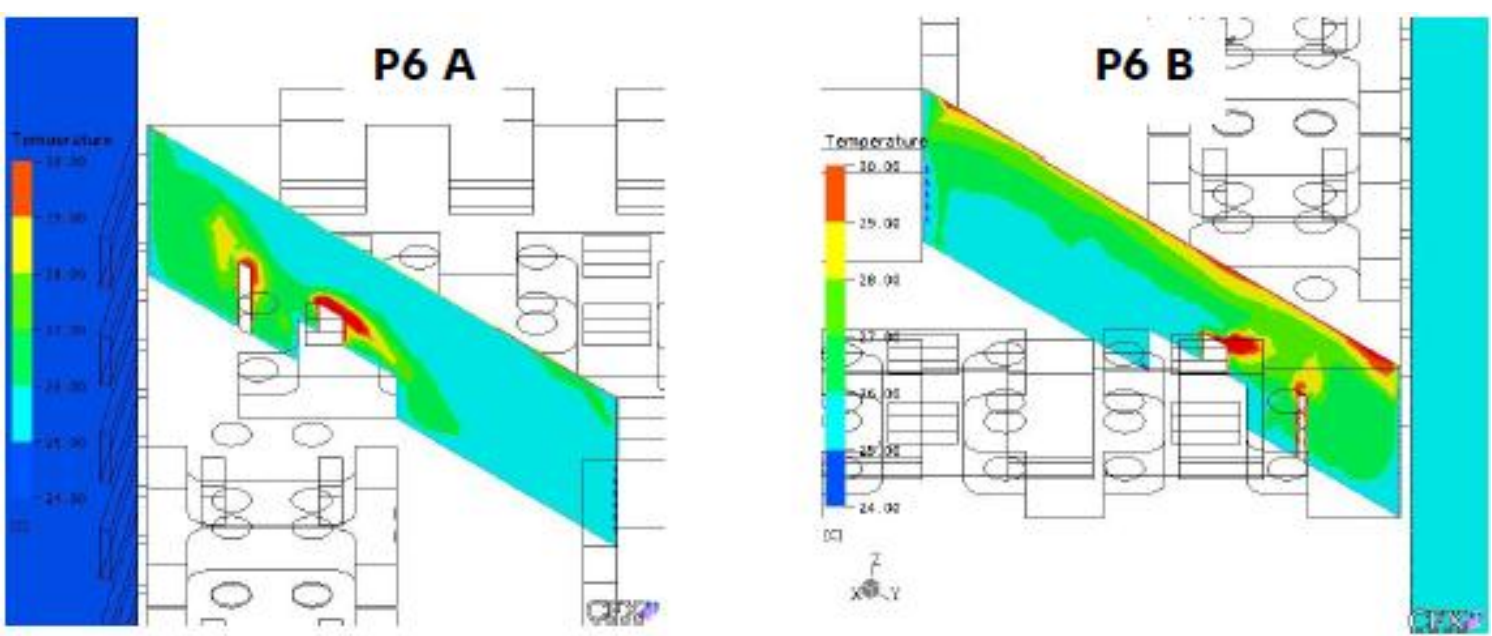

Figura 3.3.4: Perfil de temperatura no interior do edifício analisado por Figueiredo (2007). 


\section{CAPÍTULO 4 SIMULAÇÃO NUMÉRICA DA VENTILAÇÃO NATURAL EM AMBIENTES DE ESCRITÓRIOS}

Este capítulo apresenta detalhes das geometrias analisadas em trabalhos anteriores, assim como as geometrias escolhidas na presente dissertação. Em seguida, são descritas características das malhas utilizadas, como tamanhos de elementos e condições de contorno das simulações. Por fim, são apresentadas as configurações analisadas para verificar quais situações propiciam melhores condições de ventilação dos ambientes, assim como os parâmetros adotados para verificar a eficiência da ventilação natural nos ambientes estudados.

\subsection{GEOMETRIAS ANALISADAS}

Para se aferir a aplicabilidade da ventilação natural em ambientes de escritórios necessita-se utilizar uma ou mais geometrias que possuam boa representatividade, ou seja, modelos onde as condições analisadas possam ser verificadas em uma quantidade maior de ambientes de escritórios.

Alguns trabalhos analisaram computacionalmente aspectos de ventilação natural em ambientes de escritórios e/ou foram citados por estes trabalhos, como por exemplo Gratia, Bruyère e De Herde (2004), Pirró (2005), Benedetto (2007), Figueiredo (2007) e Marcondes (2010). Nestes trabalhos são apresentadas algumas geometrias, dentre as quais uma delas foi utilizada na presente dissertação.

O estudo de Gratia, Bruyère e De Herde (2004) consistiu na análise da influência de parâmetros como direção do vento, proteções da incidência direta de radiação solar e rajadas de vento, além de variações nas aberturas sobre a ventilação natural em um edifício de escritórios de cinco pavimentos situado em Bruxelas. Para as simulações, usando o programa TAS, os autores empregaram uma edificação de planta retangular estreita, com divisórias internas separando os escritórios e duas áreas de serviço nas extremidades, conforme ilustra a figura 4.1.1. As cores desta figura indicam a separação das zonas térmicas utilizada nas simulações. 


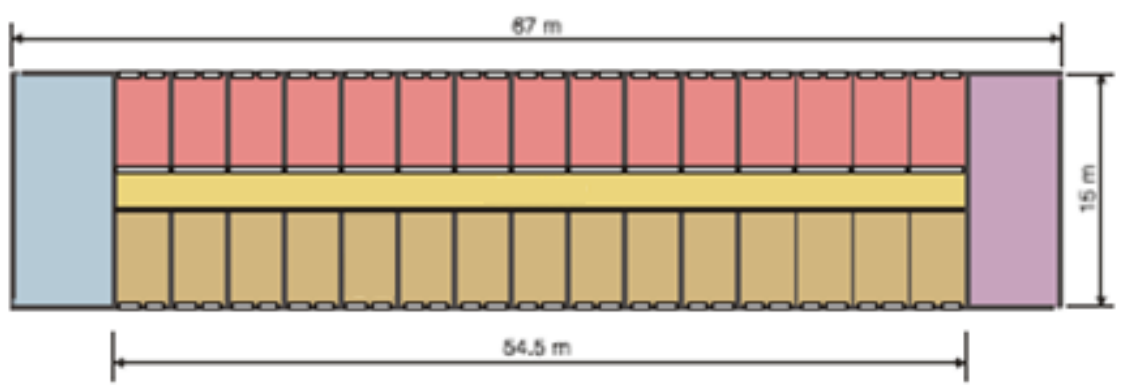

Figura 4.1.1: Planta utilizada por Gratia, Bruyère e De Herde (2004).

As janelas utilizadas na análise eram em número de quatro para cada escritório, sendo posicionadas duas a duas, com uma sobre a outra, como indica a figura 4.1.2. Nas partições internas houve a modelagem de uma janela sobre a porta dos escritórios, como mostra a figura 4.1.3. Um corte sobre estes ambientes é apresentado na figura 4.1.4.

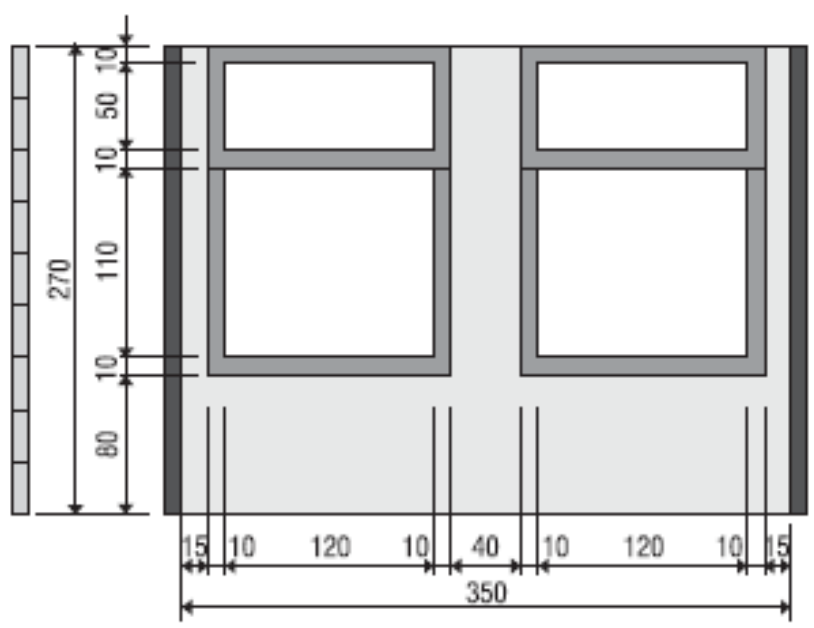

Figura 4.1.2: Vista externa das janelas dos escritórios analisados por Gratia, Bruyère e De Herde (2004).

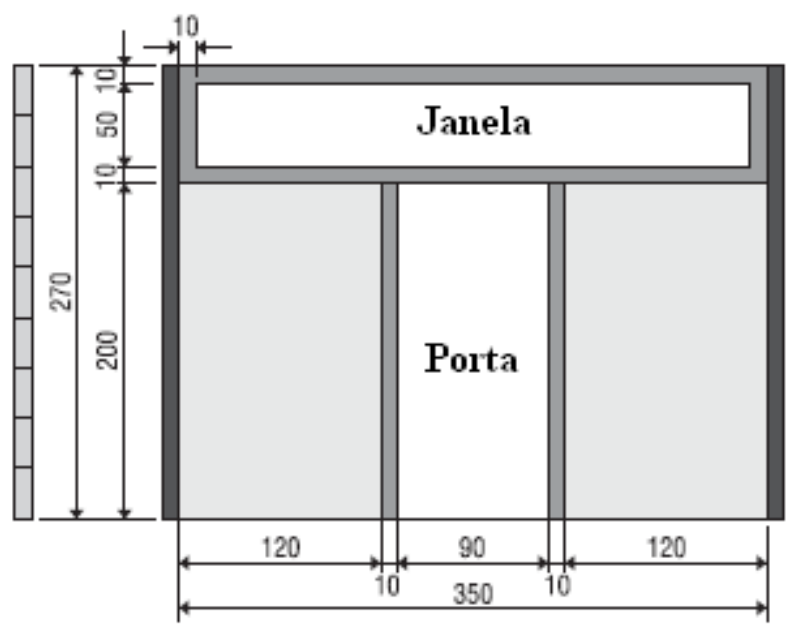

Figura 4.1.3: Vista das partições e aberturas internas utilizadas por Gratia, Bruyère e De Herde (2004). 


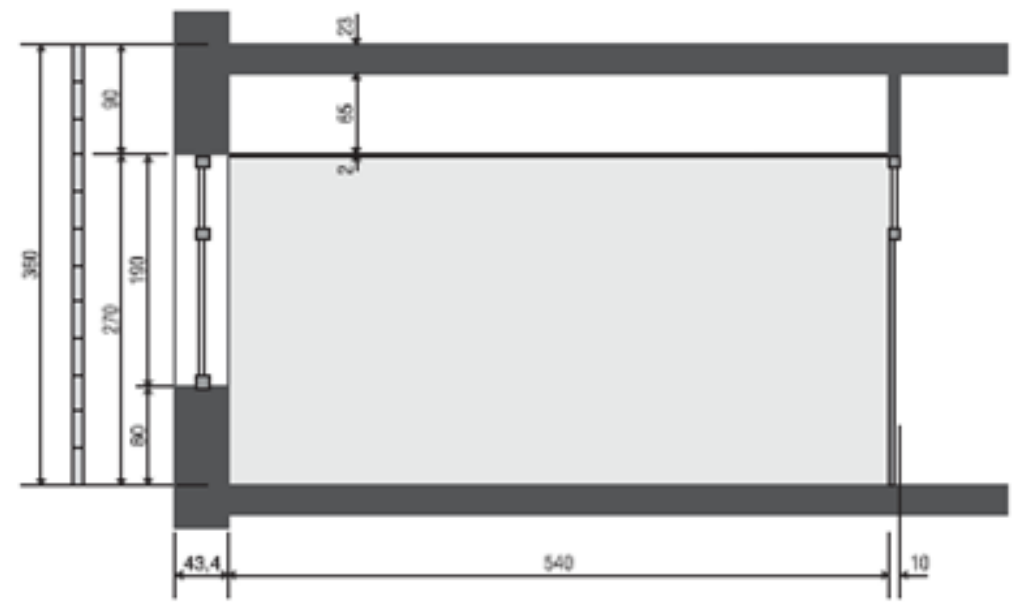

Figura 4.1.4: Corte do escritório simulado por Gratia, Bruyère e De Herde (2004).

Na tese de Pirró (2005) é analisado o impacto das envolventes verticais sobre o consumo de energia de edifícios comerciais. Em seu trabalho foi desenvolvido para o programa Energy Plus um modelo computacional, tendo este características baseadas em pesquisa realizada no setor comercial de São Paulo no período dos anos de 1980 a 2000 por Dilonardo (2001). O modelo empregado consiste em um pavimento tipo com planta quadrada, de $35 \mathrm{~m} \times 35 \mathrm{~m}$, core interno com $7 \mathrm{~m} \times 7 \mathrm{~m}$, altura do pé direito de $2,70 \mathrm{~m}$ e quatro zonas térmicas internas, conforme mostra a figura 4.1.5.

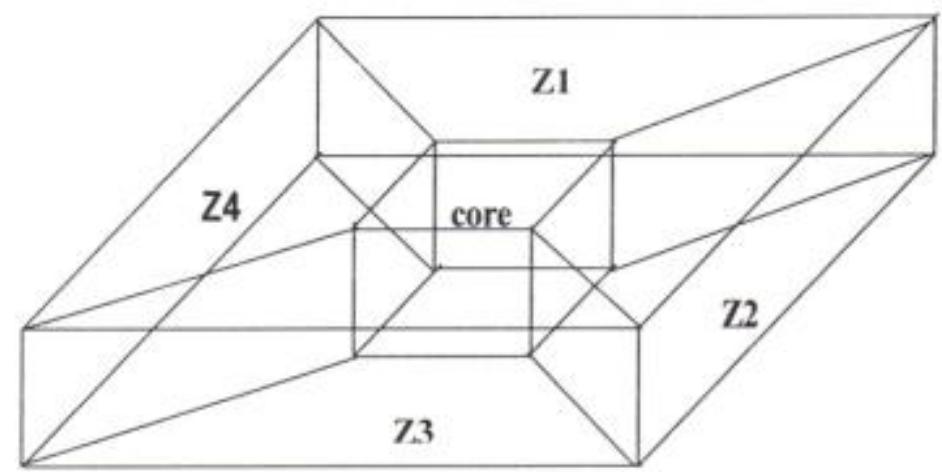

Figura 4.1.5: Planta quadrada utilizada por Pirró (2005).

Benedetto (2007) desenvolveu, inicialmente, dois modelos computacionais com geometrias idênticas aos trabalhos de Dilonardo (2001) e Pirró (2005), sendo diferenciadas entre si pela área externa envidraçada e pela presença de dispositivos de proteção solar. $\mathrm{O}$ modelo utilizado por Benedetto (2007) encontra-se na figura 4.1.6. 


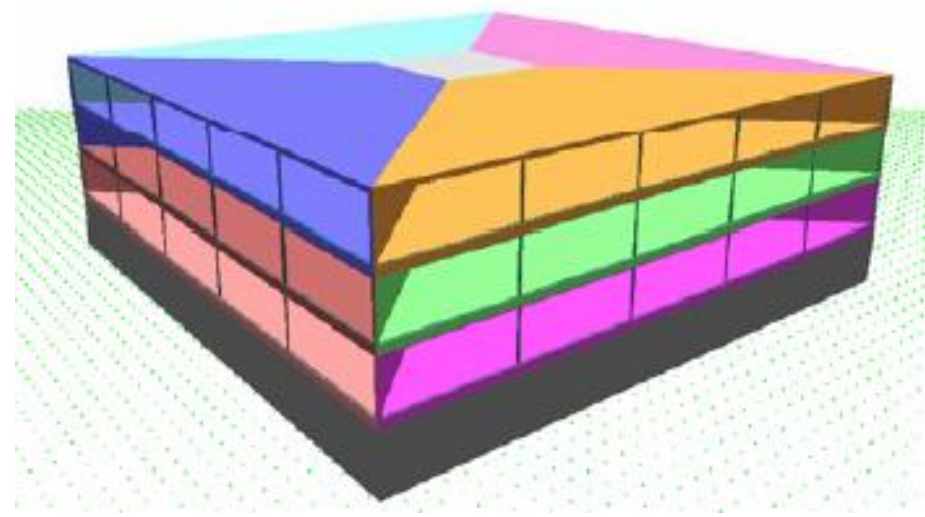

Figura 4.1.6: Perspectiva do modelo de edificação utilizado por Benedetto (2007)

(Adaptado de BENEDETTO, 2007).

Posteriormente, Benedetto (2007) desenvolveu um terceiro modelo direcionando o edifício analisado para o modo híbrido de ventilação. Para tanto, houve algumas mudanças em relação aos modelos originais, como utilização de planta baixa menos profunda, melhorando a possibilidade de ventilação cruzada, pé-direito mais alto e ausência de forro, permitindo trocas térmicas com a estrutura da edificação. As figuras 4.1.7 e 4.1.8 apresentam uma comparação entre as plantas destes modelos utilizados por Benedetto (2007), enquanto que a figura 4.1.9 contém cortes destes modelos.

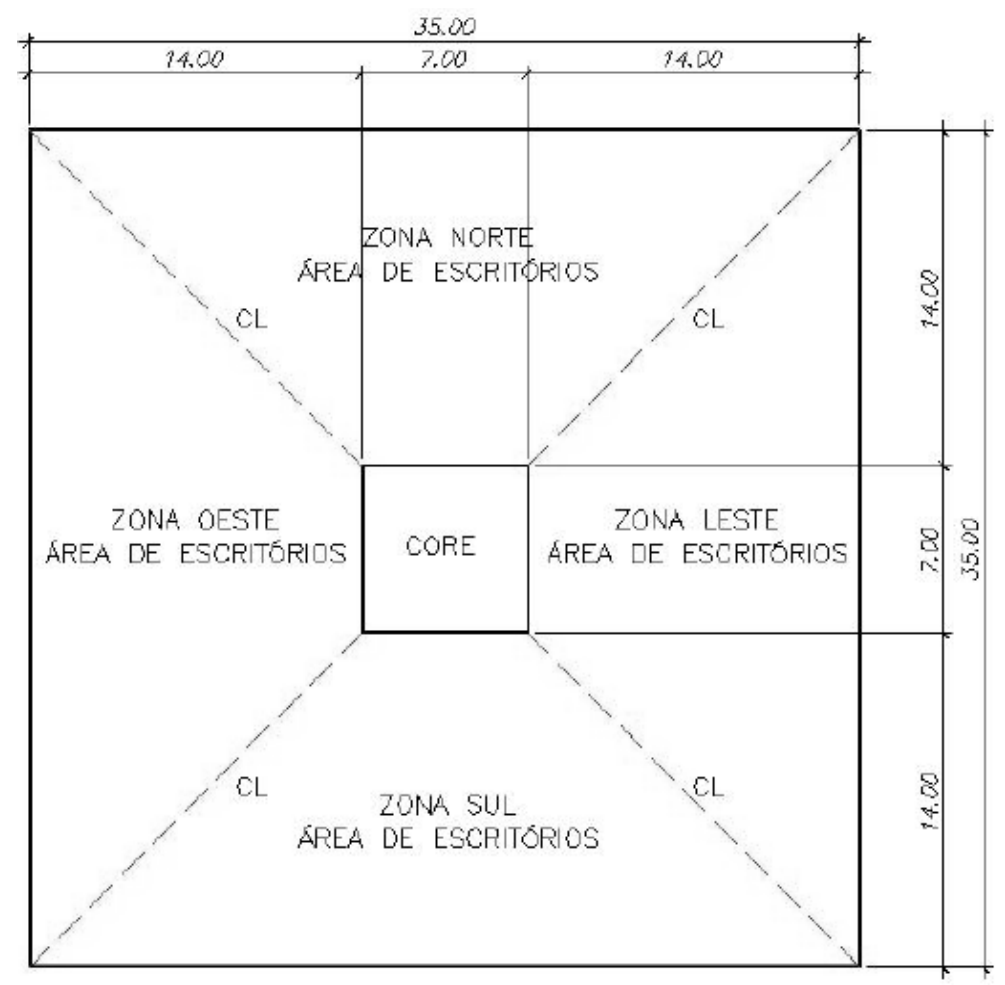

Figura 4.1.7: Planta baixa do modelo M2 utilizado por Benedetto (2007) 


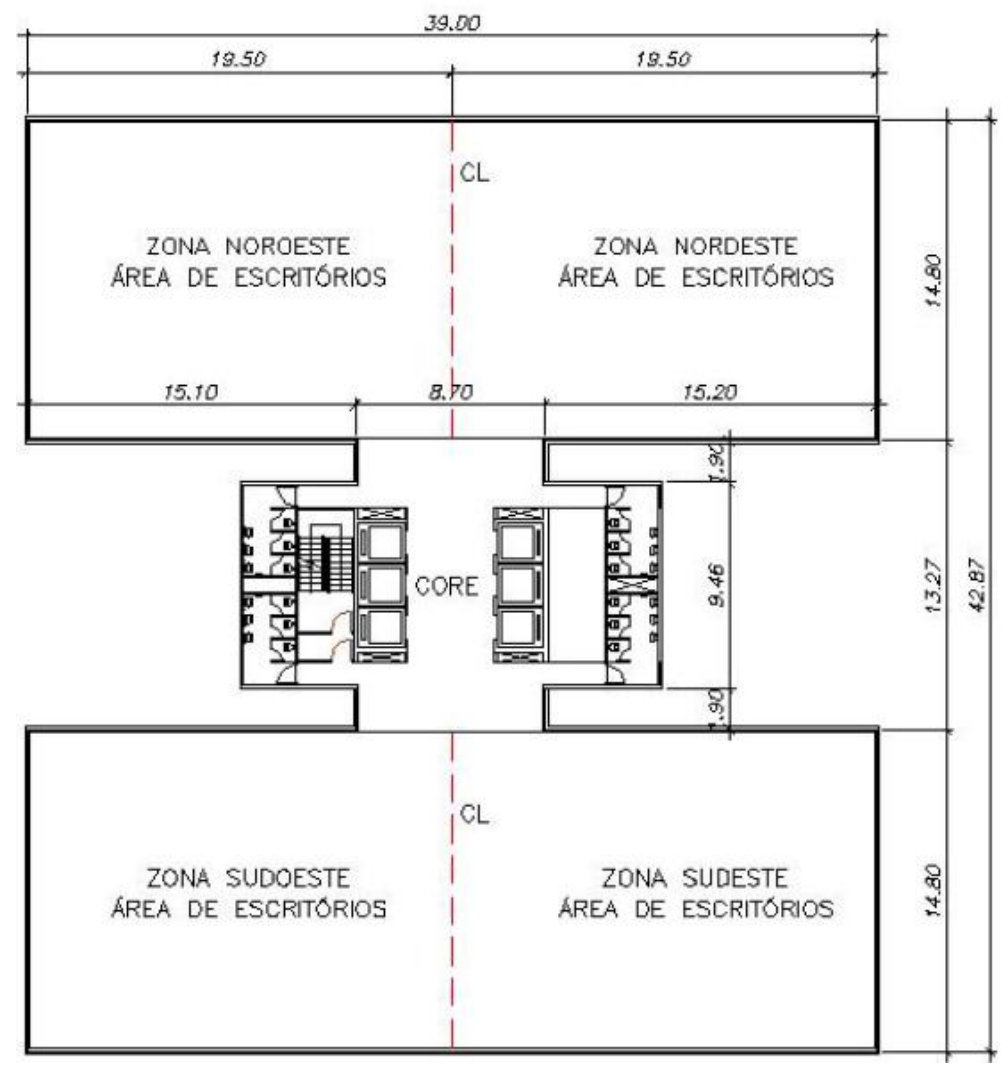

Figura 4.1.8: Planta baixa do modelo M3 utilizado por Benedetto (2007)

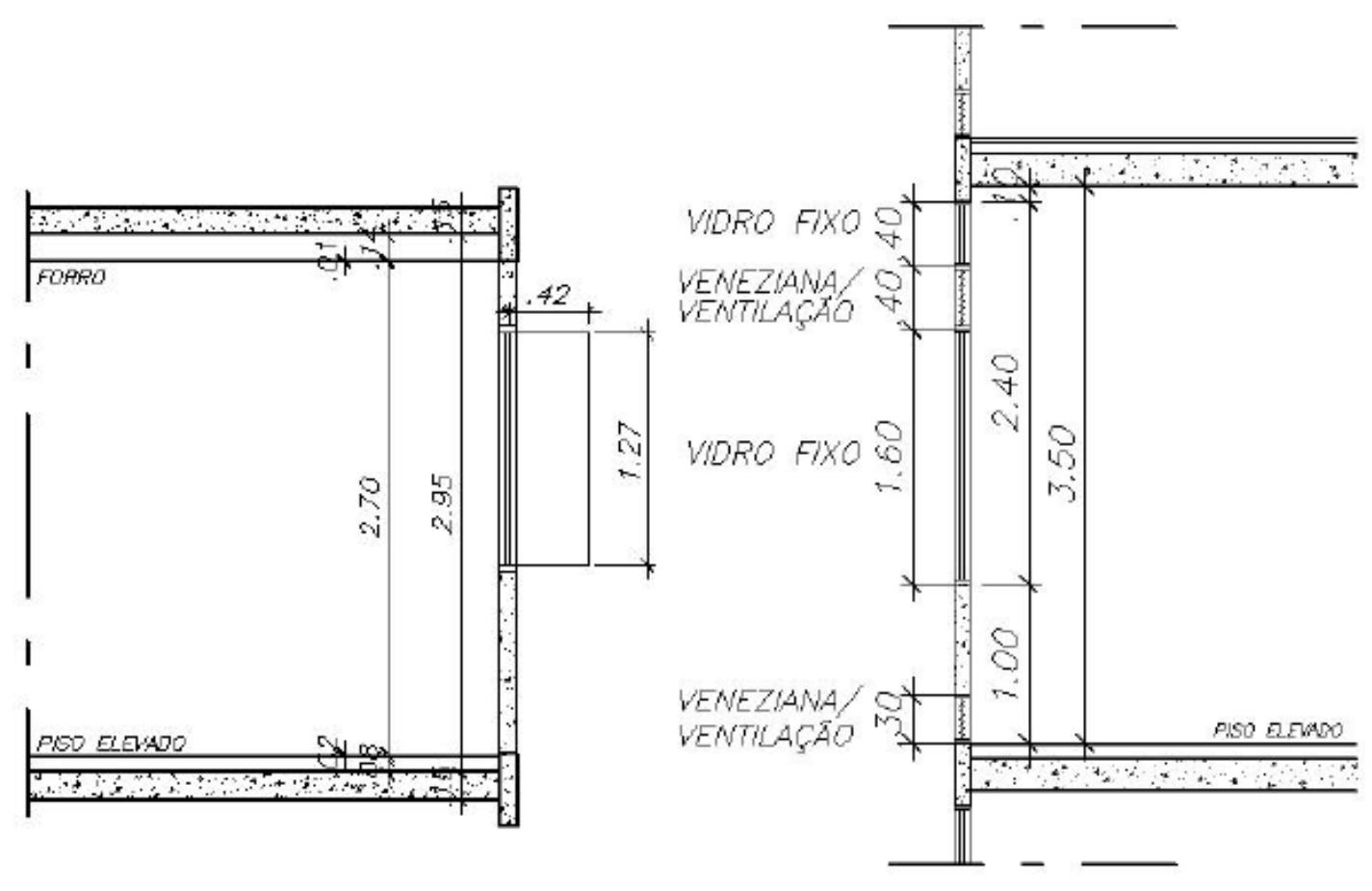

(a)

(b)

Figura 4.1.9: Cortes esquemáticos dos modelos M2 (a) e M3 (b) utilizados por Benedetto (2007) 
Dentre as características principais das edificações analisadas por Figueiredo (2007), apontam-se grandes áreas de pavimentos, com $1.000 \mathrm{~m}^{2}$ ou mais, altos percentuais de áreas envidraçadas nas fachadas, variando de $40 \%$ a $100 \%$, plantas retangulares ou quadradas e alturas de pelo menos cinco andares.

Considerando as aberturas para ventilação natural, Figueiredo (2007) ressalta que a tipologia utilizada é a maxim-ar, uma classe de top-hung, onde são alternados quadros fixos e móveis. Com base nestes dados, Figueiredo (2007) desenvolveu um modelo de planta quadrada com 75 metros de altura, distribuídos em 20 pavimentos, com core central quadrado, conforme apresentado nas figuras 4.1.10 e 4.1.11.

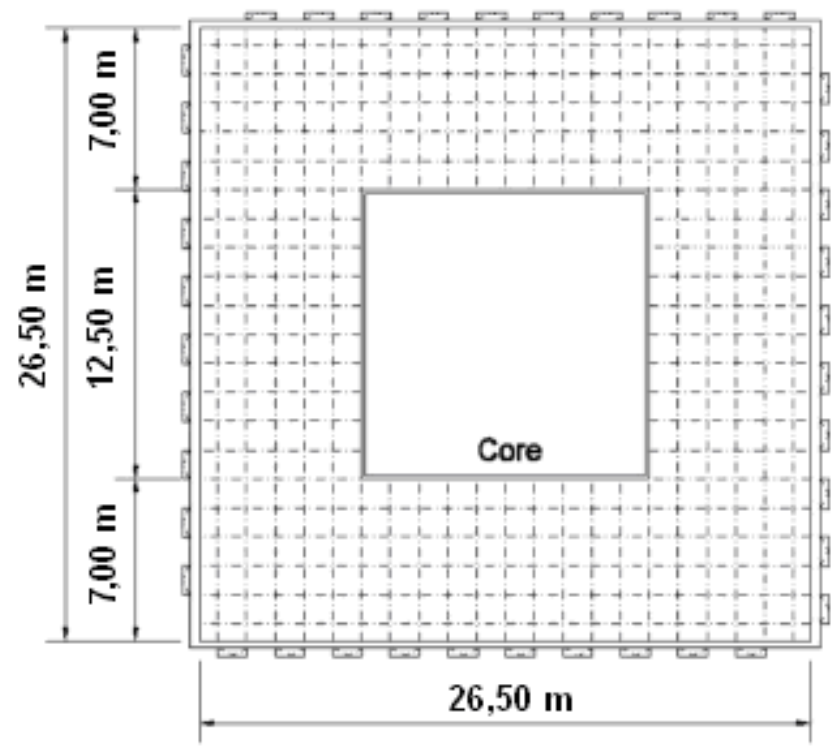

Figura 4.1.10: Planta quadrada utilizada por Figueiredo (2007) (Adaptado de FIGUEIREDO, 2007).

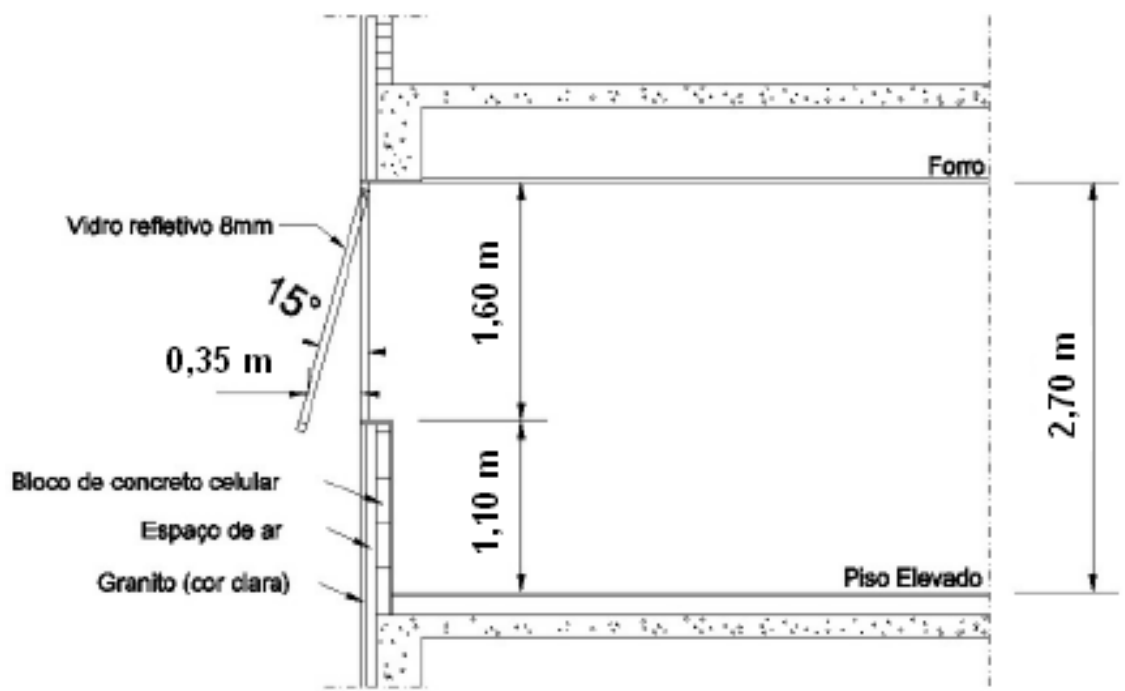

Figura 4.1.11: Corte do modelo utilizado por Figueiredo (2007) (Adaptado de FIGUEIREDO, 2007). 
Em seu modelo de edificação, Figueiredo (2007) utilizou um pavimento localizado no décimo andar como pavimento tipo, contendo em seu interior a modelagem de um layout completo (mesas, armários), equipamentos (computadores), pessoas sentadas, iluminação artificial e janelas do tipo maxim-ar abertas. A figura 4.1.12 apresenta uma perspectiva deste pavimento tipo utilizado, incluindo o layout empregado.

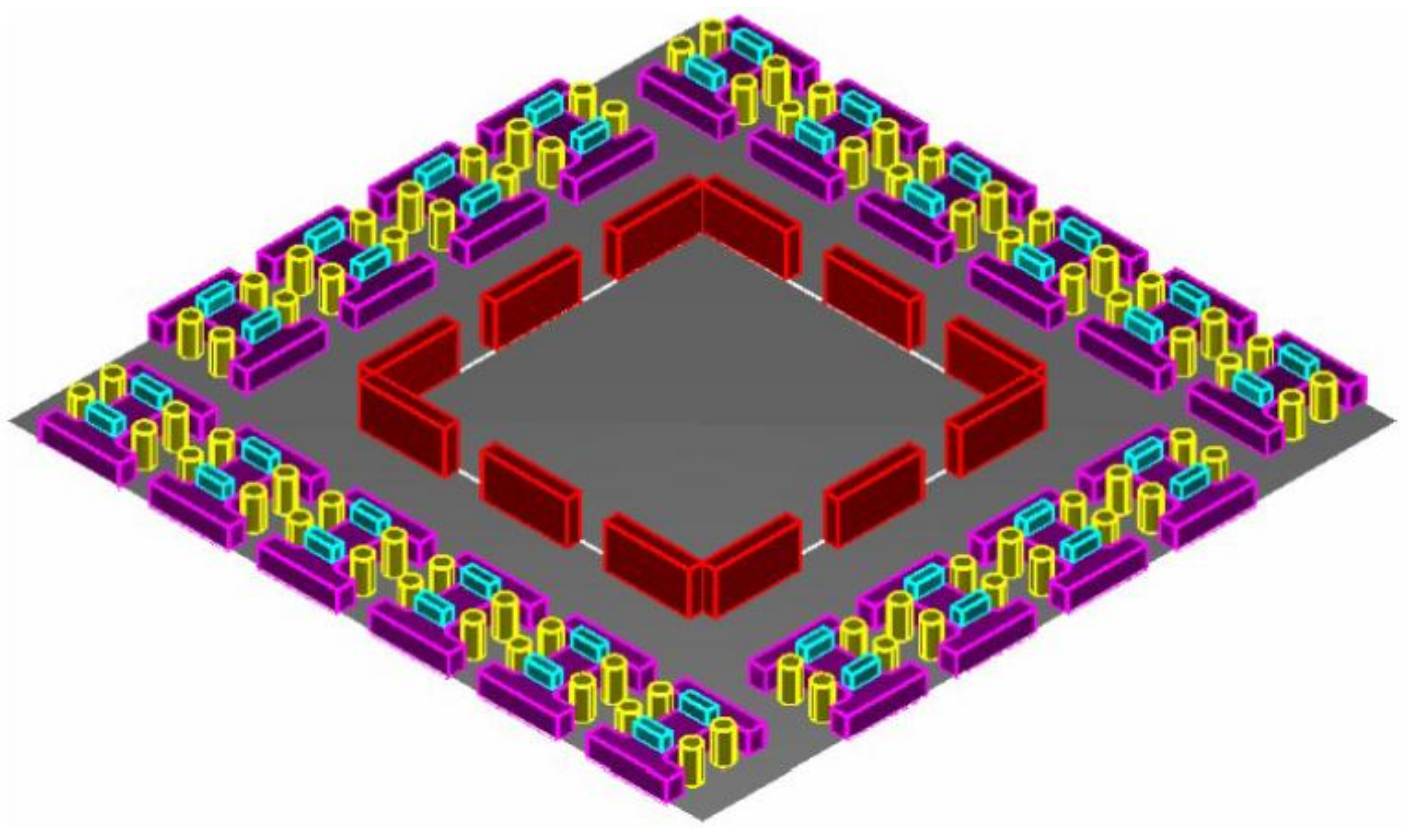

Figura 4.1.12: Perspectiva do pavimento tipo utilizado por Figueiredo (2007).

Em seu trabalho, Marcondes (2010) apresenta no capítulo dedicado à descrição das geometrias um panorama sobre a caracterização dos ambientes de escritório em São Paulo no final da década de 2000. A autora verificou que ocorre uma tendência ao uso de plantas retangulares ou quadradas, com áreas de aproximadamente $1.000 \mathrm{~m}^{2}$, sendo divididos aproximadamente em $70 \%$ para os escritórios e $30 \%$ para o core.

Aliando esta característica às demais apontadas anteriormente, Marcondes (2010) propôs dois modelos, ambos com $675 \mathrm{~m}^{2}$ de área útil, sendo um deles considerado mais propício para o emprego de ventilação natural, que consiste em uma planta retangular com pavimento tipo de $60 \mathrm{~m} \times 15 \mathrm{~m}$, com dois cores laterais, apresentado na figura 4.1.13. O outro modelo contém pavimento tipo de $30 \mathrm{~m}$ x 30m e core central de $15 \mathrm{~m}$ x $15 \mathrm{~m}$, conforme ilustra a figura 4.1.14, e proporção de superfícies transparentes e opacas de 50\% na fachada. 


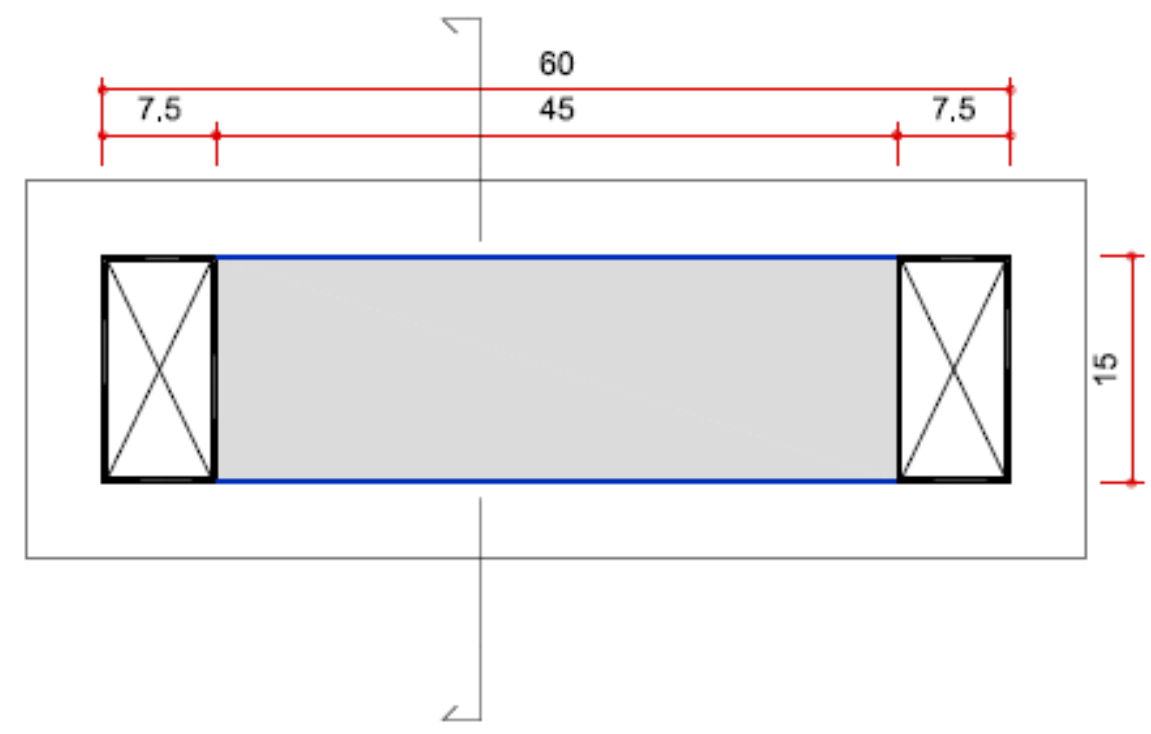

Figura 4.1.13: Planta retangular utilizada por Marcondes (2010).

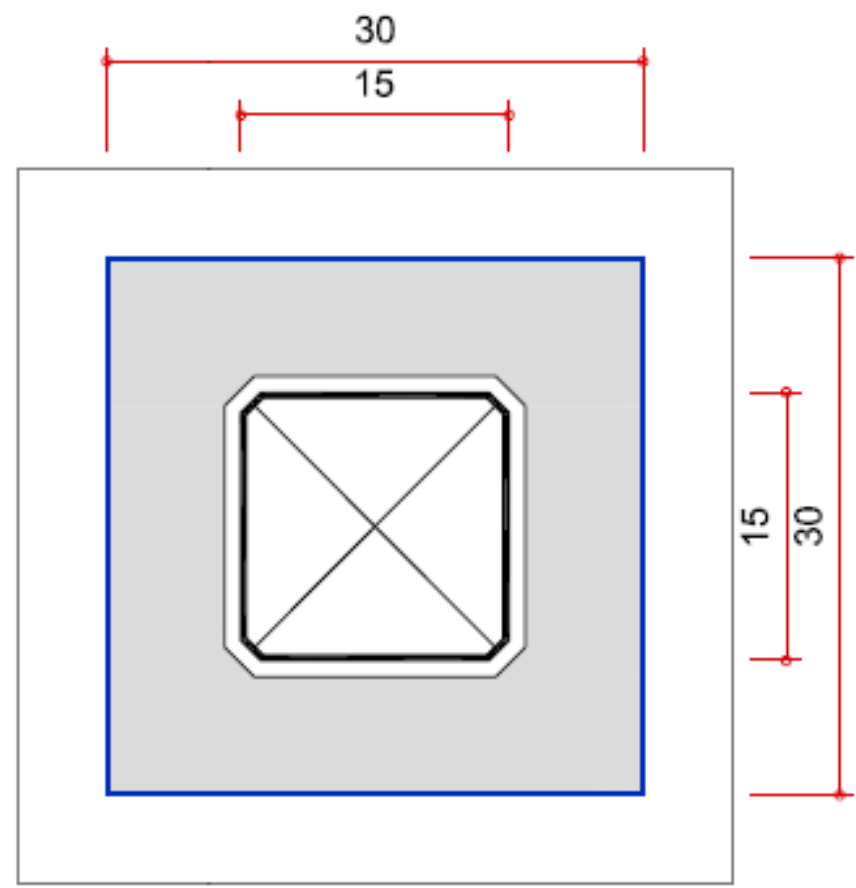

Figura 4.1.14: Planta quadrada utilizada por Marcondes (2010).

Resultado da análise dos trabalhos apresentados neste item, no presente trabalho foram realizadas simulações numéricas considerando somente a planta retangular, mais propícia para o emprego de ventilação natural. Considerando os dados recentes sobre a tendência de área de pavimentos e de geometria para edifícios de escritórios apresentados por Marcondes (2010), a planta simulada será a mesma utilizada naquele trabalho, conforme apresentado na figura 4.1.15. 


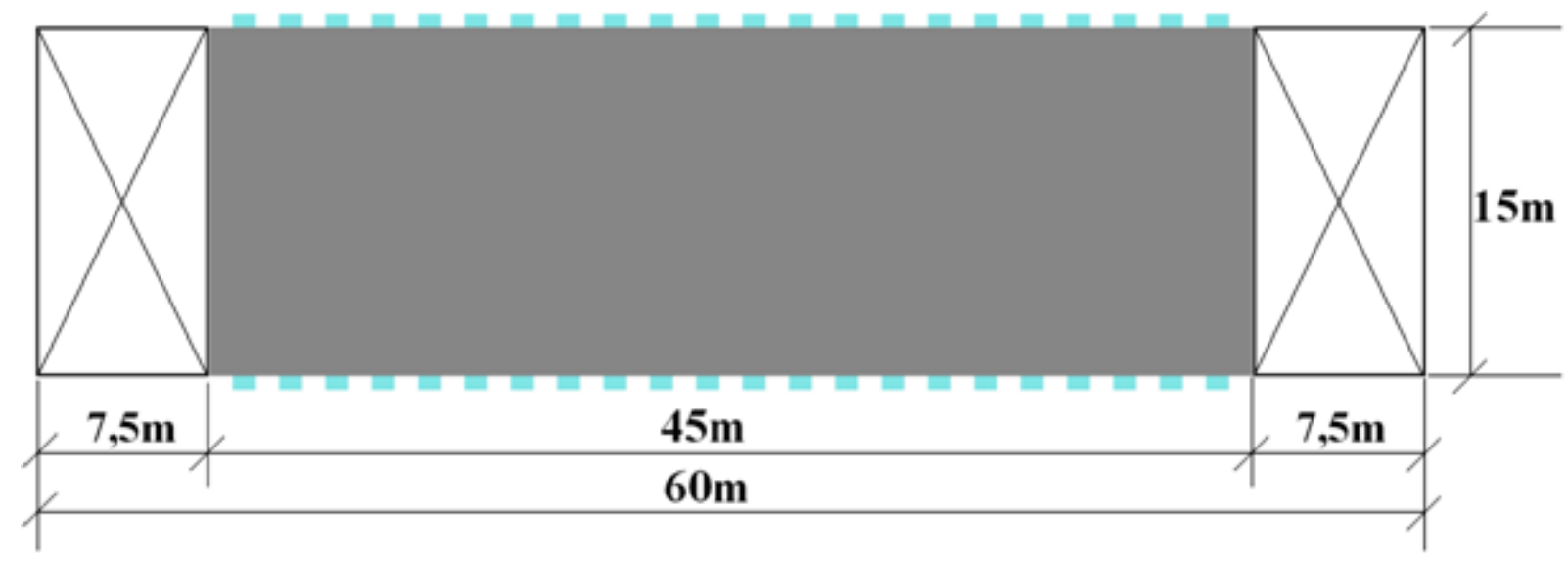

Figura 4.1.15: Planta retangular utilizada nas simulações.

Como em geral a ventilação natural é empregada em edificações baixas, com poucos pavimentos, neste trabalho foi arbitrada uma edificação com cinco pavimentos de altura, como mostra a figura 4.1.16. Embora os cinco pavimentos possuam janelas abertas, permitindo o fluxo de ar através de todas as aberturas, apenas no escritório analisado foram modelados os ocupantes e mobiliário, permanecendo os demais pavimentos vazios. $\mathrm{O}$ pavimento analisado foi o mais alto, pois caso as condições ambientais neste local não permitissem obter conforto térmico, nos demais andares também não seriam obtidas as condições favoráveis necessárias. Isto decorre do perfil de velocidades do vento (ver item 4.4.2), que favorece uma entrada maior de ar nos pavimentos mais altos.

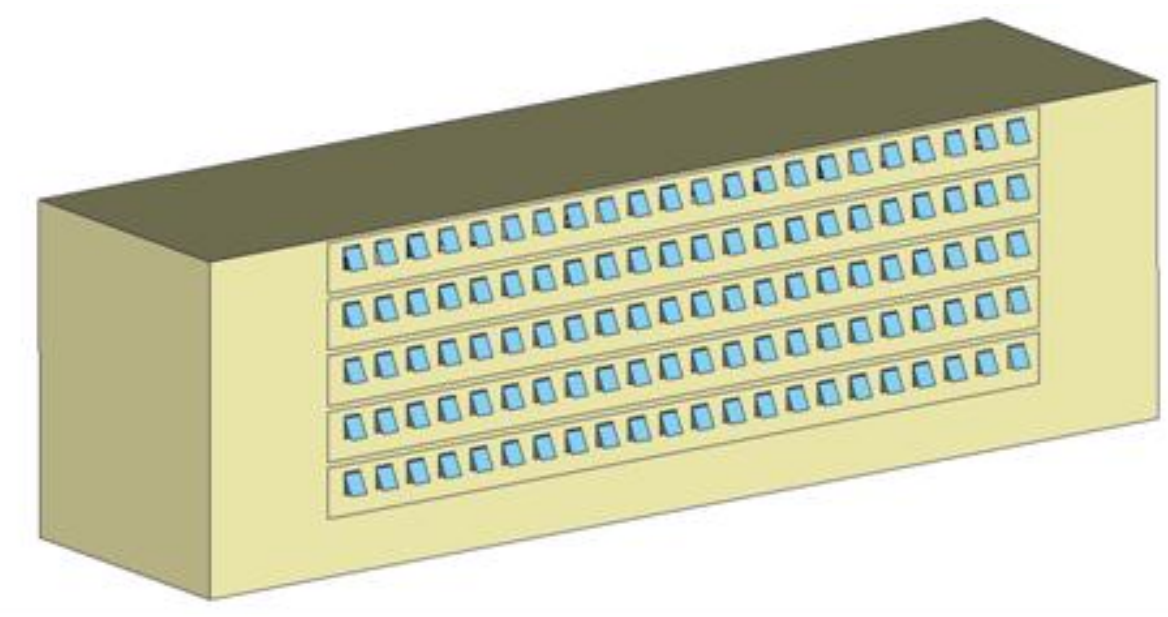

Figura 4.1.16: Vista em perspectiva da edificação utilizada nas análises numéricas.

Foram modeladas 22 aberturas em cada pavimento, com dimensões de 1,20m de altura e 1,00m largura. A altura do peitoril e das janelas é de 1,10m e entre cada uma das janelas foi 
deixado o espaço de $1,00 \mathrm{~m}$, conforme ilustra a figura 4.1.17. Além disso, o pé-direito de cada ambiente é de 2,70m, totalizando uma distância de 3,00m entre cada pavimento.

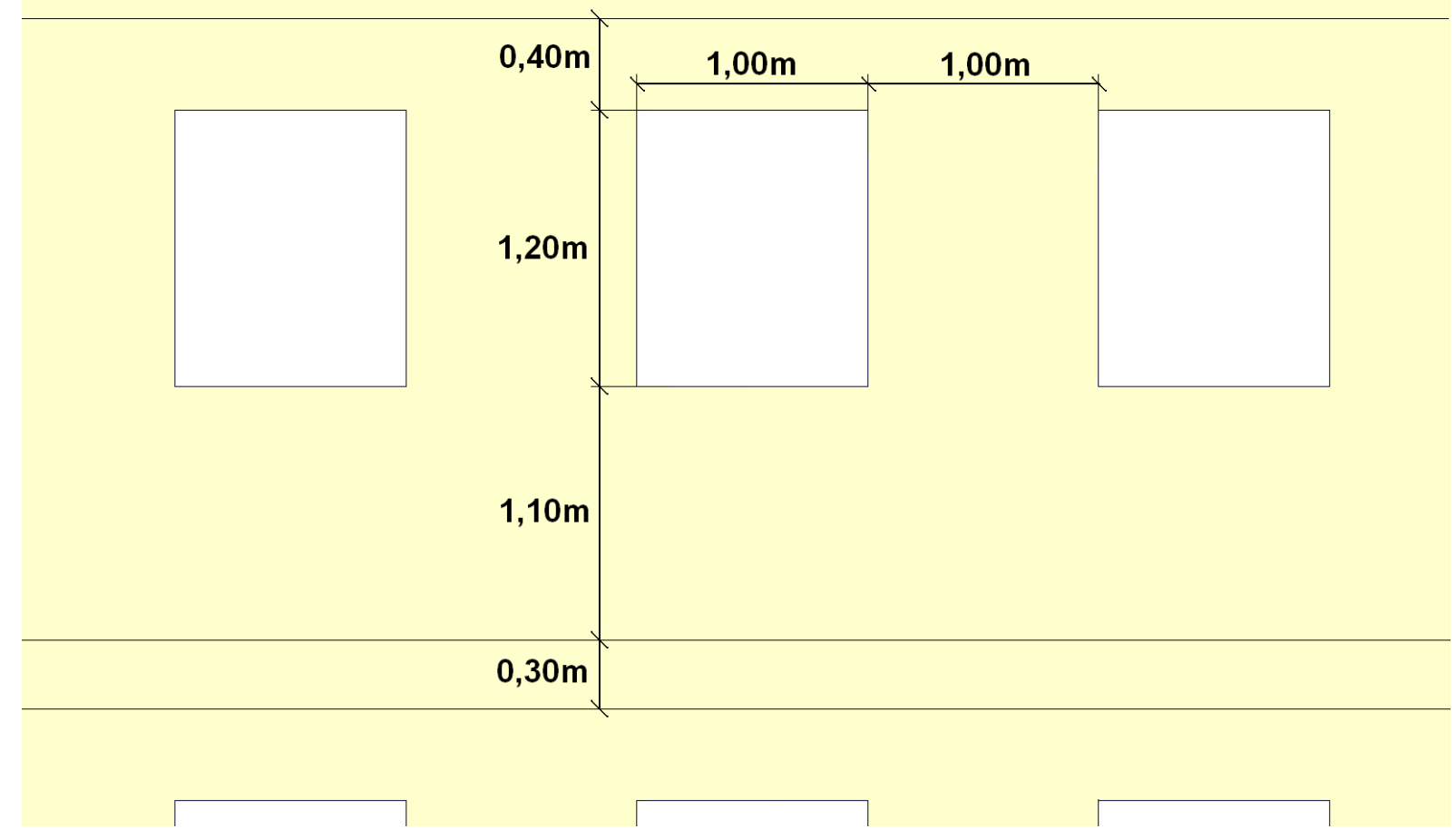

Figura 4.1.17: Dimensões principais das aberturas e seu posicionamento na fachada.

\subsection{MALHA UTILIZADA}

Uma boa malha é fundamental para que o resultado da simulação descreva adequadamente os fenômenos representados. A seguir, encontra-se uma discussão sobre os principais elementos utilizados na construção da malha do domínio simulado nesta dissertação.

\subsubsection{Domínio ao redor da edificação}

Evola e Popov (2006) simularam uma edificação cúbica, sendo o domínio de simulação descrito em função do comprimento da aresta, conforme ilustra a figura 4.2.1. Verifica-se que a extensão a jusante da edificação é o dobro da encontrada a montante, assim como de suas laterais. 


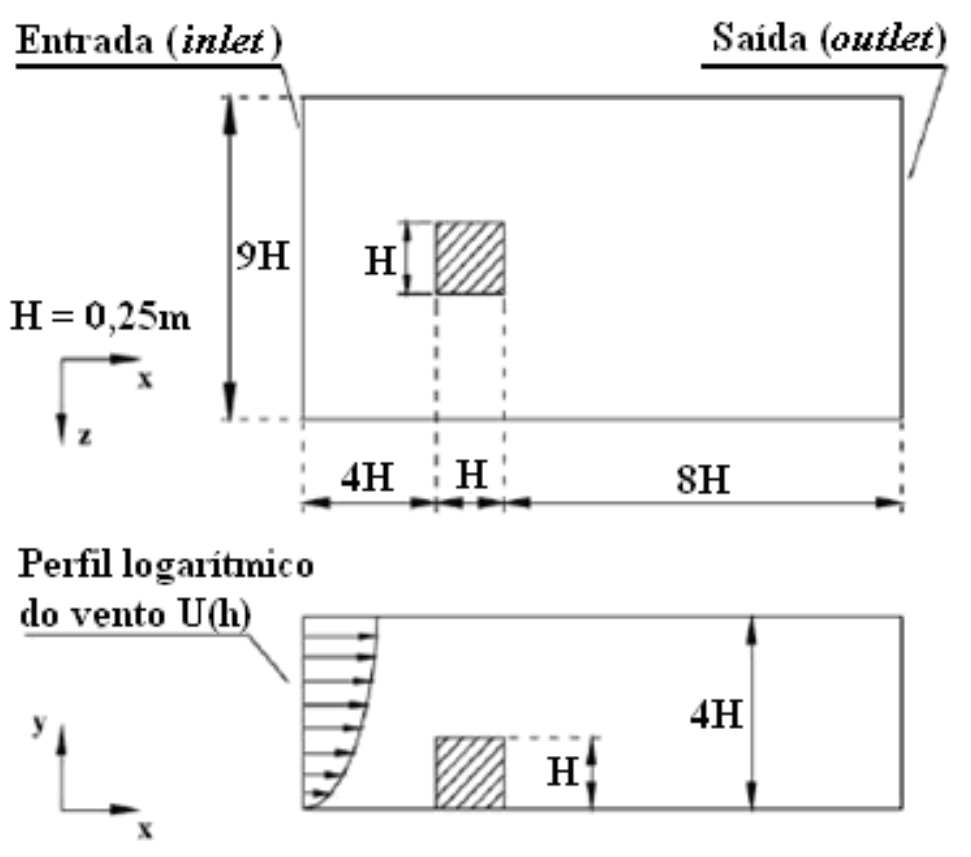

Figura 4.2.1: Domínio utilizado nas simulações de Evola e Popov (2006).

O domínio de base retangular utilizado por Cóstola (2006) possui dimensões baseadas nas recomendações do guia de boas práticas no uso de CFD para estudos de simulação de ambientes urbanos (COST, 2004), e se encontra ilustrado na figura 4.2.2. Estes mesmos dados foram adotados por Figueiredo (2007), como pode ser visto na figura 4.2.3, havendo apenas pequenas mudanças em função da altura diferente das edificações analisadas.

Uma atualização e ampliação do guia citado anteriormente recomenda que o domínio tenha no mínimo as dimensões indicadas na figura 4.2.2, tendo a distância posterior à construção o valor de 15H (COST, 2007).

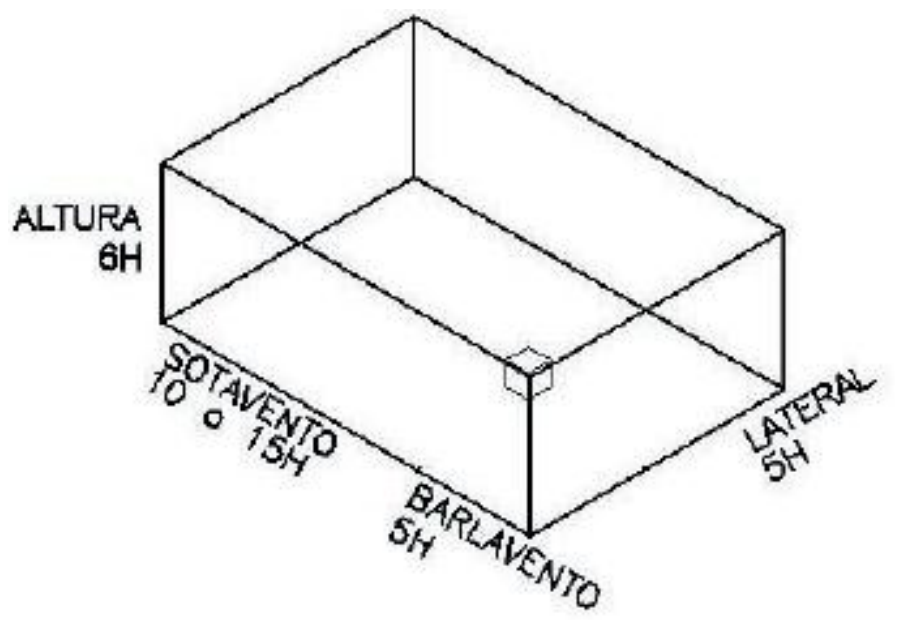

Figura 4.2.2: Domínio de base retangular utilizado por Cóstola (2006). 


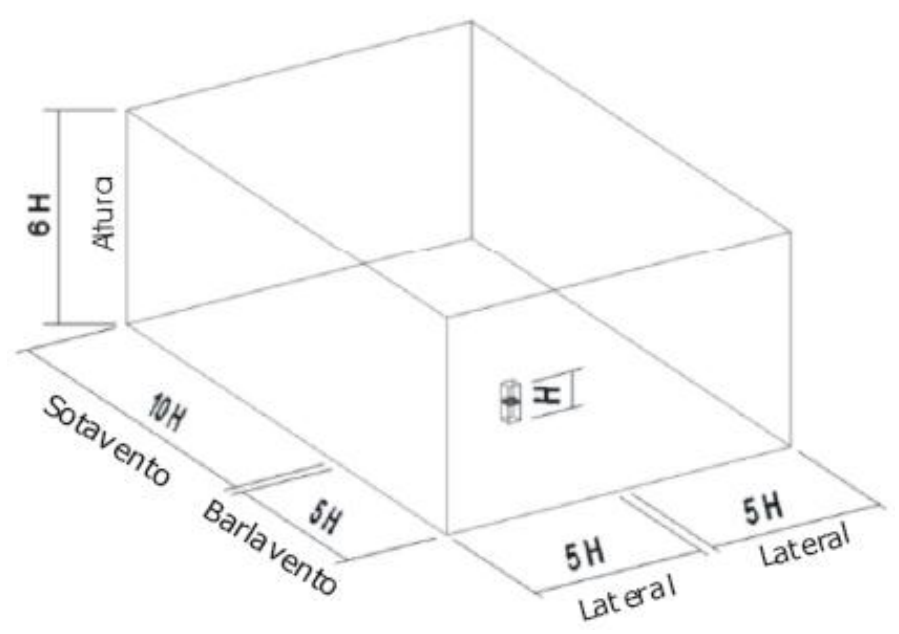

Figura 4.2.3: Domínio utilizado por Figueiredo (2007).

É necessário ter em mente que COST (2007) possui maior interesse na região ao redor das edificações, a fim de analisar o impacto na movimentação de ar na escala urbana. Desta forma, inicialmente foi imaginado utilizar o mesmo domínio de Evola e Popov (2006). Entretanto, como a edificação daquele trabalho possui planta significativamente diferente, como mostra a figura 4.4.15, optou-se por uma abordagem mais conservadora e foi adotada a base do domínio utilizada por Cóstola (2006) e Figueiredo (2007), como mostra a figura 4.2.4.

Uma vez que a região de maior interesse neste trabalho é o volume do escritório, foi criado um volume de refinamento da malha, indicado em verde na figura 4.2 .4 , a fim de garantir uma melhor precisão da interação do ar com a construção. Este volume de refinamento permite utilizar mais elementos de menor tamanho próximo à edificação, de forma a discretizar melhor as propriedades do escoamento nesta região.

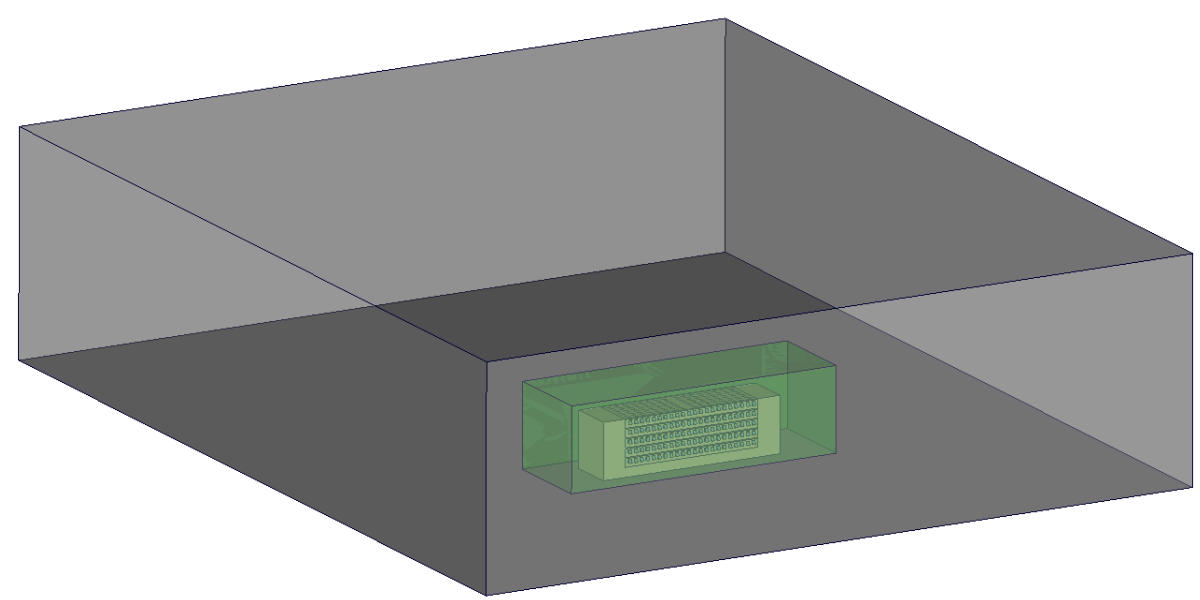

Figura 4.2.4: Representação do domínio utilizado no trabalho. 


\subsubsection{Qualidade dos elementos}

Um aspecto importante para se obter malhas de boa qualidade é evitar distorções excessivas dos elementos volumétricos que compõem o domínio de cálculo. Um critério utilizado no programa ANSYS FLUENT é denominado por skew, e ele mede a diferença no formato da célula comparativamente com uma célula ortogonal. Células com elevado valor de skew podem diminuir a precisão e desestabilizar a solução (ANSYS FLUENT, 2010).

No manual ANSYS Fluent (2010) é recomendado que o valor de skew seja menor do que 0,95 , em uma escala de 0 a 1 , onde 0 refere-se a um elemento perfeitamente ortogonal e 1 refere-se a um elemento completamente distorcido. Entretanto, o programa TGrid, utilizado para gerar malhas volumétricas, sugere como valores bons manter o skew máximo abaixo de 0,90, e o valor médio abaixo de 0,40 (ANSYS TGRID, 2010). Decidiu-se utilizar então este critério mais rigoroso, a fim de garantir boa convergência das grandezas físicas calculadas.

\subsection{CRITÉRIOS DE CONVERGÊNCIA}

Em simulações de CFD, muitas vezes utiliza-se como critério de convergência especificar o valor máximo dos resíduos das equações utilizadas, sendo no caso desta dissertação o resíduo da continuidade, das componentes $x, y$ e $z$ da velocidade, da energia cinética turbulenta $k$, da dissipação $\varepsilon$ desta energia cinética, além da equação da energia térmica.

Valores distintos de resíduos destas equações são apontados por diferentes fontes, dificultando a determinação de um valor específico. O programa computacional ANSYS Fluent (2010), utilizado neste trabalho, adota como critério de convergência de resíduos 10e-6 para a equação da energia térmica e 10e-3 para as demais equações supracitadas, enquanto que o software CFX, utilizado por Figueiredo (2007) em sua dissertação, sugere 10e-4 (CFX, 2003).

Entretanto, considerar que a simulação convergiu baseando-se somente nos resíduos pode ser incorreto, levando a conclusões precipitadas. Pode ser citado como exemplo um escoamento bidimensional ao redor de um cilindro, com número de Reynolds igual a 2,0 $0^{\cdot} 10^{6}$, como ilustrado na figura 4.3.1, onde a pressão média é monitorada em uma região a jusante do cilindro. 


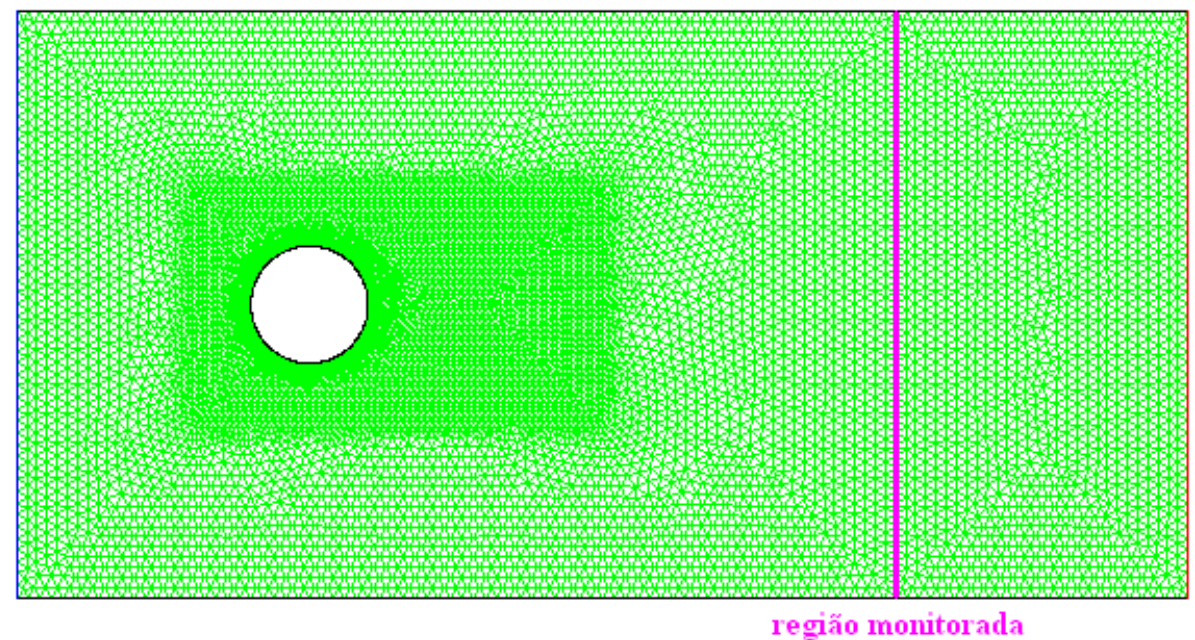

Figura 4.3.1: Malha utilizada para escoamento ao redor de um cilindro.

Se a simulação fosse concluída na iteração 467, onde houve convergência dos resíduos, a pressão média na região monitorada seria de $-0,225 \mathrm{~Pa}$. Entretanto, efetuando-se mais 1000 iterações, verifica-se da figura 4.3.2 que a pressão média é de -0,110 Pa e que esta propriedade já não varia mais, podendo-se considerar a simulação efetivamente concluída. É interessante verificar que houve uma diferença de $104 \%$ nos valores obtidos, ressaltando a necessidade de maior cuidado com os critérios de convergência adotados.

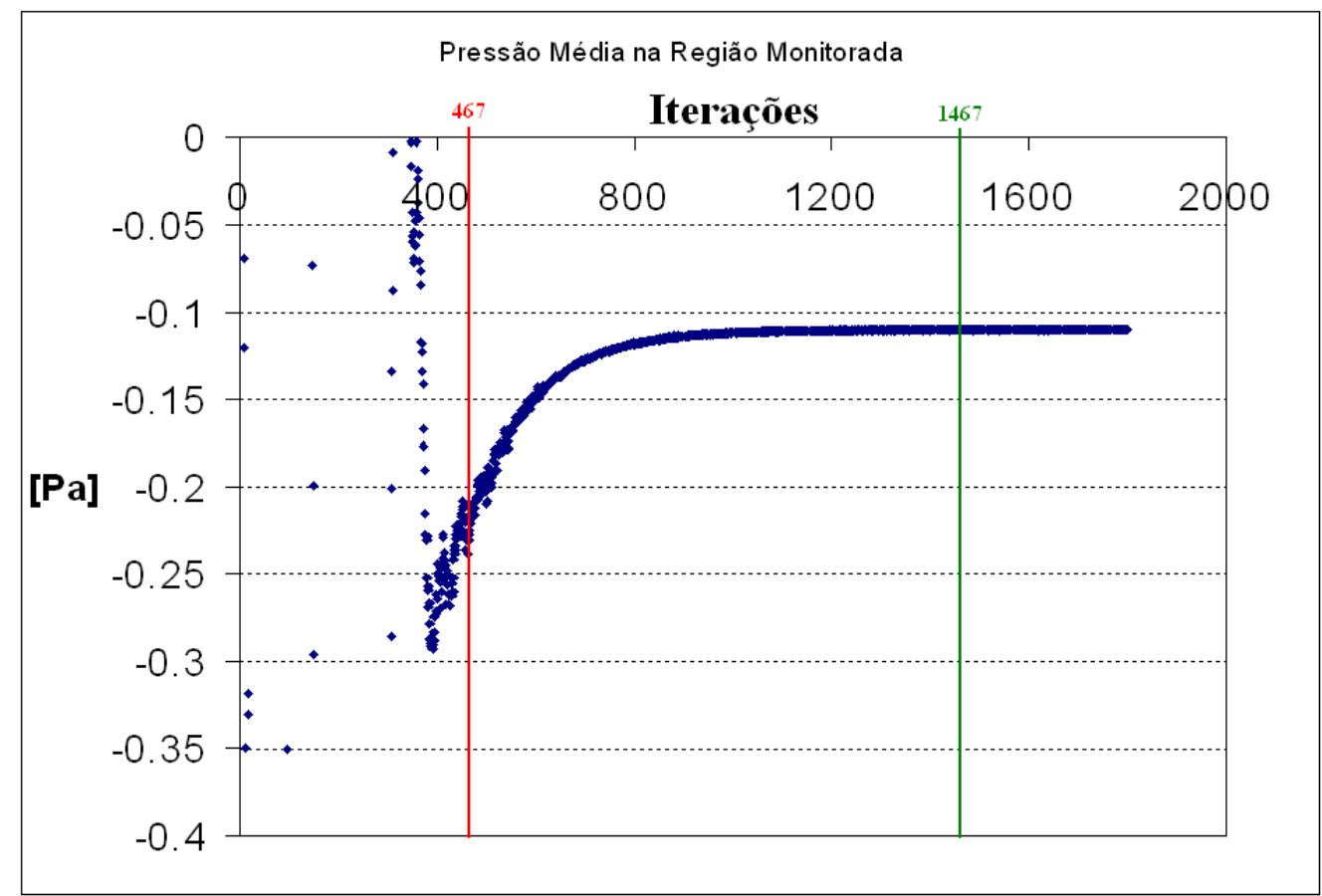

Figura 4.3.2: Comparação dos resultados com diferentes critérios de convergência. 
Desta forma, utilizou-se como critérios de convergência a vazão mássica de ar através das aberturas nas fachadas das edificações analisadas e a temperatura em um ponto arbitrário do ambiente naturalmente ventilado, além dos resíduos das equações resolvidas. Para os casos simulados, verificou-se que eram necessárias 4000 iterações para atender os critérios de convergência apresentados na tabela 4.3.1.

Tabela 4.3.1: Critérios de convergência adotados para a simulação numérica

\begin{tabular}{|c|c|c|}
\hline Propriedade Avaliada & \multicolumn{2}{|c|}{ Critério de Convergência } \\
\hline Continuidade & erro $<1 e-3$ & \\
\hline $\begin{array}{c}\text { Componentes da velocidade } \\
\qquad(\mathrm{u}, \mathrm{v}, \mathrm{w})\end{array}$ & erro $<1 e-3$ & \\
\hline $\begin{array}{l}\text { Propriedades da turbulência } \\
\qquad(\mathrm{k} \text { e } \varepsilon)\end{array}$ & erro $<1 e-3$ & \\
\hline Energia & erro $<1 e-6$ & \\
\hline Radiação & erro $<1 e-6$ & \\
\hline Vazão mássica nas janelas & $\begin{array}{l}\text { variação das últimas } \\
1.000 \text { iterações }\end{array}$ & $<1 e-3$ \\
\hline $\begin{array}{l}\text { Temperatura em um ponto } \\
\text { arbitrário do ambiente }\end{array}$ & $\begin{array}{c}\text { variação das últimas } \\
1.000 \text { iterações }\end{array}$ & $<1 e-3$ \\
\hline
\end{tabular}

\subsubsection{Parâmetros de subrelaxação}

Uma grande dificuldade obtida para se obter convergência estava relacionada aos parâmetros de subrelaxação utilizados. Como citado no item 3.3.1, estes parâmetros controlam a velocidade com que o processo iterativo avança até a solução, porém outros efeitos podem ser obtidos ajustando estes coeficientes.

No caso da ventilação natural, o fenômeno descrito é essencialmente transiente, pois a convecção natural possui papel fundamental, especialmente quando as velocidades do ar envolvidas são baixas. Entretanto, esta transitoriedade pode ser descrita como uma flutuação em torno de um valor médio, de forma que uma solução em regime permanente pode descrever satisfatoriamente o problema. 
Entretanto, ao adotar a solução em regime permanente não foi possível obter a convergência dos resíduos da equação da continuidade. Como descrito no manual do programa utilizado (ANSYS FLUENT, 2010), casos envolvendo convecção natural necessitam de subrelaxação mais rigorosa para se obter bons resultados, o que significa reduzir o valor destes coeficientes.

A figura 4.3.3 ilustra de maneira qualitativa o problema descrito. A linha azul apresenta o que seria a média de uma determinada variável analisada e a linha lilás seria o valor real desta variável, considerando o caráter transiente do fenômeno. Ao se utilizar uma subrelaxação leve, o valor calculado pelo programa tende a seguir mais a solução real, transiente, porém não se torna possível que esta variação ocorra dentro dos limites especificados para se obter a convergência dos resíduos.

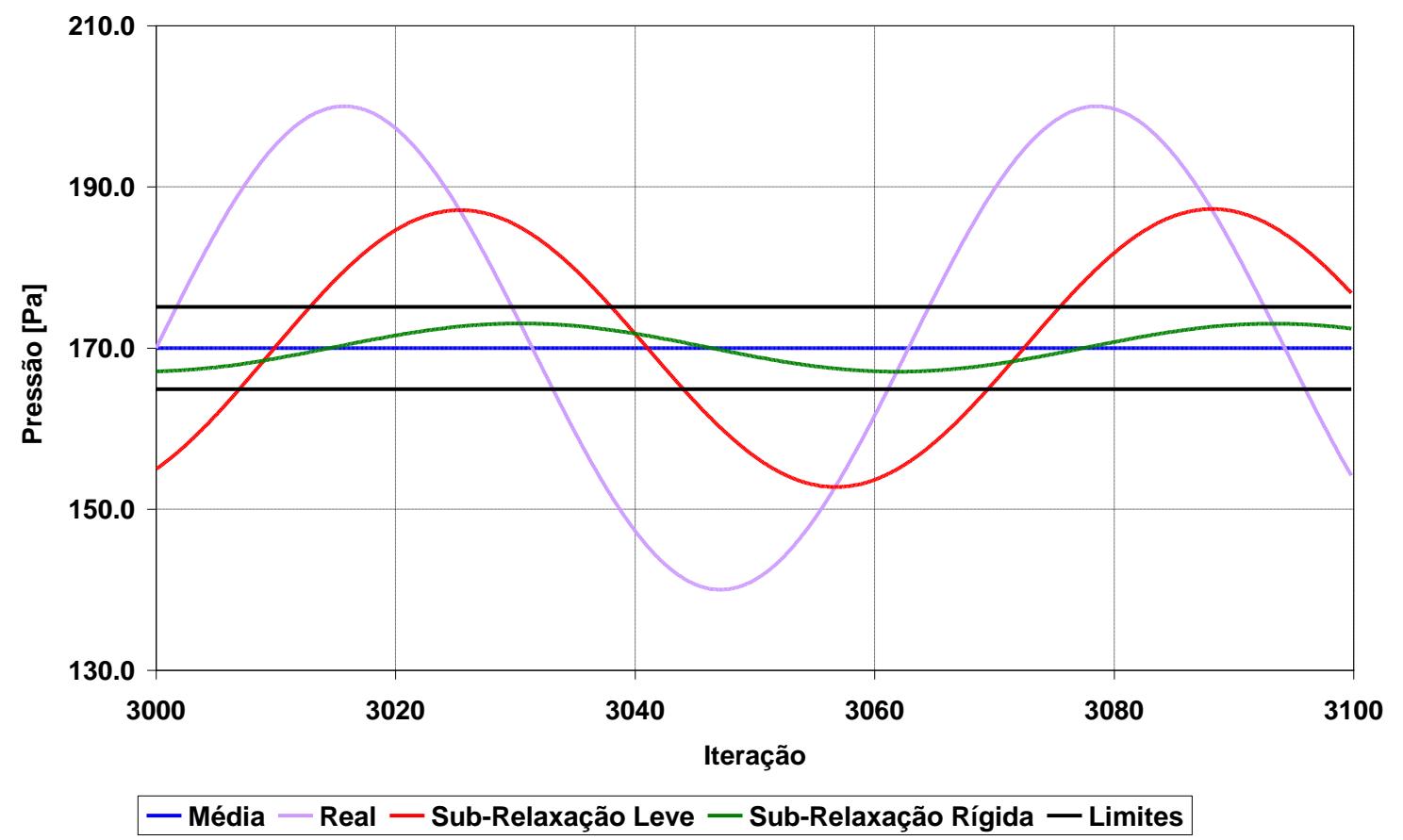

Figura 4.3.3: Ilustração qualitativa da influência dos parâmetros de subrelaxação na solução numérica em regime permanente de um fenômeno naturalmente transiente.

Contudo, ao tornar mais rígida a subrelaxação, o programa impede que o avanço da solução seja muito rápido, fazendo com que os valores calculados flutuem mais próximos do valor médio, que é o elemento de interesse do trabalho. Desta forma, utilizou-se os valores de subrelaxação conforme indicado na tabela 4.3.2 nas simulações para garantir a boa convergência dos resíduos. Estes valores são os valores padrão do programa, incorporando as modificações sugeridas por ANSYS FLUENT (2010) para casos de convecção natural. 
Tabela 4.3.2: Parâmetros de subrelaxação utilizados

\begin{tabular}{c|ccccc} 
Variável & Pressão & Densidade & $\begin{array}{c}\text { Forças de } \\
\text { Campo }\end{array}$ & $\begin{array}{c}\text { Quantidade de } \\
\text { Movimento }\end{array}$ & $\begin{array}{c}\text { Energia Cinética } \\
\text { Turbulenta }\end{array}$ \\
\hline $\begin{array}{c}\text { Fator de } \\
\text { Sub-relaxação }\end{array}$ & 0.3 & 1.0 & 1.0 & 0.4 & 0.7 \\
\hline \hline Variável & $\begin{array}{c}\text { Taxa de Dissipação } \\
\text { da Turbulência }\end{array}$ & $\begin{array}{c}\text { Viscosidade } \\
\text { Turbulenta }\end{array}$ & Energia & Radiação DO \\
\hline $\begin{array}{c}\text { Fator de } \\
\text { Sub-relaxação }\end{array}$ & 0.7 & 1.0 & 1.0 & 1.0
\end{tabular}

\subsection{CONDIÇÕES DE CONTORNO}

\subsubsection{Condições climáticas da cidade de São Paulo}

Para estabelecer as condições de contorno e iniciais do modelo, é fundamental obter dados climáticos representativos da cidade analisada. Para obtenção das informações de temperatura média do ar, velocidade do vento e direção do vento foram utilizadas na bibliografia diversas fontes.

Alguns trabalhos utilizaram fontes de dados internacionais, como o SWERA (INATOMI, 2008) e o IWEC (FIGUEIREDO, 2007), que podem ser obtidos na página do DOE (2011). Outros utilizaram fontes de informações nacionais, como o banco de dados do LabEEE (2011), utilizado por Cóstola (2006). Benedetto (2007) decidiu montar seu próprio banco de dados climáticos, sendo estas informações utilizadas posteriormente por Marcondes (2010).

Benedetto (2007) desenvolveu este novo banco de dados pois "não foi encontrado arquivo de clima com dados atuais disponíveis para a cidade de São Paulo”. A autora coletou informações disponibilizadas pelo Instituto de Astronomia, Geofísica e Ciências Atmosféricas (IAG) da Universidade de São Paulo (USP) e utilizou dados dos anos de 2003, 2004 e 2005 para desenvolver o ano de referência construído para este trabalho com dados recentes.

Em sua tese, Marcondes (2010) cita que "para o presente trabalho optou-se por utilizar a base de dados mais recentes elaborada por Benedetto (2007), tendo em vista a situação atual 
e as tendências futuras de mudanças climáticas", justificando assim a escolha dos dados climáticos adotados. A tabela 4.4.1 e a figura 4.4.1 trazem uma síntese das informações sobre o vento presentes no banco de dados de Benedetto (2007).

Tabela 4.4.1: Frequência de ocorrência de direção e velocidade do vento ao longo do ano de referência, SP (BENEDETTO, 2007).

\begin{tabular}{cc|c|c|c}
\multicolumn{6}{c|}{ Ventos } \\
\hline de & $\begin{array}{c}\text { até } \\
{\left[{ }^{\mathbf{0}}\right]}\end{array}$ & $\begin{array}{c}\text { velocidade } \\
{[\mathbf{m} / \mathbf{s}]}\end{array}$ & $\begin{array}{c}\text { direção } \\
{[\%]}\end{array}$ \\
\hline $\mathbf{N}$ & 337,5 & 22,5 & 2,27 & 17 \\
NE & 22,5 & 67,5 & 2,17 & 12 \\
$\mathbf{L}$ & 67,5 & 112,5 & 2,81 & 11 \\
SE & 112,5 & 157,5 & 3,27 & 23 \\
S & 157,5 & 202,5 & 4,07 & 29 \\
SO & 202,5 & 247,5 & 3,72 & 2 \\
O & 247,5 & 292,5 & 3,56 & 1 \\
NO & 292,5 & 337,5 & 3,46 & 5
\end{tabular}

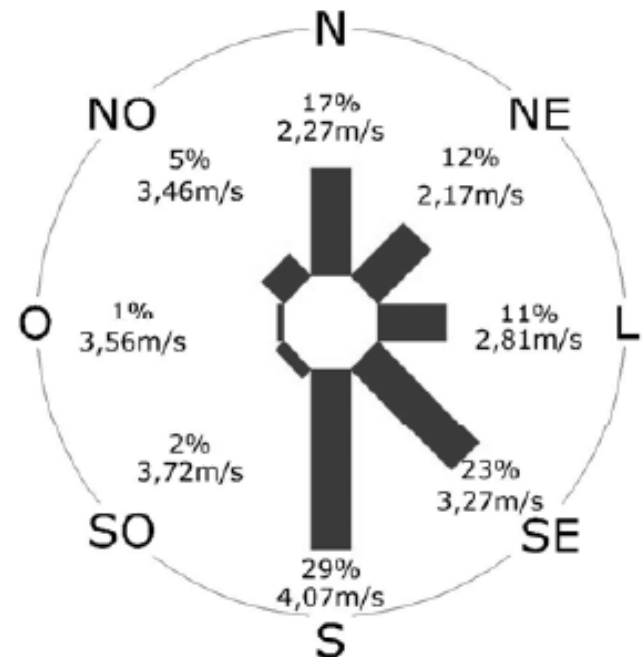

\section{ROSA DOS VENO PAULO}

Figura 4.4.1: Frequência de ocorrência de direção e velocidade do vento ao longo do ano de referência, com dados coletados na cidade de São Paulo, SP, de 2003 a2005 (BENEDETTO, 2007).

Desta forma, optou-se por utilizar o banco de dados desenvolvido por Benedetto (2007), pois consiste em um banco de dados mais atual disponível. Foram utilizadas então duas velocidades máximas do vento: $4 \mathrm{~m} / \mathrm{s}$, que corresponde ao vento mais frequente obtido por Benedetto (2007), e 2m/s, para avaliar as condições ambientais sob condições externas menos propícias. 
Não foi realizada diferenciação dos ventos médios anuais para os do verão, pois na cidade de São Paulo a variação nas estações do ano não é grande, como pode ser observado na figura 4.4.2, obtida do programa SOL-AR do Laboratório de Eficiência Energética em Edificações (LabEEE) da Universidade Federal de Santa Catarina (USFC).

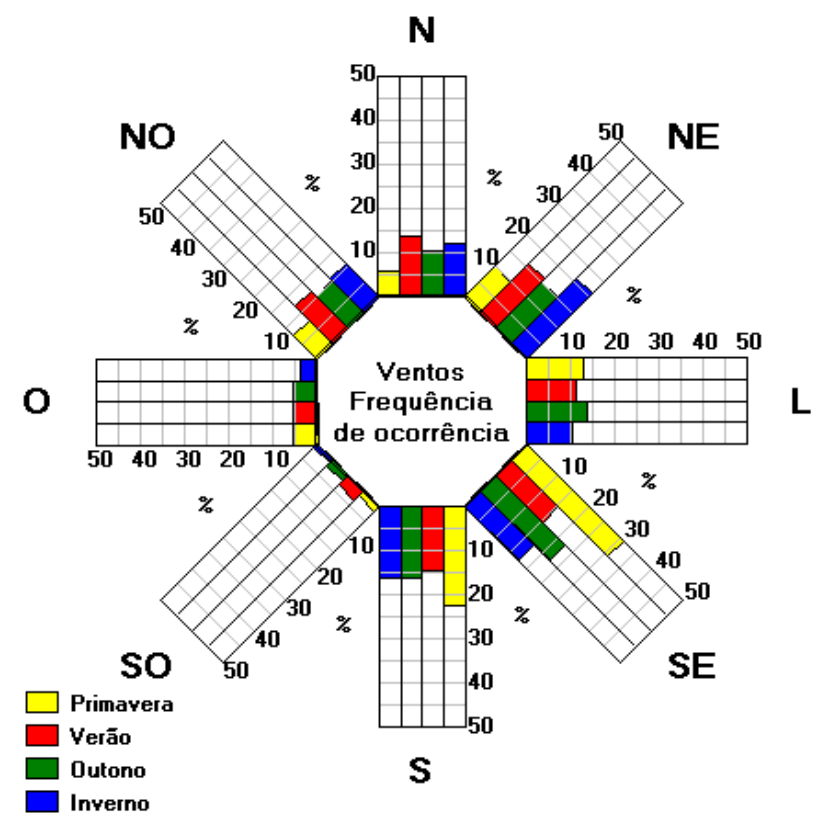

Figura 4.4.2: Frequência de ocorrência do vento em São Paulo por estação do ano obtida do programa SOL-AR, do LabEEE da UFSC, com dados coletados de 1951 a 1970.

Como temperatura do ar externo utilizou-se inicialmente 297,0K, o que corresponde à média entre a média das temperaturas máximas e mínimas na cidade de São Paulo no mês mais quente do ano (fevereiro), conforme tabela 4.4.2. Entretanto, verificou-se posteriormente que aumentando esta temperatura para $299,0 \mathrm{~K}$ e para 300,5K, era possível observar melhor os efeitos do mobiliário e das aberturas sobre as condições de ventilação natural nos escritórios.

Tabela 4.4.2: Média das temperaturas máximas e mínimas para a cidade de São Paulo, SP, de 2003 a 2005 (adaptado de BENEDETTO, 2007).

\begin{tabular}{c|c|c|c|c|c|c|c|c|c|c|c|c} 
& Jan & Fev & Mar & Abr & Mai & Jun & Jul & Ago & Set & Out & Nov & Dez \\
\hline $\begin{array}{c}\text { Média das } \\
\text { Temperaturas } \\
\text { Máximas [ㄷ] }\end{array}$ & 25,4 & 27,5 & 26,1 & 25,8 & 22,7 & 22,9 & 20,9 & 21,8 & 22,9 & 23,5 & 24,3 & 24,9 \\
\hline $\begin{array}{c}\text { Média das } \\
\text { Temperaturas } \\
\text { Mínimas [으 }\end{array}$ & 20,5 & 20,1 & 19,8 & 19,2 & 16,3 & 15,5 & 13,9 & 14,3 & 15,8 & 17,2 & 18,1 & 19,0
\end{tabular}




\subsubsection{Perfil de velocidades do vento}

O escoamento do vento pode ser caracterizado como turbulento, devido às grandes flutuações que existem ao redor de um valor médio, tanto espacialmente como em função do tempo. A figura 4.4.3 apresenta graficamente uma comparação entre um perfil mais real e um perfil médio.

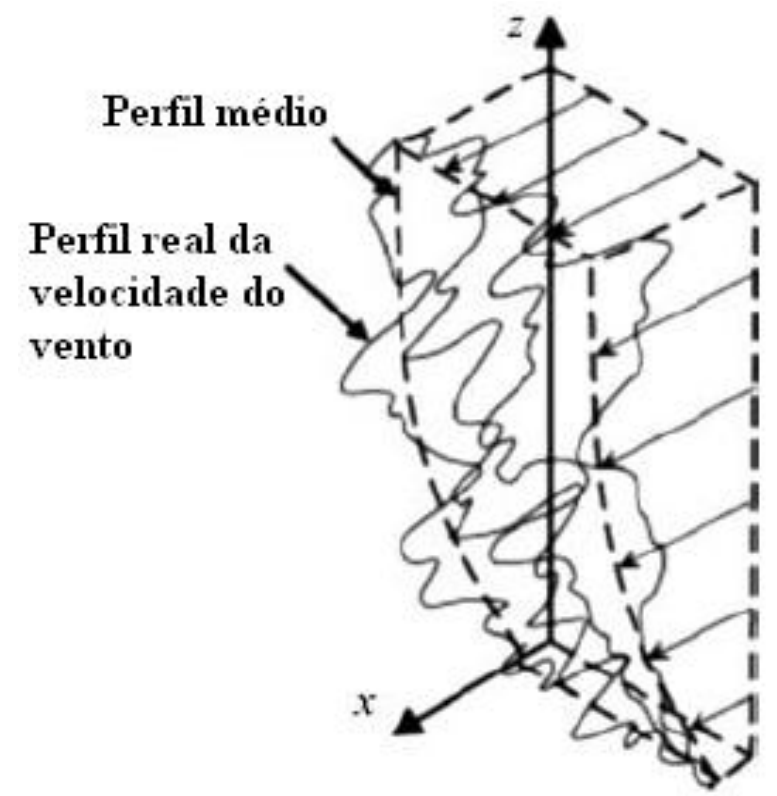

Figura 4.4.3: Sobreposição do perfil real e médio de velocidades do vento

(Adaptado de MANWELL; MCGOWAN; ROGERS, 2009).

Existem duas maneiras principais de representar o perfil médio do vento: o modelo logarítmico e o das potências. Na bibliografia constatou-se que, quando empregado um modelo para representar o perfil de velocidades do vento, optou-se pelo logarítmico (EVOLA; POPOV, 2006; CÓSTOLA, 2006), pois o modelo de potências é mais simplificado (MANWELL; MCGOWAN; ROGERS, 2009).

O modelo matemático para o perfil logarítmico do vento se encontra na equação 4.4.1, que relaciona a velocidade em uma altura qualquer com a velocidade de atrito, constante de von Kármán e comprimento de rugosidade. Uma forma mais simplificada pode ser obtida sendo conhecida a velocidade de uma altura de referência, como apresentado na equação 4.4.2. 


$$
\begin{array}{r}
\mathrm{U}(\mathrm{h})=\frac{\mathrm{U}^{*}}{\kappa} \ln \left(\frac{\mathrm{h}}{\mathrm{h}_{\mathrm{r}}}\right) \\
\mathrm{U}(\mathrm{h})=\mathrm{U}\left(\mathrm{h}_{\mathrm{o}}\right) \frac{\ln \left(\frac{\mathrm{h}}{\mathrm{h}_{\mathrm{r}}}\right)}{\ln \left(\frac{\mathrm{h}_{\mathrm{o}}}{\mathrm{h}_{\mathrm{r}}}\right)}
\end{array}
$$

onde $U$ é a velocidade na altura de referência $[\mathrm{m} / \mathrm{s}], \mathrm{U}^{*}$ é a velocidade de atrito $[\mathrm{m} / \mathrm{s}], \kappa$ é a constante de von Kármán [-], h é a altura [m], $\mathrm{h}_{\mathrm{r}}$ é o comprimento de rugosidade [m], $\mathrm{h}_{\mathrm{o}}$ é a altura de referência $[\mathrm{m}]$.

Como condições de referência foram adotadas a velocidade média que representa bem as condições climáticas de São Paulo, e será considerado que esta velocidade é alcançada no ponto mais alto do domínio. A condição de rugosidade adotada será a de centros de cidades com edifícios altos, mais rigorosa em relação à existência de ventos a baixas alturas, obtida a partir de Manwell, McGowan e Rogers (2009), conforme tabela 4.4.3.

Tabela 4.4.3: Valores aproximados de comprimento de rugosidade para diversos tipos de terrenos (Adaptado de MANWELL; MCGOWAN; ROGERS, 2009).

\begin{tabular}{lr} 
Descrição do terreno & $\mathbf{h}_{\mathbf{r}}(\mathbf{m m})$ \\
\hline Muito suave, gelo ou lama & 0,01 \\
Mar aberto calmo & 0,20 \\
Mar agitado & 0,50 \\
Neve & 3,00 \\
Gramado & 8,00 \\
Pasto acidentado & 10,00 \\
Campo em declive & 30,00 \\
Cultivado & 50,00 \\
Poucas árvores & 100,00 \\
Muitas árvores, poucos edifícios, cercas & 250,00 \\
Florestas & 500,00 \\
Subúrbios & 1500,00 \\
Zonas urbanas com edifícios altos & 3000,00
\end{tabular}




\subsubsection{Elementos geradores de carga térmica}

Outras condições de contorno que devem ser descritas são relativas aos elementos geradores de carga térmica. Neste trabalho, utilizaram-se inicialmente quatro elementos que liberam calor para o ambiente: lâmpadas, ocupantes, computadores e monitores. Para estes três últimos, os valores de liberação de calor foram obtidos da norma NBR 16401-1 (ABNT, 2008a) e seus valores estão apresentados na tabela 4.4.4.

Tabela 4.4.4: Elementos geradores de carga térmica utilizados neste trabalho.

\begin{tabular}{l|c}
\multicolumn{1}{c|}{ Elemento } & $\begin{array}{c}\text { Taxa de Liberação } \\
\text { de Calor }\end{array}$ \\
\hline Computadores & $55 \mathrm{~W}$ \\
$\begin{array}{l}\text { Monitor médio } \\
\begin{array}{l}\text { Ocupante com atividade moderada em } \\
\text { trabalhos de escritório }\end{array}\end{array}$ & $70 \mathrm{~W}$ \\
$\begin{array}{l}\text { Iluminação } \\
\text { numion }\end{array}$ & $130 \mathrm{~W}$ \\
\end{tabular}

O valor de densidade de potência de iluminação foi obtido da norma ASHRAE 90.1, de eficiência energética para edifícios comerciais (ASHRAE, 2007b). Neste documento considera-se eficiente o uso de $12 \mathrm{~W} / \mathrm{m}^{2}$ para ambientes de escritórios, sendo então adotado este valor. A distribuição das lâmpadas neste ambiente de escritório pode ser vista na figura 4.4.5, onde os retângulos em branco representam conjuntos com duas lâmpadas de $32 \mathrm{~W}$.

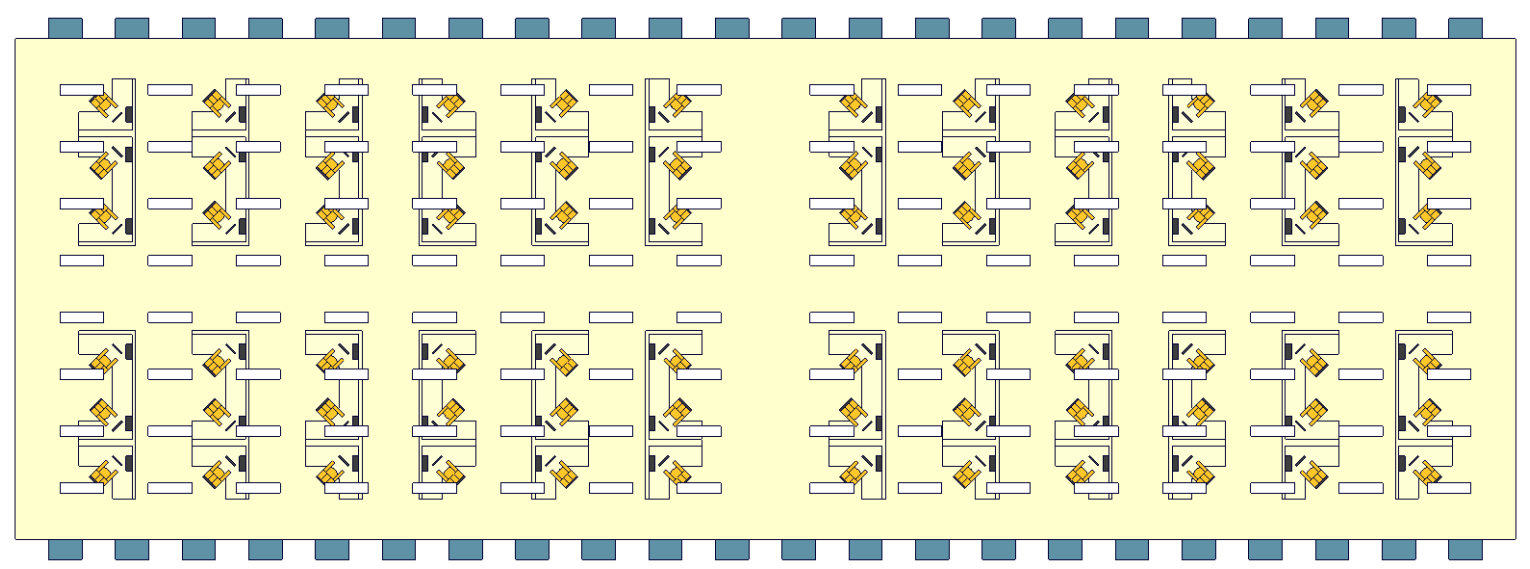

Figura 4.4.4: Distribuição das lâmpadas no ambiente de escritório. 
Para uma determinada configuração de mobiliário e aberturas estudou-se o efeito da redução da carga térmica do ambiente de escritório. Estas mudanças foram a redução da iluminação na região periférica do escritório, conforme indicado na figura 4.4.5, substituição dos computadores e monitores por computadores portáteis, e as duas alternativas juntas.

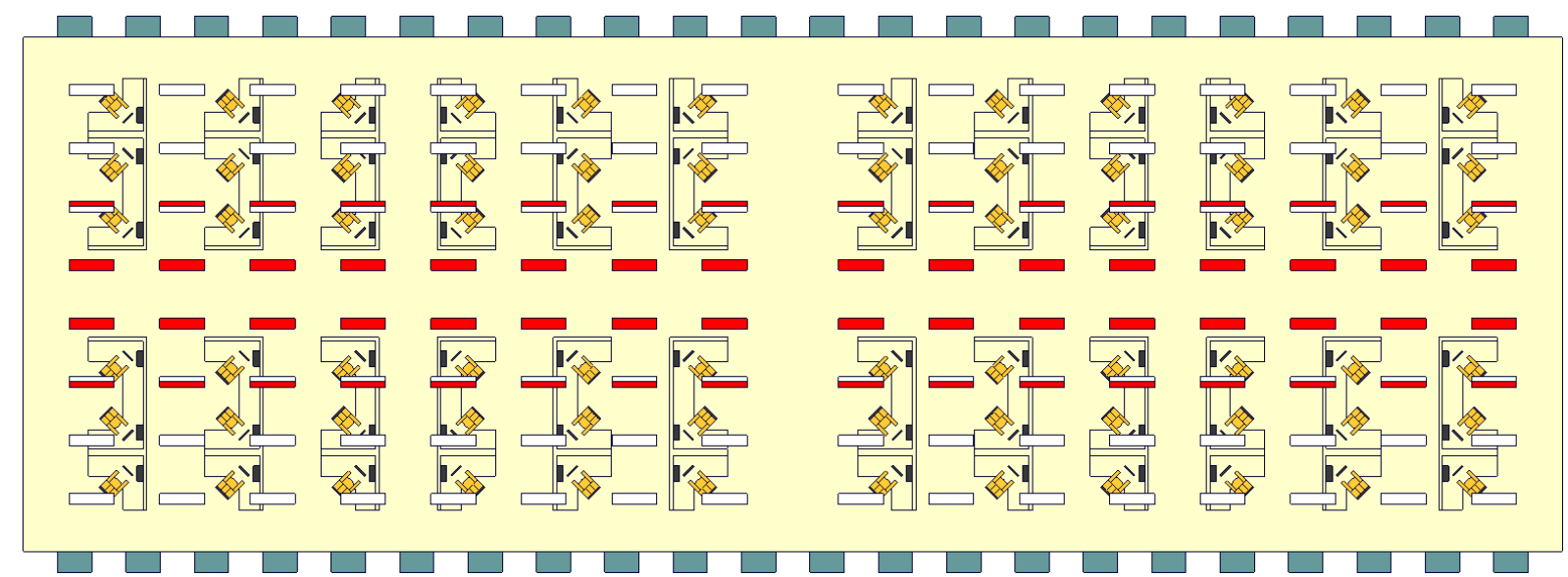

Figura 4.4.5: Lâmpadas (em vermelho) que permaneceram acesas na modificação da densidade de potência de iluminação.

O valor resultante de densidade de potência de iluminação foi de $4,5 \mathrm{~W} / \mathrm{m}^{2}$, e a carga térmica dos computadores portáteis foi de $15 \mathrm{~W}$. Embora o valor de $4,5 \mathrm{~W} / \mathrm{m}^{2}$ seja demasiadamente pequeno, os resultados deste exercício de redução de carga térmica foram interessantes, conforme apresentado na seção 5.7.1. O valor de $15 \mathrm{~W}$ para os computadores portáteis foi obtido de um estudo de Kawamoto et al (2001), que avaliou o consumo de energia de diversos equipamentos eletrônicos utilizados em escritórios nos Estados Unidos.

\subsubsection{Condições de contorno do modelo numérico}

No programa ANSYS Fluent é necessário fornecer características de todas as condições de contorno do modelo numérico, para que o solver possa resolver as equações de transporte necessárias na simulação. Nos modelos desta dissertação, existirão quatro tipos de condições de contorno:

a) Inlet (entrada): superfície de entrada do ar no modelo numérico. Nesta superfície são especificadas características da turbulência do escoamento e temperatura do ar, assim como o perfil de velocidades do vento. Este perfil é descrito no ANSYS Fluent utilizando-se UDF's (User Defined Functions). 
b) Outlet (saída): superfície de saída do ar no modelo numérico. Nesta superfície são especificadas a pressão e características da turbulência do escoamento. Também é fornecida uma temperatura do ar, caso ocorra escoamento reverso.

c) Wall (parede): superfícies sólidas contidas no modelo numérico. Todos os obstáculos, como janelas, paredes, forro, piso, fachada, mobiliário, pessoas e chão externo oferecem resistência ao escoamento e são modeladas com esta condição de contorno. As características que devem ser fornecidas ao programa são a rugosidade da parede, assim como características térmicas (temperatura ou fluxo de calor constante, geração de calor uniforme, coeficiente de transferência de calor, dentre outras).

d) Symmetry (simetria): superfícies laterais e superior do modelo. A condição de simetria impõe que os gradientes na parede sejam nulos, funcionando como um espelho para as propriedades calculadas.

Utiliza-se a condição de simetria nas paredes ao longe por se considerar que o escoamento nestas regiões já não sofre mais influência do elemento analisado. Uma vez que o modelo estudado possui um plano de simetria geométrica, este mesmo plano foi modelado com a condição de symmetry, visando reduzir pela metade a quantidade de células da malha empregada no modelo numérico. Desta forma, o domínio de cálculo resulta na geometria apresentada na figura 4.4.5.

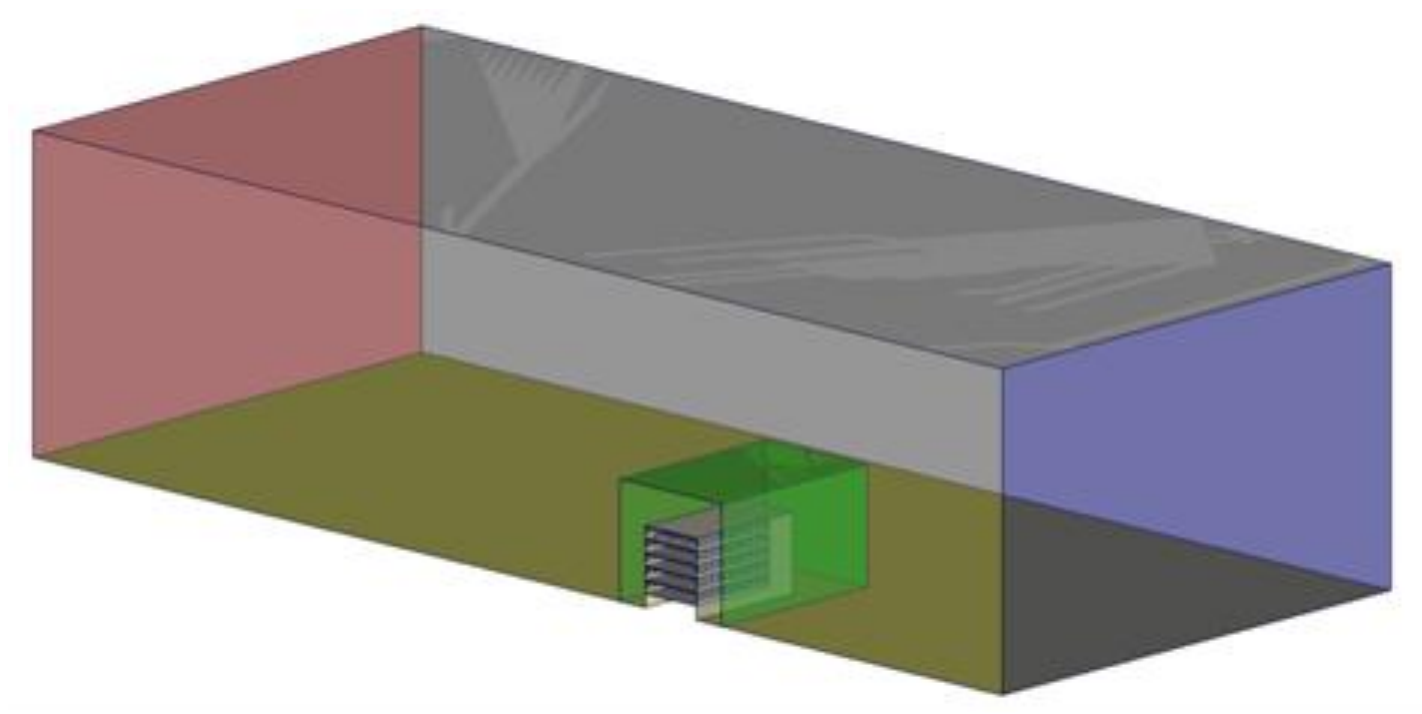

Figura 4.4.5: Domínio efetivamente utilizado no trabalho. 


\subsection{CONFIGURAÇÕES ANALISADAS}

Nesta dissertação foram variados os tipos de aberturas da fachada das edificações, ou seja, as janelas empregadas para ventilação natural, assim como a disposição do mobiliário nos ambientes. Nos próximos itens encontra-se uma descrição mais detalhada destes elementos a serem variados, a fim de buscar as condições que proporcionam melhora no uso da ventilação natural.

Como citado no item 2.4, não cabe no contexto desta dissertação a análise de estratégias assistidas mecanicamente, pois seria necessária a inclusão de elementos mecânicos de ventilação, tais como ventiladores e dutos específicos para este fim. De forma semelhante, como a ventilação noturna se caracteriza por ser uma estratégia diferente de operação dos mesmos componentes já utilizados, esta não será avaliada.

\subsubsection{Aberturas da fachada}

Dentre as janelas apresentadas no item 2.2.1, duas foram escolhidas para análise nesta dissertação: maxim-ar e de correr vertical. Uma representação gráfica delas encontra-se na figura 4.5.1.

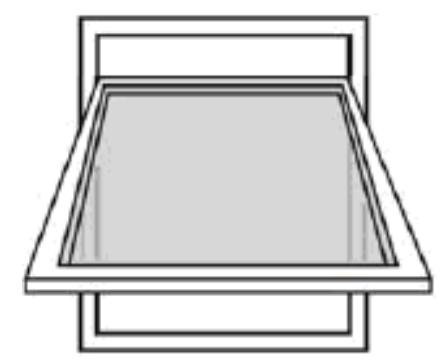

a) maxim-ar

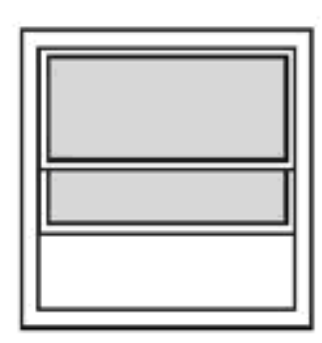

b) de correr vertical

Figura 4.5.1: Geometrias analisadas de janelas (adaptado de CIBSE, 2005).

Definiu-se a utilização destas janelas em função dos estudos da revisão bibliográfica que analisaram ventilação natural em ambientes de escritórios com recursos computacionais e descreveram a geometria simulada da abertura (FIGUEIREDO, 2007; GRATIA; BRUYÈRE; DE HERDE, 2004; MARCONDES, 2010). Benedetto (2007) apenas especificou o percentual de abertura efetivo das janelas, sem caracterizar sua geometria. 
As estratégias de ventilação por efeito chaminé e fachada dupla, embora válidas para melhorar a ventilação natural dos ambientes, requerem mudanças muito significativas na fachada das edificações. Estas mudanças aumentariam significativamente o tempo necessário para desenvolvimento das geometrias, de forma que foram analisadas apenas as mudanças de janelas da edificação.

Em análises de CFD, deve haver uma simplificação da geometria, de modo que detalhes são omitidos. Por exemplo, na janela maxim-ar, a geometria é modelada apenas como uma lâmina de vidro inclinada como mostra a figura 4.5.2, ou seja, os elementos utilizados para fixação e controle não foram modelados por serem demasiadamente pequenos.

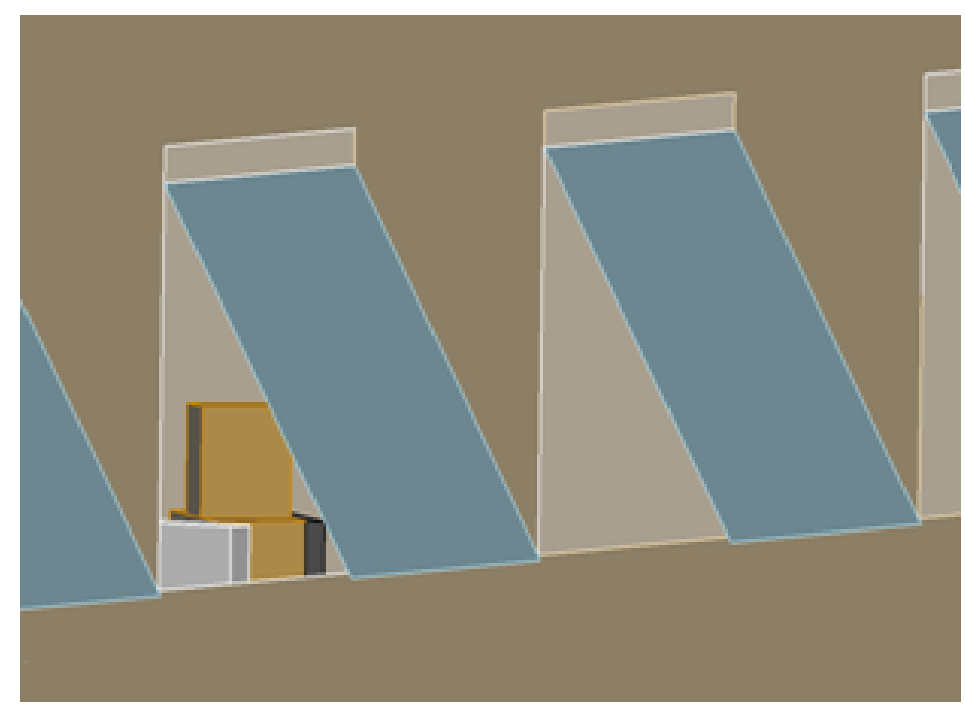

Figura 4.5.2: Modelagem das janelas maxim-ar.

As janelas maxim-ar adotadas permitem a existência de uma abertura na parte superior, criando assim duas áreas para passagem do ar. Como mostra a figura 4.5.3, o ângulo de abertura utilizado é o de $30^{\circ}$, seguindo as recomendações de Yang et al (2010), com 0,10m de altura da abertura superior.

Para fins de comparação, optou-se por utilizar as janelas de correr vertical no mesmo espaço destinado aos caixilhos das janelas maxim-ar, de forma a manter o restante da geometria da edificação constante, como mostra a figura 4.5.4. Nesta figura verifica-se que esta geometria foi modelada apenas como uma barreira cobrindo a metade superior do espaço destinado ao caixilho, com dimensões indicadas na figura 4.5.5. 

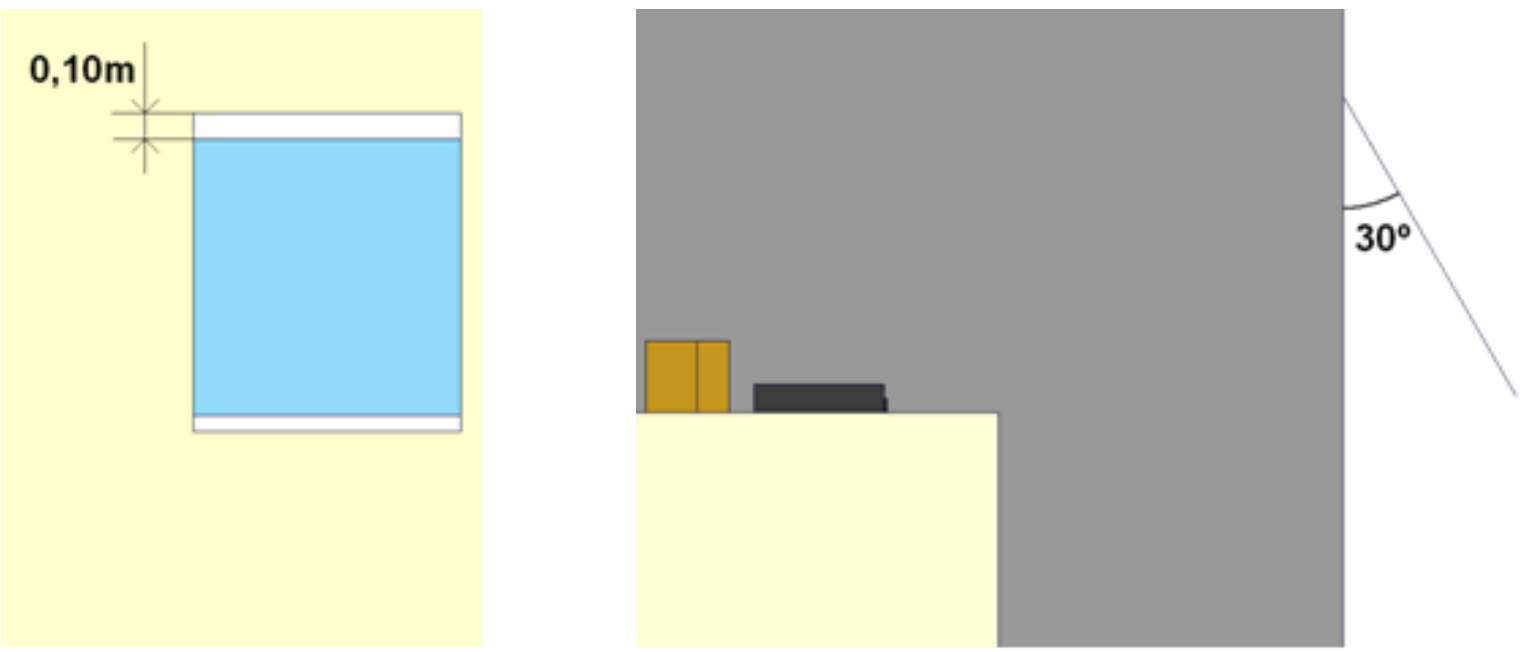

Figura 4.5.3: Dimensões do modelo utilizado da janela maxim-ar.

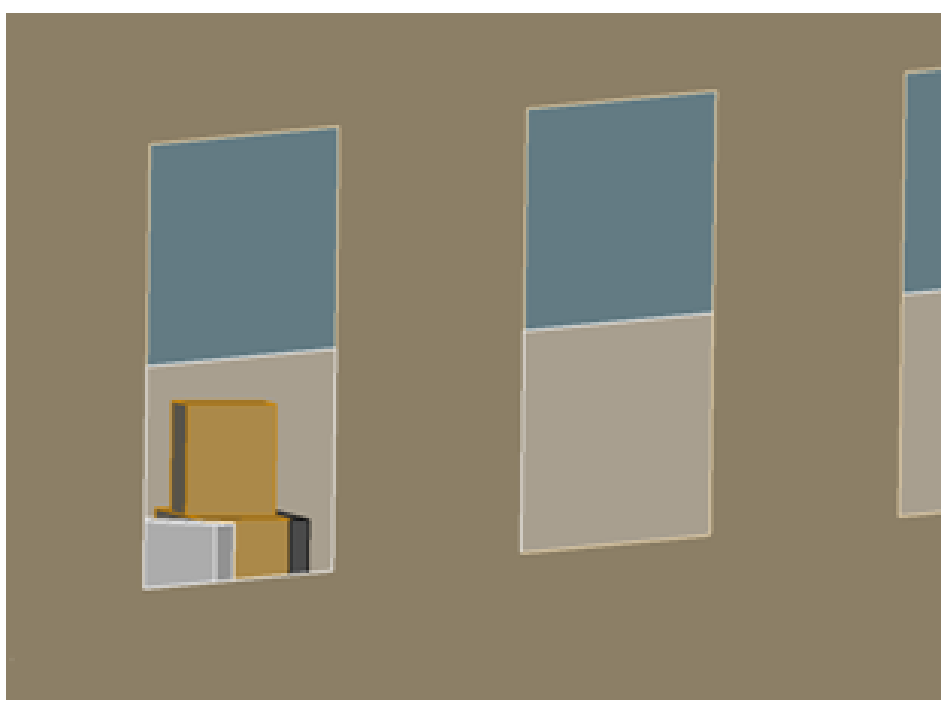

Figura 4.5.4: Modelagem das janelas de correr vertical.

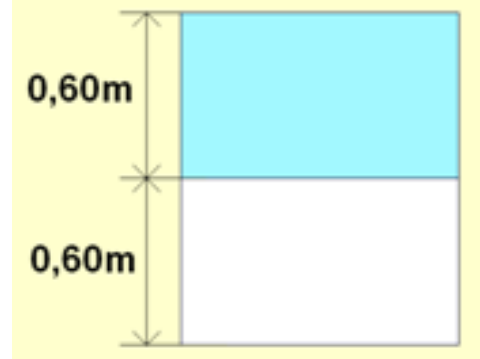

Figura 4.5.5: Dimensões do modelo utilizado da janela de correr vertical. 


\subsubsection{Mobiliário interno}

Como apresentado na seção 3.2.1, o mobiliário interno possui impacto direto sobre o escoamento de ar dentro do ambiente ventilado através de mudanças das características geométricas, resistindo ao escoamento e mudando sua direção.

No estudo de Andrade (2005) são apontados cinco elementos que constituem uma estação de trabalho:
a) Superfícies de trabalho;
b) Armários e volantes;
c) Divisórias;
d) Acessórios;
e) Cadeiras.

Destes cinco, na presente dissertação foi analisada a influência da altura das divisórias, mantendo os demais elementos constantes na estação de trabalho: superfície de trabalho, armários, cadeiras e acessórios. Também foi analisada neste trabalho a influência da disposição das superfícies de trabalho no ambiente, ou seja, a influência do layout das estações de trabalho. Estes foram escolhidos por possuírem o maior impacto sobre a geometria e o fluxo de ar no ambiente.

As divisórias são utilizadas para particionar os locais de trabalho, criando diferentes níveis de ambientes. As partições mais altas têm o benefício de melhorar a privacidade acústica do indivíduo, assim como reduzir a frequência de interrupções e distrações (BRILL; WIEDEMANN, 2001), embora reduzam a facilidade para socialização no ambiente de trabalho. A norma NBR 13964 estabelece as dimensões mínimas e máximas para vários tipos de partições, conforme tabela 4.5.1 (ABNT, 2003). No presente trabalho, optou-se por analisar três alturas de divisórias: baixa $(0,90 \mathrm{~m})$, média $(1,10 \mathrm{~m})$ e alta $(1,50 \mathrm{~m})$, sendo esta última ilustrada na figura 4.5.5.

Tabela 4.5.1: Alturas de divisórias segundo sua classificação (ABNT, 2003).

\begin{tabular}{l|cc}
\multicolumn{1}{c|}{ Nome da variável } & $\begin{array}{c}\text { Valor mín. } \\
{[\mathrm{mm}]}\end{array}$ & $\begin{array}{c}\text { Valor máx. } \\
{[\mathrm{mm}]}\end{array}$ \\
\hline Altura do módulo da divisória baixa & - & 900 \\
Altura do módulo da divisória média & 901 & 1400 \\
Altura do módulo da divisória alta & 1401 & 1800 \\
Altura do módulo da divisória extra-alta & 1801 & -
\end{tabular}




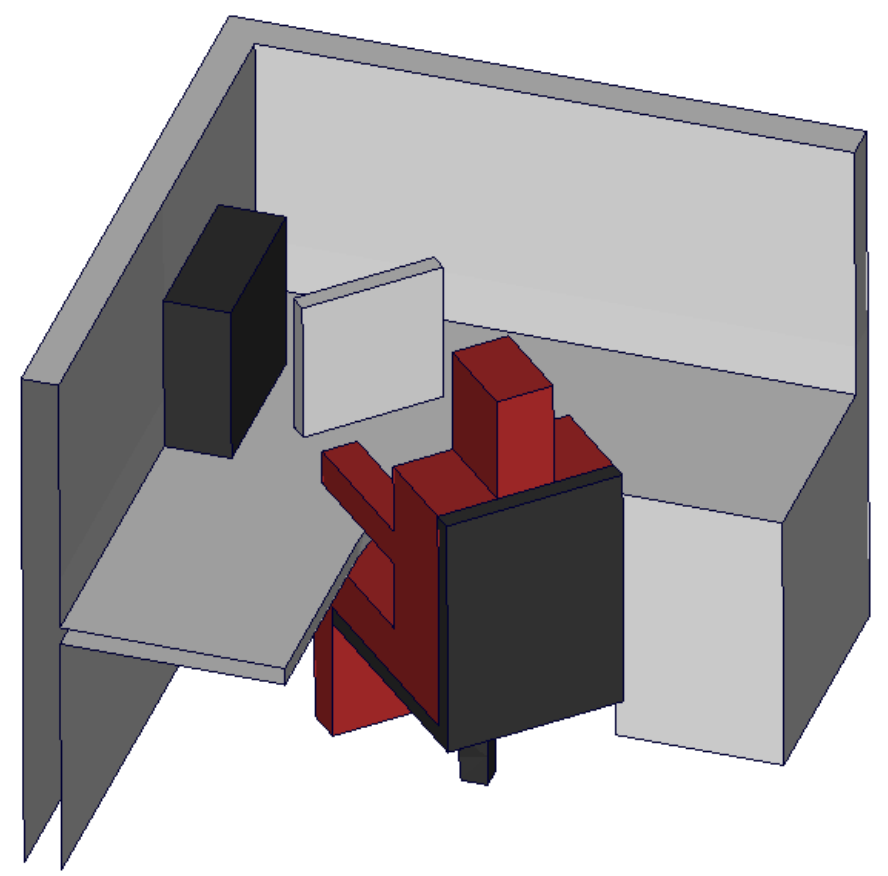

Figura 4.5.5: Estação de trabalho com partições de 1,50m.

As superfícies de trabalho normalmente influenciam o layout do ambiente de escritórios, pois as geometrias destes elementos podem modificar a distribuição das estações de trabalho no local. Segundo Andrade (2005), a disposição em "L" das superfícies de trabalho é a mais comumente utilizada no Brasil, com medidas mínimas de 1,40m x 1,40m e profundidades de tampo que variam de 0,60 a $0,80 \mathrm{~m}$. Um exemplo desta disposição encontrase na figura 4.5.6.

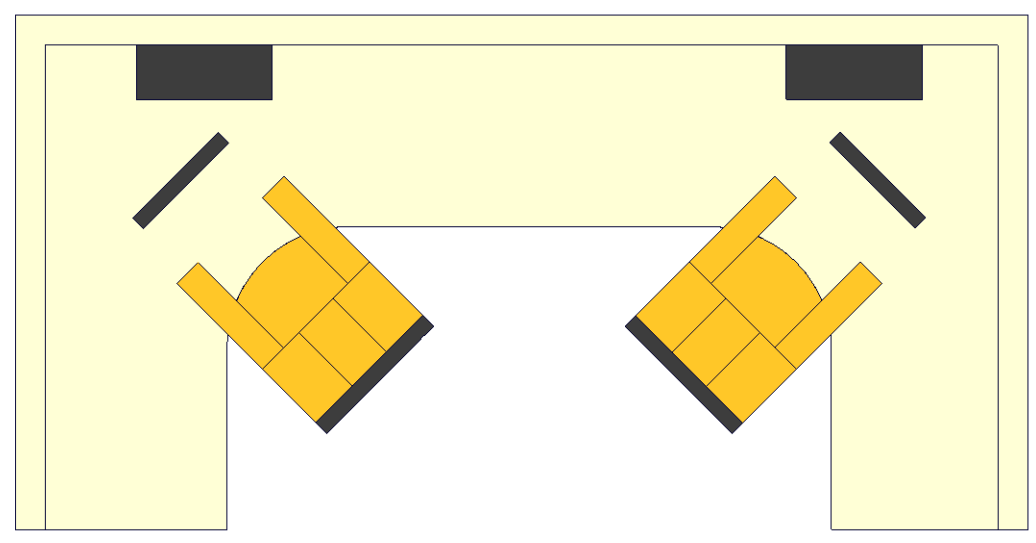

Figura 4.5.6: Superfícies de trabalho em "L" dispostas em formato "C". 
As estações de trabalho retangulares também foram encontradas por Andrade (2005) em sua pesquisa com empresas situadas na cidade de São Paulo, porém em uma frequência significativamente menor, de modo que foi considerada nesta dissertação apenas a geometria em "L". A posição destas estações de trabalho foi arbitrada em duas configurações de layout, uma quadrada e outra em linha, como mostram as figuras 4.5.7 e 4.5.8, respectivamente.

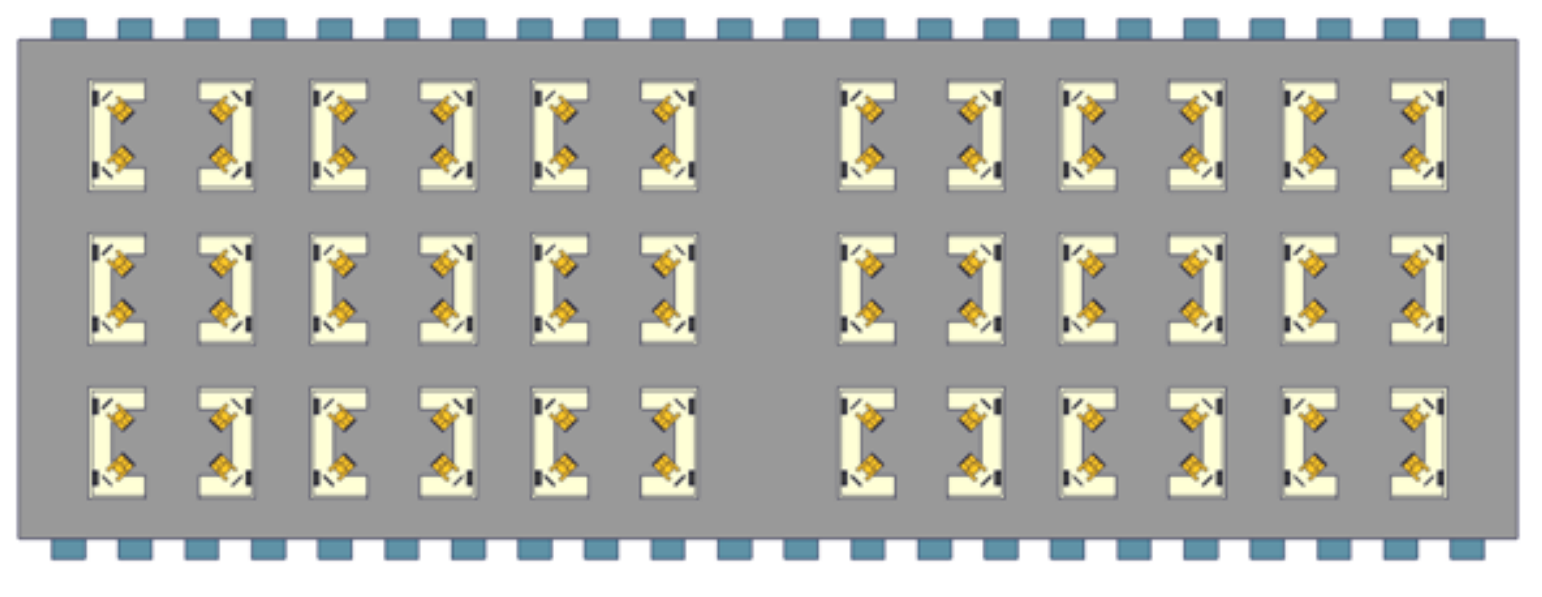

Figura 4.5.7: Layout quadrado utilizado nas simulações.

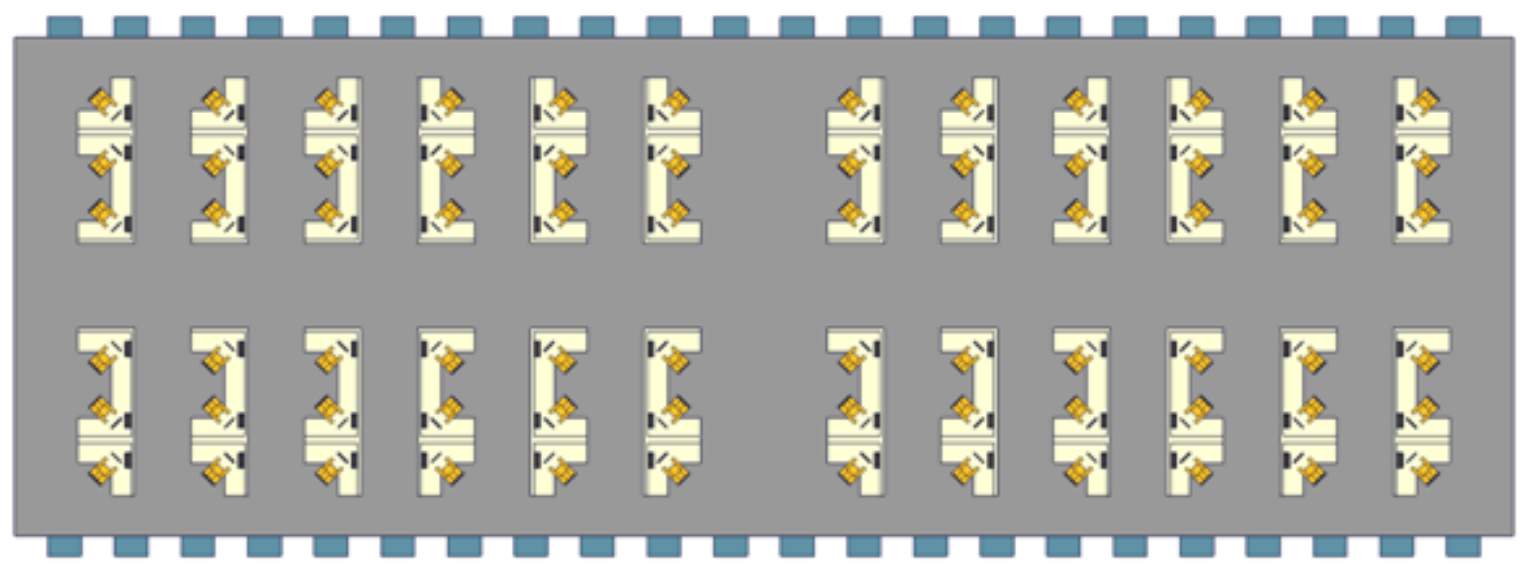

Figura 4.5.8: Layout em linha utilizado nas simulações.

\subsection{PARÂMETROS DE ANÁLISE DA EFICIÊNCIA DA VENTILAÇÃO NATURAL}

As simulações numéricas fornecem uma série de informações, das quais é possível estabelecer algumas variáveis para quantificar grandezas relevantes relacionadas aos fenômenos em estudo. A principal variável utilizada no presente trabalho para avaliar a 
eficiência da ventilação natural é a temperatura do $\operatorname{ar}\left(\mathrm{T}_{\mathrm{ar}}\right)$, pois esta variável está diretamente relacionada com o conforto térmico dos ocupantes (ASHRAE, 2010). Estas temperaturas também permitem verificar a ocorrência de estratificação de temperatura do ar na zona ocupada na análise do conforto térmico.

A vazão de ar (Q) é outra variável analisada nas simulações, pois ambientes com maior entrada de ar podem propiciar melhores condições de conforto, caso as condições climáticas externas sejam favoráveis. Com maior ventilação do ambiente, é possível para os ocupantes mudarem a abertura de janelas operáveis e regular o fluxo de ar de acordo com as necessidades do momento, condição mais difícil de ser obtida com menor ventilação.

Por fim, os parâmetros qualitativos ajudam a ilustrar graficamente as vantagens de uma solução em comparação com outra, detalhando a distribuição de temperaturas e de velocidade do ar no pavimento analisado, conforme detalhado na seção 4.6.4.

\subsubsection{Conforto térmico}

A norma ASHRAE 55 (ASHRAE, 2010) utiliza o conceito de conforto adaptativo para avaliar ambientes naturalmente ventilados, onde os ocupantes têm possibilidade de atuar sobre as aberturas e a sua vestimenta. A temperatura operativa ideal $\left(\mathrm{T}_{\mathrm{id}}\right)$ pode ser obtida por meio da equação 4.3.1.

$$
\mathrm{T}_{\mathrm{id}}=0,31 \cdot \overline{\mathrm{T}}_{\mathrm{o}}+206,3
$$

onde $\mathrm{T}_{\mathrm{id}}$ é a temperatura operativa ideal $[\mathrm{K}], \overline{\mathrm{T}}_{\mathrm{o}}$ é a temperatura média mensal do ar externo $[\mathrm{K}]$.

Para a Eq. 4.3.1 ser válida, é necessário que a temperatura média mensal externa esteja em uma faixa de $10^{\circ} \mathrm{C}$ a $33,5^{\circ} \mathrm{C}$ (ASHRAE, 2010). Existe ainda um intervalo de tolerância para a temperatura operativa ideal de conforto, considerando condições de conforto para $90 \%$ ou $80 \%$ dos ocupantes do ambiente, conforme indica a figura 4.6.1. 


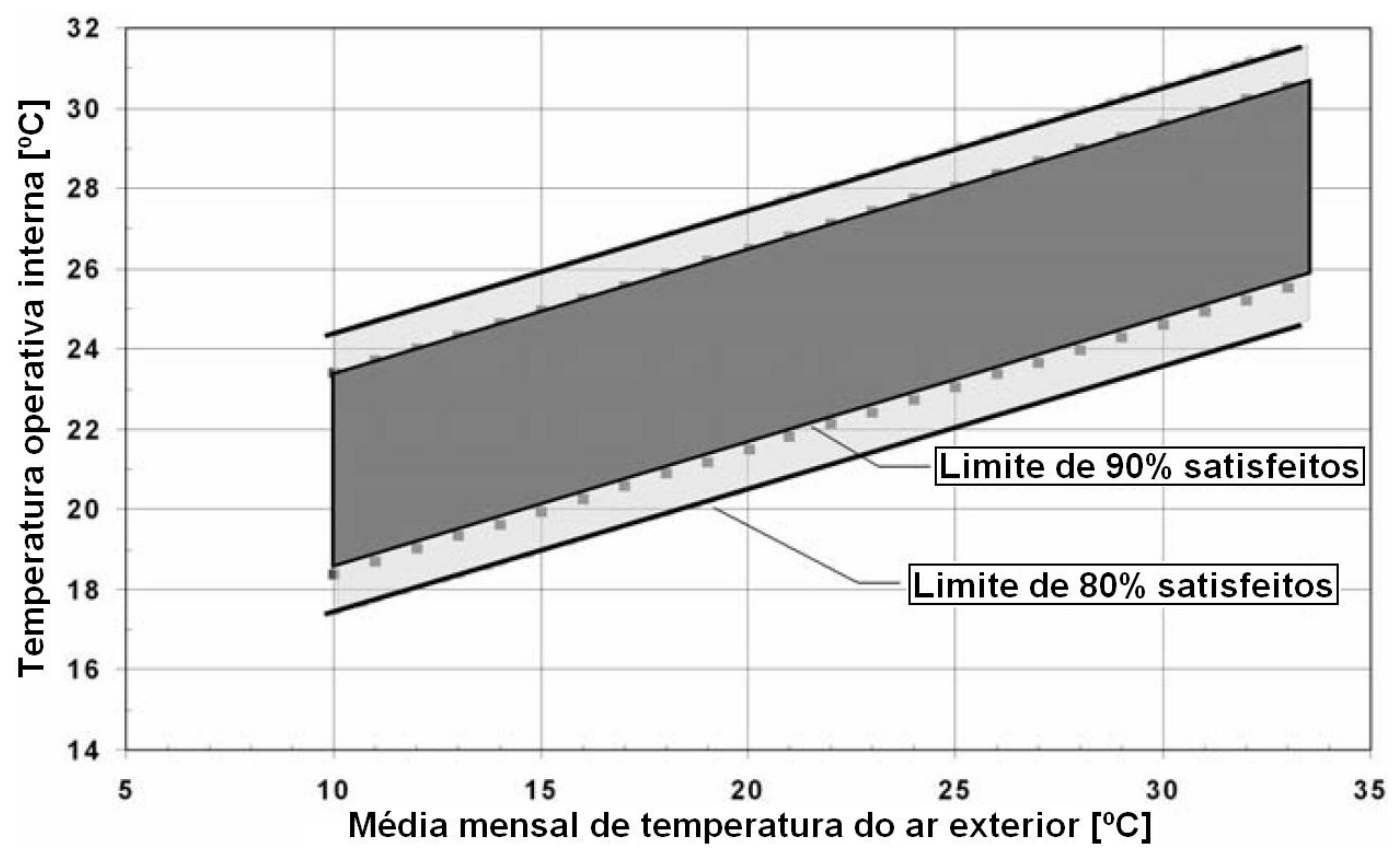

Figura 4.6.1: Faixas de temperaturas operativas aceitáveis para conforto em ambientes ventilados naturalmente (adaptado de ASHRAE, 2010).

Para verificar a ocorrência de condições de conforto térmico deve-se comparar a temperatura operativa do limite de $90 \%$ ou $80 \%$ satisfeitos, indicada na Figura 4.6.1, com a temperatura operativa nas estações de trabalho, $\mathrm{T}_{\mathrm{op}}$, dada pela equação 4.3.2.

$$
\mathrm{T}_{\mathrm{op}}=\left(\frac{\mathrm{h}_{\mathrm{c}} \mathrm{T}_{\mathrm{ar}}+\mathrm{h}_{\mathrm{r}} \overline{\mathrm{T}}_{\mathrm{r}}}{\mathrm{h}_{\mathrm{c}}+\mathrm{h}_{\mathrm{r}}}\right)
$$

onde $\mathrm{T}_{\mathrm{op}}$ é a temperatura operativa no ambiente $[\mathrm{K}] . \mathrm{h}_{\mathrm{c}}$ é o coeficiente de película da troca de calor por convecção $\left[\mathrm{W} /\left(\mathrm{m}^{2} \mathrm{~K}\right)\right], \mathrm{T}_{\mathrm{ar}}$ é a temperatura do ar $[\mathrm{K}], \mathrm{h}_{\mathrm{r}}$ é o coeficiente de película da troca de calor por radiação $\left[\mathrm{W} /\left(\mathrm{m}^{2} \cdot \mathrm{K}\right)\right], \overline{\mathrm{T}}_{\mathrm{r}}$ é a temperatura radiante média $[\mathrm{K}]$.

Considerando que no presente trabalho pretende-se analisar somente os efeitos da ventilação natural e, portanto, da temperatura do ar, $\mathrm{T}_{\mathrm{ar}}$, na avaliação de condições de conforto térmico não serão considerados efeitos da transferência de calor por radiação e, portanto, será considerado $\mathrm{T}_{\mathrm{ar}}=\overline{\mathrm{T}}_{\mathrm{r}}$. Assim, a equação 4.3.2 pode ser reescrita na forma da equação 4.3.3.

$$
\mathrm{T}_{\mathrm{op}}=\mathrm{T}_{\mathrm{ar}}
$$

onde $\mathrm{T}_{\mathrm{op}}$ é a temperatura operativa no ambiente $[\mathrm{K}], \mathrm{T}_{\mathrm{ar}}$ é a temperatura do ar $[\mathrm{K}]$. 
É importante ressaltar que os efeitos da troca de calor por radiação foram considerados nas simulações numéricas (ver item 3.3.2) para determinação das temperaturas do $\operatorname{ar}, \mathrm{T}_{\mathrm{ar}}$. $\mathrm{O}$ que está se desconsiderando é tão somente o efeito de uma temperatura radiante média, $\overline{\mathrm{T}}_{\mathrm{r}}$ diferente da temperatura do ar, $\mathrm{T}_{\mathrm{ar}}$, na análise do conforto térmico, como forma de melhor se verificar os efeitos da ventilação natural nas condições de conforto térmico.

De acordo com a norma ASHRAE 55 (ASHRAE, 2010) a temperatura do ar, $\mathrm{T}_{\mathrm{ar}}$, a ser considerada nas equações 4.3.2 ou 4.3.3 é a média local e temporal das temperaturas do ar ao redor de um ocupante, medidas na altura dos tornozelos, cintura e cabeça. Para ocupantes sentados, estas alturas equivalem a $0,10 \mathrm{~m}, 0,60 \mathrm{~m}$ e $1,10 \mathrm{~m}$ de altura em relação ao piso, respectivamente.

Para determinar estas temperaturas do ar foram calculadas as temperaturas do ar ao redor de todos os ocupantes do escritório obtidas nas simulações. Para cada indivíduo, calculou-se a temperatura da cabeça e dos tornozelos utilizando a média da temperatura de quatro pontos ao redor de cada um destes, e a temperatura da cintura utilizando três pontos, devido à presença da mesa na estação de trabalho. A figura 4.6.2 ilustra os pontos de medição, em azul, para um dos ocupantes.

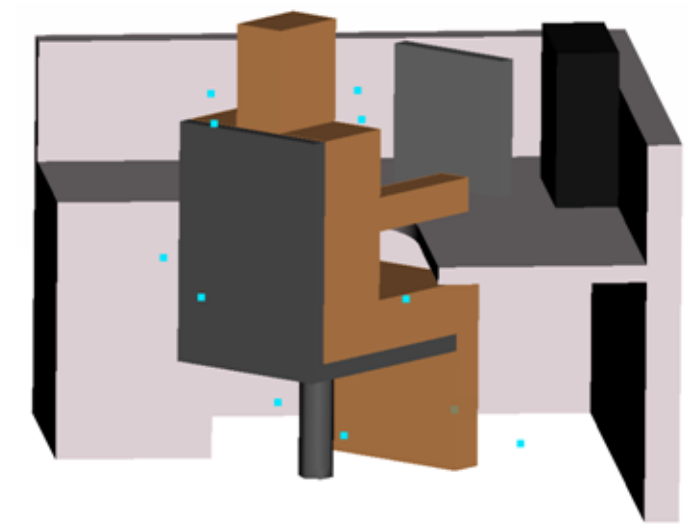

Figura 4.6.2: Pontos de medição da temperatura do ar ao redor de um ocupante.

A partir dos pontos em um mesmo plano horizontal foi calculada então a temperatura de tornozelo, cintura e cabeça para cada um dos ocupantes. A média destes três valores resulta na temperatura média do ar da estação de trabalho, e a partir destas foi calculada a temperatura para os conjuntos de estações de trabalho, sempre utilizando a média aritmética. 


\subsubsection{Estratificação da temperatura do ar}

Diferenças locais de temperatura podem levar a situações de desconforto, mesmo que o ambiente propicie uma condição global adequada. A norma ASHRAE 55 (ASHRAE, 2010) recomenda que, para evitar estas situações, a diferença de temperatura entre a cabeça dos ocupantes e os tornozelos não exceda $3^{\circ} \mathrm{C}$. Alternativamente, uma abordagem gráfica é apresentada, onde a estratificação de temperatura leva a um percentual de ocupantes insatisfeitos, como na figura 4.6.3.

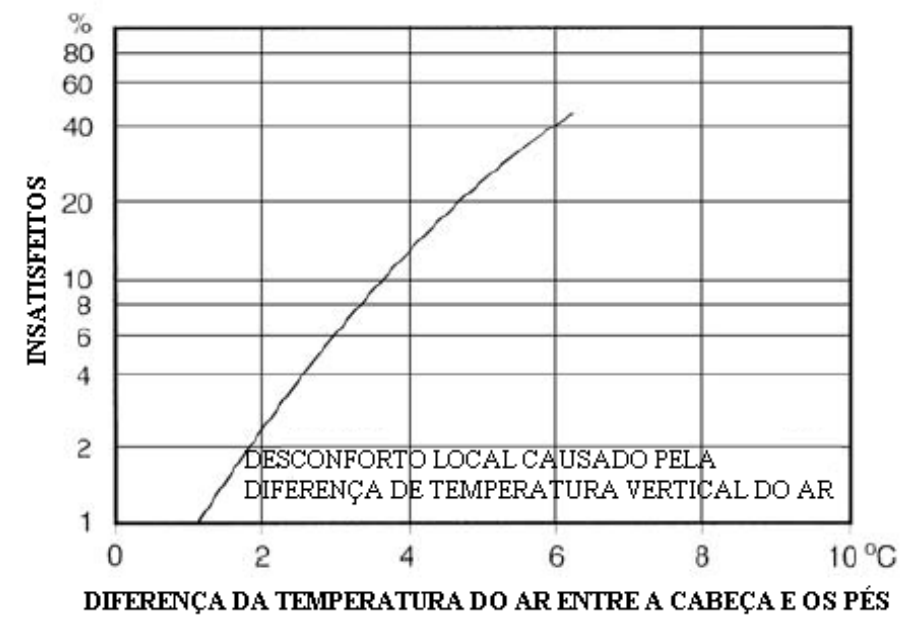

Figura 4.6.3: Ocupantes insatisfeitos versus diferença vertical de temperatura (adaptado de ASHRAE, 2010).

A verificação da ocorrência da estratificação de temperatura foi realizada a partir do cálculo do módulo da diferença da temperatura do ar na região da cabeça e dos tornozelos em cada estação de trabalho. A partir destes resultados foram calculadas as diferenças de temperatura do ar para grupos de estações de trabalho utilizando a média aritmética dos valores.

\subsubsection{Vazão de ar}

Outro item que foi analisado é a vazão de ar pelas janelas nos ambientes de escritório simulados. Foi modelada uma superfície de controle em cada janela, na posição que ocuparia o vidro em caso de fechamento completo, e feita a soma do valor obtido em todas as aberturas de entrada de ar do pavimento. 
A vazão do ar foi utilizada para verificação do processo de simulação, por meio da comparação dos resultados numéricos com equações empíricas de ventilação dos ambientes disponibilizados pela norma BS 5925 (BSI, 1991). A publicação contém formulações para o cálculo da vazão de ar em um ambiente sem partições internas sob ação de ventilação unilateral e cruzada, sob ação do gradiente de temperaturas, pressão do vento e combinação destas duas, conforme apresentado nas figuras 4.6.4 a 4.6.6.

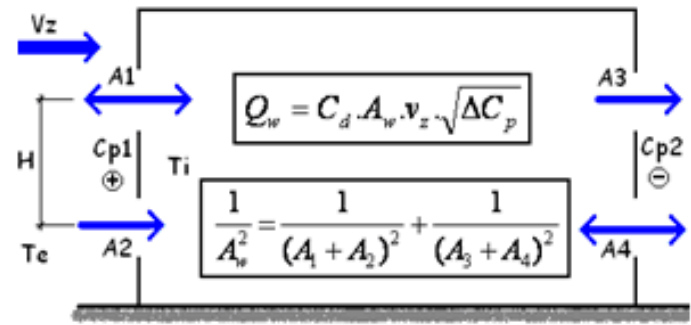

ventilação cruzada

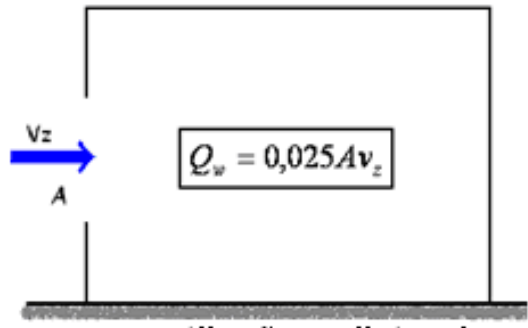

ventilação unilateral

Figura 4.6.4: Equações para ventilação do ambiente por ação da pressão do vento (adaptado de BSI, 1991).

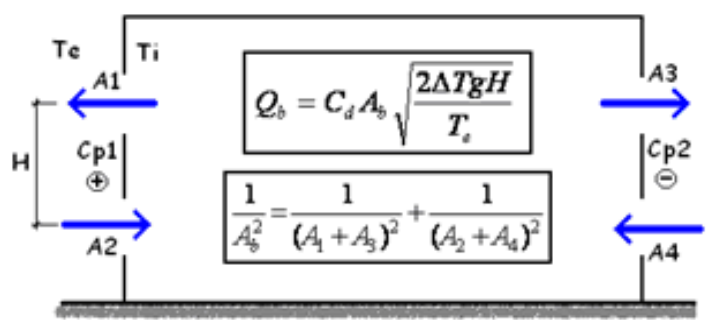

ventilação cruzada

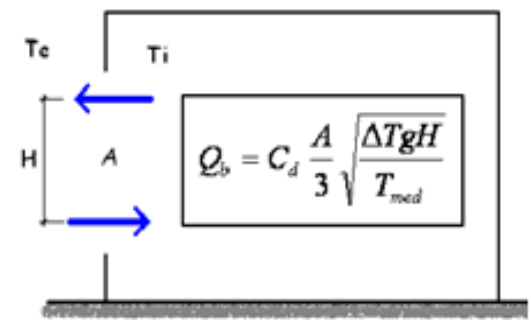

ventilação unilateral

Figura 4.6.5: Equações para ventilação do ambiente por ação gradiente de temperaturas (adaptado de BSI, 1991).

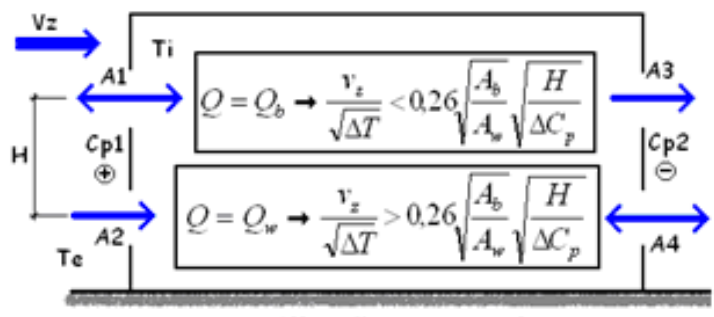

ventilação cruzada

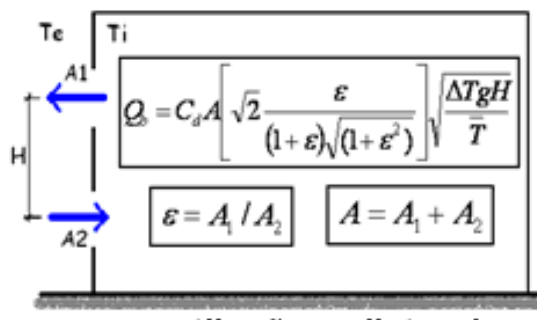

ventilação unilateral

Figura 4.6.6: Equações para ventilação do ambiente por ação combinada da pressão do vento e gradiente de temperaturas (adaptado de BSI, 1991).

Para o cálculo da vazão de ar segundo o procedimento desta norma, são necessários como dados de entrada o coeficiente de pressão nas fachadas, a área de abertura das fachadas, o coeficiente de descarga das aberturas e a velocidade de referência do vento. Esta última é 
definida como a velocidade do vento não perturbado na mesma altura do topo da edificação analisada.

Os dados de coeficiente de pressão e coeficiente de descarga foram obtidos da própria norma BS 5925 (BSI, 1991), enquanto que a velocidade de referência do vento foi calculada para a altura de $18 \mathrm{~m}$ utilizando a metodologia descrita na seção 4.4.2. A área de abertura foi calculada a partir do próprio modelo, e a partir destes dados foi calculada a vazão de ar para as velocidades máximas do vento de $2 \mathrm{~m} / \mathrm{s}$ e $4 \mathrm{~m} / \mathrm{s}$ com janelas de correr vertical.

\subsubsection{Análise qualitativa do escoamento do ar no ambiente}

Além dos parâmetros apresentados anteriormente, que quantificam algumas grandezas relacionadas com a ventilação natural de ambientes, existem algumas análises qualitativas interessantes para modelos numéricos, que também são realizadas na análise dos resultados e da eficiência da ventilação natural no Capítulo 5.

Por exemplo, a análise da distribuição de temperaturas no domínio permite obter informações mais detalhadas de fenômenos locais como a formação de plumas térmicas ao redor de um elemento gerador de carga térmica, como mostra a figura 4.6.7.

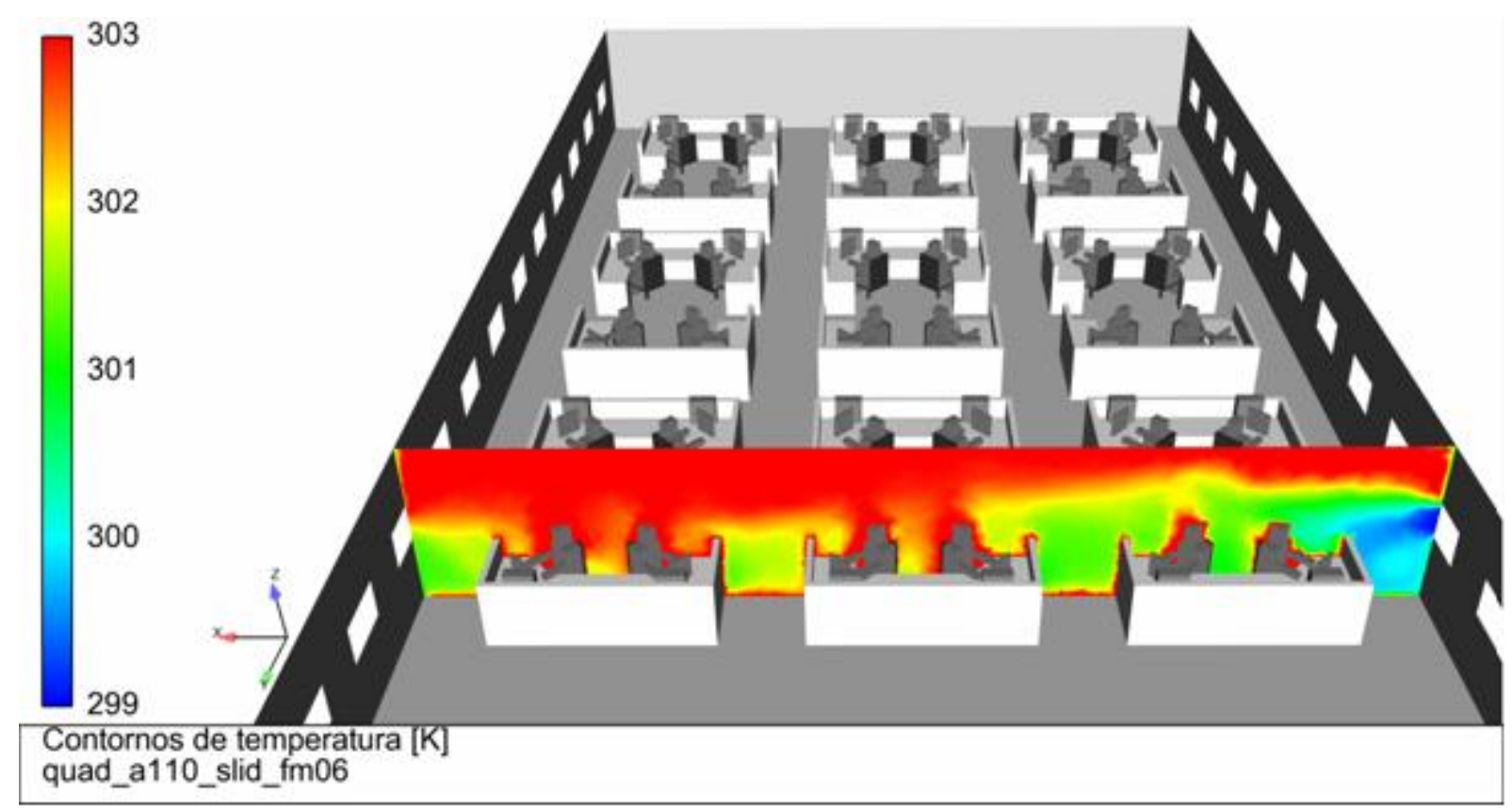

Figura 4.6.7: Perfil de temperaturas do ar em um plano vertical no domínio do escritório. 
Da figura 4.6.7 é possível também verificar como a temperatura no ambiente aumenta conforme o ar atravessa o escritório, e que apenas uma pequena região permanece com temperaturas próximas às externas. Estes planos de temperatura ajudam a compreender dados como diferenças das temperaturas com a altura ou mesmo temperaturas do ar em diversas estações de trabalho.

A distribuição de velocidades também ajuda a compreender melhor a distribuição de ar no escritório, que tem influência direta sobre as condições de conforto térmico dos ocupantes. Velocidades do ar acima de $0,5 \mathrm{~m} / \mathrm{s}$ não são recomendáveis dentro da zona ocupada, por gerarem desconforto por correntes de ar. Utilizando imagens como a da figura 4.6.8, verifica-se que estas velocidades demasiadamente altas não são encontradas.

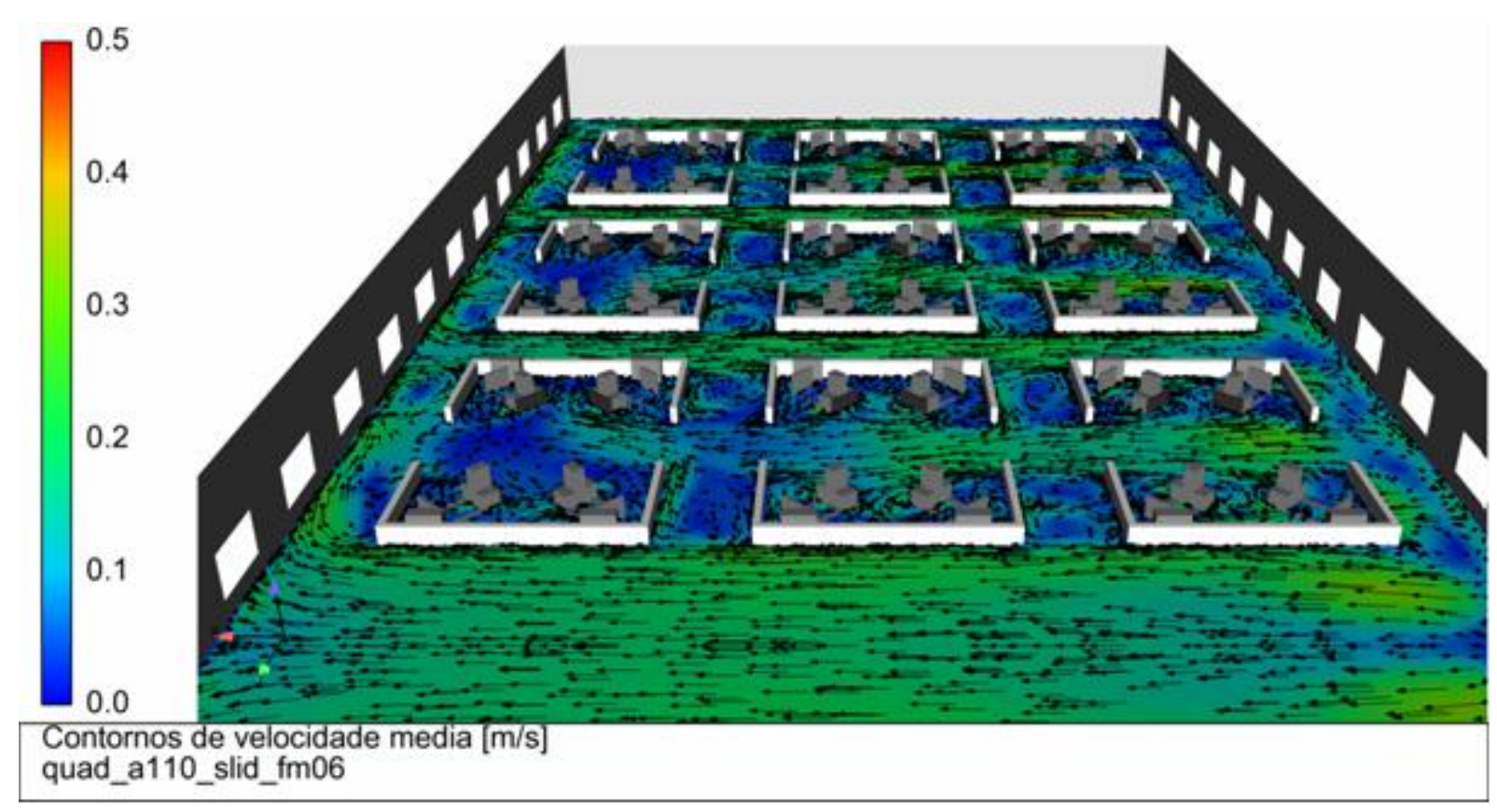

Figura 4.6.8: Perfil de velocidades do ar em um plano horizontal no domínio do escritório.

Também é possível observar na figura 4.6.8 vetores de velocidade no plano, que auxiliam a compreender o fluxo de ar dentro do ambiente. Nas estações de trabalho à esquerda, verifica-se com estes vetores que a velocidade do ar não só reduz sua intensidade como também deixa de ter um sentido principal, como nas estações de trabalho à direita.

Uma alternativa interessante é combinar os vetores de velocidade do ar com perfis de temperatura, como ilustrado na figura 4.6.9. Utilizando este recurso, é possível verificar melhor certas interações entre o campo de velocidade e de temperatura, como por exemplo a influência da entrada do ar no ambiente com a formação das plumas térmicas. 


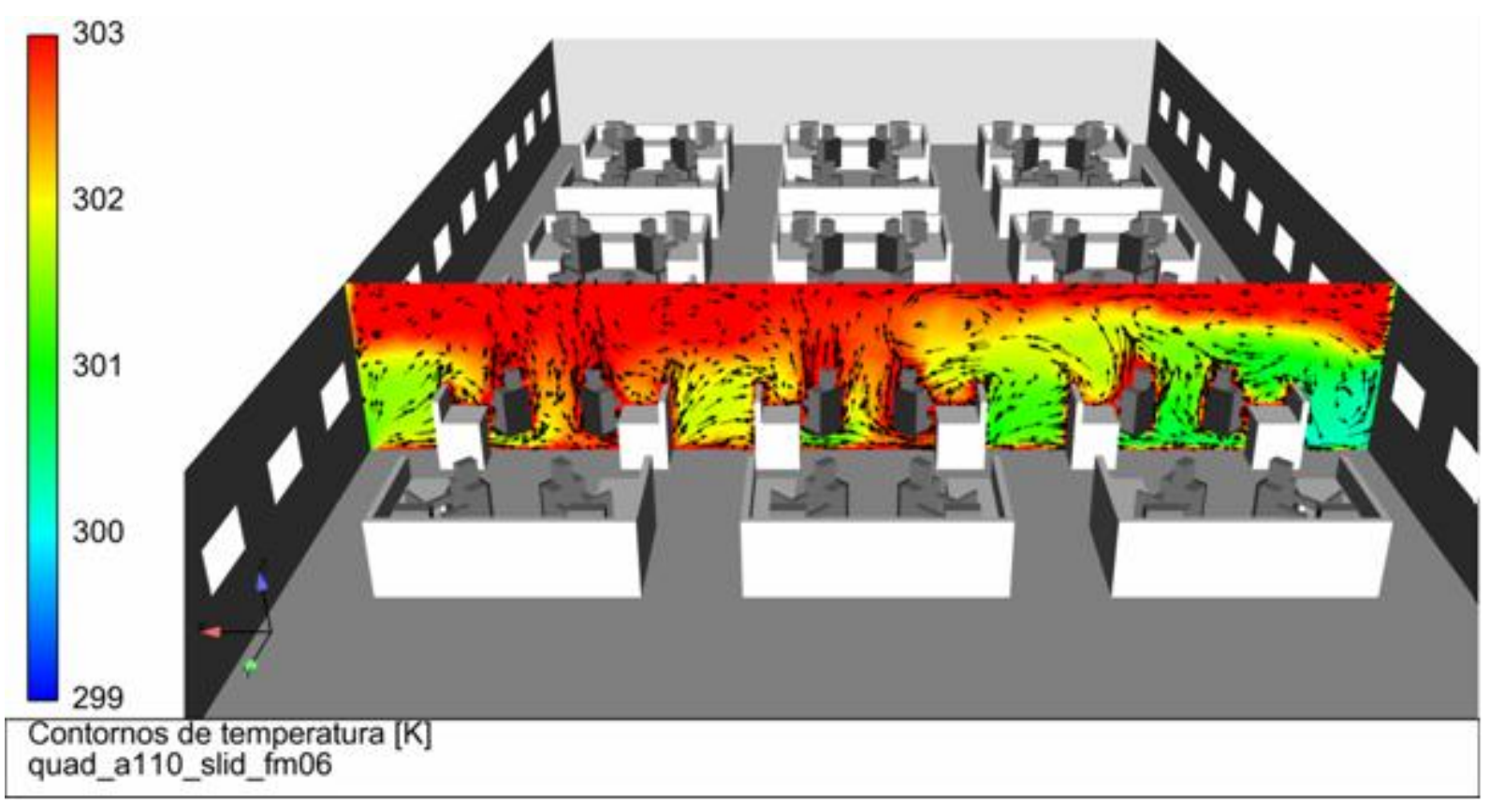

Figura 4.6.8: Perfil de velocidades em um plano horizontal no domínio do escritório.

Nesta figura, verifica-se que o ar quente, mais presente na região à esquerda, espalhase pela região próxima do teto. Com estes recursos do CFD, poderiam ser realizadas melhorias no ambiente, como por exemplo o direcionamento de certo fluxo de ar frio para o teto, impedindo que o ar quente volte para a região de entrada do ar exterior. 


\section{CAPÍTULO 5}

\section{RESULTADOS E ANÁLISE DA EFICIÊNCIA DA VENTILAÇÃO NATURAL NOS AMBIENTES}

Neste capítulo estão apresentados os resultados obtidos nas simulações numéricas com as geometrias e condições apresentadas no capítulo anterior. As primeiras informações apresentadas referem-se à análise de independência de malha e encontram-se na seção 5.1. Já na seção 5.2 encontra-se a comparação da vazão de ar calculada numericamente com a vazão de ar da norma BS 5925 (BSI, 1991).

Quanto aos resultados obtidos com as configurações avaliadas, os dados estão divididos entre os principais elementos abordados: altura das partições, layout e geometria das aberturas, e são encontrados nas seções 5.3 a 5.5. Além destes, analisou-se a variação da velocidade do vento na seção 5.6.

Posteriormente, para a configuração de mobiliário e de tipo de janela que apresentou os melhores resultados de eficiência da ventilação natural, analisou-se a variação de elementos geradores de carga térmica, como iluminação e equipamentos elétricos, e da temperatura do ar externo, na seção 5.7.

Por fim, na seção 5.8 são apresentados os resultados de análise de conforto térmico nos ambientes avaliados, utilizando os resultados de temperatura do ar, $\mathrm{T}_{\mathrm{ar}}$, obtidos nas simulações numéricas e o procedimento descrito na seção 4.6.12.

Nas simulações as malhas volumétricas utilizadas no presente trabalho possuem em média 3,5 milhões de elementos, sendo necessárias cerca de 10,6 horas para calcular cada situação em um servidor com oito processadores Intel Xeon E5520 2.26GHz e 37GB de memória.

2 Resultados preliminares deste trabalho foram publicados no $14^{\circ}$ Encontro Nacional de Ciências Térmicas ENCIT 2012 (MARIANA; TRIBESS, 2012b) e no $7^{\circ}$ Congresso Nacional de Engenharia Mecânica - CONEM 2012 (MARIANA; TRIBESS, 2012a). 


\subsection{INDEPENDÊNCIA DE MALHA}

Uma etapa importante das análises numéricas que empregam CFD é o estudo da independência de malha. A princípio, espera-se que o refinamento da malha torne possível obter mais detalhes do fenômeno estudado e por consequência mude os resultados obtidos.

Entretanto, verifica-se que após determinado nível de refinamento alguns parâmetros permanecem inalterados. Desta forma o refinamento da malha trará apenas um aumento dos recursos computacionais necessários, sem obter o benefício esperado de resultados mais precisos.

Para garantir a precisão dos resultados obtidos sem comprometer os recursos computacionais, varia-se um parâmetro relativo ao tamanho da malha a fim de se obter o menor tamanho de malha necessário. Por exemplo, seria possível mudar o comprimento médio dos elementos da malha superficial, a fim de determinar o comprimento mínimo suficiente.

Neste trabalho optou-se por variar a taxa de crescimento dos elementos tetraédricos da malha volumétrica. Desta forma, a análise parte de uma mesma malha superficial, reduzindo a quantidade de malhas totais necessárias e o tempo necessário para o estudo da independência de malha. A figura 5.1.1 apresenta um corte onde é possível observar parte da malha volumétrica empregada nos escritórios com as três taxas de crescimento foram analisadas: $1,3,1,6$ e 1,9 .

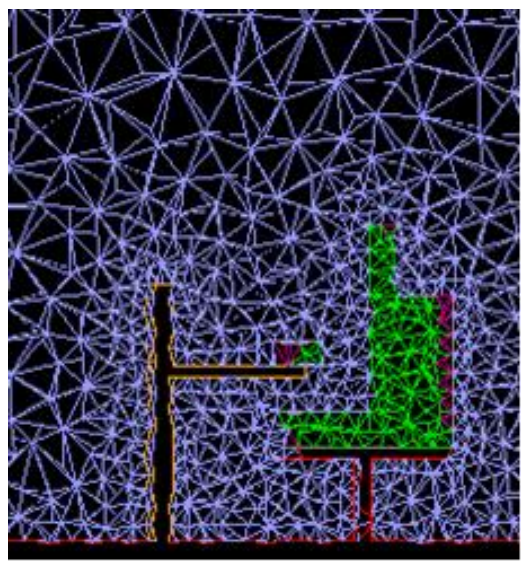

(a)

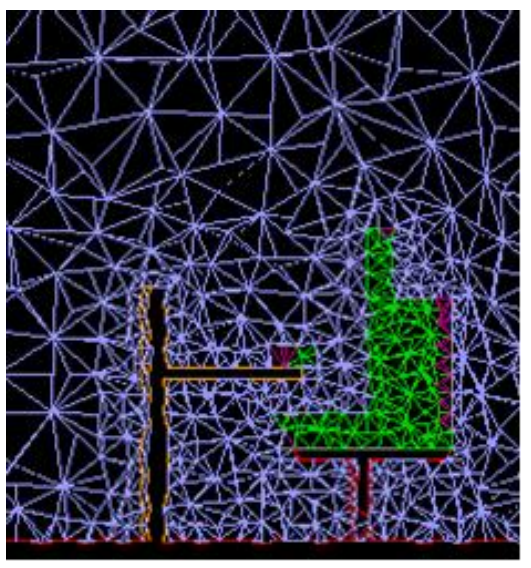

(b)

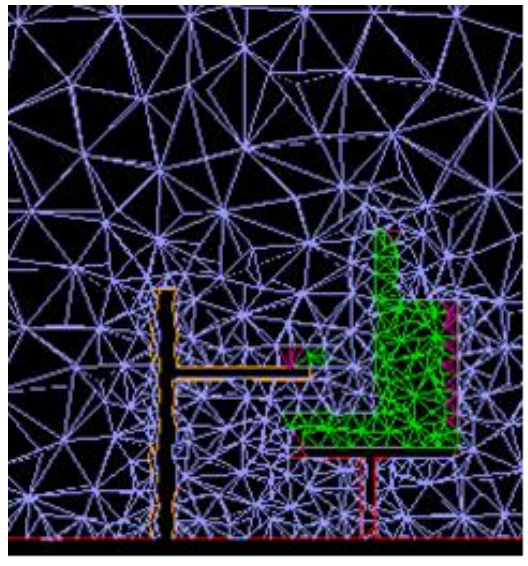

(c)

Figura 5.1.1: Malhas volumétricas com taxa de crescimento 1,3 (a), 1,6 (b) e 1,9 (c) utilizada nos escritórios. 
Estas três taxas de crescimento foram utilizadas para dois escritórios semelhantes, onde a altura das partições foi variada de $1,10 \mathrm{~m}$ para $1,50 \mathrm{~m}$, e os demais parâmetros (geometria das aberturas, layout e condições ambientais externas) foram mantidos constantes. Como resultados foram obtidos seis modelos numéricos, para os quais se comparou os parâmetros quantitativos citados na seção 4.6.

A tabela 5.1.1 apresenta os resultados dos principais parâmetros quantitativos obtidos das simulações. Nesta tabela é possível verificar que a diferença nos três parâmetros avaliados é constante para as taxas de crescimento de 1,3 e 1,6, enquanto que esses valores variam para a taxa de 1,9 .

Tabela 5.1.1: Parâmetros quantitativos analisados para análise de independência de malha.

\begin{tabular}{|c|c|c|c|c|}
\hline \multirow{2}{*}{$\begin{array}{c}\text { Taxa de } \\
\text { Crescimento }\end{array}$} & \multirow{2}{*}{$\begin{array}{c}\text { Parâmetro } \\
\text { Avaliado }\end{array}$} & \multicolumn{2}{|c|}{ Altura das Partições } & \multirow{2}{*}{ Diferença } \\
\hline & & $1,10 \mathrm{~m}$ & $1,50 \mathrm{~m}$ & \\
\hline \multirow{2}{*}{1,3} & Vazão de $\operatorname{Ar}[\mathrm{kg} / \mathrm{s}]$ & 10,67 & 10,42 & $-0,25$ \\
\hline & $\begin{array}{c}\text { Temperatura Média } \\
\text { do } \operatorname{Ar}[\mathrm{K}]\end{array}$ & 301,8 & 302,0 & 0,2 \\
\hline \multirow{2}{*}{1,6} & Vazão de $\operatorname{Ar}[\mathrm{kg} / \mathrm{s}]$ & 10,63 & 10,38 & $-0,25$ \\
\hline & $\begin{array}{c}\text { Temperatura Média } \\
\text { do } \operatorname{Ar}[\mathrm{K}]\end{array}$ & 301,7 & 301,9 & 0,2 \\
\hline \multirow{2}{*}{1,9} & Vazão de $\operatorname{Ar}[\mathrm{kg} / \mathrm{s}]$ & 10,66 & 10,33 & $-0,33$ \\
\hline & $\begin{array}{c}\text { Temperatura Média } \\
\text { do } \operatorname{Ar}[\mathrm{K}]\end{array}$ & 302,0 & 301,9 & $-0,1$ \\
\hline
\end{tabular}

É importante observar que utilizando a taxa de crescimento de 1,9 existe uma diminuição na temperatura média do ar com o aumento da partição, enquanto que o senso comum indica que mais obstruções causariam piores condições ambientais. Entretanto, utilizando-se as taxas de crescimento de 1,3 e 1,6 essa tendência esperada foi efetivamente verificada, indicando que estes resultados encontram-se mais próximos da realidade.

Uma vez que este trabalho tem por objetivo quantificar a diferença entre as estratégias adotadas, é possível afirmar que a taxa de crescimento de 1,6 é suficiente para obter os resultados desejados, uma vez que o refinamento da malha não altera a diferença dos parâmetros analisados. 


\subsection{VAZÃO DE AR}

De acordo com os dados apresentados na tabela 5.2.1, a vazão de ar calculada pela metodologia da norma BS 5925 (BSI, 1991) seria de 6,42kg/s e 12,84kg/s para as velocidades máximas do vento de $2 \mathrm{~m} / \mathrm{s}$ e $4 \mathrm{~m} / \mathrm{s}$, respectivamente. Das simulações numéricas foram obtidos valores médios de vazão de ar de $7,24 \mathrm{~kg} / \mathrm{s}$ e $14,58 \mathrm{~kg} / \mathrm{s}$ para as velocidades máximas do vento de $2 \mathrm{~m} / \mathrm{s}$ e $4 \mathrm{~m} / \mathrm{s}$, respectivamente.

Tabela 5.2.1: Dados utilizados para o cálculo analítica da vazão de ar dos escritórios com janelas de correr vertical.

\begin{tabular}{|c|c|c|c|}
\hline Propriedade & Valor & Propriedade & Valor \\
\hline $\begin{array}{l}\text { Massa Específica do Ar } \\
{\left[\mathrm{kg} / \mathrm{m}^{3}\right]}\end{array}$ & 1,225 & $\begin{array}{c}\text { Área das aberturas de saída do } \\
\operatorname{ar}\left[\mathrm{m}^{2}\right]\end{array}$ & 13,2 \\
\hline $\begin{array}{l}\text { Coeficiente de pressão na } \\
\text { fachada de entrada do ar [-] }\end{array}$ & 0,7 & $\begin{array}{l}\text { Velocidade de referência do } \\
\text { vento máximo de } 2 \mathrm{~m} / \mathrm{s}[\mathrm{m} / \mathrm{s}]\end{array}$ & 1,13 \\
\hline $\begin{array}{l}\text { Coeficiente de pressão na } \\
\text { fachada de saída do ar [-] }\end{array}$ & $-0,3$ & $\begin{array}{l}\text { Velocidade de referência do } \\
\text { vento máximo de } 4 \mathrm{~m} / \mathrm{s}[\mathrm{m} / \mathrm{s}]\end{array}$ & 2,26 \\
\hline $\begin{array}{c}\text { Área das aberturas de entrada } \\
\text { do } \operatorname{ar}\left[\mathrm{m}^{2}\right]\end{array}$ & 13,2 & Coeficiente de descarga [-] & 0,61 \\
\hline
\end{tabular}

A diferença de resultado ficou próxima de $13 \%$ para ambos os casos, como mostra a tabela 5.2.2, sendo possível então afirmar que a simulação numérica forneceu resultados de vazão de ar próximos do esperado. Como as janelas monitoradas se encontram no último pavimento da edificação, que recebe ventos mais intensos do que os pavimentos inferiores, devido ao perfil logarítmico do vento, uma vazão de ar maior obtida na simulação numérica era esperada.

Tabela 5.2.2: Comparação da vazão de ar calculada analiticamente e numericamente para os escritórios com janelas de correr vertical.

\begin{tabular}{c|c||c|c}
\multicolumn{2}{l||}{ Velocidade Máxima do Vento de 2m/s } & \multicolumn{2}{|c}{ Velocidade Máxima do Vento de 4m/s } \\
$\begin{array}{c}\text { Vazão de ar calculada } \\
\text { analiticamente }[\mathrm{kg} / \mathrm{s}]\end{array}$ & 6,43 & $\begin{array}{c}\text { Vazão de ar calculada } \\
\text { analiticamente }[\mathrm{kg} / \mathrm{s}]\end{array}$ & 12,87 \\
$\begin{array}{c}\text { Vazão de ar média calculada } \\
\text { numericamente }[\mathrm{kg} / \mathrm{s}]\end{array}$ & 7,24 & $\begin{array}{c}\text { Vazão de ar média calculada } \\
\text { numericamente }[\mathrm{kg} / \mathrm{s}]\end{array}$ & 14,58 \\
Diferença & $\mathbf{1 2 , 6 \%}$ & Diferença & $\mathbf{1 3 , 3 \%}$
\end{tabular}




\subsection{VARIAÇÃO DA ALTURA DAS PARTIÇÕES}

O aumento da altura das partições apresentou uma indicação de tendência de aumentar também a temperatura média do ar, como pode ser observado nas tabelas 5.3.1 e 5.3.2. De um modo geral, o aumento da temperatura foi de apenas $0,1 \mathrm{~K}$ ou $0,2 \mathrm{~K}$, o que não é suficiente para assegurar as piores condições. No caso mais extremo, com layout quadrado, janelas de correr vertical e velocidade do vento mais baixa, esta variação foi de $0,4 \mathrm{~K}$.

Tabela 5.3.1: Temperatura média do ar para velocidade do ar exterior máxima de $2 \mathrm{~m} / \mathrm{s}$.

Temperatura média do ar [K]

\begin{tabular}{c|c|c|c|c|}
\hline \multirow{2}{*}{ Layout } & Geometria das & \multicolumn{3}{|c|}{ Altura das Partições } \\
& Janelas & $\mathbf{0 , 9 0 m}$ & $\mathbf{1 , 1 0 m}$ & $\mathbf{1 , 5 0 m}$ \\
\hline \multirow{2}{*}{ quadrado } & Maxim-ar & 301,0 & 301,1 & 301,2 \\
& De correr vertical & 302,0 & 302,0 & 302,4 \\
\hline \multirow{2}{*}{ linha } & Maxim-ar & 301,1 & 301,1 & 301,0 \\
& De correr vertical & 301,9 & 301,8 & 302,0
\end{tabular}

Tabela 5.3.2: Temperatura média do ar para velocidade do ar exterior máxima de $4 \mathrm{~m} / \mathrm{s}$.

Temperatura média do ar $[\mathrm{K}]$

\begin{tabular}{c|c|c|c|c|}
\hline \multirow{2}{*}{ Layout } & Geometria das & \multicolumn{3}{|c|}{ Altura das Partições } \\
& Janelas & $\mathbf{0 , 9 0 m}$ & $\mathbf{1 , 1 0 m}$ & $\mathbf{1 , 5 0 m}$ \\
\hline \multirow{3}{*}{ quadrado } & Maxim-ar & 300,4 & 300,4 & 300,4 \\
& De correr vertical & 300,7 & 300,7 & 300,8 \\
\hline \multirow{2}{*}{ linha } & Maxim-ar & 300,5 & 300,5 & 300,4 \\
& De correr vertical & 300,6 & 300,6 & 300,6
\end{tabular}

Verifica-se que com quase as mesmas condições, apenas mudando o layout para linha, as variações de temperatura foram muito menores, apenas oscilando em $+/-0,1 \mathrm{~K}$ do valor das divisórias mais baixas. Tendo em vista estes valores, verifica-se uma indicação de maior sensibilidade ao aumento da altura das partições do layout quadrado.

Considerando os resultados obtidos para a velocidade mais elevado do vento, $4 \mathrm{~m} / \mathrm{s}$, verifica-se das tabelas 5.3.1 e 5.3.2 que as mudanças de temperatura do ar, quando ocorrem, 
são de $0,1 \mathrm{~K}$. Apesar das pequenas diferenças de temperatura, verifica-se uma sensibilidade maior na temperatura do ar no ambiente para as situações de ventos mais amenos, que diminuem a convecção forçada e por consequência reduzem a remoção da carga térmica do ambiente.

Analisando a estratificação das temperaturas, é possível afirmar que também houve uma indicação de tendência de aumento com as partições mais altas. Neste caso, a variação desta variável foi um pouco menor do que a da temperatura do ar, como se verifica das tabelas 5.3.3 e 5.3.4. Desta forma, não é possível novamente assegurar a tendência, apesar dos valores sempre maiores para as partições de $1,50 \mathrm{~m}$ do que para as partições de $0,90 \mathrm{~m}$.

Tabela 5.3.3: Estratificação de temperatura entre pés e cabeça para velocidade do ar exterior máxima de $2 \mathrm{~m} / \mathrm{s}$.

\begin{tabular}{c|c|c|c|c|}
\hline \multirow{2}{*}{ Layout } & Geometria das & \multicolumn{3}{|c|}{ Altura das Partições } \\
& Janelas & $\mathbf{0 , 9 0 m}$ & $\mathbf{1 , 1 0 m}$ & $\mathbf{1 , 5 0 m}$ \\
\hline \multirow{2}{*}{ quadrado } & Maxim-ar & 0,5 & 0,5 & 0,6 \\
& De correr vertical & 0,5 & 0,6 & 0,8 \\
\hline \multirow{2}{*}{ linha } & Maxim-ar & 0,4 & 0,6 & 0,5 \\
& De correr vertical & 0,6 & 0,6 & 0,8
\end{tabular}

Tabela 5.3.4: Estratificação de temperatura entre pés e cabeça para velocidade do ar exterior máxima de $4 \mathrm{~m} / \mathrm{s}$.

\begin{tabular}{c|c|c|c|c|}
\hline \multirow{2}{*}{ Layout } & $\begin{array}{c}\text { Geometria das } \\
\text { Janelas }\end{array}$ & \multicolumn{3}{|c|}{ Altura das Partições } \\
& Maxim-ar & 0,3 & 0,4 & 0,4 \\
\hline \multirow{2}{*}{ quadrado } & De correr vertical & 0,4 & 0,4 & 0,5 \\
\cline { 5 - 5 } & Maxim-ar & 0,3 & 0,4 & 0,4 \\
& De correr vertical & 0,4 & 0,4 & 0,5
\end{tabular}

Na configuração onde a variação de altura da partição teve maior influência, com layout quadrado, janelas de correr vertical e velocidade máxima do ar de $2 \mathrm{~m} / \mathrm{s}$, é interessante verificar que a principal diferença de temperatura deu-se no plano da cabeça, a 1,10m do piso, onde a diferença de temperatura média foi de $0,7 \mathrm{~K}$. Já as temperaturas médias nos planos do 
tornozelo (altura de $0,10 \mathrm{~m}$ ) e da cintura (altura de $0,60 \mathrm{~m}$ ), por sua vez, diferem entre si de 0,2K, como é possível observar na tabela 5.3.5.

Tabela 5.3.5: Temperaturas médias, mínimas e máximas do ar nos três planos de medição para o layout quadrado com janelas de correr vertical e velocidade máxima do ar de $2 \mathrm{~m} / \mathrm{s}$.

\begin{tabular}{c|c|c|c|c|c} 
& Altura das & \multicolumn{3}{|c|}{ Plano de medição } & Total \\
\hline $\begin{array}{c}\text { pempertições } \\
\text { Médias } \\
{[\mathbf{K}]}\end{array}$ & $\mathbf{0 , 9 0 m}$ & 301,9 & 301,8 & 302,3 & 302,0 \\
\hline $\begin{array}{c}\text { Temperaturas } \\
\text { Mínimas } \\
{[\mathbf{[ K}]}\end{array}$ & $\mathbf{1 , 5 0 m}$ & 302,1 & 302,0 & 303,0 & 302,4 \\
\hline $\begin{array}{c}\text { Temperaturas } \\
\text { Máximas } \\
{[\mathbf{K}]}\end{array}$ & $\mathbf{0 , 9 0 m}$ & 301,2 & 300,6 & 300,4 & 301,1 \\
& $\mathbf{1 , 5 0 m}$ & 301,2 & 300,9 & 302,0 & 301,4 \\
\hline $\mathbf{1 , 5 0 m}$ & 302,6 & 303,2 & 303,3 & 302,9 \\
& & 302,8 & 302,9 & 304,0 & 303,1
\end{tabular}

As figuras 5.3.1 e 5.3.2 mostram um plano vertical do ambiente colorido por velocidade com os respectivos vetores. Verifica-se que nesse plano, para as partições de altura de 0,90m, o campo de velocidades é mais intenso, fenômeno que aumenta a convecção forçada e consequentemente aumenta a transferência de calor.

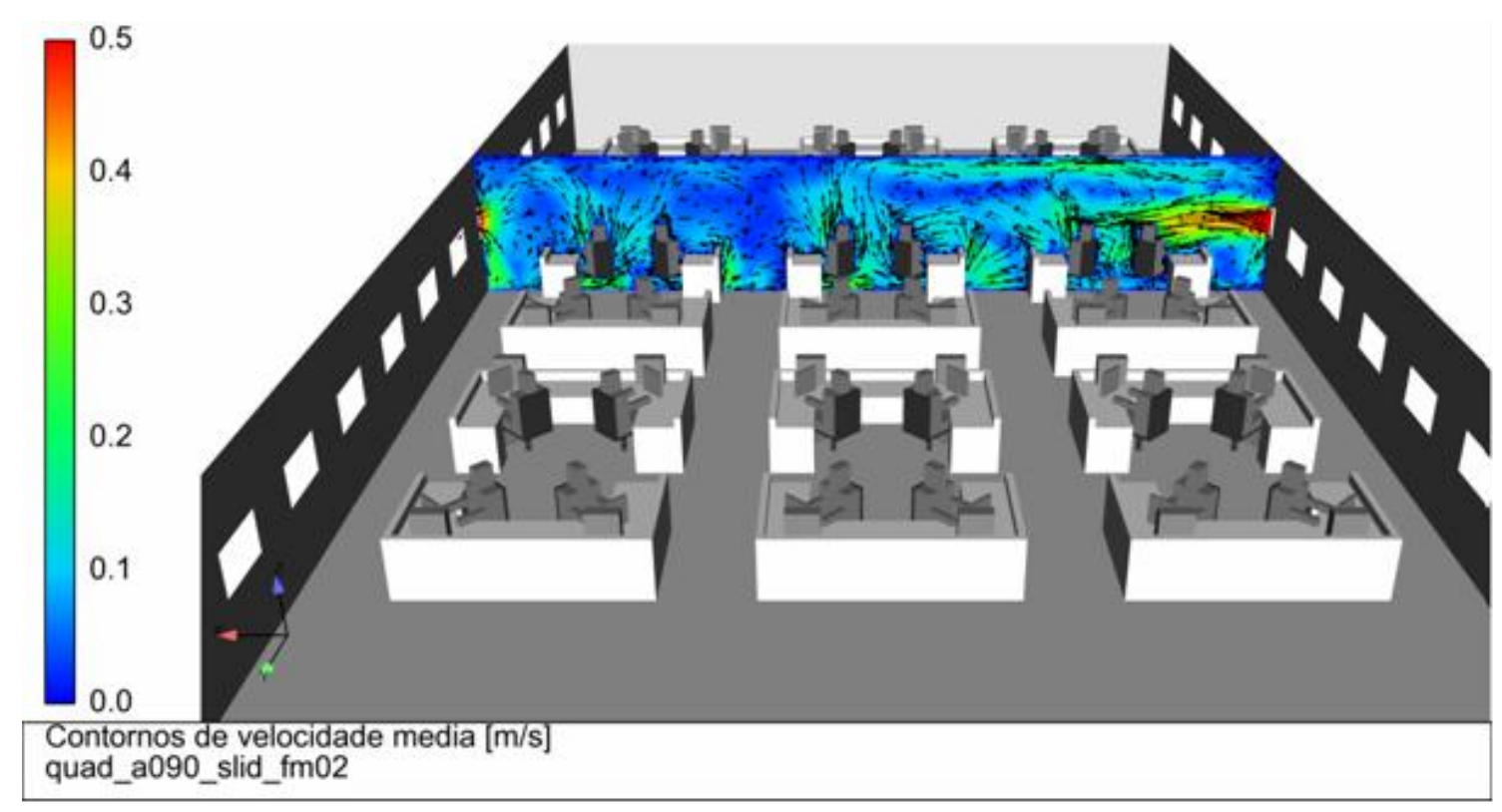

Figura 5.3.1: Plano vertical $\mathrm{y}=-12,65 \mathrm{~m}$ colorido por velocidade com os respectivos vetores para o layout quadrado com partições de $0,90 \mathrm{~m}$, janelas de correr vertical e velocidade máxima do ar de $2 \mathrm{~m} / \mathrm{s}$. 


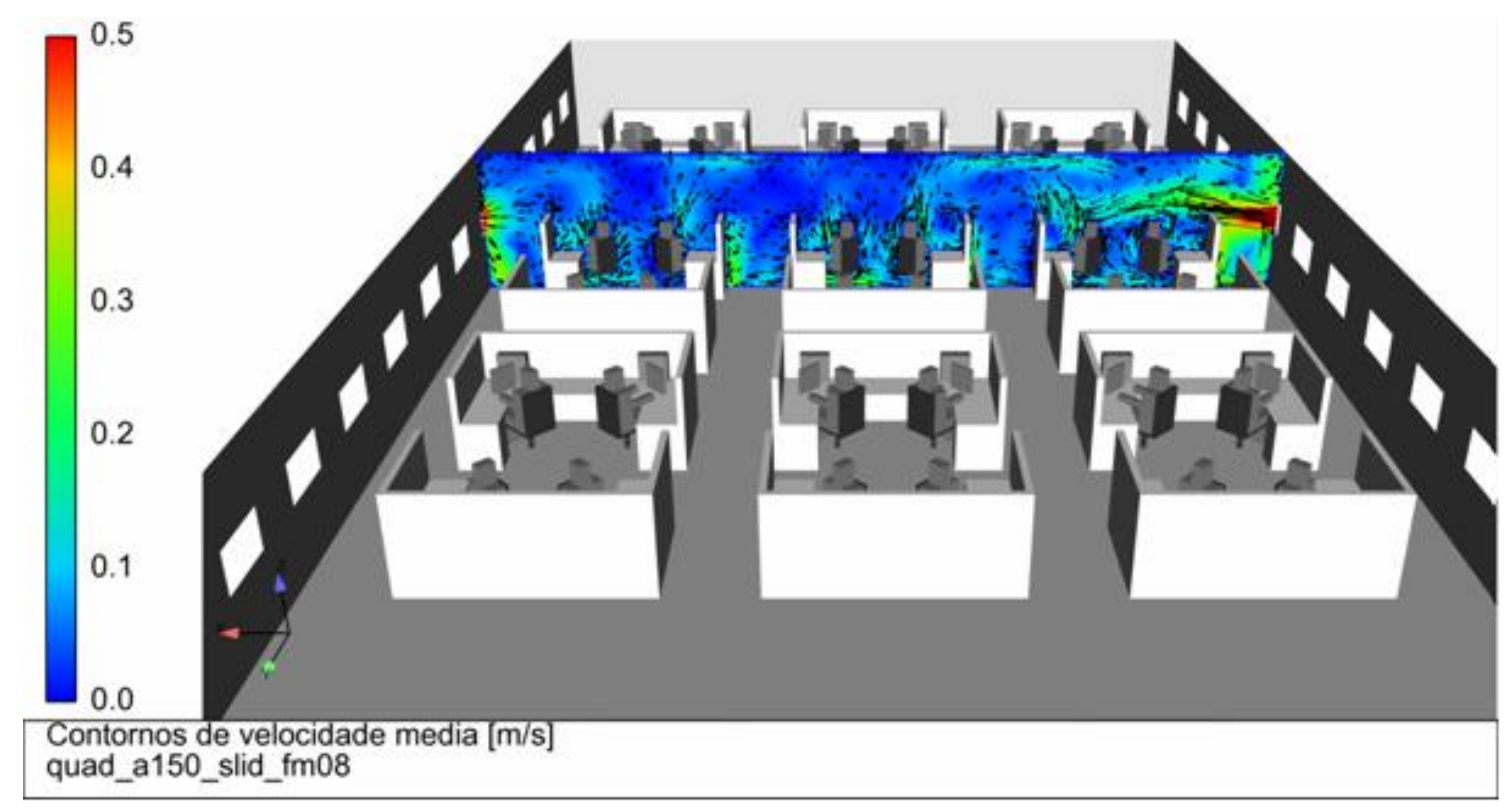

Figura 5.3.2: Plano vertical $\mathrm{y}=-12,65 \mathrm{~m}$ colorido por velocidade com os respectivos vetores para o layout quadrado com partições de $1,50 \mathrm{~m}$, janelas de correr vertical e velocidade máxima do ar de $2 \mathrm{~m} / \mathrm{s}$.

O aumento da velocidade tem como consequência esperada a redução das temperaturas, o que foi verificado na tabela 5.3.5 e pode ser visualizado nas figuras 5.3.3 e 5.3.4. Nestas figuras verifica-se de forma especial a diferença no campo de temperatura das estações de trabalho centrais, onde as partições são mais altas. É interessante também verificar como a região à montante do escritório com partições de $1,50 \mathrm{~m}$ apresenta temperaturas mais baixas, ou seja, o potencial de retirada de carga térmica foi mais utilizado nesta região.

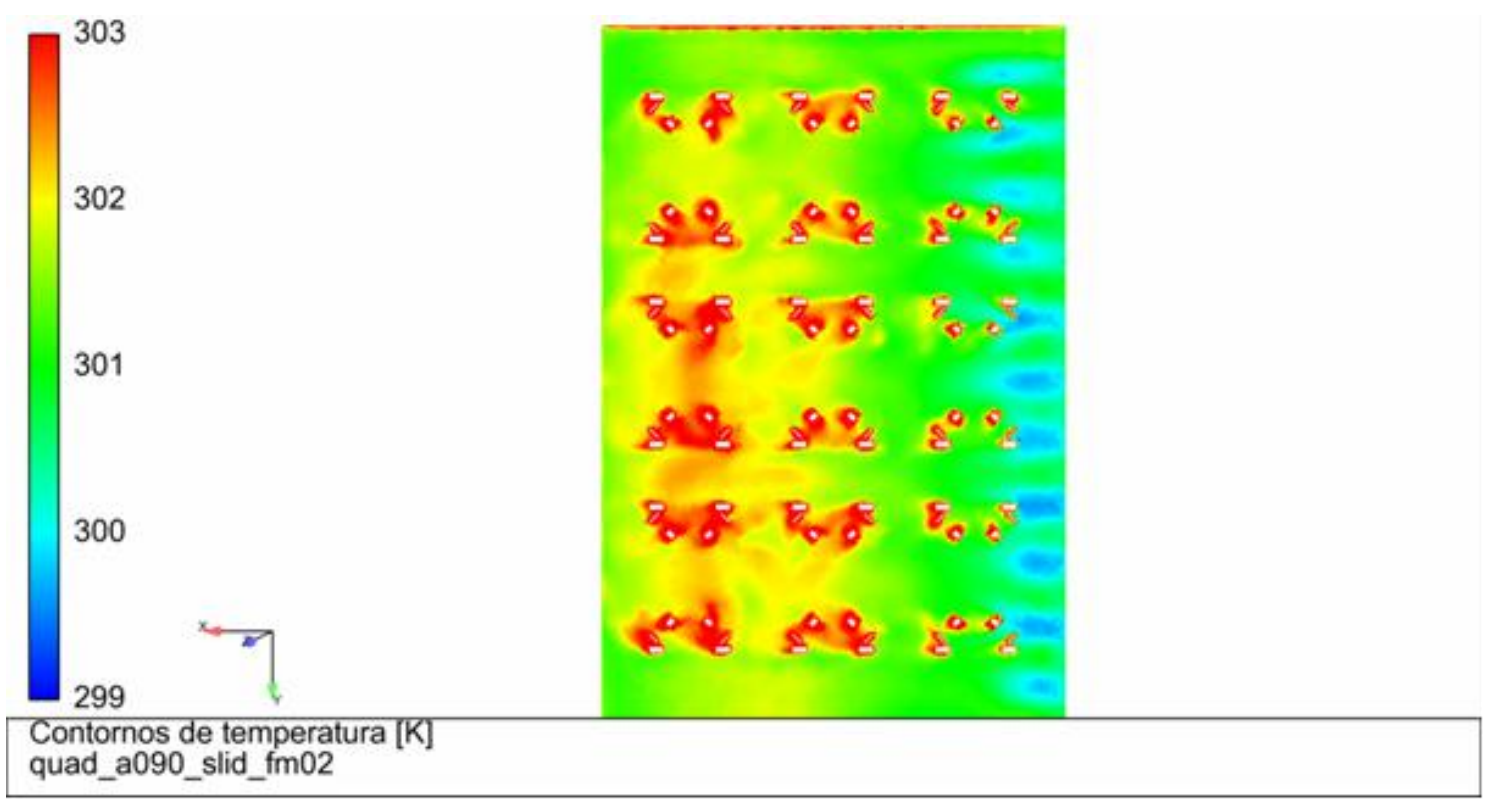

Figura 5.3.3: Plano horizontal $\mathrm{z}=1,10 \mathrm{~m}$ colorido por temperatura para o layout quadrado com partições de 0,90m, janelas de correr vertical e velocidade máxima do ar de $2 \mathrm{~m} / \mathrm{s}$. 


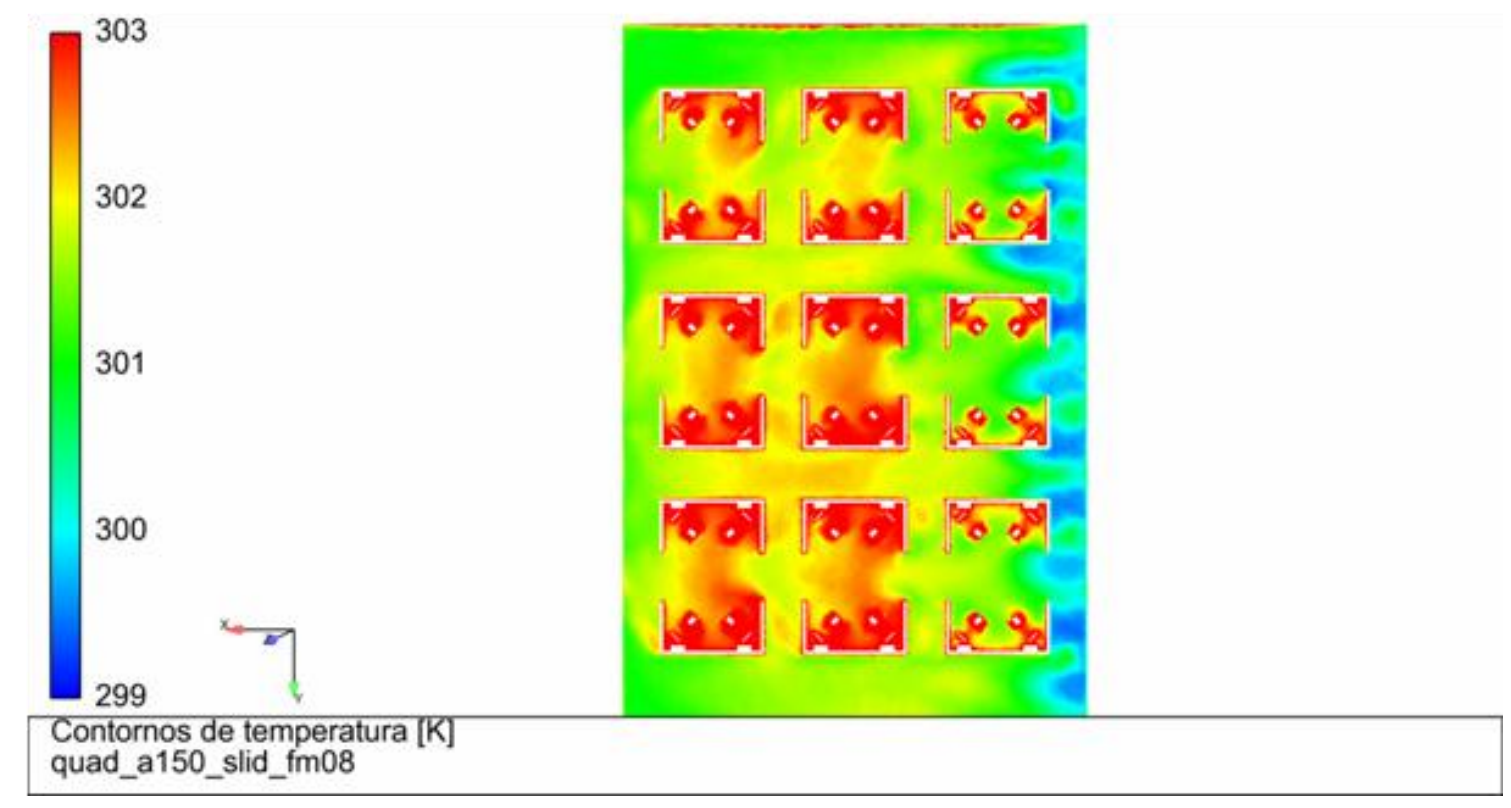

Figura 5.3.4: Plano horizontal $\mathrm{z}=1,10 \mathrm{~m}$ colorido por temperatura para o layout quadrado com partições de $1,50 \mathrm{~m}$, janelas de correr vertical e velocidade máxima do ar de $2 \mathrm{~m} / \mathrm{s}$.

Análises semelhantes podem ser feitas para as configurações que resultaram em condições de conforto mais próximas, como por exemplo a mudança de layout para as estações de trabalho em linha. Verifica-se da tabela 5.3.6 que os valores médios são idênticos para os planos de medição dos tornozelos e cinturas, e o ambiente com as partições mais altas tem apenas $0,2 \mathrm{~K}$ a mais no plano das cabeças.

Tabela 5.3.6: Temperaturas médias, mínimas e máximas do ar nos três planos de medição para o layout em linha com janelas de correr vertical e velocidade máxima do ar de $2 \mathrm{~m} / \mathrm{s}$.

\begin{tabular}{c|c|c|c|c|} 
& Altura das & \multicolumn{3}{|c|}{ Plano de mediç̃o } \\
& partições & $\mathbf{0 , 1 0 m}$ & $\mathbf{0 , 6 0 m}$ & $\mathbf{1 , 1 0 m}$ \\
\hline $\begin{array}{c}\text { Temperaturas } \\
\text { Médias } \\
{[\mathbf{K}]}\end{array}$ & $\mathbf{0 , 9 0 m}$ & 301,8 & 301,7 & 302,2 \\
\hline $\begin{array}{c}\text { Temperaturas } \\
\text { Mínimas } \\
{[\mathbf{K}]}\end{array}$ & $\mathbf{1 , 5 0 m}$ & 301,8 & 301,7 & 302,4 \\
\hline $\begin{array}{c}\text { Temperaturas } \\
\text { Máximas } \\
{[\mathbf{0 , 9 0 m}}\end{array}$ & $\mathbf{1 , 5 0 m}$ & 300,9 & 300,3 & 300,3 \\
& $\mathbf{0 , 9 0 m}$ & 302,3 & 300,3 & 300,3 \\
\hline $\mathbf{1 , 5 0 m}$ & 302,5 & 302,7 & 303,4
\end{tabular}


Verifica-se das figuras 5.3.5 e 5.3.6 que as diferenças no campo de velocidade são bem menores do que aquelas das figuras 5.3.1 e 5.3.2, o que reflete nos resultados mais próximos de temperatura do ar e sua menor estratificação. A diferença mais significativa pode ser verificada no terceiro ocupante da esquerda para a direita, onde a pluma térmica pode ser mais facilmente percebida quando foram utilizadas as partições mais altas.

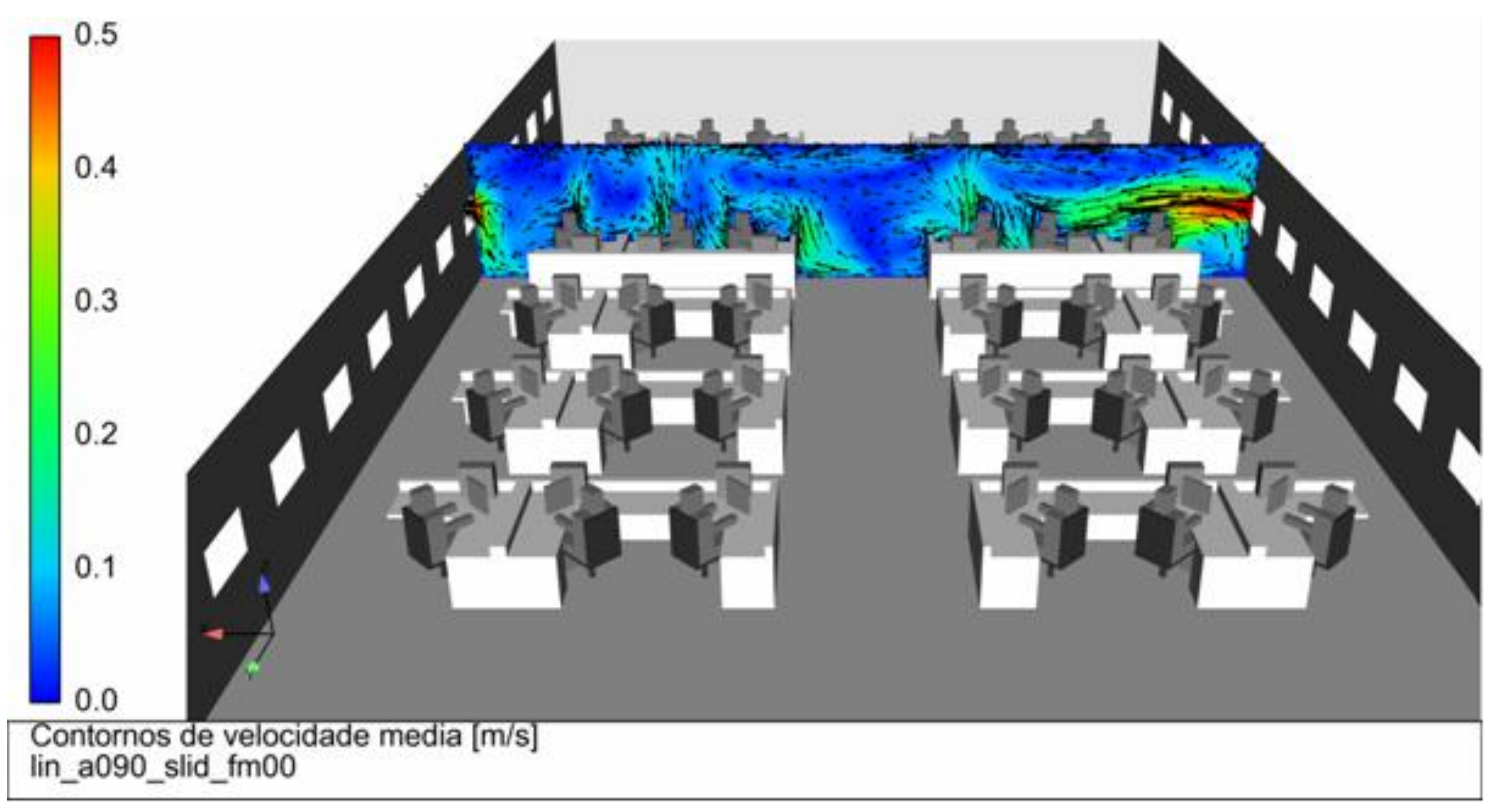

Figura 5.3.5: Plano vertical $\mathrm{y}=-13,20 \mathrm{~m}$ colorido por velocidade com os respectivos vetores para o layout quadrado com partições de $0,90 \mathrm{~m}$, janelas de correr vertical e velocidade máxima do ar de $2 \mathrm{~m} / \mathrm{s}$.

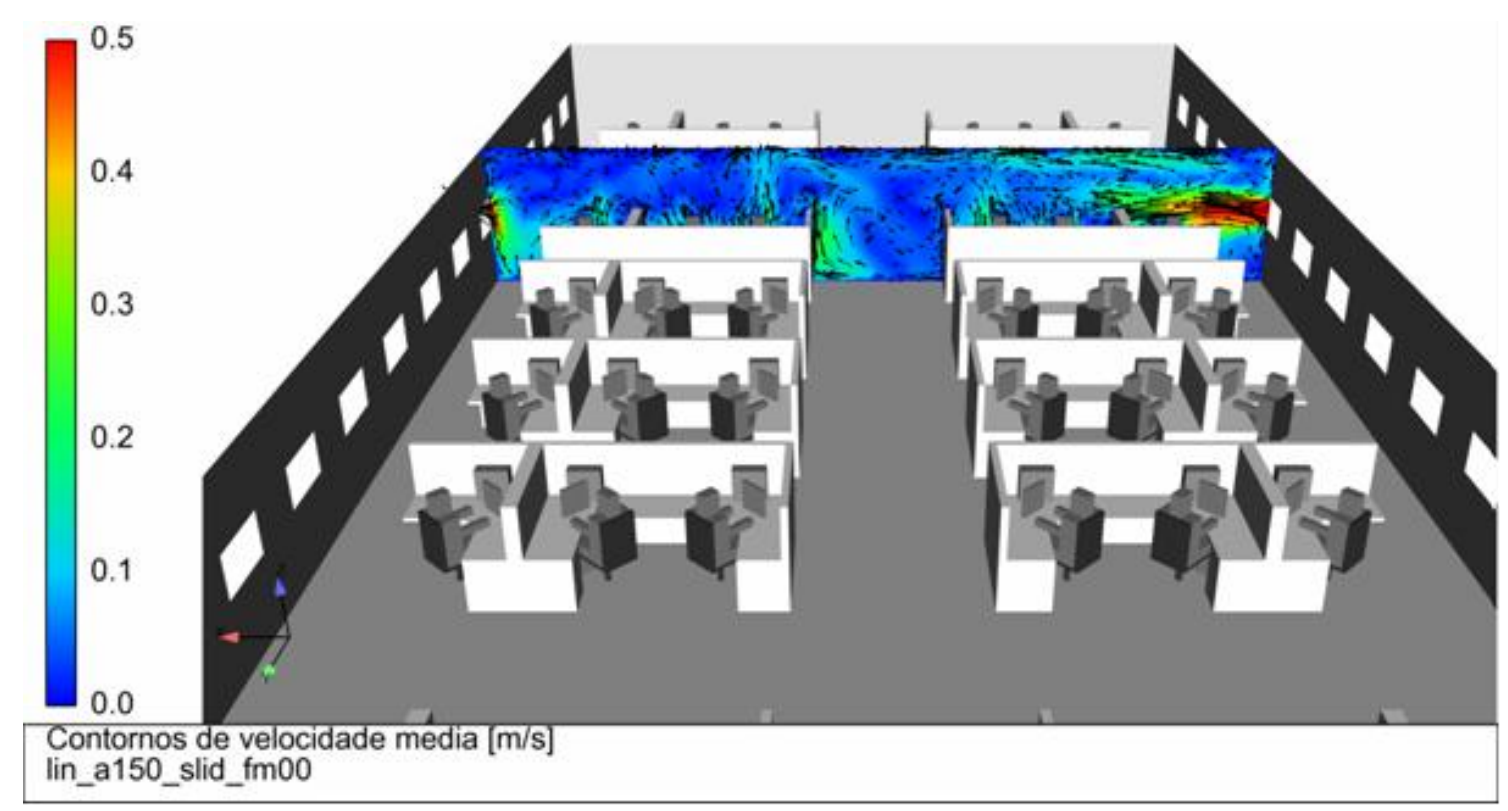

Figura 5.3.6: Plano vertical $y=-13,20 \mathrm{~m}$ colorido por velocidade com os respectivos vetores para o layout quadrado com partições de 1,50m, janelas de correr vertical e velocidade máxima do ar de $2 \mathrm{~m} / \mathrm{s}$. 
As figuras 5.3.7 e 5.3.8 mostram os planos horizontais na altura das cabeças dos ocupantes, onde apenas pequenas mudanças podem ser percebidas. A mudança mais significativa ocorre na área central das figuras, entre as estações de trabalho, região esta que possui menor influência sobre a temperatura do ar para o conforto dos ocupantes.

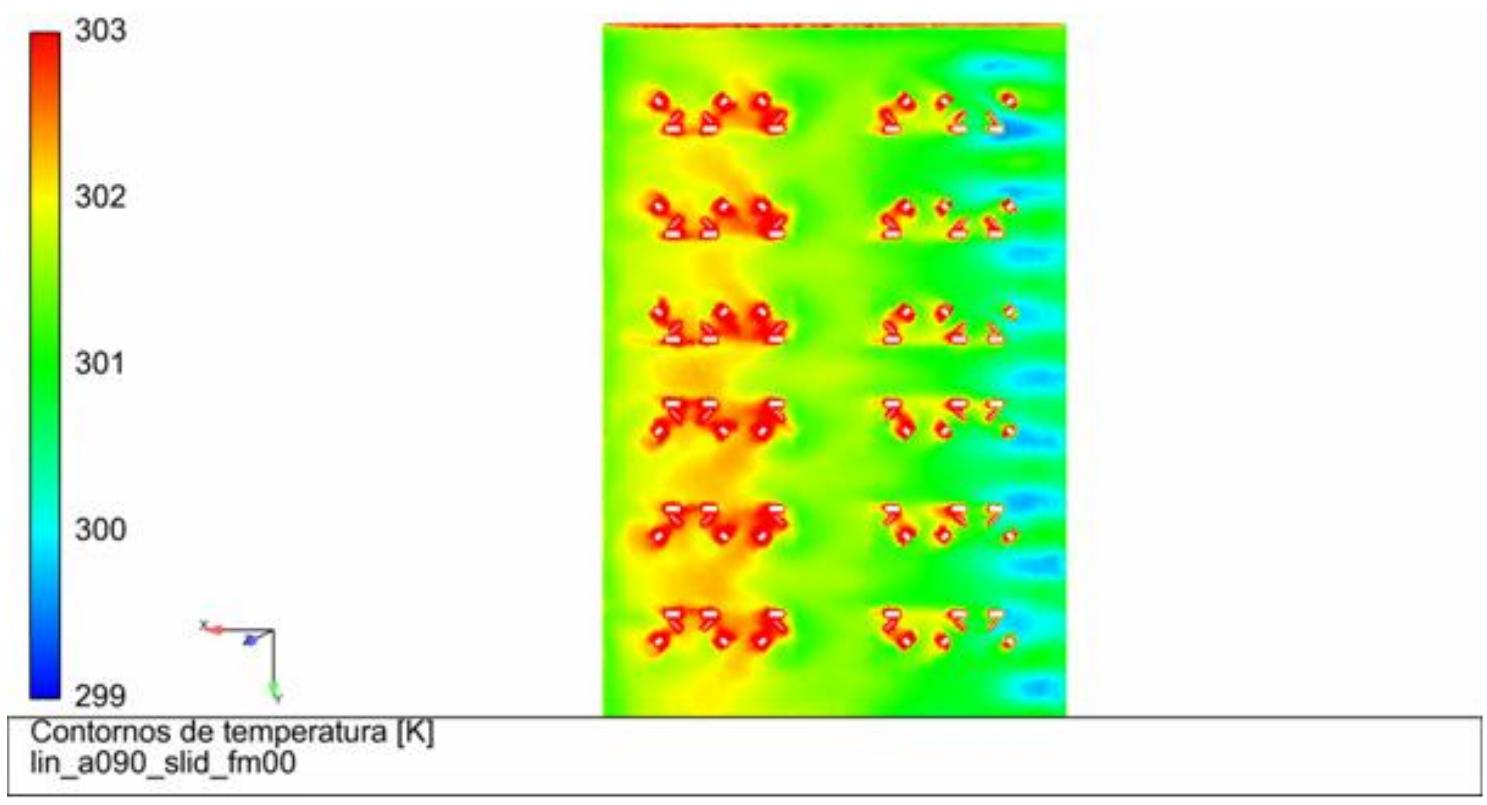

Figura 5.3.7: Plano horizontal $\mathrm{z}=1,10 \mathrm{~m}$ colorido por temperatura para o layout em linha com partições de $0,90 \mathrm{~m}$, janelas de correr vertical e velocidade máxima do ar de $2 \mathrm{~m} / \mathrm{s}$.

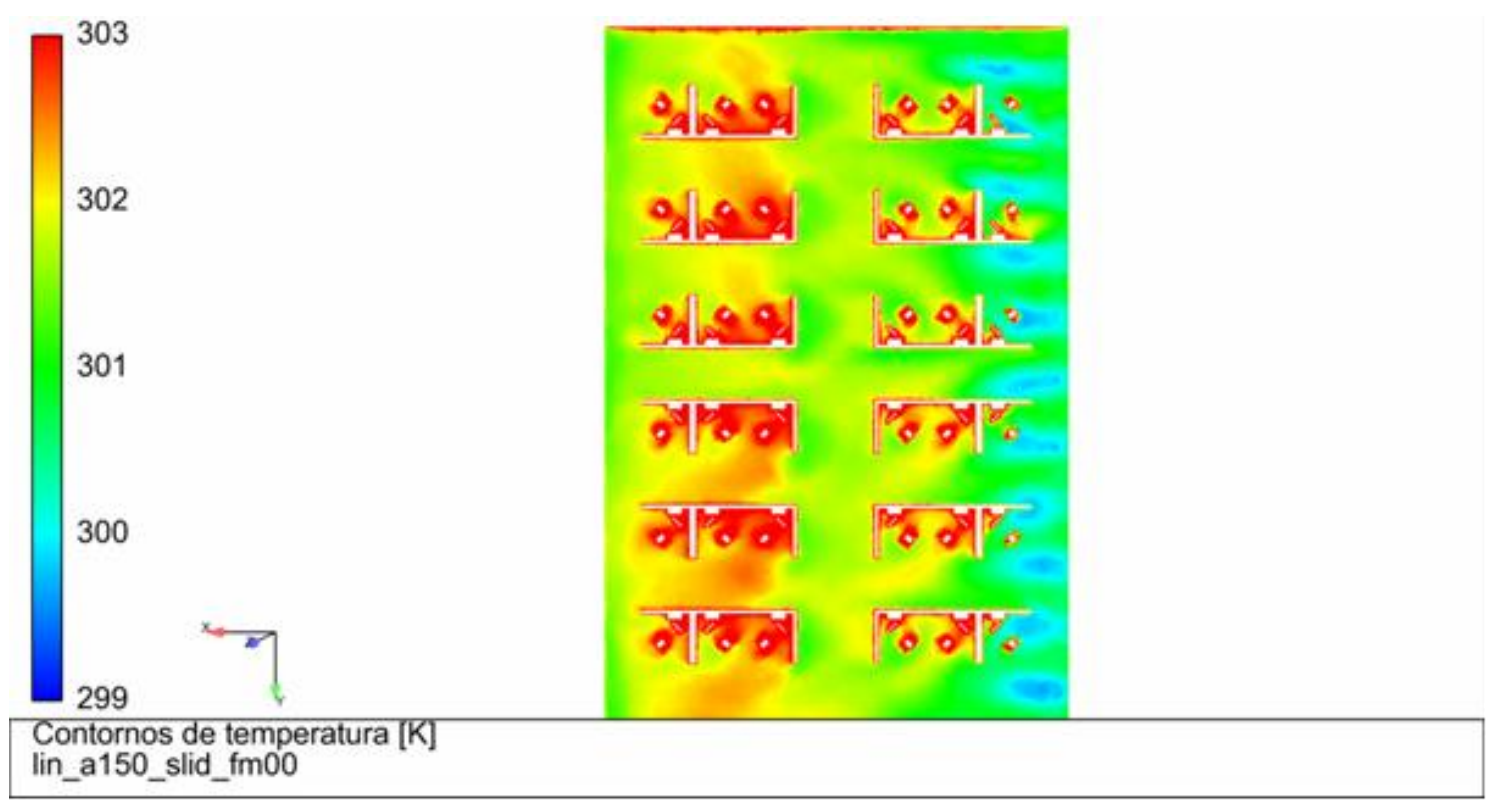

Figura 5.3.8: Plano horizontal $\mathrm{z}=1,10 \mathrm{~m}$ colorido por temperatura para o layout em linha com partições de $1,50 \mathrm{~m}$, janelas de correr vertical e velocidade máxima do ar de $2 \mathrm{~m} / \mathrm{s}$. 
A vazão de ar nos ambientes apresentou comportamentos diferentes para cada análise. No layout quadrado com janelas maxim-ar, por exemplo, verifica-se uma tendência na redução na quantidade de ar que entra nos ambientes com o aumento das divisórias, tanto para velocidade do vento de $2 \mathrm{~m} / \mathrm{s}$ ou $4 \mathrm{~m} / \mathrm{s}$.

Entretanto, como pode ser visto nas tabelas 5.3.7 e 5.3.8, esse comportamento não é repetido em todos os cenários, sendo que o layout em linha com as mesmas janelas apresentou aumento do fluxo de ar com o aumento das partições. Desta maneira, os dados são insuficientes para se concluir de maneira geral que a altura das partições efetivamente modifica a quantidade de ar que entra no ambiente.

Tabela 5.3.7: Vazão mássica de ar através das janelas para velocidade do ar de $2 \mathrm{~m} / \mathrm{s}$.

Vazão de ar nas janelas [kg/s]

\begin{tabular}{c|c|c|c|c|}
\hline \multirow{2}{*}{ Layout } & Geometria das & \multicolumn{3}{|c|}{ Altura das Partições } \\
& Janelas & $\mathbf{0 , 9 0 m}$ & $\mathbf{1 , 1 0 m}$ & $\mathbf{1 , 5 0 m}$ \\
\hline \multirow{2}{*}{ quadrado } & Maxim-ar & 10,69 & 10,63 & 10,38 \\
& De correr vertical & 7,14 & 7,25 & 7,12 \\
\hline \multirow{2}{*}{ linha } & Maxim-ar & 10,44 & 10,48 & 10,47 \\
& De correr vertical & 7,24 & 7,47 & 7,23
\end{tabular}

Tabela 5.3.8: Vazão mássica de ar através das janelas para velocidade do ar de 4m/s.

Vazão de ar nas janelas [kg/s]

\begin{tabular}{c|c|c|c|c|}
\hline \multirow{2}{*}{ Layout } & Geometria das & \multicolumn{3}{|c|}{ Altura das Partiçóes } \\
& Janelas & $\mathbf{0 , 9 0 m}$ & $\mathbf{1 , 1 0 m}$ & $\mathbf{1 , 5 0 m}$ \\
\hline \multirow{2}{*}{ quadrado } & Maxim-ar & 22,91 & 22,55 & 21,96 \\
& De correr vertical & 14,34 & 14,56 & 14,26 \\
\hline \multirow{2}{*}{ linha } & Maxim-ar & 22,24 & 22,46 & 22,61 \\
& De correr vertical & 14,59 & 15,03 & 14,71
\end{tabular}




\subsection{VARIAÇÃO DO LAYOUT}

A mudança do layout de quadrado para em linha em pouco modificou a temperatura média do ar do ambiente ocupado, como mostram os resultados das tabelas 5.3.1 e 5.3.2. Uma vez mais, as diferenças de temperatura, quando observadas, foram de apenas $0,1 \mathrm{~K}$ ou $0,2 \mathrm{~K}$, algo que não torna possível garantir uma melhora nas condições ambientais de um modo geral.

Entretanto, quando utilizadas as partições de 1,50m com as janelas de correr vertical sob ação dos ventos mais fracos, a utilização do layout em linha fez com a temperatura média do ar tivesse uma queda de $0,4 \mathrm{~K}$. Considerando os ventos mais fortes, verifica-se que esta configuração traz diferença de apenas $0,2 \mathrm{~K}$, de modo que aparentemente a mudança de layout é mais sensível para velocidades do vento mais baixas.

Com os ventos mais amenos, verifica-se das tabelas 5.3.3 e 5.3.4 que a mudança de layout não implicou em uma mudança da estratificação da temperatura, sendo as diferenças obtidas de no máximo $0,1 \mathrm{~K}$. Mesmo na configuração onde foi obtida a maior diferença de temperatura do ar, a diferença da estratificação de temperaturas foi nula, de forma a tornar impossível obter alguma indicação de influência do layout neste parâmetro.

Se a diferença foi de apenas $0,1 \mathrm{~K}$ para as simulações com velocidade do vento máxima de $2 \mathrm{~m} / \mathrm{s}$, quando utilizada a velocidade mais intensa a estratificação de temperatura é rigorosamente igual, reforçando a hipótese de que não é possível apontar uma influência do layout sobre a estratificação de temperaturas.

Analisando mais dados dos ambientes com maior diferença de temperatura do ar, verifica-se que na utilização do layout quadrado houve aumento da temperatura em todos os planos de medição, como pode ser visto na tabela 5.4.1. Entretanto, mais uma vez a maior diferença deu-se no plano das cabeças, onde a diferença de temperatura foi de $0,6 \mathrm{~K}$, o dobro dos outros planos de medição.

Para ilustrar essa diferença de temperaturas, é possível observar as figuras $5.4 .1 \mathrm{e}$ 5.4.2, que apresentam planos verticais de temperatura para estes ambientes. A primeira diferença destacada encontra-se da região próxima à estação de trabalho da direita das imagens, junto da entrada de ar externo. No layout quadrado, verifica-se uma pequena região azulada, de temperaturas mais baixas, que não existe na outra configuração, de forma que certa quantidade de ar está deixando de retirar carga térmica do ambiente. Como consequência, verifica-se um aumento da região vermelha ao redor do ocupante no layout quadrado. 
Tabela 5.4.1: Temperaturas médias, mínimas e máximas do ar nos três planos de medição para as configurações com janelas de correr vertical, alturas das partições de $1,50 \mathrm{~m}$ e velocidade máxima do ar de $2 \mathrm{~m} / \mathrm{s}$.

\begin{tabular}{|c|c|c|c|c|c|}
\hline & I avout & & o de me & & Tatol \\
\hline & Tayout & $0,10 \mathrm{~m}$ & $0,60 \mathrm{~m}$ & $1,10 \mathrm{~m}$ & Totat \\
\hline Temperaturas & quadrado & 302,1 & 302,0 & 303,0 & 302,4 \\
\hline$[\mathbf{K}]$ & linha & 301,8 & 301,7 & 302,4 & 302,0 \\
\hline Temperaturas & quadrado & 301,2 & 300,9 & 302,0 & 301,4 \\
\hline$[\mathbf{K}]$ & linha & 300,8 & 300,3 & 300,3 & 300,6 \\
\hline Temperaturas & quadrado & 302,8 & 302,9 & 304,0 & 303,1 \\
\hline$[\mathbf{K}]$ & linha & 302,5 & 302,7 & 303,4 & 302,8 \\
\hline
\end{tabular}

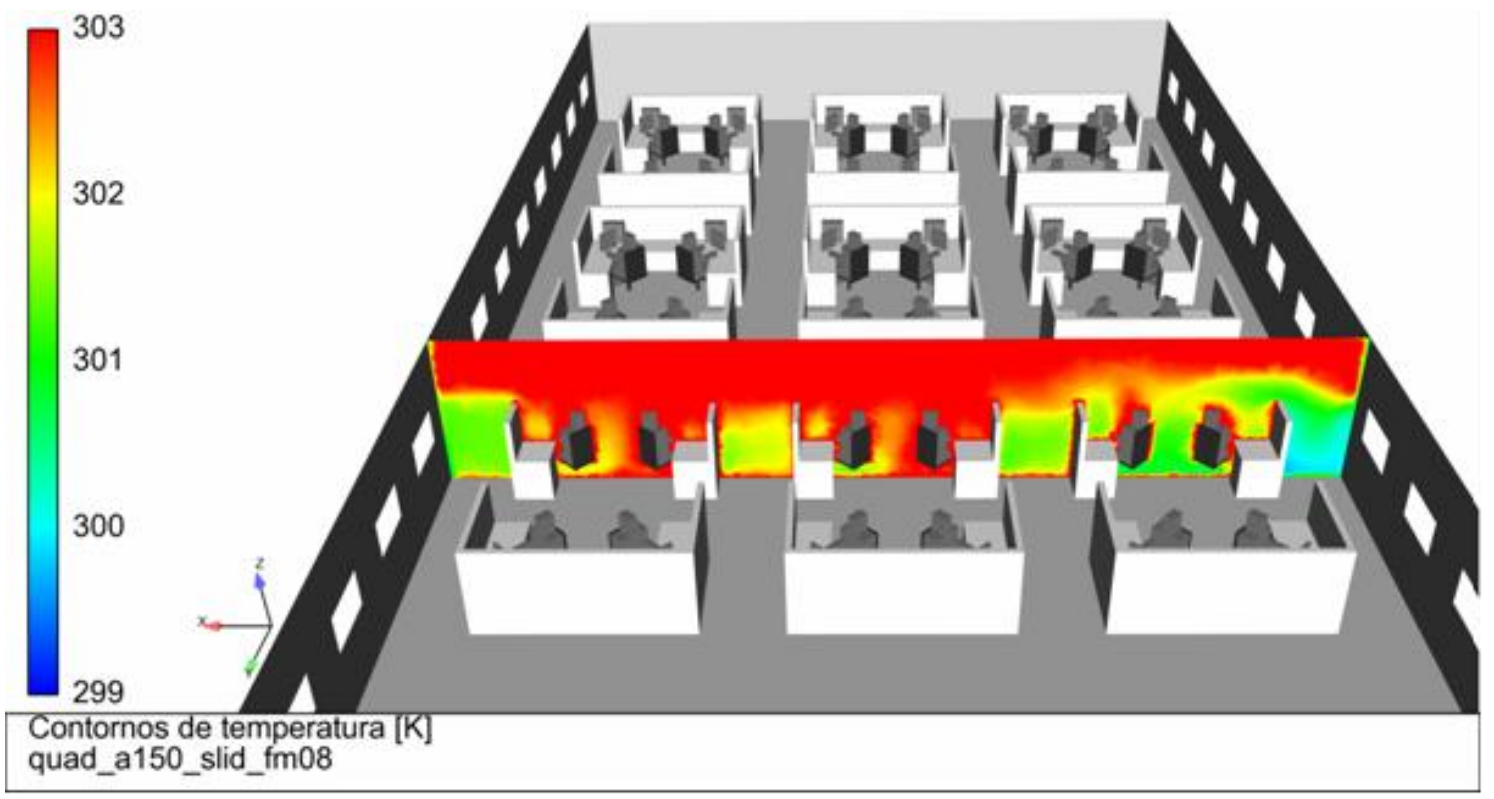

Figura 5.4.1: Plano vertical y $=-06,00 \mathrm{~m}$ colorido por temperatura para o layout quadrado com partições de $1,50 \mathrm{~m}$, janelas de correr vertical e velocidade máxima do ar de $2 \mathrm{~m} / \mathrm{s}$. 


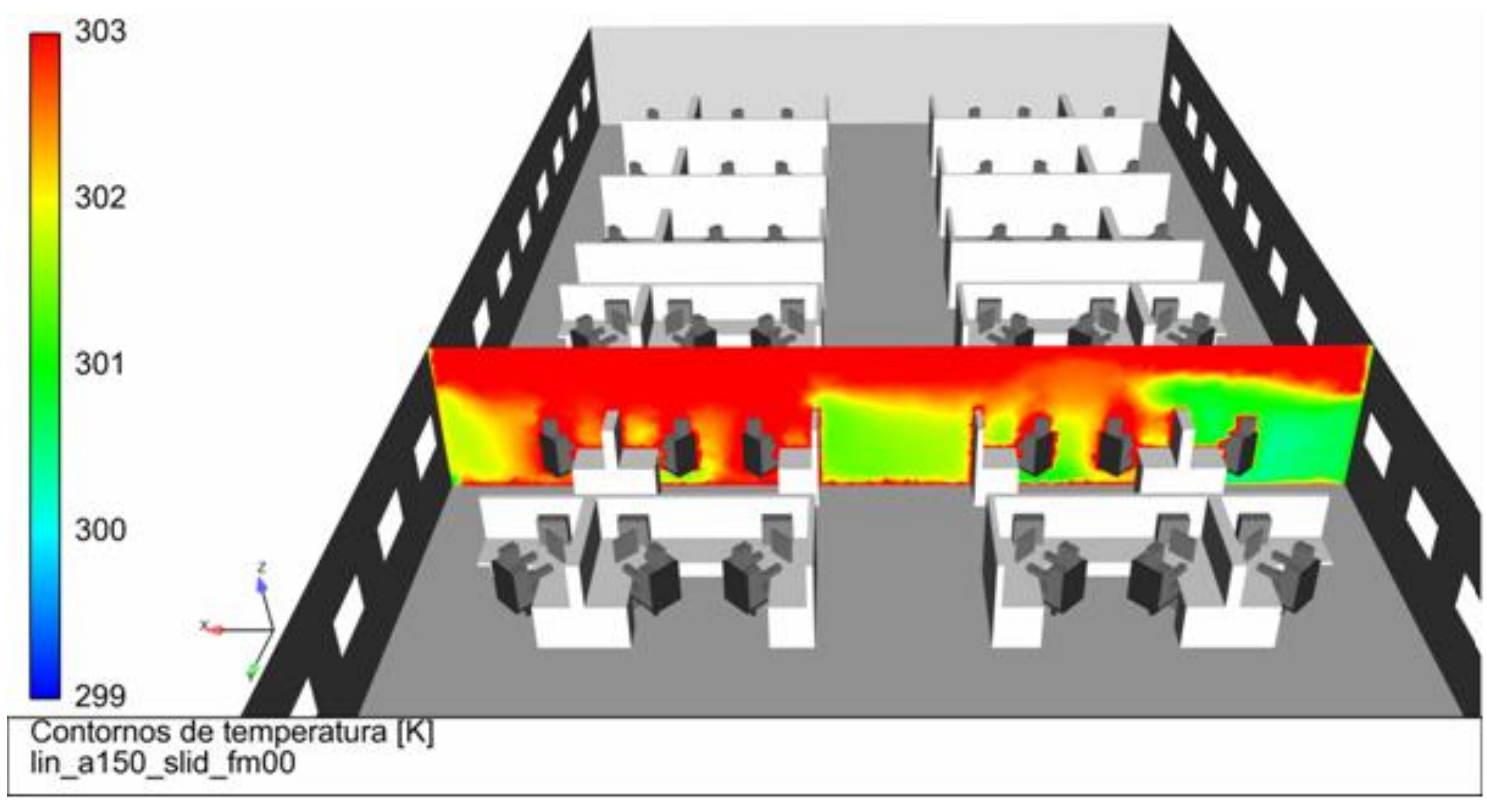

Figura 5.4.2: Plano vertical y = -05,90m colorido por temperatura para o layout em linha com partições de $1,50 \mathrm{~m}$, janelas de correr vertical e velocidade máxima do ar de $2 \mathrm{~m} / \mathrm{s}$.

A segunda diferença pode ser observada próxima à estação de trabalho localizada na esquerda da figura, junto da janela de saída do ar. Nela, o layout em linha apresenta temperaturas do ar mais altas devido à retirada de carga térmica mais fácil do ambiente. No layout quadrado, o ar quente deve subir e somente após os 1,50m de altura da partição é possível ser deslocado para fora do ambiente. Contudo, como no layout em linha não há partição separando o ocupante da janela, o fluxo de ar ocorre de maneira mais fácil, melhorando as condições térmicas do ambiente.

Outra estação de trabalho que merece destaque é a terceira da direita para a esquerda, onde se verifica no layout quadrado uma grande região vermelha ao redor do ocupante, enquanto que no outro cenário a região de altas temperaturas é bem mais restrita. Como resultado, as temperaturas médias nos planos de medição tornam-se bem menores, como mostra a tabela 5.4.2.

Tabela 5.4.2: Temperaturas médias, mínimas e máximas do ar nos três planos de medição para a terceira fileira dos escritórios com janelas de correr vertical, alturas das partições de 1,50m e velocidade máxima do ar de $2 \mathrm{~m} / \mathrm{s}$.

\begin{tabular}{c|c|c|c|c|c} 
& Layout & \multicolumn{2}{|c|}{ Plano de medição } & Total \\
& quadrado & 302,5 & 302,8 & 303,5 & 302,9 \\
$\begin{array}{c}\text { Temperaturas } \\
\text { MK] }\end{array}$ & linha & 301,4 & 301,1 & 302,4 & 301,7
\end{tabular}


Estes valores da tabela 5.4.2 podem ser visualizados graficamente com as figuras 5.4.3 e 5.4.4, onde pode ser visto nitidamente a maior temperatura do ar para o layout quadrado. É interessante ressaltar que uma diferença significativa, embora não tão grande, também é obtida para a fileira localizada à montante do escritório, como mostram a tabela 5.4 .3 e as figuras 5.4.5 e 5.4.6.

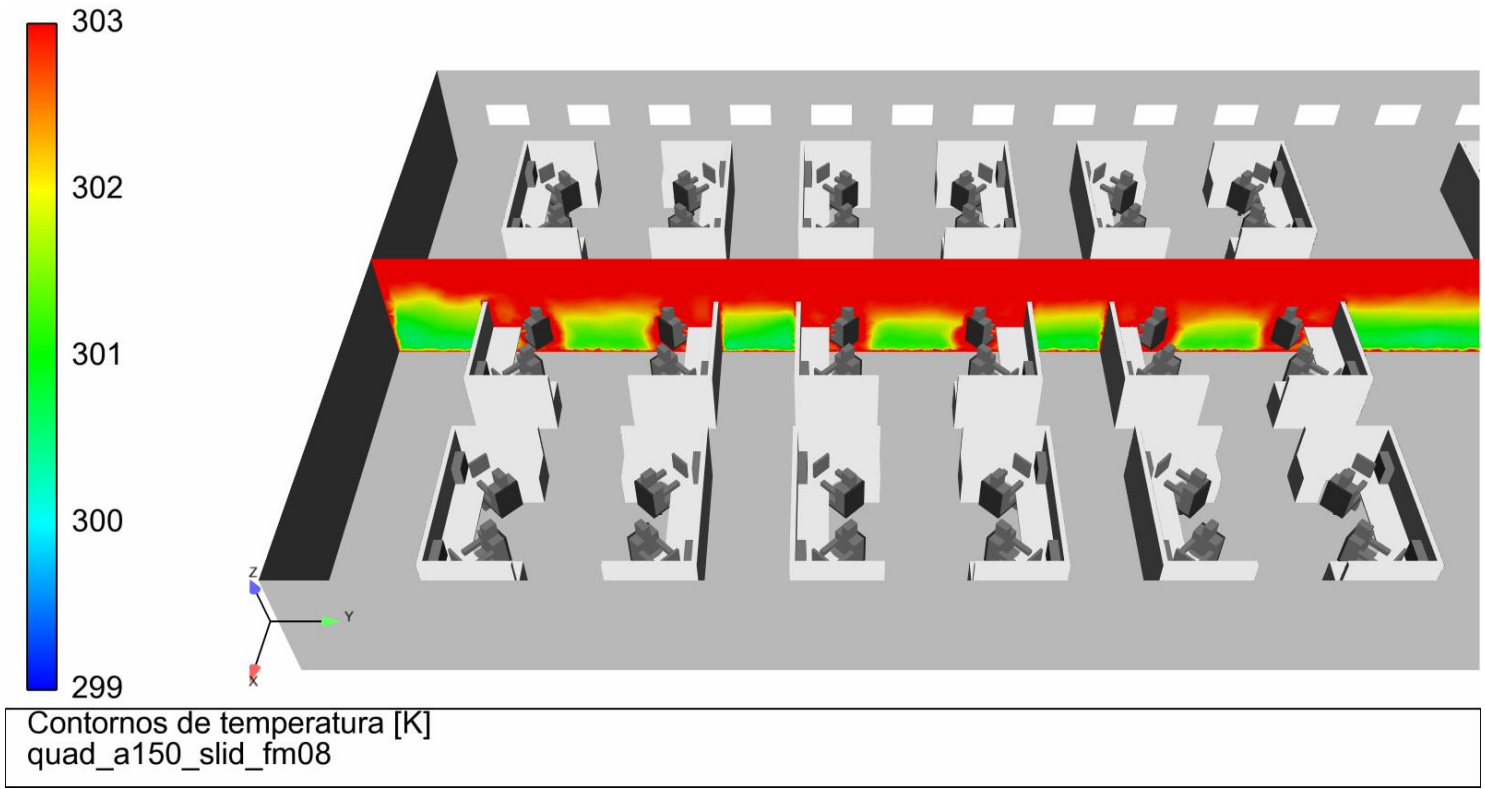

Figura 5.4.3: Plano vertical $\mathrm{x}=06,90 \mathrm{~m}$ colorido por temperatura para o layout quadrado com partições de $1,50 \mathrm{~m}$, janelas de correr vertical e velocidade máxima do ar de $2 \mathrm{~m} / \mathrm{s}$.

Figura 5.4.4: Plano vertical $\mathrm{x}=05,15 \mathrm{~m}$ colorido por temperatura para o layout $\mathrm{em}$ linha com partições de $1,50 \mathrm{~m}$, janelas de correr vertical e velocidade máxima do ar de $2 \mathrm{~m} / \mathrm{s}$. 
Tabela 5.4.3: Temperaturas médias, mínimas e máximas do ar nos três planos de medição para a primeira fileira dos escritórios com janelas de correr vertical, alturas das partições de $1,50 \mathrm{~m}$ e velocidade máxima do ar de $2 \mathrm{~m} / \mathrm{s}$.

\begin{tabular}{c|c|c|c|c|c} 
& \multirow{2}{*}{ Layout } & \multicolumn{3}{|c|}{ Plano de medição } & \multirow{2}{*}{ Total } \\
\hline $\begin{array}{c}\text { Temperaturas } \\
\text { Médias } \\
{[\text { [K] }}\end{array}$ & quadrado & 301,5 & 301,3 & 302,3 & 301,7 \\
& linha & 301,2 & 300,8 & 300,7 & 300,9
\end{tabular}

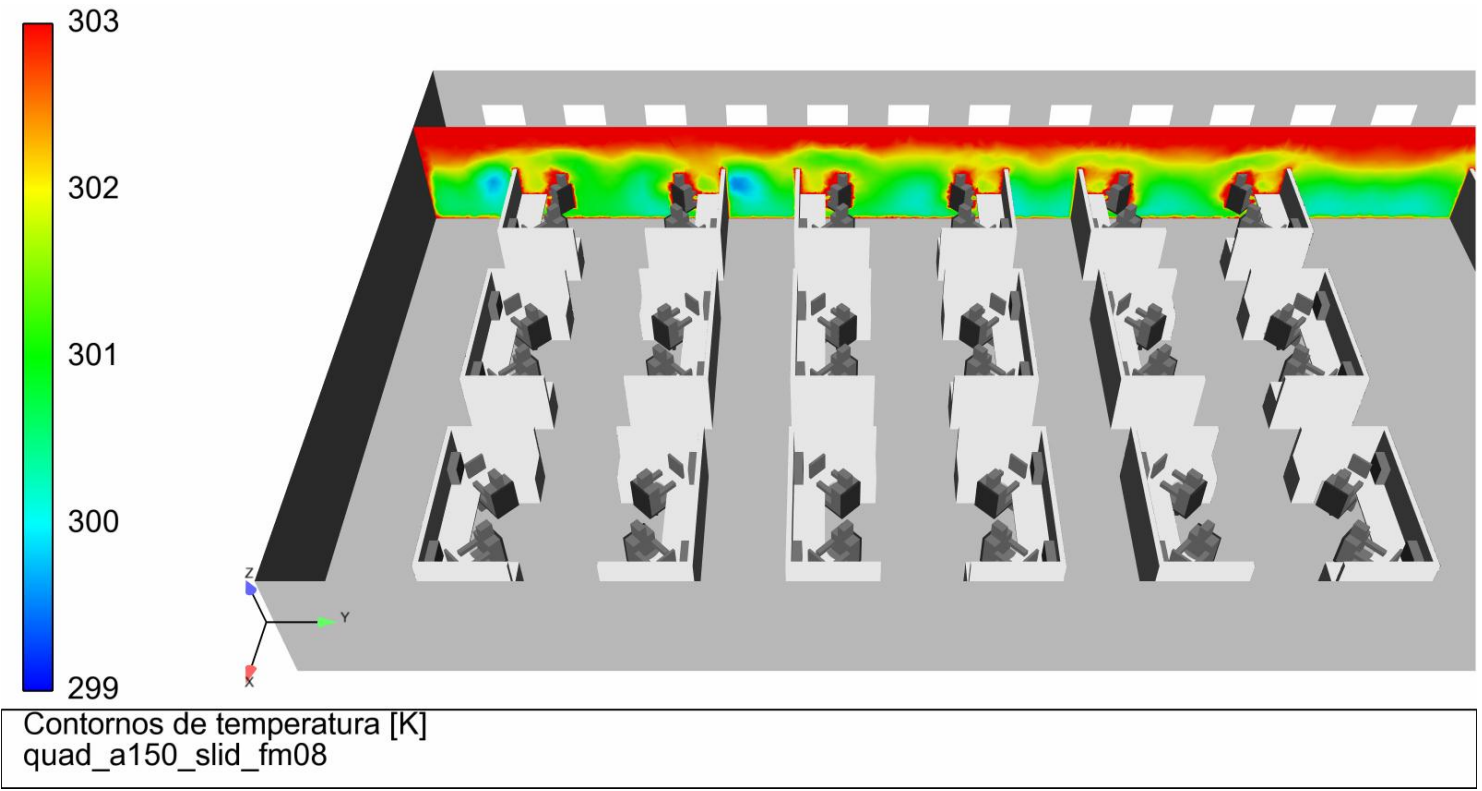

Figura 5.4.5: Plano vertical $\mathrm{x}=02,30 \mathrm{~m}$ colorido por temperatura para o layout quadrado com partições de $1,50 \mathrm{~m}$, janelas de correr vertical e velocidade máxima do ar de $2 \mathrm{~m} / \mathrm{s}$.

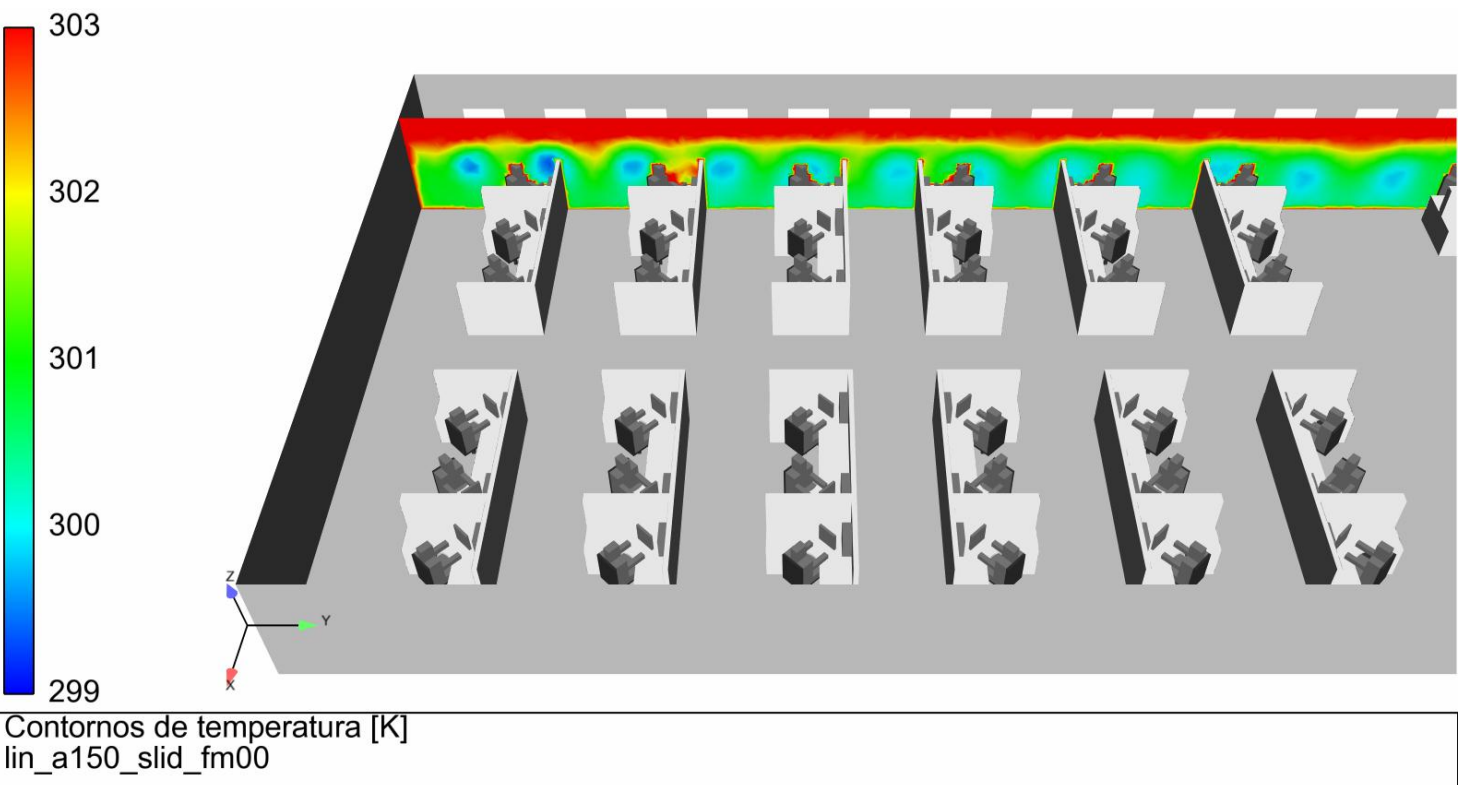

Figura 5.4.6: Plano vertical $\mathrm{x}=01,80 \mathrm{~m}$ colorido por temperatura para o layout $\mathrm{em}$ linha com partições de 1,50m, janelas de correr vertical e velocidade máxima do ar de $2 \mathrm{~m} / \mathrm{s}$. 
As estações de trabalho mais próximas das janelas, onde se verificam diferenças no campo de temperaturas, também apresentam diferenças no campo de velocidades. Como pode ser visto nas figuras 5.4.7 e 5.4.8, o ocupante da estação de trabalho à montante no escritório recebe diretamente o fluxo de ar exterior no layout em linha, não ocorrendo o mesmo no layout quadrado, devido à altura das partições. Verifica-se que, apesar da incidência direta, não são percebidas velocidades maiores do que $0,5 \mathrm{~m} / \mathrm{s}$ na região da superfície de trabalho, o que poderia acarretar desconforto do ocupante.

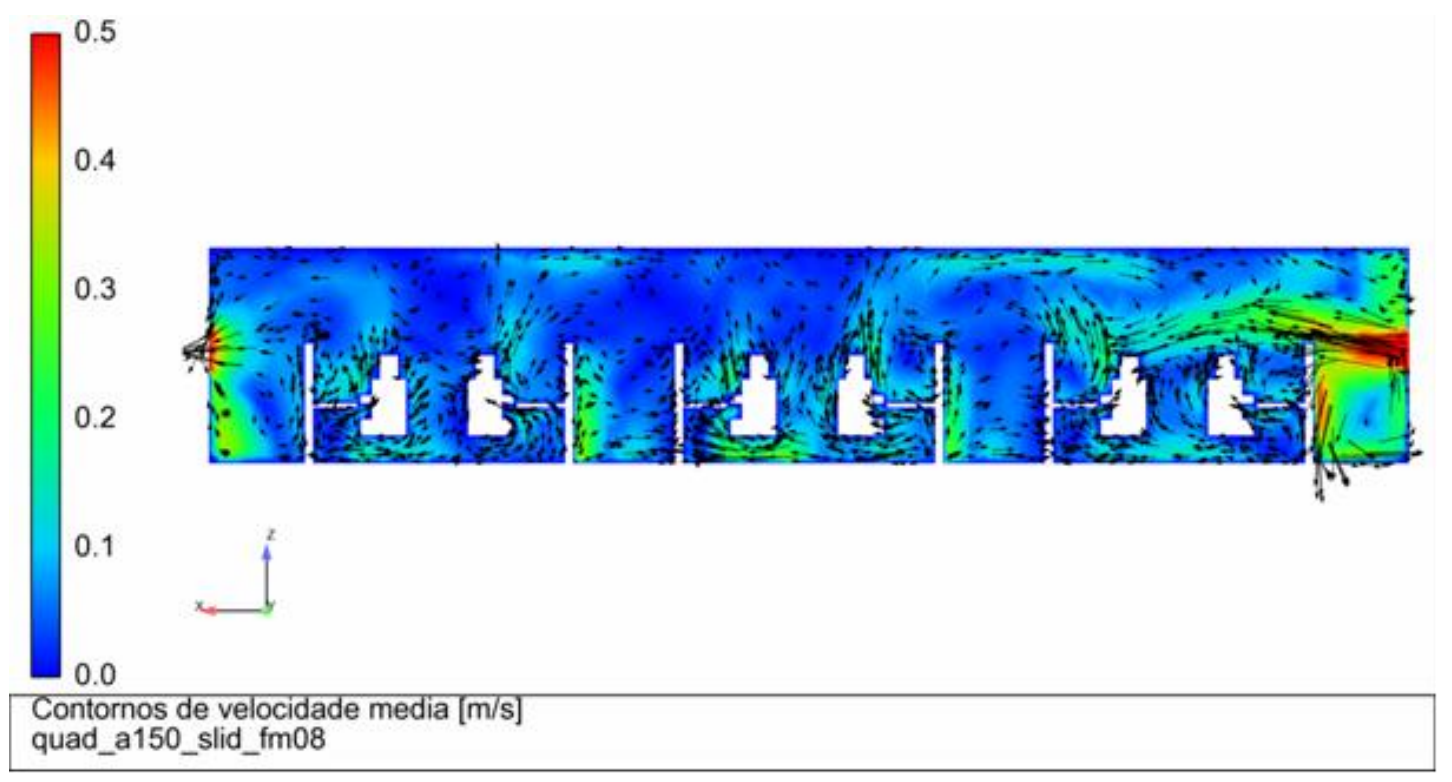

Figura 5.4.7: Plano vertical y $=-12,65 \mathrm{~m}$ colorido por velocidade com os respectivos vetores para o layout quadrado com partições de $1,50 \mathrm{~m}$, janelas de correr vertical e velocidade máxima do ar de $2 \mathrm{~m} / \mathrm{s}$.

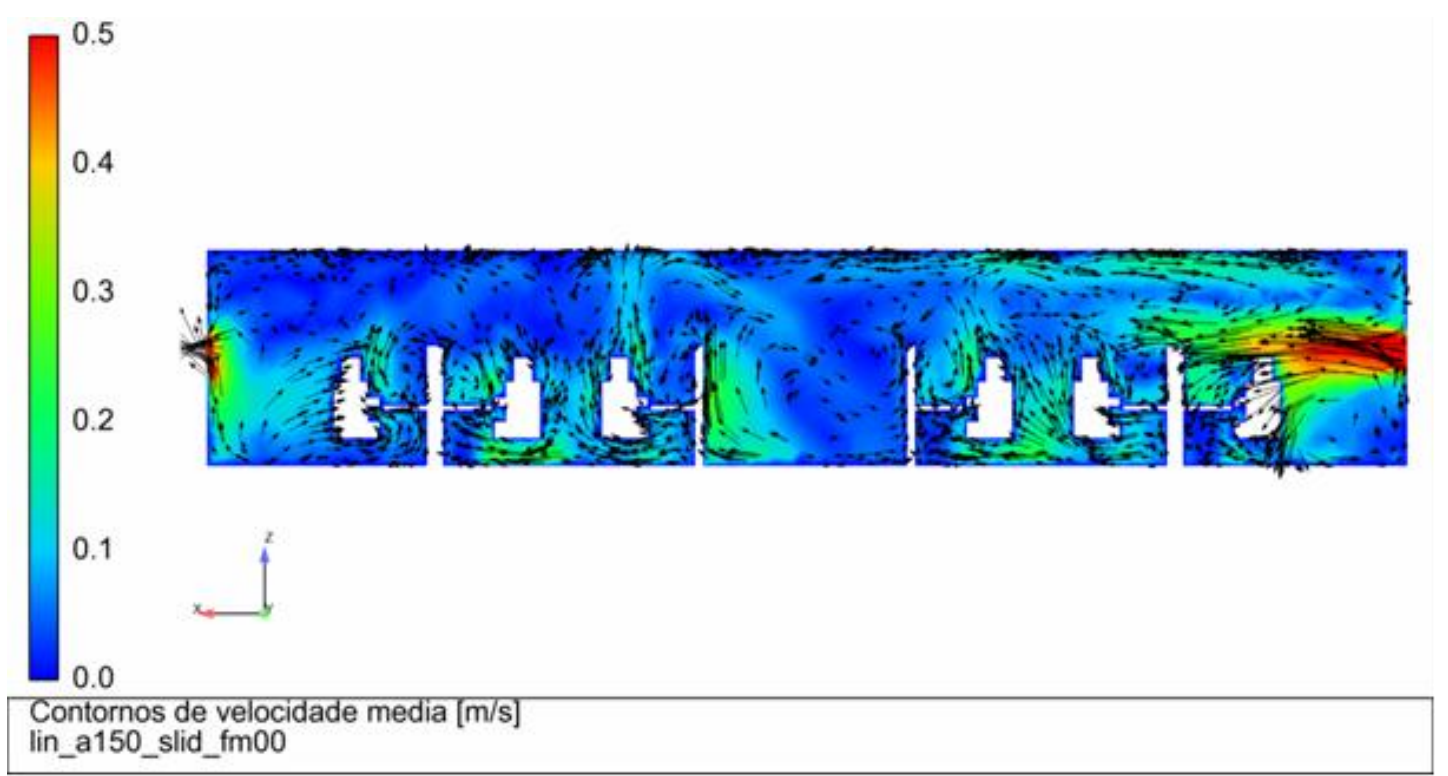

Figura 5.4.8: Plano vertical y $=-13,20 \mathrm{~m}$ colorido por velocidade com os respectivos vetores para o layout em linha com partições de $1,50 \mathrm{~m}$, janelas de correr vertical e velocidade máxima do ar de $2 \mathrm{~m} / \mathrm{s}$. 
Além disso, verifica-se também como o acesso direto da janela para o ocupante à jusante facilita o fluxo de ar no layout em linha. Desta forma, o ar não precisa dar a volta pela partição antes de sair do escritório, como ocorre no layout quadrado.

É interessante verificar que ao se utilizar as janelas maxim-ar e velocidades do vento mais intensas as diferenças tornam-se menores, como mostram as figuras 5.4.9 e 5.4.10. Com estas configurações, a entrada de ar mais intensa faz com que exista boa condição de convecção forçada para os ocupantes à montante do escritório, reduzindo a importância da incidência direta. Além disso, verifica-se nas estações à jusante que a intensidade da velocidade do ar é semelhante, reduzindo assim a necessidade do acesso direto à janela.

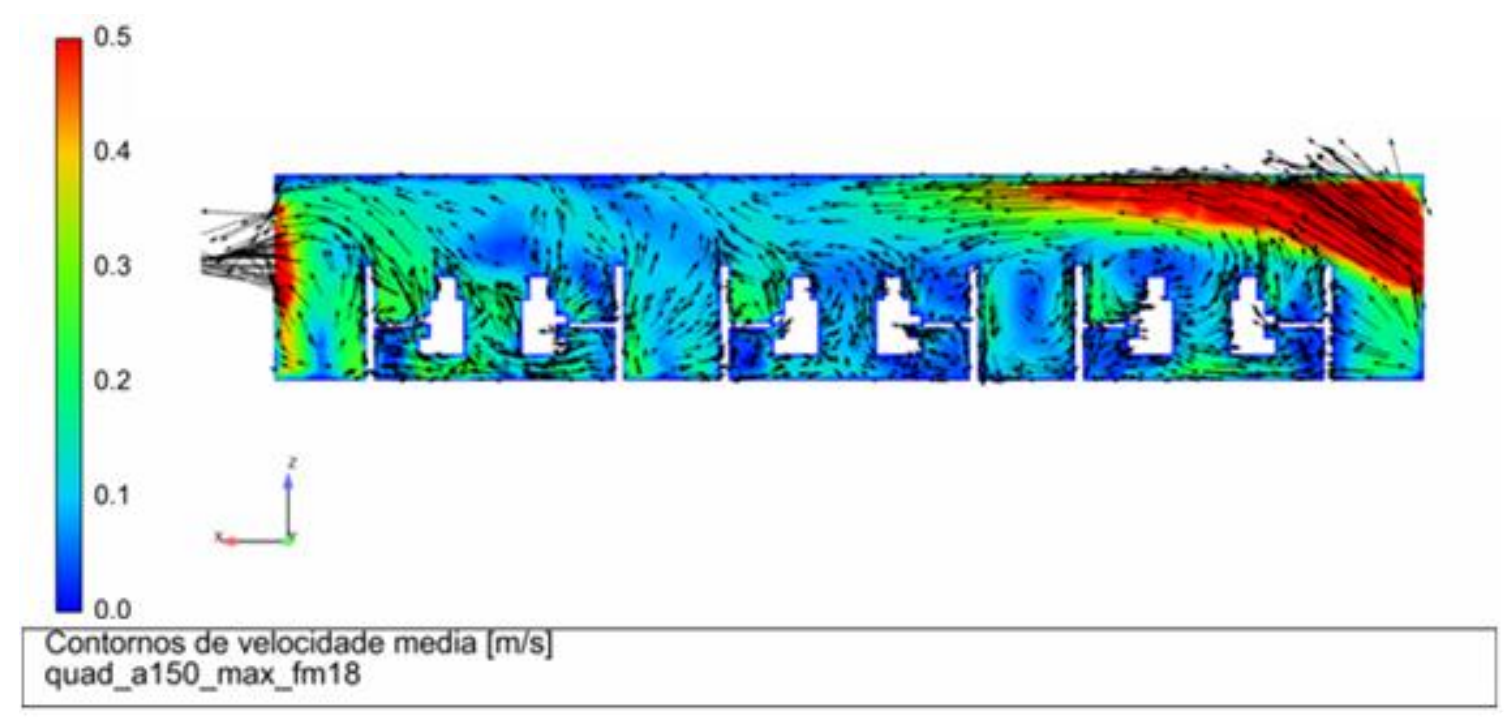

Figura 5.4.9: Plano vertical $y=-13,20 \mathrm{~m}$ colorido por velocidade com os respectivos vetores para o layout quadrado com partições de 1,50m, janelas maxim-ar e velocidade máxima do ar de $4 \mathrm{~m} / \mathrm{s}$.

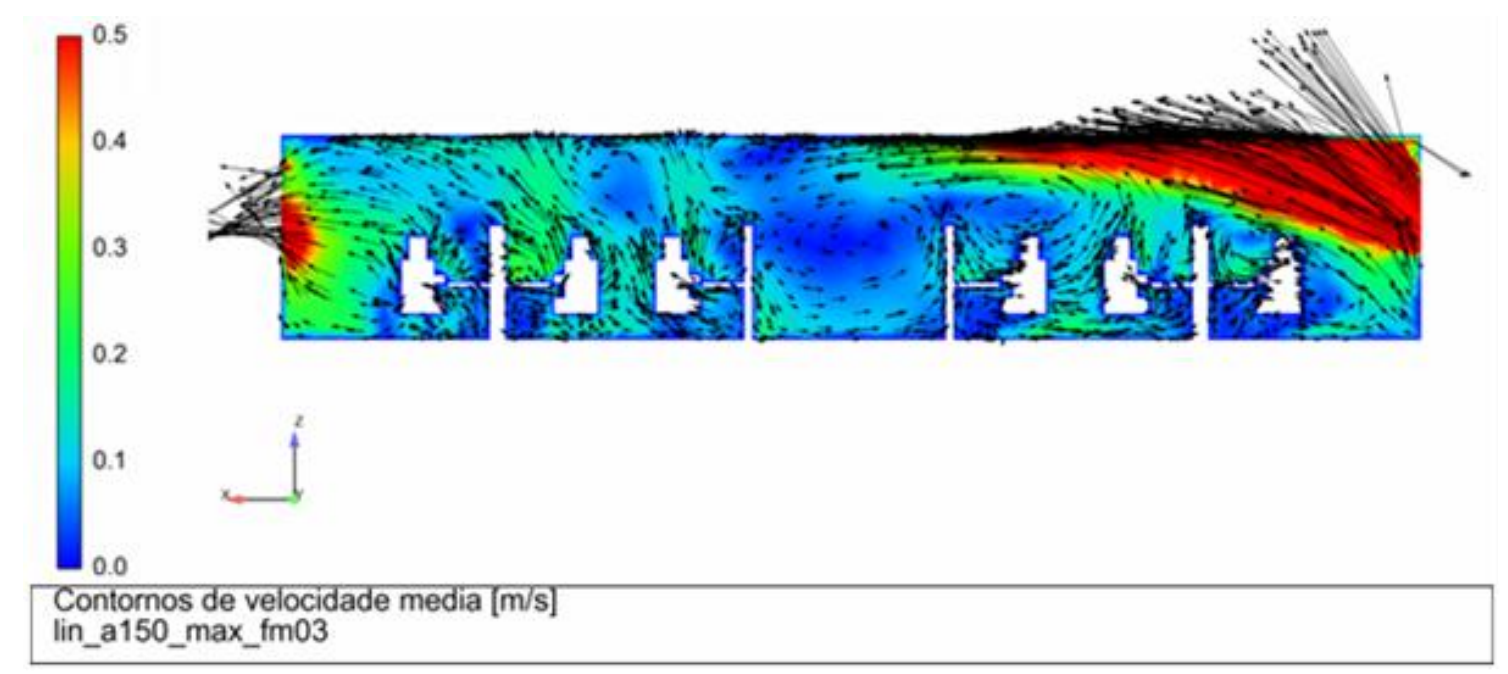

Figura 5.4.10: Plano vertical y $=-13,20 \mathrm{~m}$ colorido por velocidade com os respectivos vetores para o layout em linha com partições de 1,50m, janelas maxim-ar e velocidade máxima do ar de $4 \mathrm{~m} / \mathrm{s}$. 
Essa maior semelhança no campo de velocidades reflete-se também no campo de temperaturas dos escritórios. Como pode ser visto nas figuras 5.4.11 e 5.4.12, as condições de temperatura tornam-se semelhantes mesmo em locais críticos da análise dos ambientes anteriores, no caso a terceira fileira de estações de trabalho.

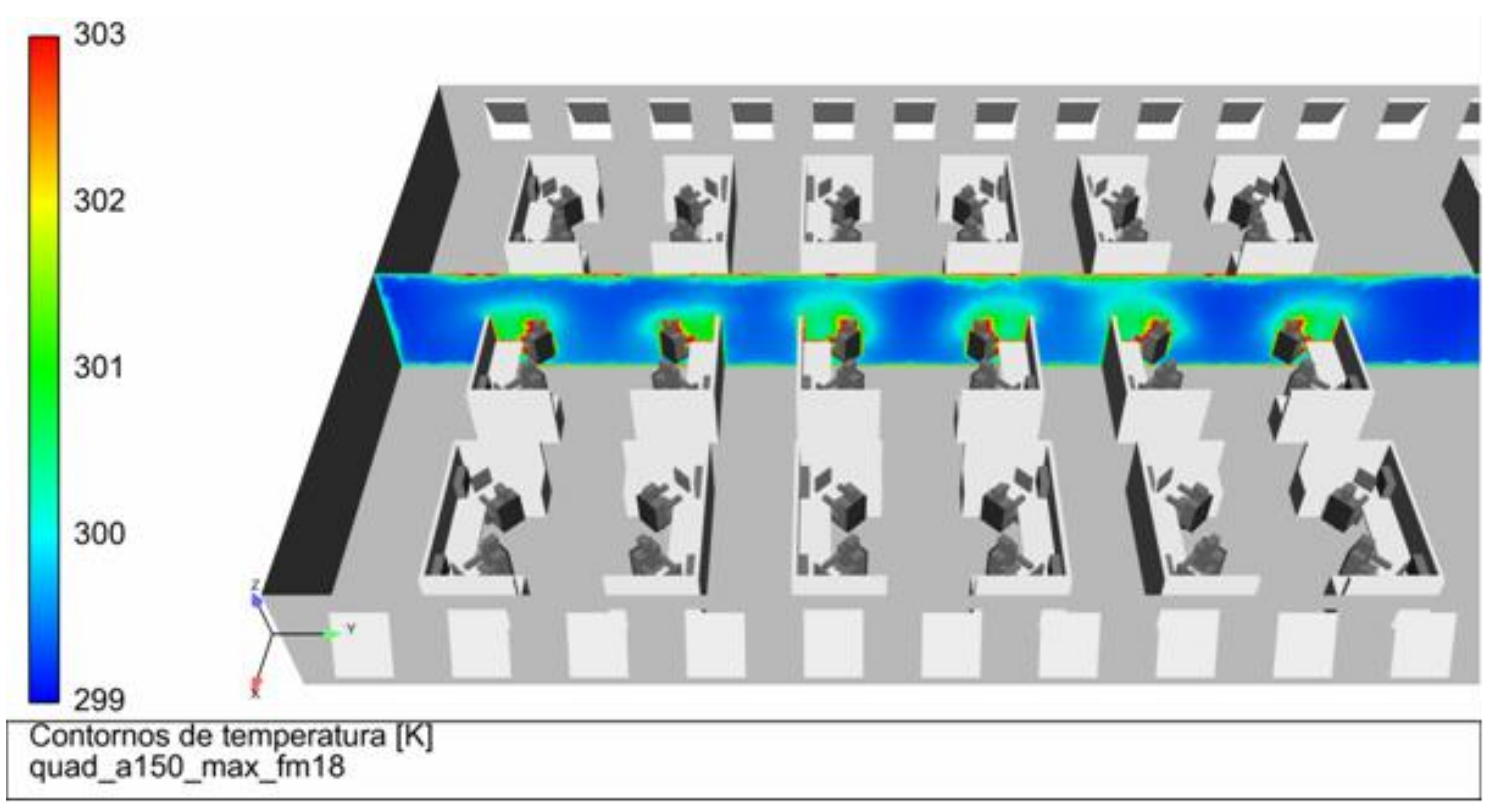

Figura 5.4.11: Plano vertical $\mathrm{x}=06,90 \mathrm{~m}$ colorido por temperatura para o layout quadrado com partições de 1,50m, janelas maxim-ar e velocidade máxima do ar de $4 \mathrm{~m} / \mathrm{s}$.

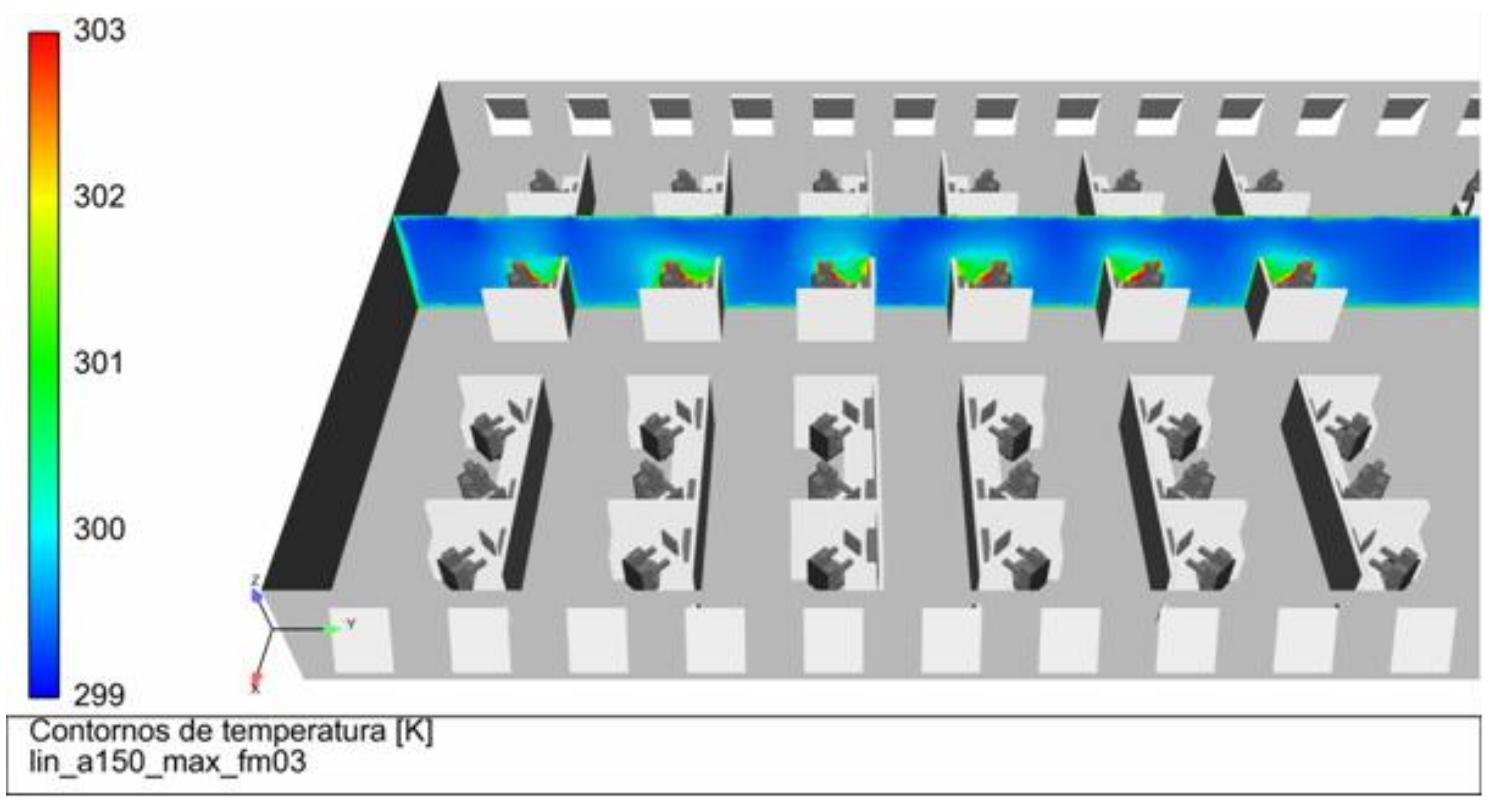

Figura 5.4.12: Plano vertical $\mathrm{x}=05,15 \mathrm{~m}$ colorido por temperatura para o layout $\mathrm{em}$ linha com partições de 1,50m, janelas maxim-ar e velocidade máxima do ar de $4 \mathrm{~m} / \mathrm{s}$. 
A tabela 5.4.4 mostra que os valores médios de temperatura do ar para esta fileira variaram apenas $0,1 \mathrm{~K}$, apesar da existência de variações maiores entre os planos de medida. Além disso, a tabela 5.4.5 apresenta dados consolidados de temperaturas avaliadas em cada um dos planos de medição.

Tabela 5.4.4: Temperaturas médias, mínimas e máximas do ar nos três planos de medição para a terceira fileira dos escritórios com janelas maxim-ar, alturas das partições de 1,50m e velocidade máxima do ar de 4m/s.

\begin{tabular}{c|c|c|c|c} 
& Layout & \multicolumn{3}{|c}{ Plano de medição } \\
& quadrado & 300,4 & 299,9 & 301,0 \\
$\begin{array}{c}\text { Temperaturas } \\
\text { Médias } \\
{[\mathbf{K K}]}\end{array}$ & linha & 300,7 & 300,4 & 300,5 \\
\hline $\begin{array}{c}\text { Temperaturas } \\
\text { Mínimas } \\
{[\mathbf{K}]}\end{array}$ & quadrado & 300,3 & 299,8 & 300,8 \\
\hline $\begin{array}{c}\text { Temperaturas } \\
\text { Máximas } \\
{[\mathbf{[ K}]}\end{array}$ & linha & 300,5 & 300,0 & 300,3 \\
\hline
\end{tabular}

Tabela 5.4.5: Temperaturas médias, mínimas e máximas do ar nos três planos de medição para as configurações com janelas maxim-ar, alturas das partições de 1,50m e velocidade máxima do ar de $4 \mathrm{~m} / \mathrm{s}$.

\begin{tabular}{c|c|c|c|c} 
& \multirow{2}{*}{ Layout } & \multicolumn{3}{|c}{ Plano de medição } \\
& quadrado & 300,4 & 300,0 & 300,6 \\
$\begin{array}{c}\text { Temperaturas } \\
\text { Médias } \\
{[\mathbf{K}]}\end{array}$ & linha & 300,4 & 300,2 & 300,6 \\
\hline $\begin{array}{c}\text { Temperaturas } \\
\text { Mínimas } \\
{[\mathbf{K}]}\end{array}$ & quadrado & 300,0 & 299,6 & 300,0 \\
\hline $\begin{array}{c}\text { Temperaturas } \\
\text { Máximas } \\
\text { [K] }\end{array}$ & quadrado & 300,9 & 300,8 & 301,1 \\
& linha & 301,1 & 300,8 & 301,4
\end{tabular}

A vazão de ar não segue uma tendência clara de modificação em função do layout adotado, como pode ser visto nas tabelas 5.3.7 e 5.3.8. Por exemplo, quando as janelas adotadas são a de correr vertical, em todos os casos o layout em linha apresentou um fluxo maior de ar entrando no ambiente, sendo este valor de 1,4\% a 3,2\% maior de acordo com o 
cenário analisado. Entretanto, quando as janelas maxim-ar são empregadas, existem mudanças de comportamento de acordo com a altura da partição utilizada.

Para as alturas de $0,90 \mathrm{~m}$ e $1,10 \mathrm{~m}$, o layout quadrado apresentou vazões de ar de 0,4\% a 2,9\% maiores, sendo este cenário revertido para as partições de $1,50 \mathrm{~m}$, onde o layout quadrado apresentou resultados de $0,9 \%$ e 3,0\% maiores. Desta forma, não foi possível obter uma tendência de mudança no fluxo de ar em função da mudança do layout do escritório.

\subsection{VARIAÇÃO DA GEOMETRIA DAS ABERTURAS}

A variação da geometria das janelas causou efeitos bem mais significativos sobre as condições térmicas dos escritórios. Como pode ser visto nas tabelas 5.3.1 e 5.3.2, em todos os casos analisados a utilização de janelas de correr vertical causou um aumento da temperatura média do ar. Estas variações de temperatura foram de $0,1 \mathrm{~K}$, para dois casos, até $1,2 \mathrm{~K}$ para o caso mais significativo, uma vez mais a configuração com layout quadrado, janelas de correr vertical, partições com $1,50 \mathrm{~m}$ de altura e velocidade máxima do ar de $2 \mathrm{~m} / \mathrm{s}$.

Das variações descritas, ressalta-se que com as velocidades do vento mais baixas foram obtidos os maiores aumentos de temperatura do ar, variando de $0,7 \mathrm{~K}$ a $1,2 \mathrm{~K}$, suficiente para afirmar que as janelas maxim-ar são mais eficientes para ventilar naturalmente os ambientes simulados. Conforme ilustrado na tabela 5.5.1, houve aumento mais significativo da temperatura do ar em todos os planos de medição do caso mais desfavorável.

Tabela 5.5.1: Temperaturas médias, mínimas e máximas do ar nos três planos de medição para as configurações com layout quadrado, alturas das partições de 1,50m e velocidade máxima do ar de $2 \mathrm{~m} / \mathrm{s}$.

\begin{tabular}{c|c|c|c|c|c} 
& Janela & \multicolumn{3}{|c|}{ Plano de medição } & \multirow{2}{*}{ Total } \\
\hline $\begin{array}{c}\text { Temperaturas } \\
\text { Médias } \\
{[\mathbf{K}]}\end{array}$ & maxim-ar & 301,1 & 300,9 & 301,6 & 301,2 \\
\hline $\begin{array}{c}\text { Temperaturas } \\
\text { Mínimas } \\
{[\mathbf{K}]}\end{array}$ & de correr vertical & 302,1 & 302,0 & 303,0 & 302,4 \\
\hline $\begin{array}{c}\text { Temperaturas } \\
\text { Máximas } \\
{[\mathbf{[ K}]}\end{array}$ & de correr vertical & 301,2 & 300,9 & 302,0 & 301,4 \\
\hline de correr vertical & 302,8 & 302,9 & 304,0 & 303,1
\end{tabular}


Estas variações mais significativas nas temperaturas do ambiente podem ser facilmente percebidas também nas figuras 5.5.1 e 5.5.2, onde são apresentados planos verticais coloridos por temperatura e vetores de velocidade do escoamento. Analisando as estações de trabalho da direita para a esquerda, ou seja, no sentido do fluxo de ar, o primeiro elemento que chama a atenção é a área com temperatura menor, em azul, que praticamente envolve o primeiro ocupante quando foram empregadas as janelas maxim-ar.

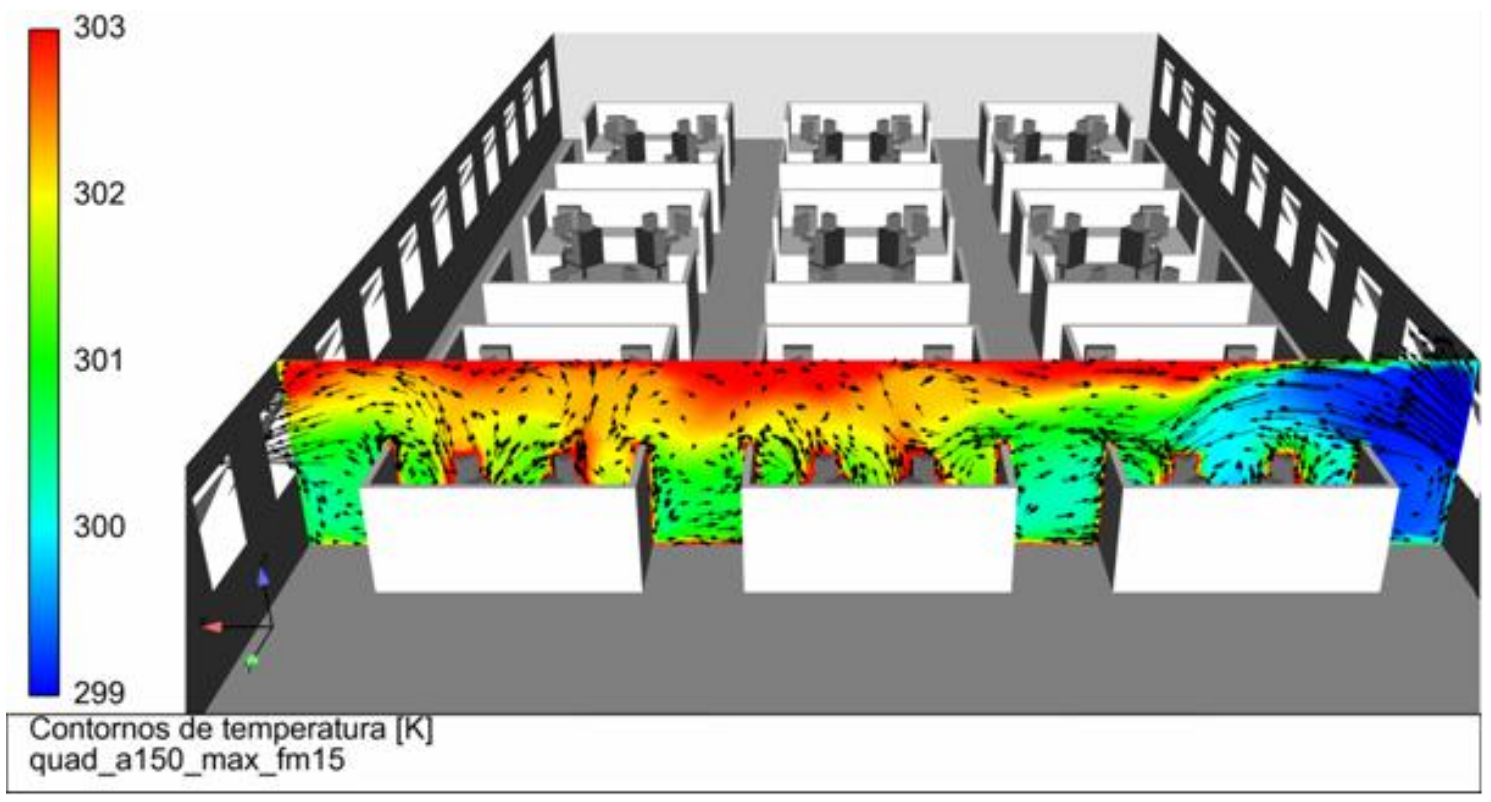

Figura 5.5.1: Plano vertical $y=-03,20 \mathrm{~m}$ colorido por temperatura com vetores de velocidade para o layout quadrado com partições de $1,50 \mathrm{~m}$, janelas maxim-ar e velocidade máxima do ar de $2 \mathrm{~m} / \mathrm{s}$.

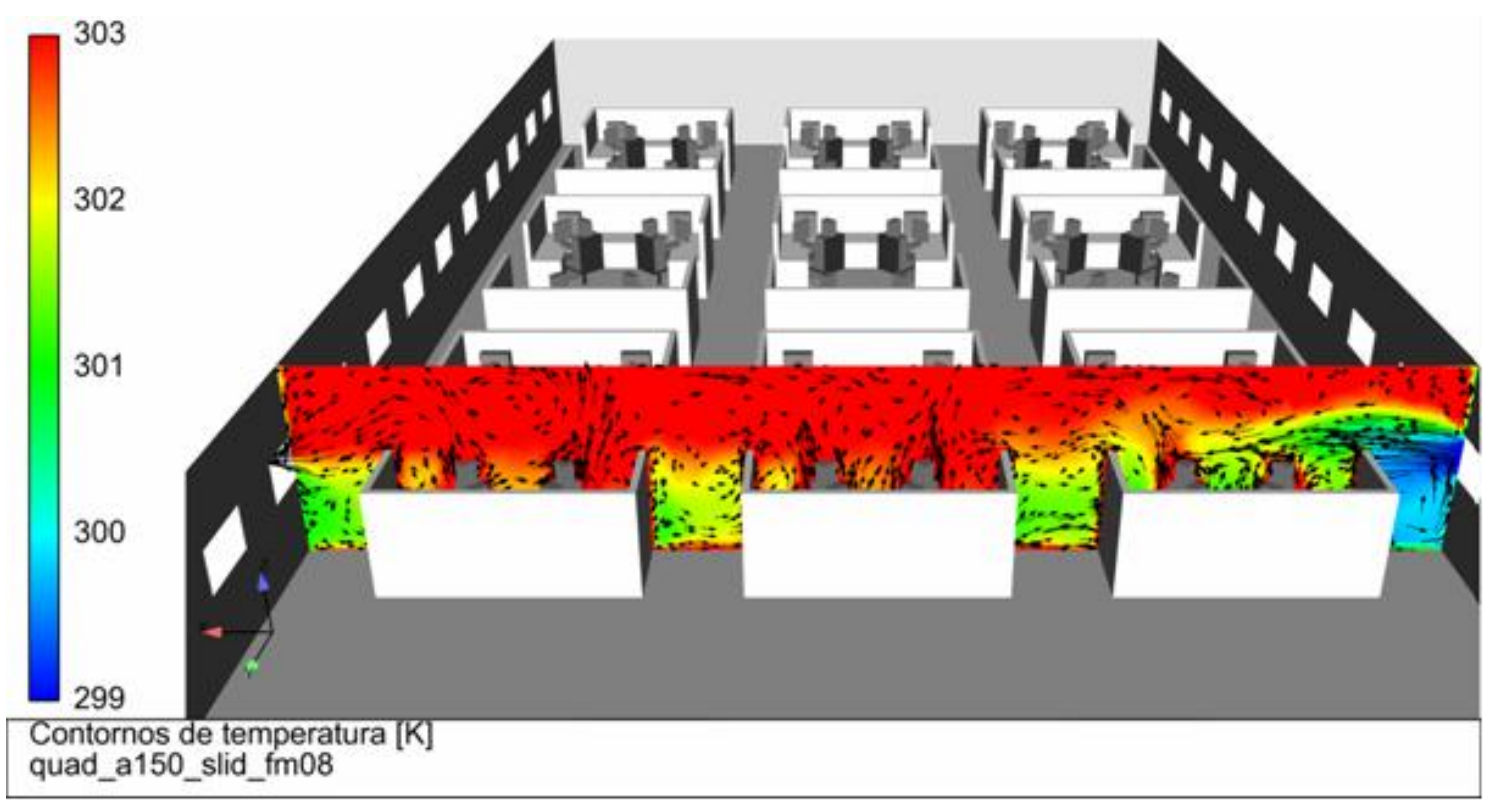

Figura 5.5.2: Plano vertical y $=-03,20 \mathrm{~m}$ colorido por temperatura com vetores de velocidade para o layout quadrado com partições de $1,50 \mathrm{~m}$, janelas de correr vertical e velocidade máxima do ar de $2 \mathrm{~m} / \mathrm{s}$. 
Em segundo lugar, verifica-se que para a estação de trabalho seguinte já existe a formação de plumas térmicas de convecção natural quando são utilizadas as janelas de correr vertical. No escritório com as janelas maxim-ar, o escoamento ao redor deste ocupante possui tendência mais horizontal do que vertical, o que neste caso é consequência da presença mais intensa da convecção forçada. Esta forma de transferência de calor, que remove mais eficientemente a carga térmica gerada, faz com que as temperaturas sejam mais baixas em toda esta fileira, assim como nas demais, como pode ser visto na tabela 5.5.2.

Tabela 5.5.2: Temperaturas médias em cada fileira das estações de trabalho para as configurações com layout quadrado, alturas das partições de 1,50m e velocidade máxima do ar de $2 \mathrm{~m} / \mathrm{s}$.

\begin{tabular}{c|c|c|c|c|c|c|} 
Janela & $\mathbf{1}$ & $\mathbf{2}$ & $\mathbf{3}$ & $\mathbf{4}$ & $\mathbf{5}$ & $\mathbf{6}$ \\
\hline maxim-ar & 300,5 & 300,4 & 301,6 & 301,2 & 301,9 & 301,5 \\
de correr vertical & 301,7 & 301,5 & 302,9 & 302,4 & 303,0 & 302,6
\end{tabular}

Passando para a terceira fileira, verifica-se que os ocupantes no escritório com janelas maxim-ar as temperaturas estão mais amenas ao redor da estação de trabalho, sendo possível observar áreas de menor temperatura na região dos pés e até mesmo uma estação de trabalho sem a formação de plumas térmicas, como mostra a figura 5.5.3.

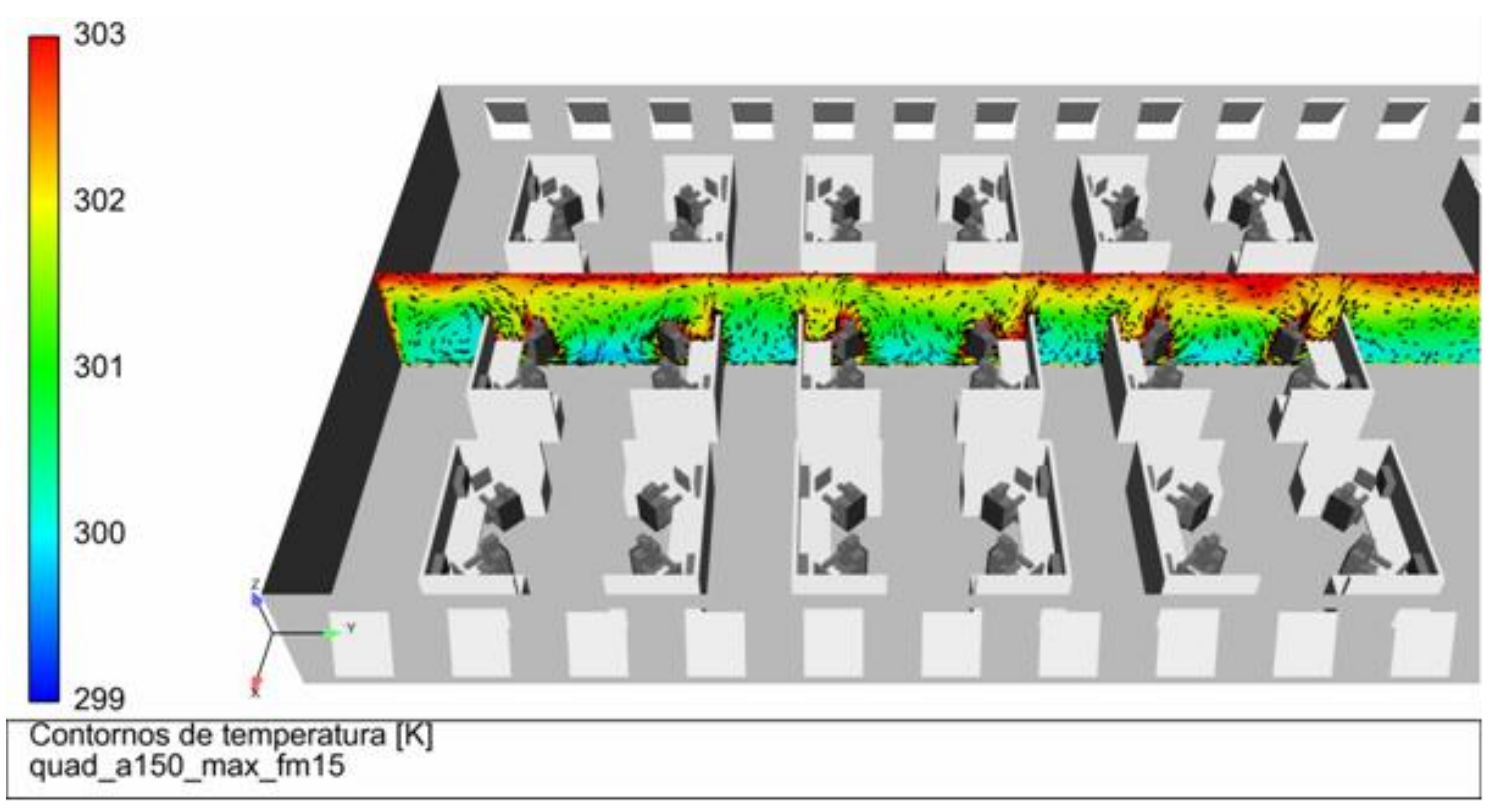

Figura 5.5.3: Plano vertical $\mathrm{x}=06,90 \mathrm{~m}$ colorido por temperatura com vetores de velocidade para o layout quadrado com partições de 1,50m, janelas maxim-ar e velocidade máxima do ar de $2 \mathrm{~m} / \mathrm{s}$. 
Em comparação, o escritório com janelas de correr vertical apresenta temperaturas mais elevadas ao redor de toda a estação de trabalho, com grandes áreas vermelhas, e os vetores de velocidade já indicam a formação das plumas térmicas mais intensas e em todos os seis ocupantes, como mostra a figura 5.5.4.

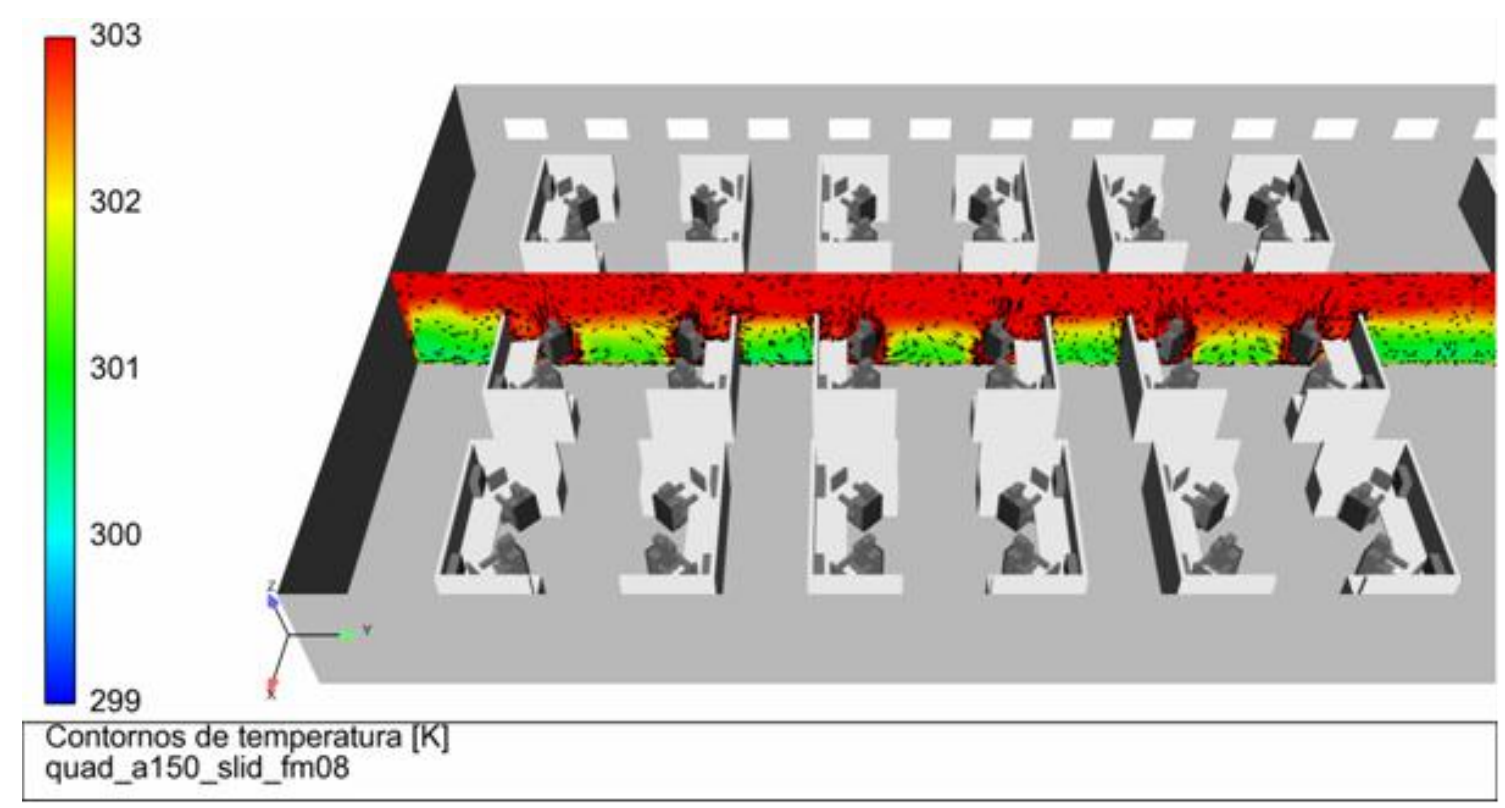

Figura 5.5.4: Plano vertical $\mathrm{x}=06,90 \mathrm{~m}$ colorido por temperatura com vetores de velocidade para o layout quadrado com partições de $1,50 \mathrm{~m}$, janelas de correr vertical e velocidade máxima do ar de $2 \mathrm{~m} / \mathrm{s}$.

É interessante verificar que até mesmo a estratificação de temperatura apresentou ligeira tendência de aumento, de $0,6 \mathrm{~K}$ com as janelas maxim-ar para $0,8 \mathrm{~K}$ para as janelas de correr vertical. Desta forma, não só as temperaturas se encontram em patamares menos adequados para o conforto, mas também a maior diferença de temperatura entre os pés e as cabeças, com temperaturas maiores no plano das cabeças, provê condições mais desfavoráveis para os ocupantes

Entretanto, estas variações mais significativas de temperatura e fluxo de ar nos ambientes devido à geometria das janelas não foram verificadas em todos os casos. Por exemplo, quando utilizadas divisórias mais baixas, o layout em linha e velocidades mais altas do vento, a diferença na temperatura do ar foi de apenas $0,1 \mathrm{~K}$, conforme apresentado na tabela 5.3.2.

Nas figuras 5.5.5 e 5.5.6 é possível ver os planos verticais coloridos por temperatura com vetores de velocidade para os layouts em linha com partições de $1,10 \mathrm{~m}$ de altura e velocidade máxima do vento de $4 \mathrm{~m} / \mathrm{s}$. Com as janelas maxim-ar, verifica-se que o ambiente de um modo geral encontra-se com temperaturas mais amenas do que com as janelas de correr 
vertical. Contudo, próximo aos ocupantes, estas diferenças tornam-se reduzidas, o que ajuda a compreender a pequena diferença de temperatura verificada.

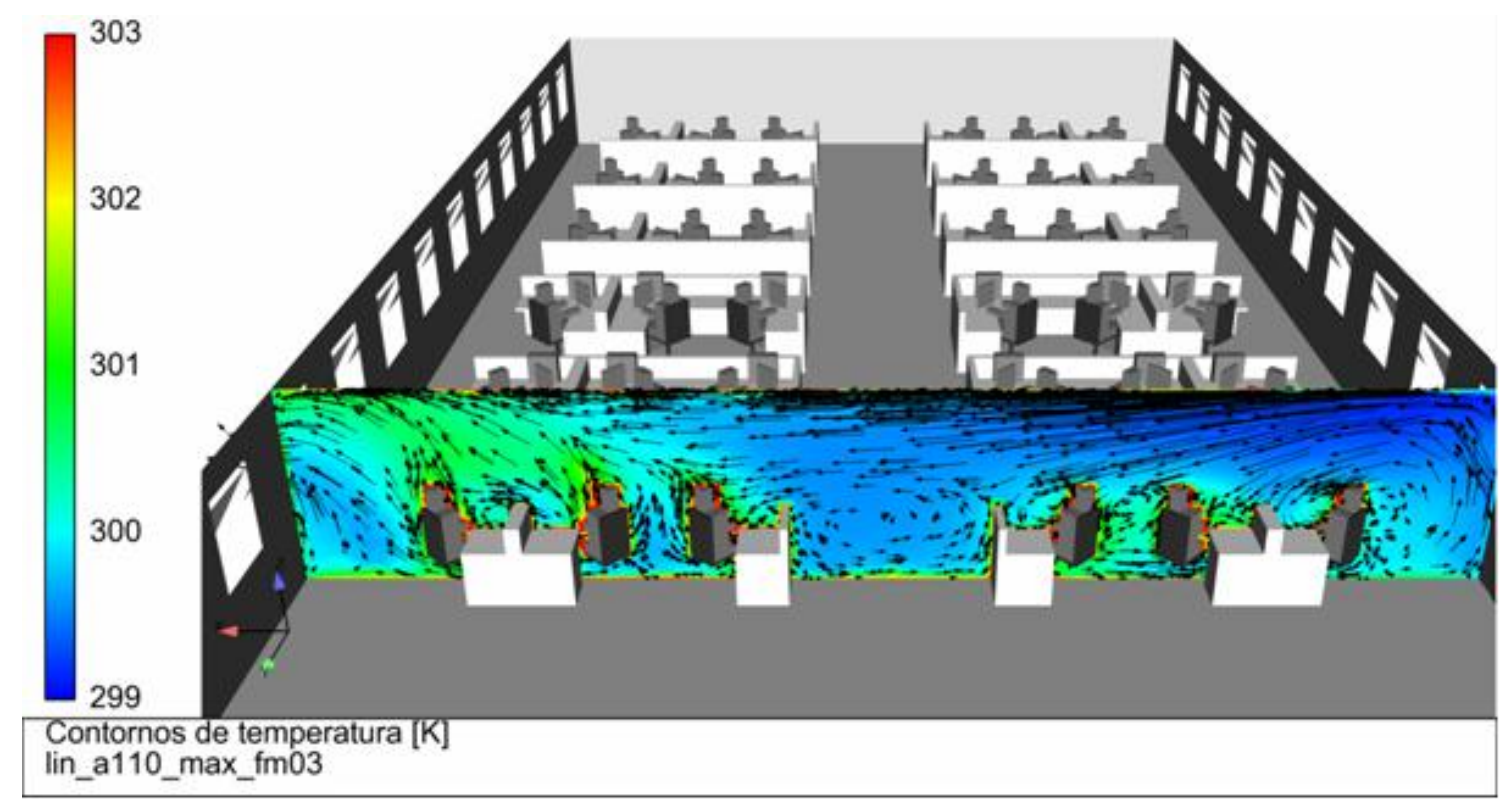

Figura 5.5.5: Plano vertical $\mathrm{y}=-02,50 \mathrm{~m}$ colorido por temperatura com vetores de velocidade para o layout $\mathrm{em}$ linha com partições de 1,10m, janelas maxim-ar e velocidade máxima do ar de $4 \mathrm{~m} / \mathrm{s}$.

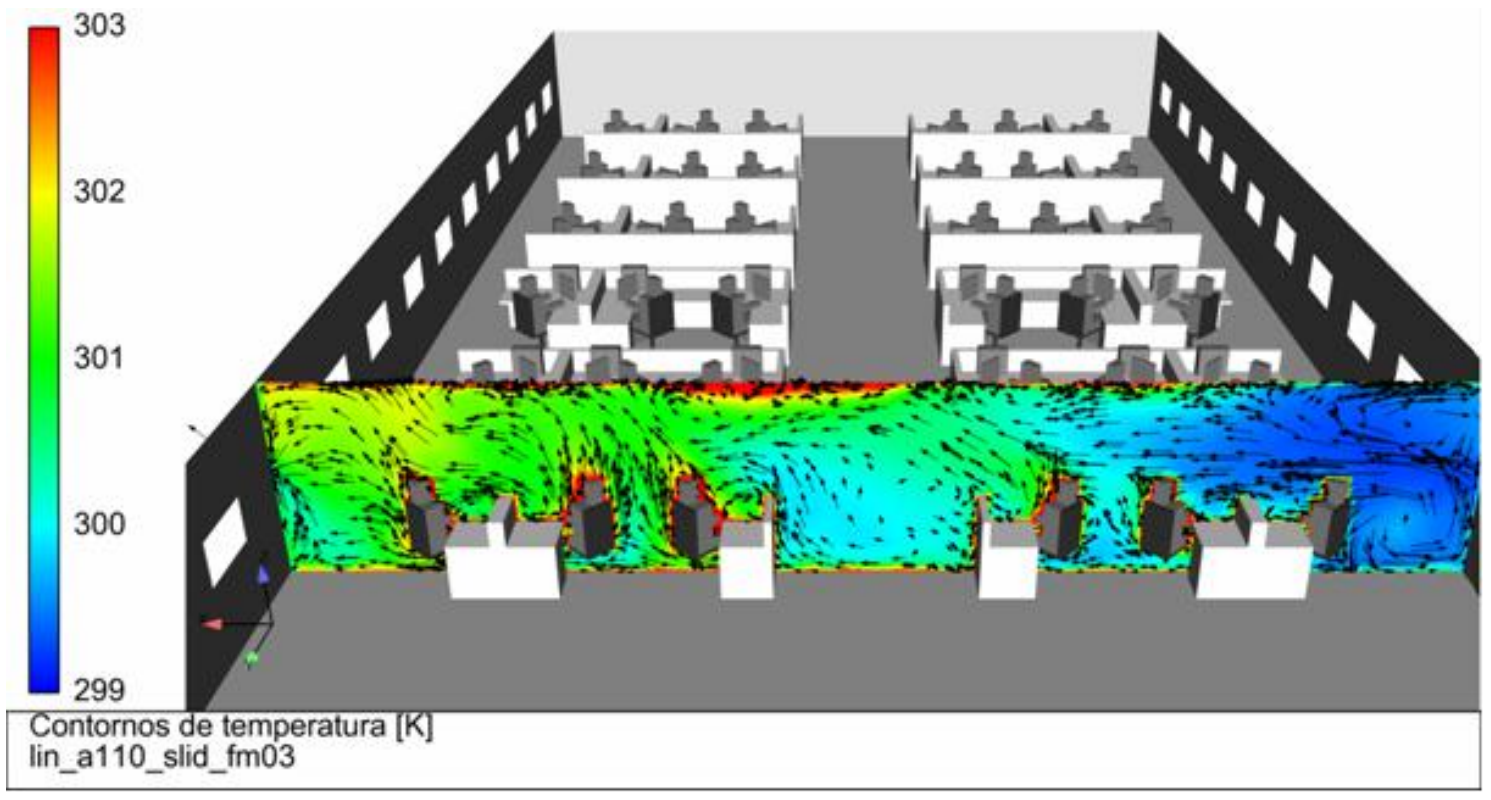

Figura 5.5.6: Plano vertical $\mathrm{y}=-02,50 \mathrm{~m}$ colorido por temperatura com vetores de velocidade para o layout em linha com partições de 1,10m, janelas de correr vertical e velocidade máxima do ar de $4 \mathrm{~m} / \mathrm{s}$.

Ainda, é interessante observar como a formação das plumas térmicas é mais facilmente visualizada no escritório com janelas de correr vertical. Neste caso, os três ocupantes à jusante do escoamento já apresentam estas características, enquanto que com as 
janelas maxim-ar a entrada do ar externo é tão distante que chega a afetar a formação da pluma do último ocupante, mais próximo das janelas de saída do ar.

Analisando os terceiros ocupantes da direita para a esquerda, verifica-se que com as janelas maxim-ar não existe nenhum indício das plumas térmicas, ao contrário do que se verifica para o escritório com as janelas de correr vertical. Como mostram as figuras 5.5.7 e 5.5.8, este fenômeno se repete em algumas estações de trabalho desta fileira.

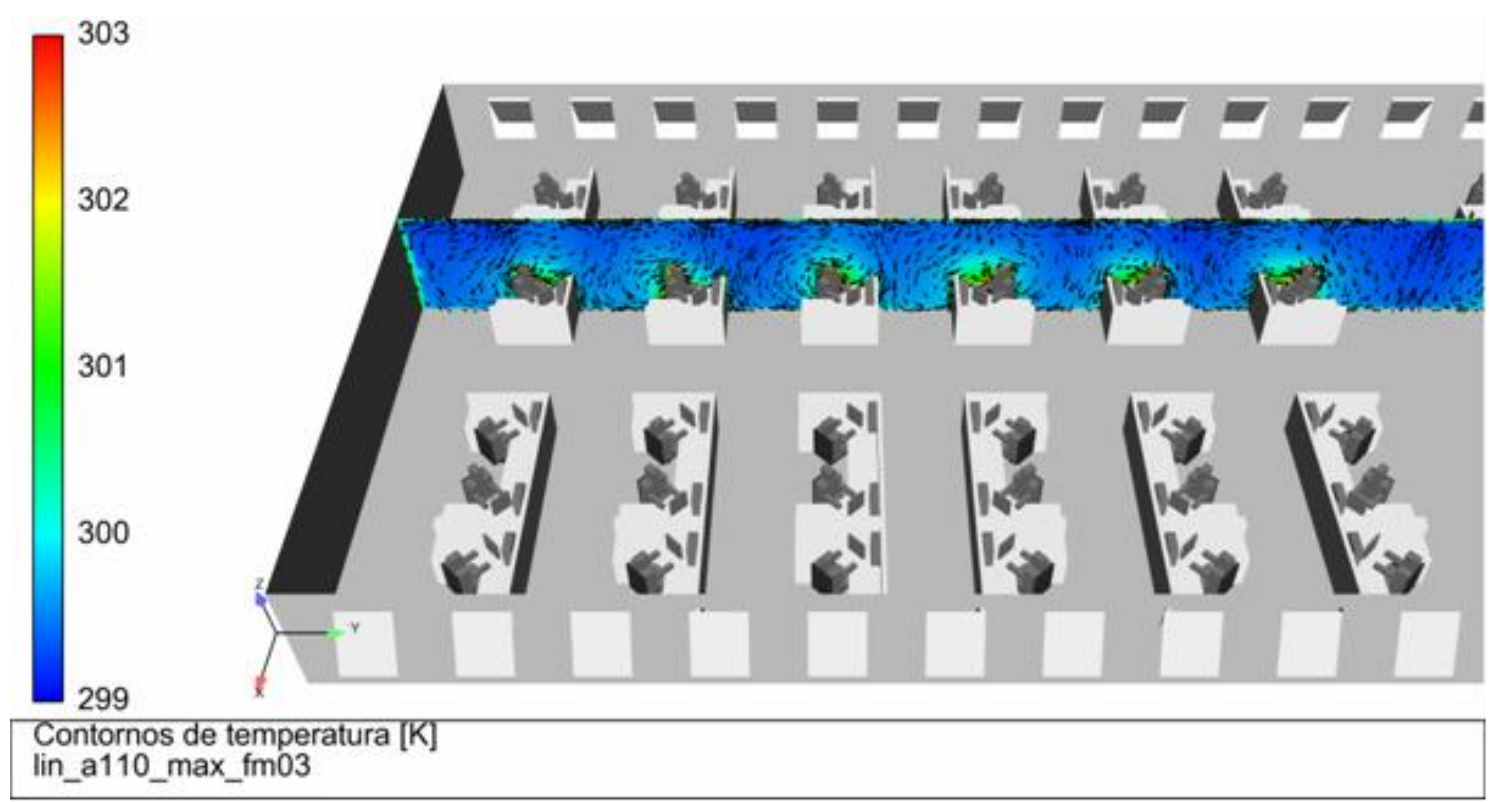

Figura 5.5.7: Plano vertical $\mathrm{x}=05,15 \mathrm{~m}$ colorido por temperatura com vetores de velocidade para o layout em linha com partições de $1,10 \mathrm{~m}$, janelas maxim-ar e velocidade máxima do ar de $4 \mathrm{~m} / \mathrm{s}$.

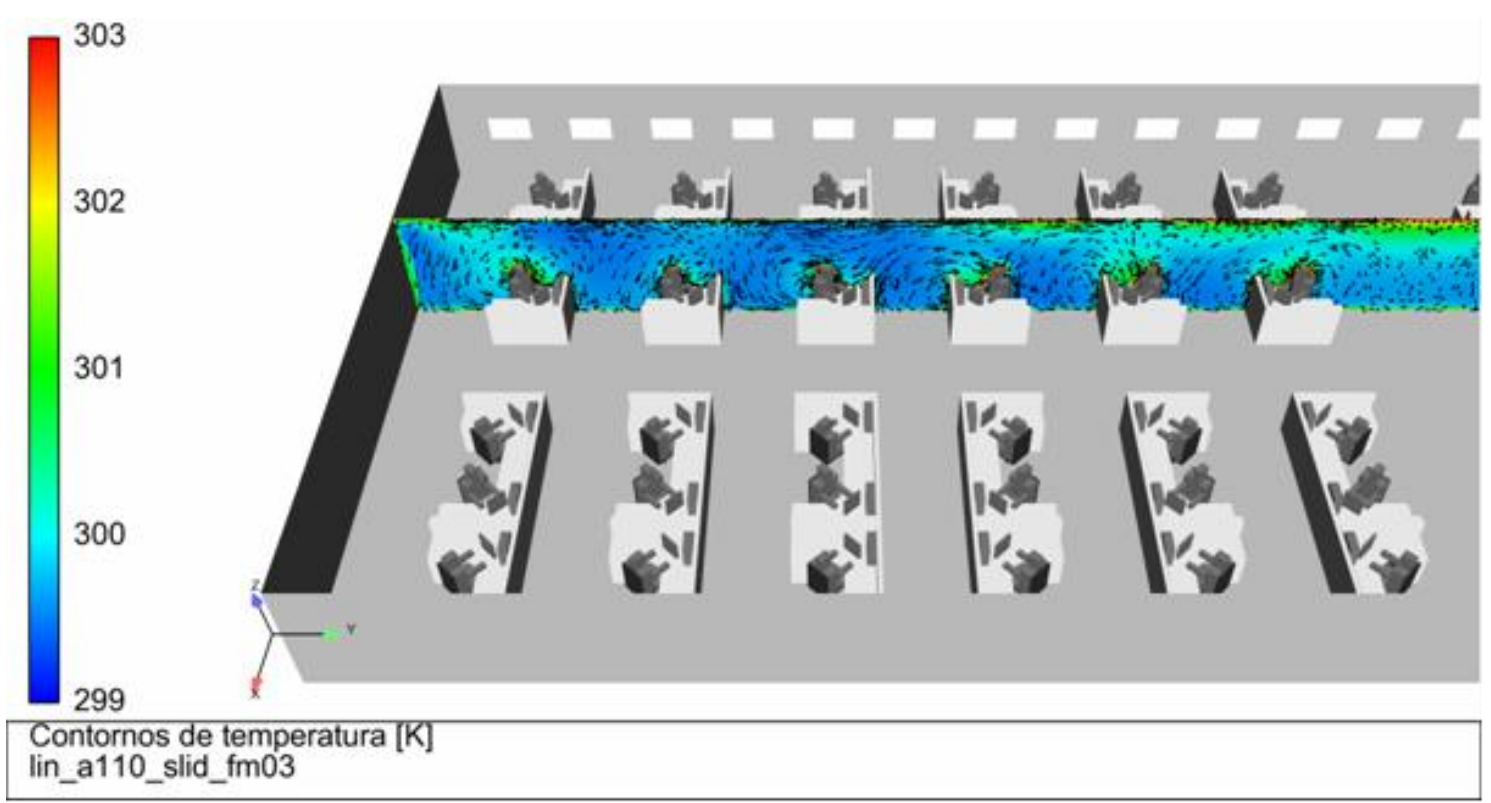

Figura 5.5.8: Plano vertical $\mathrm{x}=05,15 \mathrm{~m}$ colorido por temperatura com vetores de velocidade para o layout em linha com partições de 1,10m, janelas de correr vertical e velocidade máxima do ar de 4m/s. 
Verificou-se que as janelas maxim-ar permitem um fluxo maior de ar para os escritórios, como pode ser visto nas tabelas 5.3.7 e 5.3.8. Estas variações foram as mais significativas obtidas apenas com a mudança de alguma geometria analisada, sendo que o uso das janelas maxim-ar resultou em um aumento da quantidade de ar de $40 \%$ a $60 \%$. O aumento da vazão de ar para a velocidade máxima do ar de $2 \mathrm{~m} / \mathrm{s}$ é ilustrado com as figuras 5.5 .9 e 5.5.10, onde o ambiente com as janelas maxim-ar apresenta à montante maior região vermelha, de velocidade mais alta, do que o ambiente com as janelas de correr vertical.

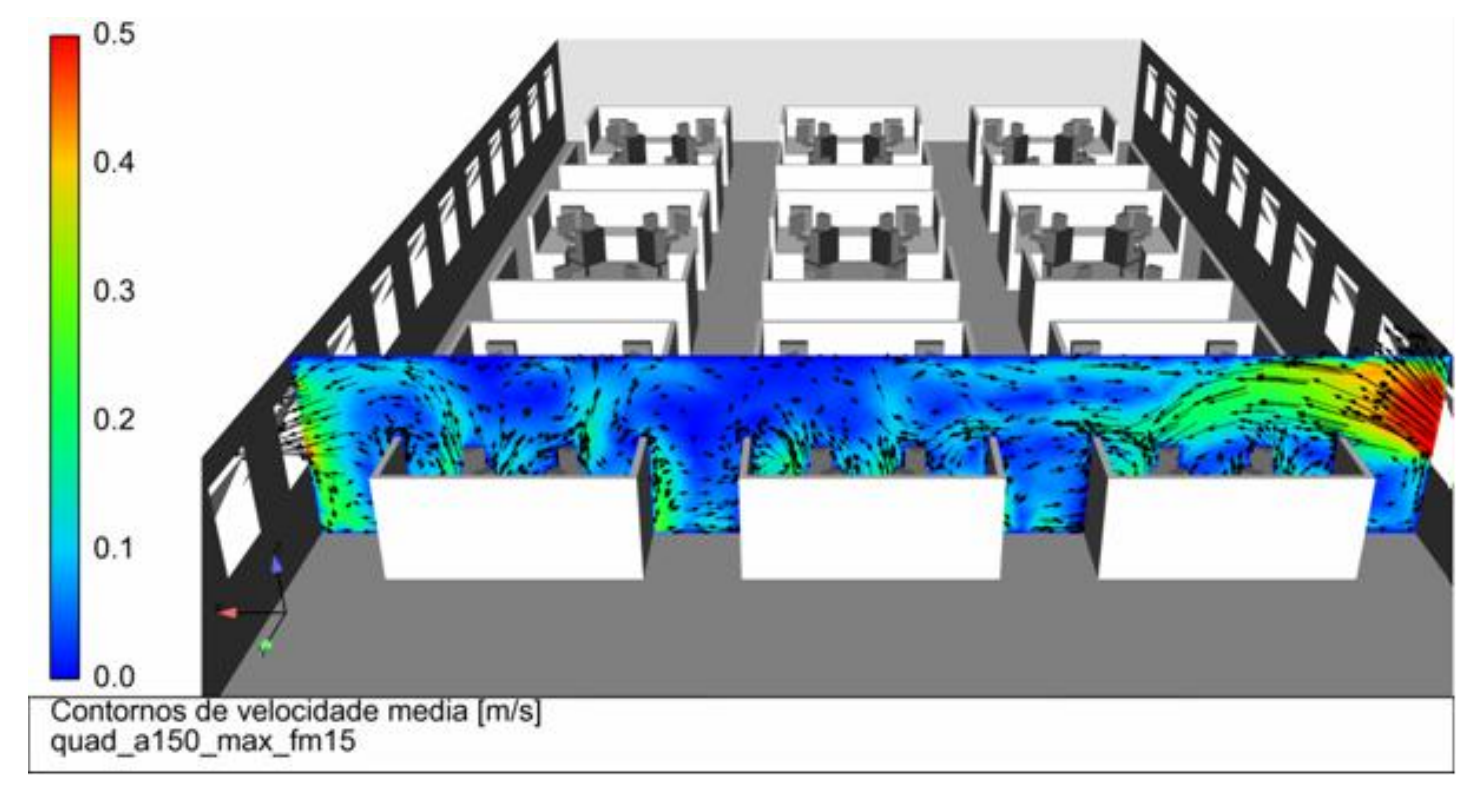

Figura 5.5.9: Plano vertical y $=-02,50 \mathrm{~m}$ colorido por velocidade com os respectivos vetores para o layout quadrado com partições de 1,50m, janelas maxim-ar e velocidade máxima do ar de $2 \mathrm{~m} / \mathrm{s}$.

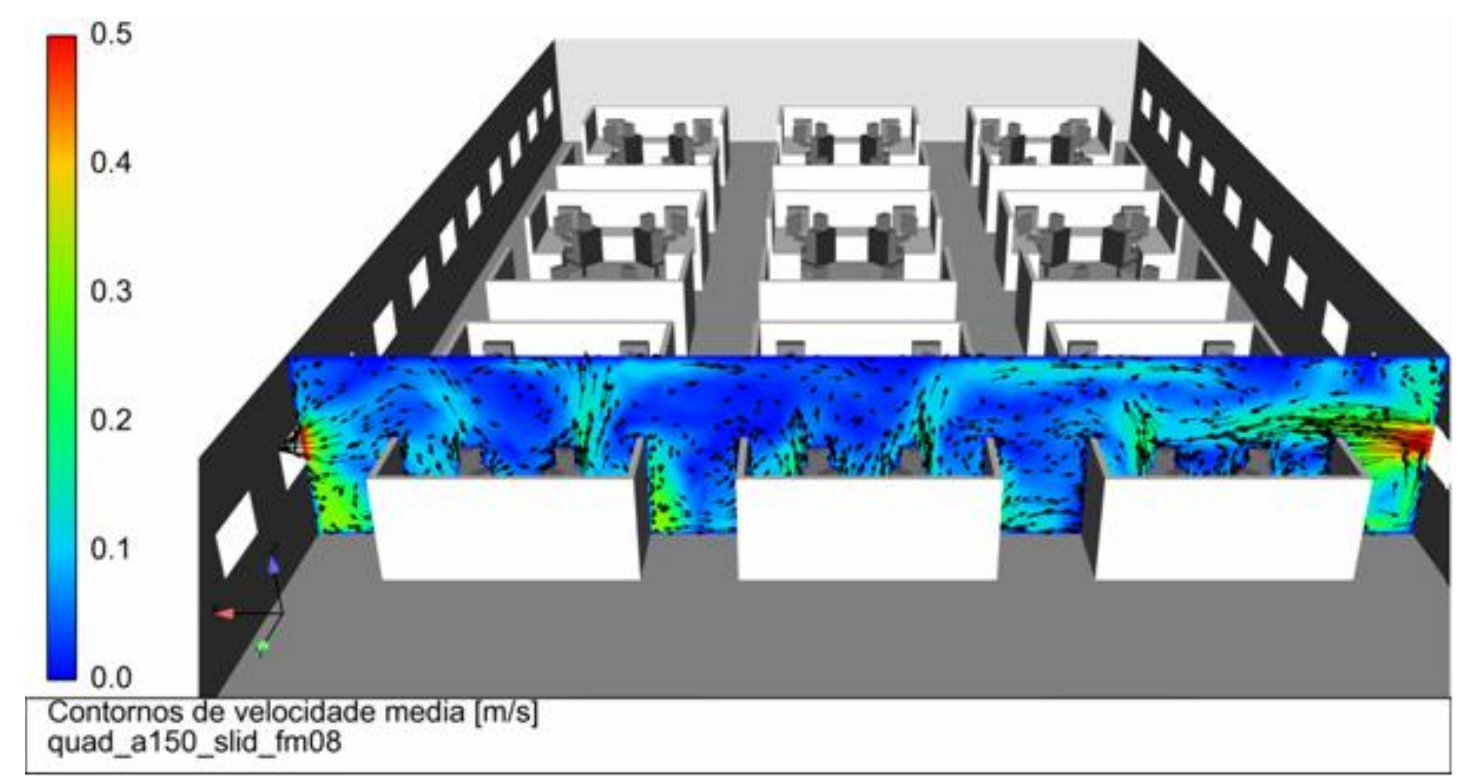

Figura 5.5.10: Plano vertical y $=-02,50 \mathrm{~m}$ colorido por velocidade com os respectivos vetores para o layout quadrado com partições de $1,50 \mathrm{~m}$, janelas de correr vertical e velocidade máxima do ar de $2 \mathrm{~m} / \mathrm{s}$. 
É interessante verificar que, com a velocidade máxima do vento de $4 \mathrm{~m} / \mathrm{s}$, essa diferença fica ainda mais acentuada, como mostram as figuras 5.5.11 e 5.5.12. Nelas, é possível observar que as janelas maxim-ar permitem a entrada de um volume maior de ar e que este ar externo consegue avançar mais para dentro do escritório, o que traz mais ar fresco para os ocupantes localizado à jusante e com piores condições ambientais de conforto térmico.

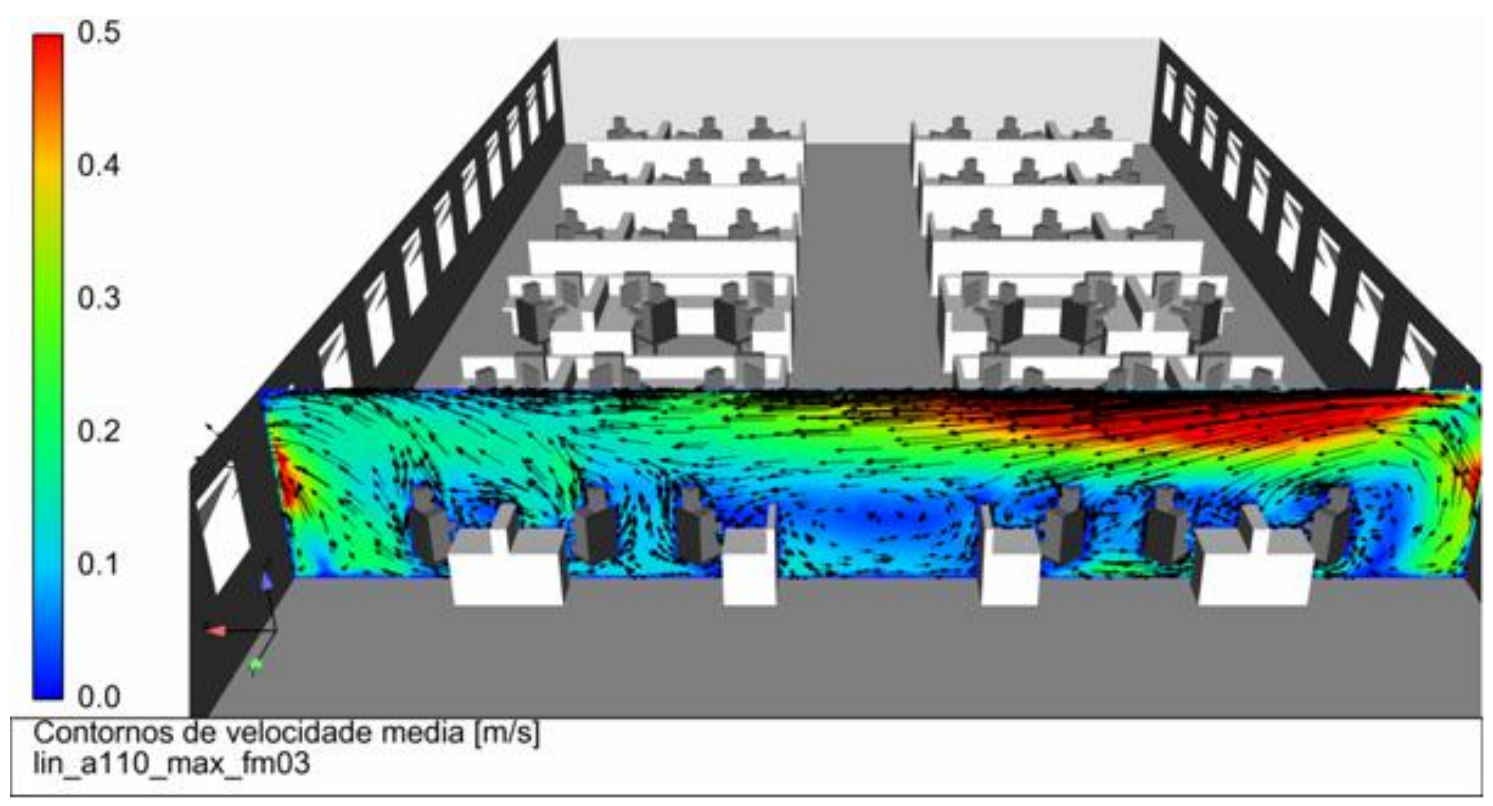

Figura 5.5.9: Plano vertical $\mathrm{y}=-02,50 \mathrm{~m}$ colorido por velocidade com os respectivos vetores para o layout quadrado com partições de $1,50 \mathrm{~m}$, janelas maxim-ar e velocidade máxima do ar de $2 \mathrm{~m} / \mathrm{s}$.

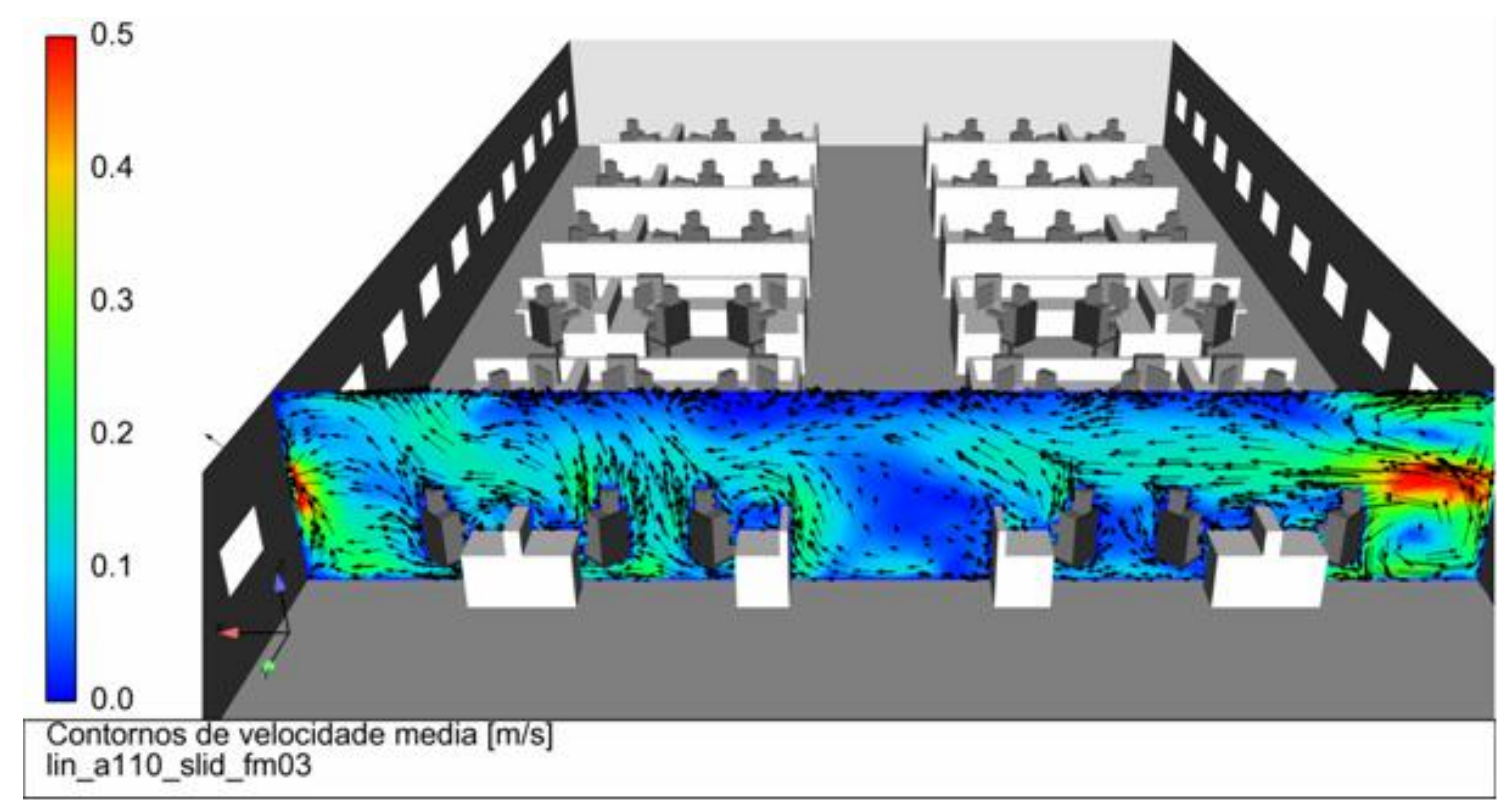

Figura 5.5.10: Plano vertical $\mathrm{y}=-02,50 \mathrm{~m}$ colorido por velocidade com os respectivos vetores para o layout quadrado com partições de $1,50 \mathrm{~m}$, janelas de correr vertical e velocidade máxima do ar de $2 \mathrm{~m} / \mathrm{s}$. 


\subsection{VARIAÇÃO DA VELOCIDADE DO VENTO}

A variação da velocidade do vento foi o único parâmetro que modificou um pouco mais significativamente a temperatura do ar em todos os casos analisados, sendo o intervalo de aumento da temperatura do ar de $0,6 \mathrm{~K}$ até $1,6 \mathrm{~K}$. Assim como destacado nas seções 5.1 a 5.3, a configuração que apresentou esta maior piora nas condições térmicas ambientais foi o layout quadrado, com janelas de correr vertical e altura das partições de 1,50m.

Este caso ilustra bem como a convecção forçada é mais eficiente do que a natural para remover a carga térmica do ambiente. Na figura 5.6.1 pode ser visto o campo de temperatura do ambiente com a mais alta temperatura do ar, onde a pluma térmica da convecção natural ocorre em quase todas as estações de trabalho. A figura 5.6.2 apresenta o mesmo escritório sob ação dos ventos mais intensos, onde a convecção forçada mais intensa reduz a temperatura do escritório e reduz as plumas térmicas.

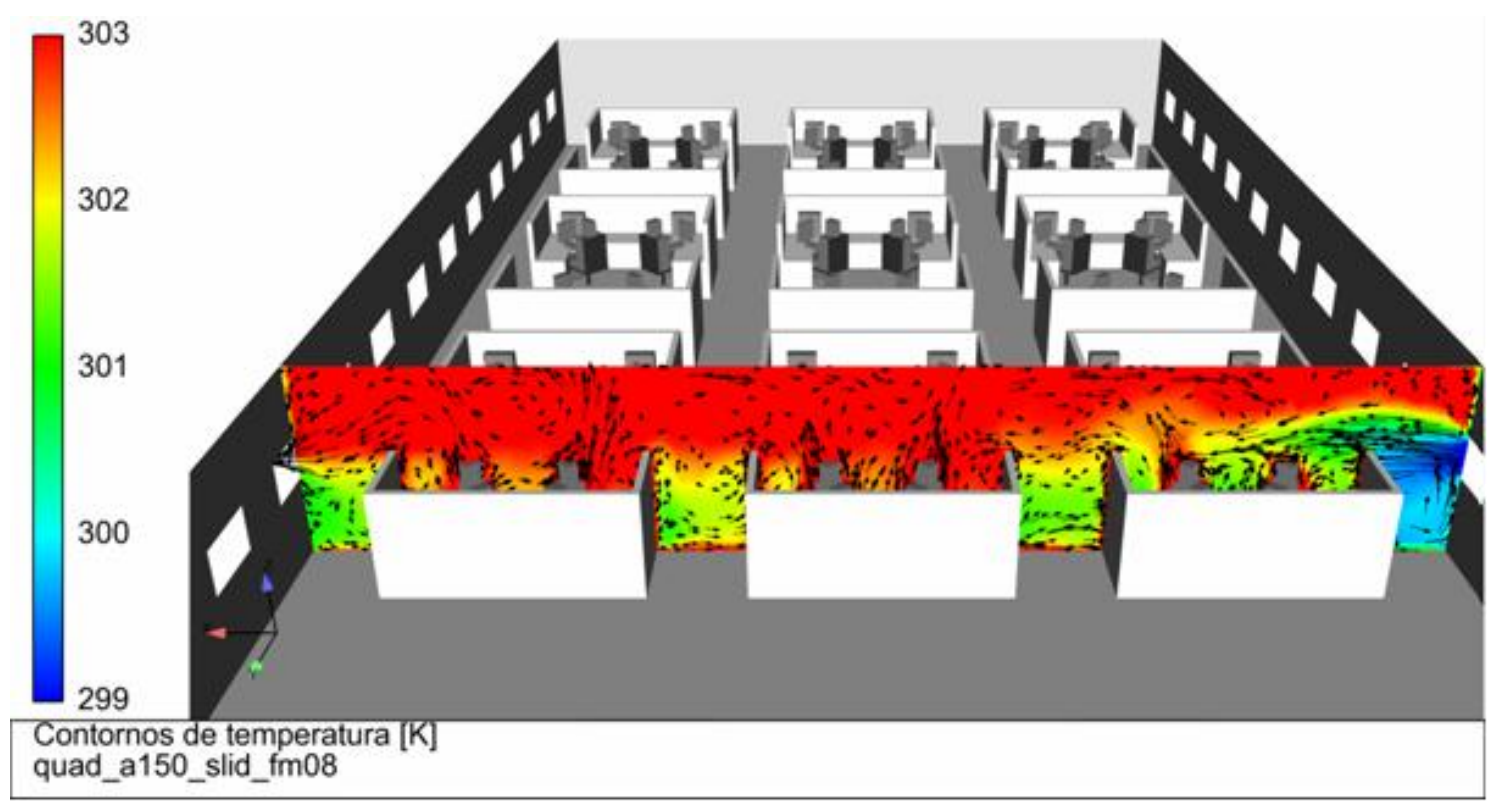

Figura 5.6.1: Plano vertical y = -03,20m colorido por temperatura com vetores de velocidade para o layout quadrado com partições de $1,50 \mathrm{~m}$, janelas de correr vertical e velocidade máxima do ar de $2 \mathrm{~m} / \mathrm{s}$. 


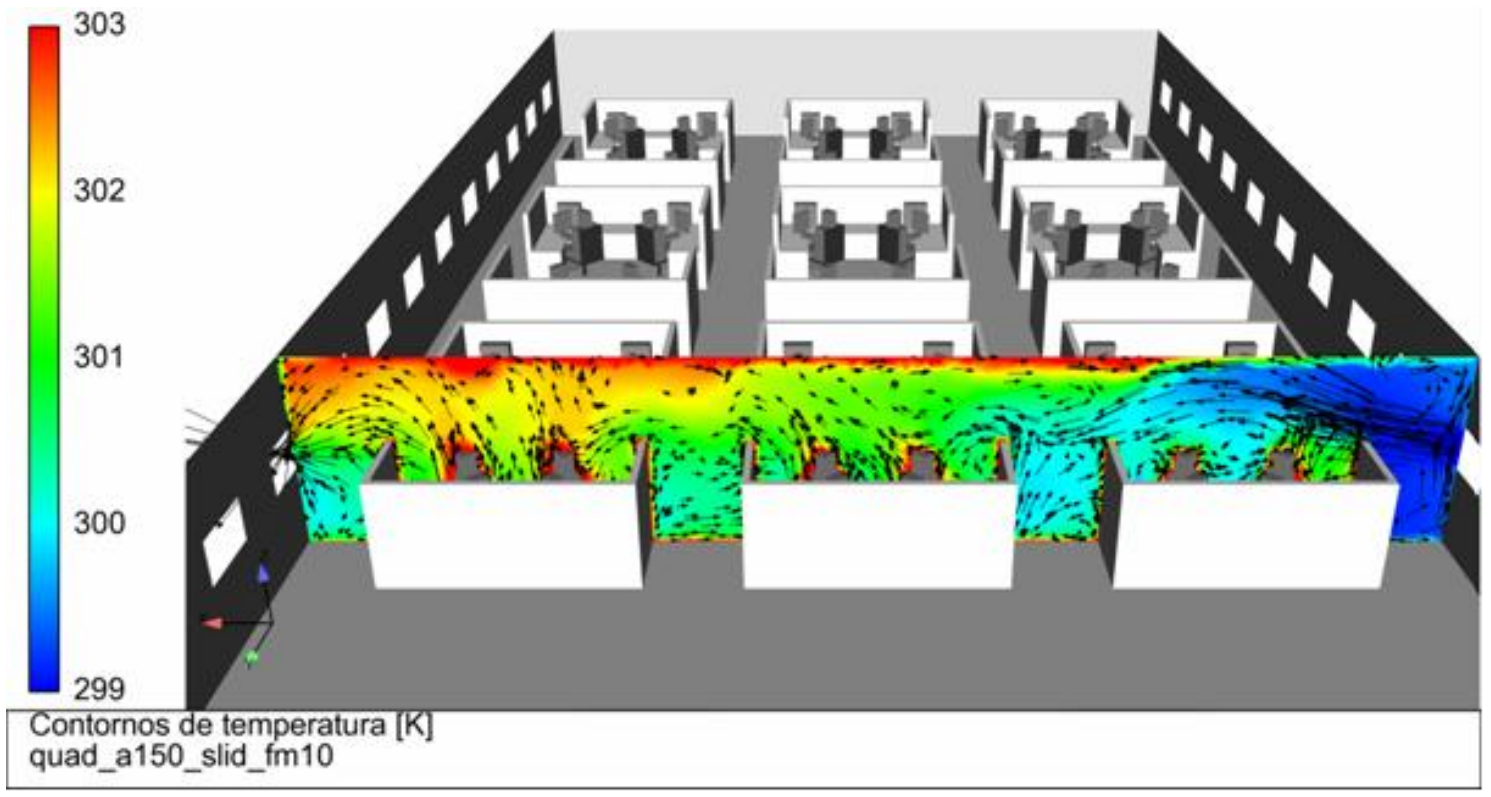

Figura 5.6.2: Plano vertical y $=-03,20 \mathrm{~m}$ colorido por temperatura com vetores de velocidade para o layout quadrado com partições de $1,50 \mathrm{~m}$, janelas de correr vertical e velocidade máxima do ar de $4 \mathrm{~m} / \mathrm{s}$.

Todas as fileiras de estações de trabalho do escritório tiveram aumento significativo de temperatura, como mostram as figuras 5.6.3 e 5.6.4 para a fileira mais próxima da janela de entrada. Entretanto, na maioria das fileiras, o aumento de temperatura foi ainda mais intenso, como pode ser visto na tabela 5.6.1.

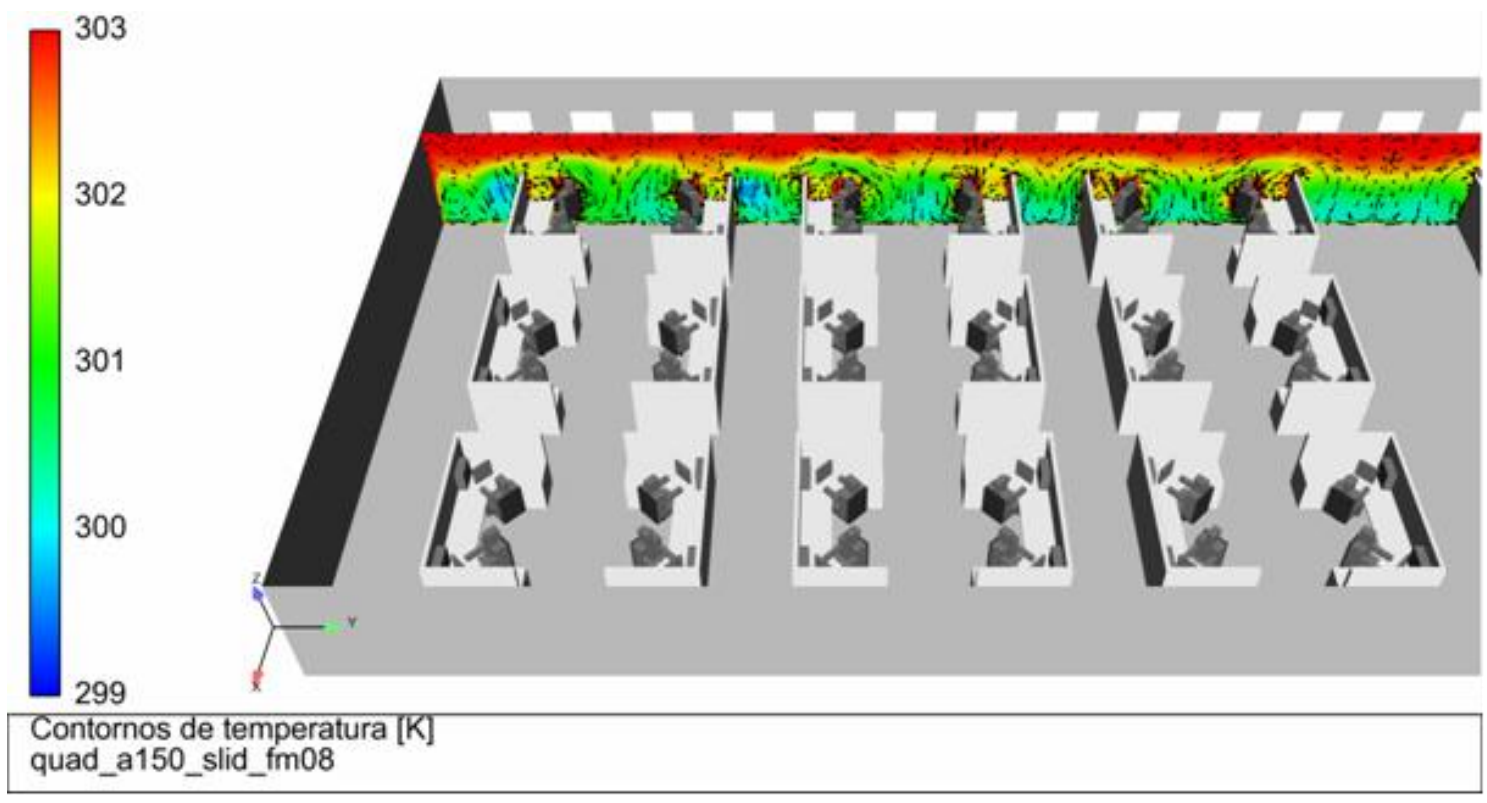

Figura 5.6.3: Plano vertical $\mathrm{x}=02,30 \mathrm{~m}$ colorido por temperatura com vetores de velocidade para o layout quadrado com partições de $1,50 \mathrm{~m}$, janelas de correr vertical e velocidade máxima do ar de $2 \mathrm{~m} / \mathrm{s}$. 


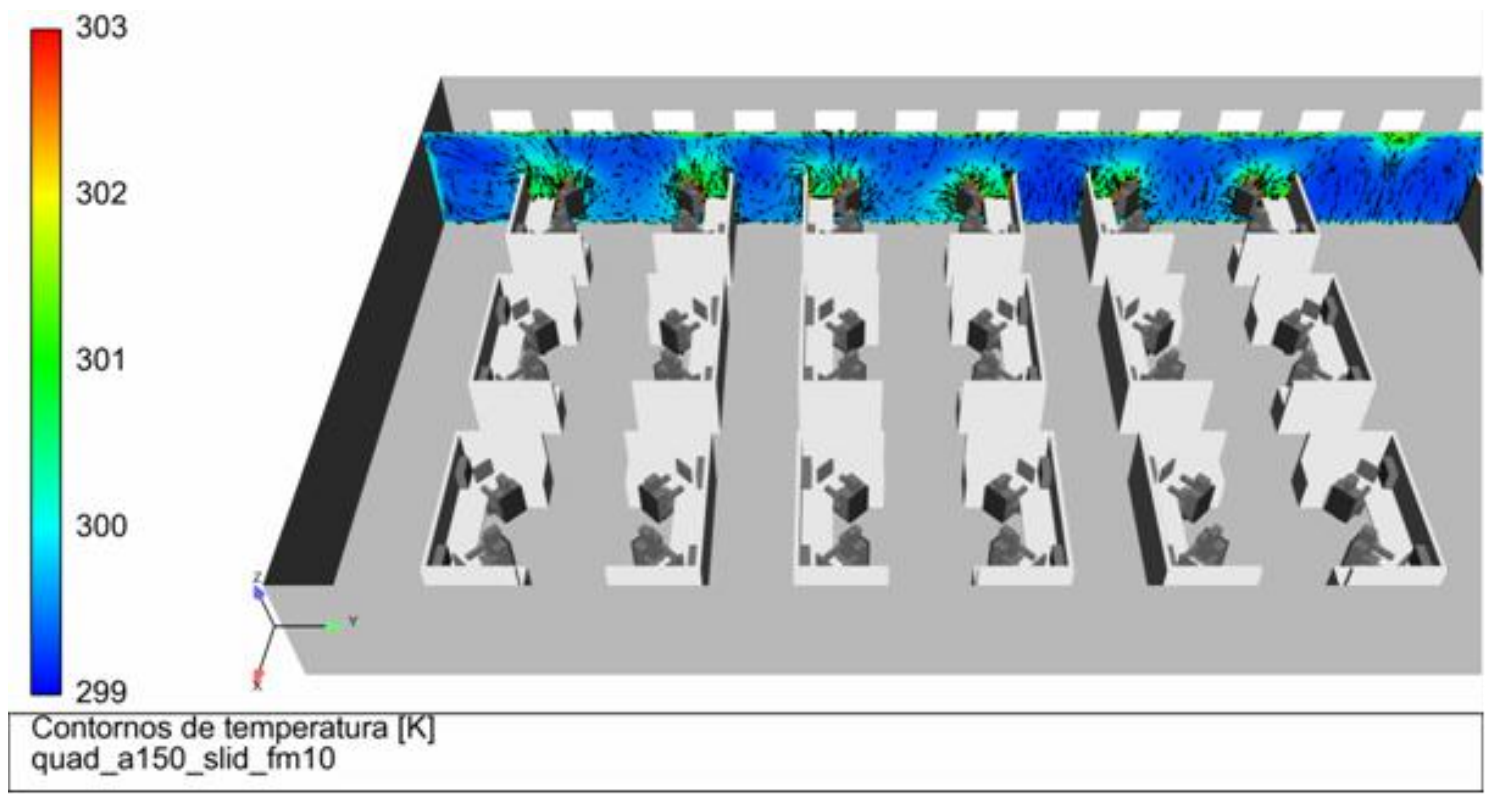

Figura 5.6.4: Plano vertical $\mathrm{x}=02,30 \mathrm{~m}$ colorido por temperatura com vetores de velocidade para o layout quadrado com partições de 1,50m, janelas de correr vertical e velocidade máxima do ar de $4 \mathrm{~m} / \mathrm{s}$.

Tabela 5.6.1: Temperaturas médias em cada fileira das estações de trabalho para as configurações com layout quadrado, alturas das partições de $1,50 \mathrm{~m}$ e janelas de correr vertical.

\begin{tabular}{c|c|c|c|c|c|c|}
$\begin{array}{c}\text { Velocidade Máxima } \\
\text { do Vento }\end{array}$ & $\mathbf{1}$ & $\mathbf{2}$ & $\mathbf{3}$ & $\mathbf{4}$ & $\mathbf{5}$ & $\mathbf{6}$ \\
\hline $\mathbf{2 m} / \mathbf{s}$ & 301,7 & 301,5 & 302,9 & 302,4 & 303,0 & 302,6 \\
$\mathbf{4 m} / \mathbf{s}$ & 300,4 & 300,4 & 300,9 & 300,7 & 301,5 & 301,1
\end{tabular}

Mesmo no caso onde houve a menor variação da temperatura do ar, com layout em linha, janelas maxim-ar e todas as alturas de partições, é possível verificar aumento de temperatura na maioria das fileiras. Como mostra a tabela 5.6.2, este aumento é da ordem de $1,0 \mathrm{~K}$ para as três fileiras à jusante do escritório, porém nas três fileiras à montante esses valores são menores.

Tabela 5.6.2: Temperaturas médias em cada fileira das estações de trabalho para as configurações com layout em linha, alturas das partições de 1,50m e janelas maxim-ar.

\begin{tabular}{|c|c|c|c|c|c|c|}
\hline \multirow{2}{*}{$\begin{array}{c}\text { Velocidade Máxima } \\
\text { do Vento }\end{array}$} & \multicolumn{6}{|c|}{ Fileira } \\
\hline & 1 & 2 & 3 & 4 & 5 & 6 \\
\hline $2 \mathrm{~m} / \mathrm{s}$ & 300,4 & 300,8 & 300,7 & 301,7 & 301,4 & 301,5 \\
\hline $4 \mathrm{~m} / \mathrm{s}$ & 300,4 & 300,3 & 300,5 & 300,6 & 300,3 & 300,5 \\
\hline
\end{tabular}


É possível visualizar este fenômeno com o auxílio das figuras 5.6.5 e 5.6.6, que mostram planos verticais coloridos referentes às temperaturas. Destas figuras, é possível verificar que a primeira fileira de estações de trabalho possui o campo de temperaturas praticamente idêntico, apesar da mudança da velocidade do vento. Já nas duas estações em sequência, já é possível verificar mudanças no campo de temperaturas, porém ainda sem a formação das plumas térmicas.

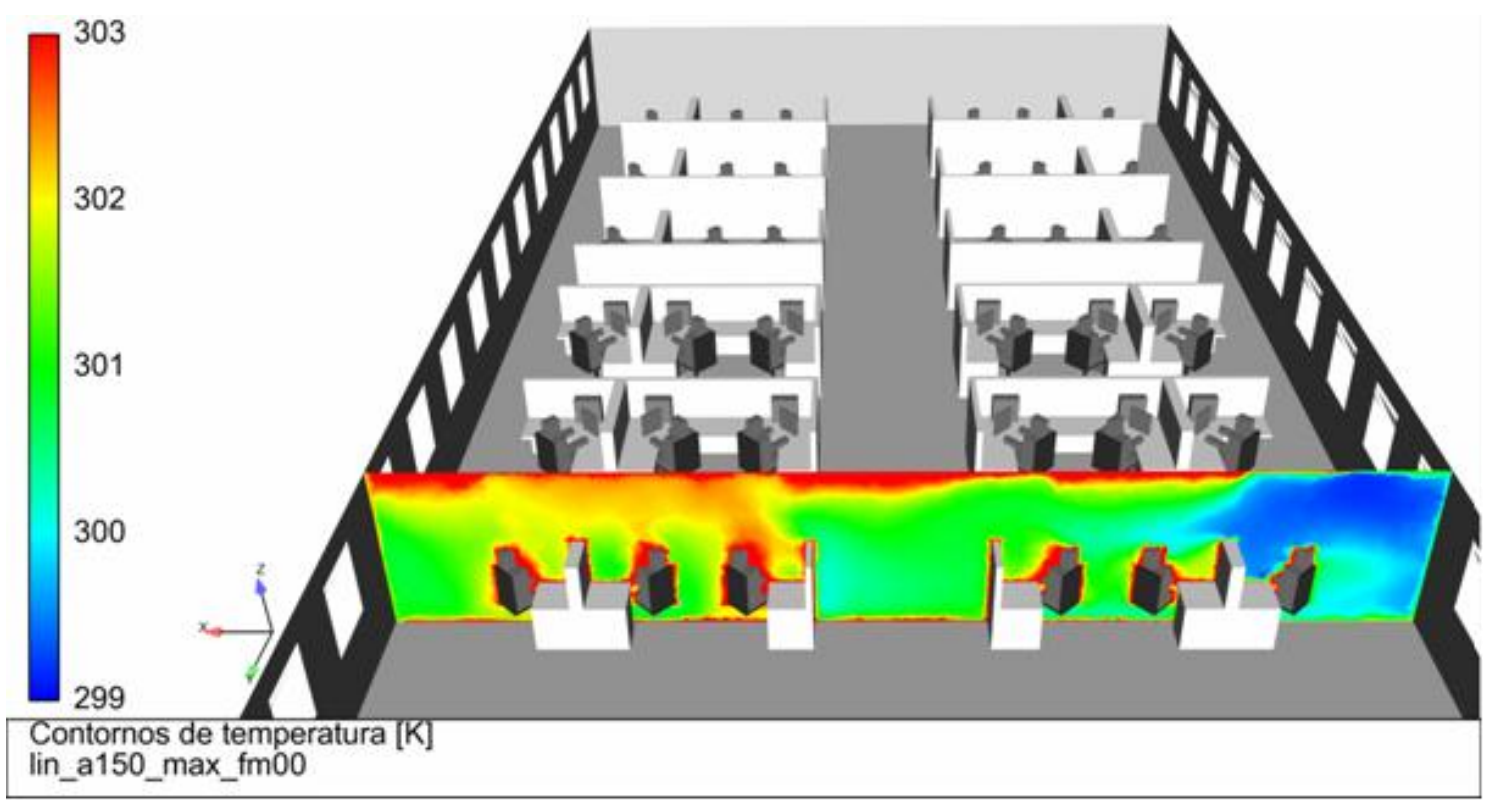

Figura 5.6.5: Plano vertical y = -02,50m colorido por temperatura para o layout em linha com partições de $1,50 \mathrm{~m}$, janelas maxim-ar e velocidade máxima do ar de $2 \mathrm{~m} / \mathrm{s}$.

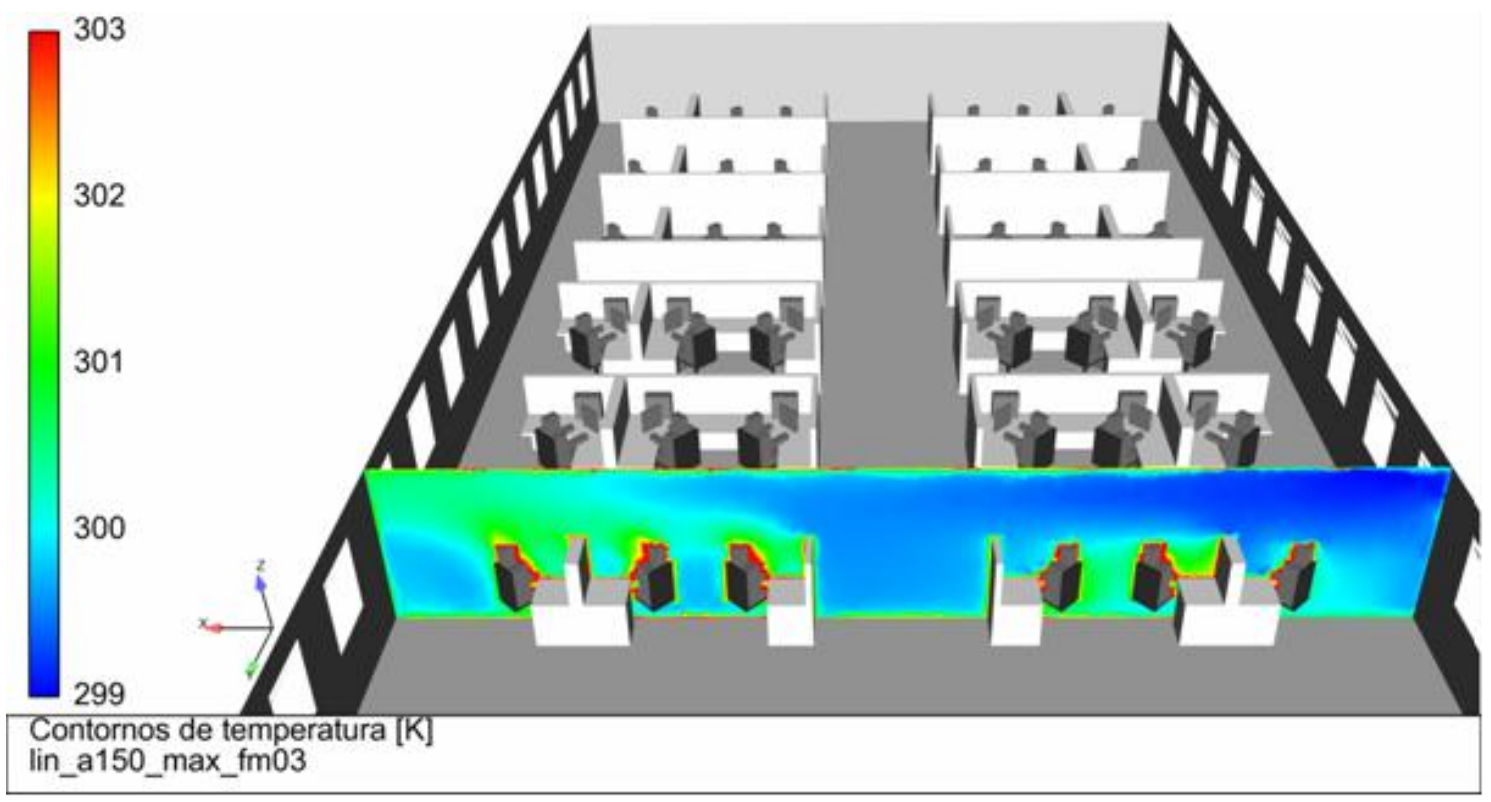

Figura 5.6.6: Plano vertical y = -02,50m colorido por temperatura para o layout em linha com partições de 1,50m, janelas maxim-ar e velocidade máxima do ar de $4 \mathrm{~m} / \mathrm{s}$. 
Já nas três estações de trabalho mais próximas das janelas de saída do ar são percebidas mudanças mais significativas, como por exemplo a formação da pluma térmica. Este fenômeno da convecção natural é outro indicativo dos resultados da tabela 5.6.2, no qual a mudança de temperatura é maior nas fileiras 4,5 e 6 .

Como é possível observar nas figuras 5.6.7 e 5.6.8, não só o maior fluxo de ar auxilia na manutenção de temperaturas mais baixas no ambiente dos escritórios, mas também a maior distância que esse ar consegue percorrer dentro do escritório. Com mais capacidade de retirada da carga térmica, aumenta a prevalência da convecção forçada, mais eficiente do que a natural.

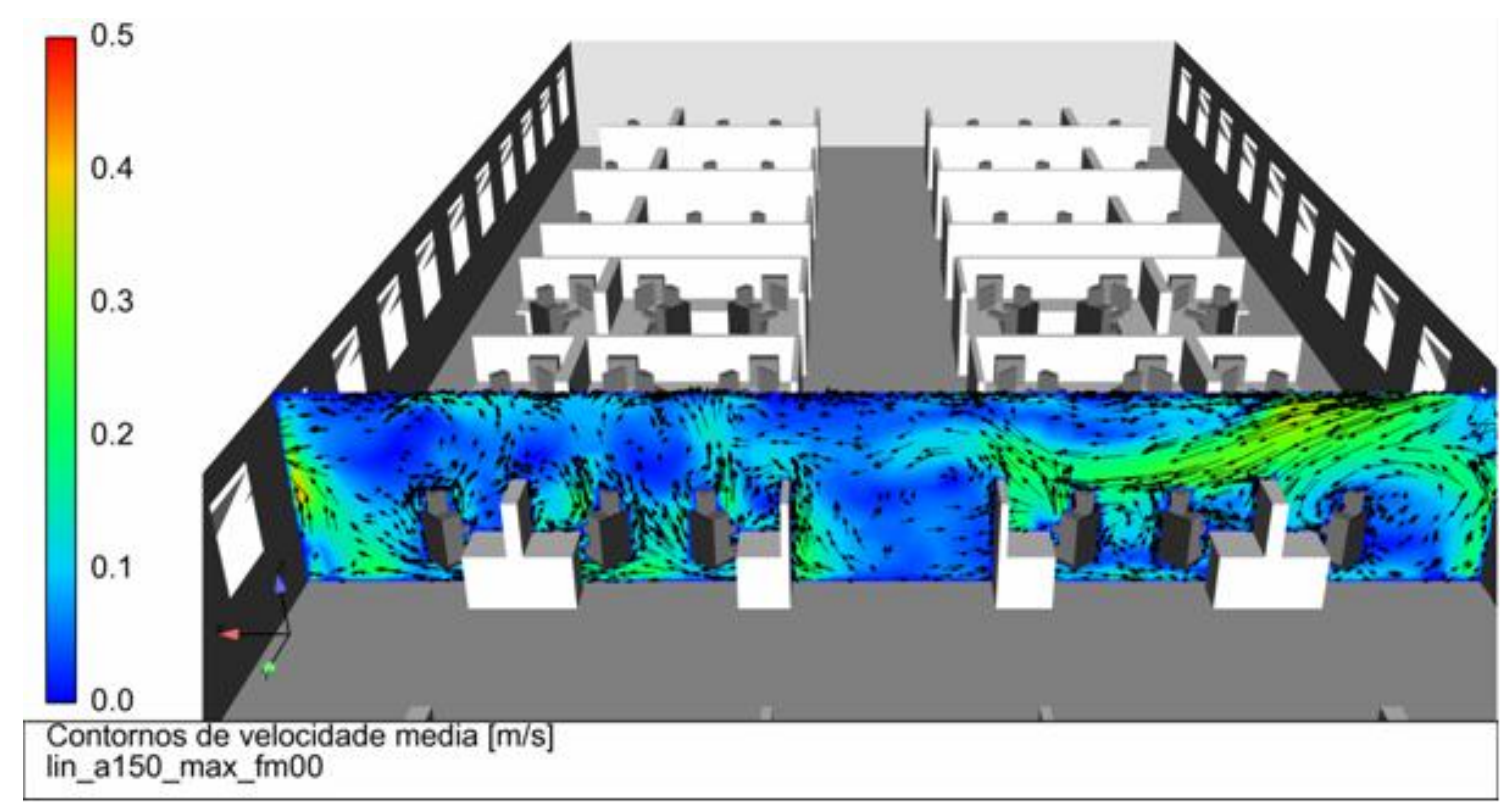

Figura 5.6.7: Plano vertical $\mathrm{y}=-02,50 \mathrm{~m}$ colorido por velocidade com os respectivos vetores para o layout $\mathrm{em}$ linha com partições de $1,50 \mathrm{~m}$, janelas maxim-ar e velocidade máxima do ar de $2 \mathrm{~m} / \mathrm{s}$.

Considerando a vazão de ar que entra nos ambientes, notou-se que com as velocidades do vento mais altas as variações de fluxo foram maiores, tanto aumentando quanto diminuindo. Os resultados apresentados nas tabelas 5.3.7 e 5.3.8 mostram que para a velocidade do vento máxima de $2 \mathrm{~m} / \mathrm{s}$ houve mudanças no fluxo de ar da ordem de $40 \%$ a $50 \%$, enquanto que para a velocidade de $4 \mathrm{~m} / \mathrm{s}$ as mudanças foram da ordem de $49 \%$ a $60 \%$. 


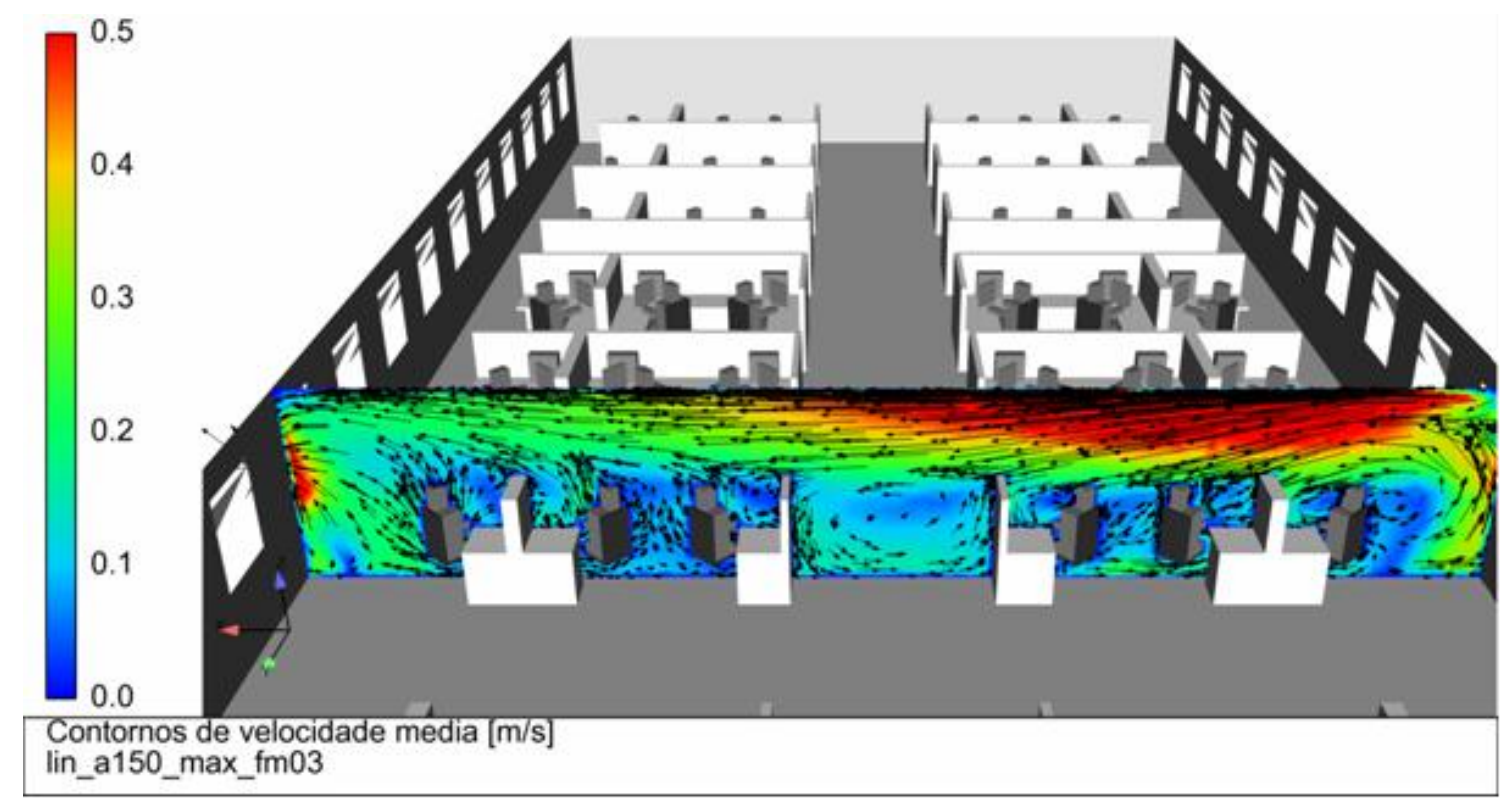

Figura 5.6.8: Plano vertical $\mathrm{y}=-02,50 \mathrm{~m}$ colorido por velocidade com os respectivos vetores para o layout em linha com partições de 1,50m, janelas maxim-ar e velocidade máxima do ar de $4 \mathrm{~m} / \mathrm{s}$.

Além das simulações apresentadas, houve também a tentativa de simular estas configurações de mobiliário e aberturas considerando a velocidade máxima do vento de $1 \mathrm{~m} / \mathrm{s}$. Entretanto, não houve boa convergência dos parâmetros monitorados apesar dos resíduos das equações de transporte estarem bem abaixo do critério apresentado na tabela 4.3.1. Tanto a temperatura do ar em um ponto arbitrado quanto a vazão de ar nas janelas apresentaram comportamentos irregulares, como pode ser visto nas figuras 5.6.9 e 5.6.10.

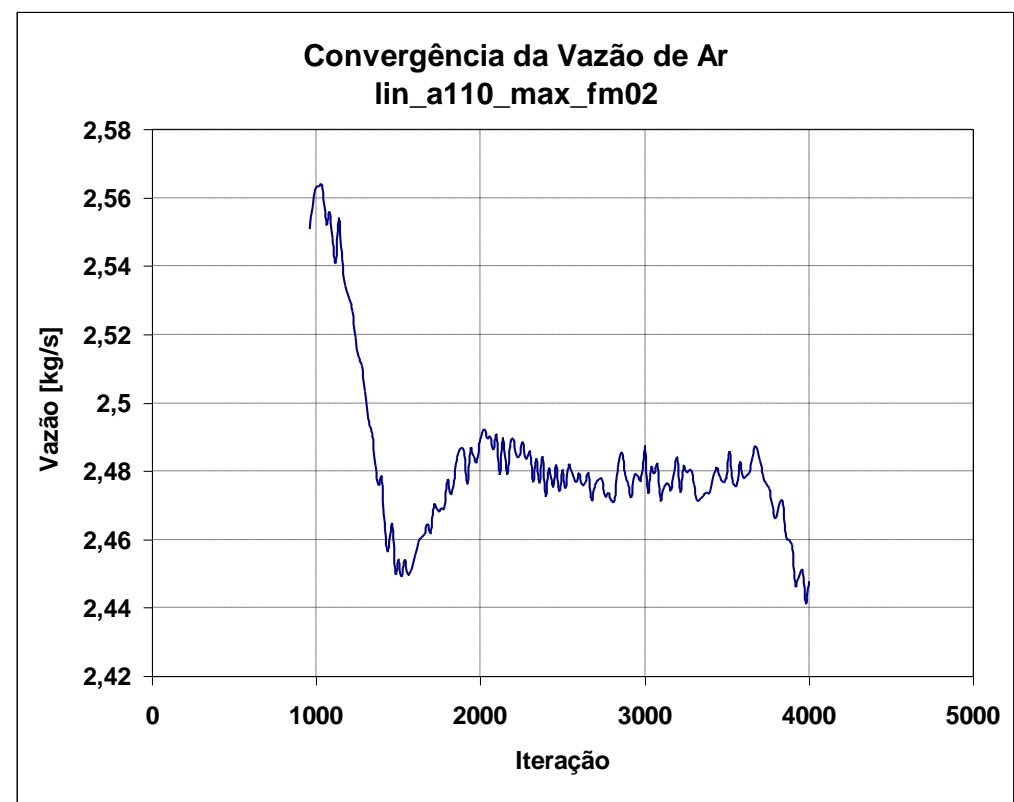

Figura 5.6.9: Convergência da vazão de ar para a configuração com layout em linha, altura das partições de $1,10 \mathrm{~m}$, janelas maxim-ar e velocidade máxima do vento de $1 \mathrm{~m} / \mathrm{s}$. 


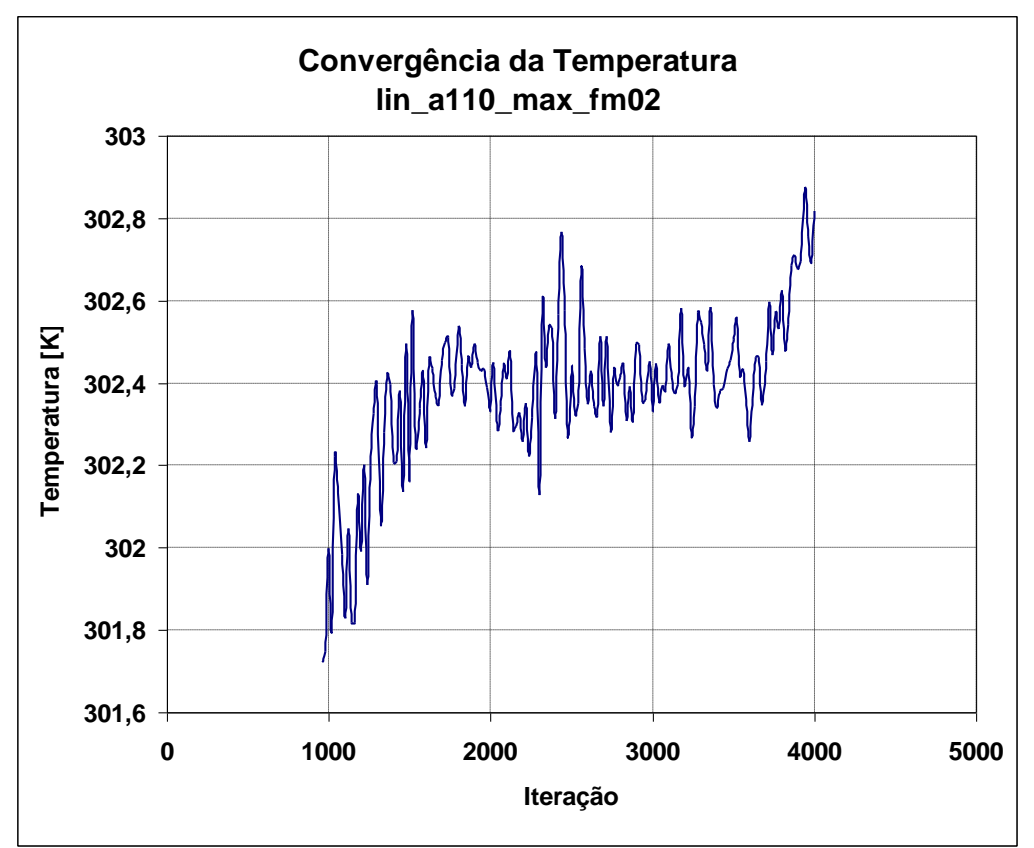

Figura 5.6.10: Convergência da temperatura para a configuração com layout em linha, altura das partições de $1,10 \mathrm{~m}$, janelas maxim-ar e velocidade máxima do vento de $1 \mathrm{~m} / \mathrm{s}$.

Para fins de comparação, nas figuras 5.6.11 e 5.6.12 são apresentados os monitoramentos das mesmas variáveis, porém quando imposta a velocidade máxima do ar de $2 \mathrm{~m} / \mathrm{s}$. Verifica-se que apesar da presença de pequenas oscilações, normais em casos de ventilação natural, existe um valor médio bem definido, do qual é possível verificar a convergência das propriedades avaliadas nas últimas 1000 iterações.

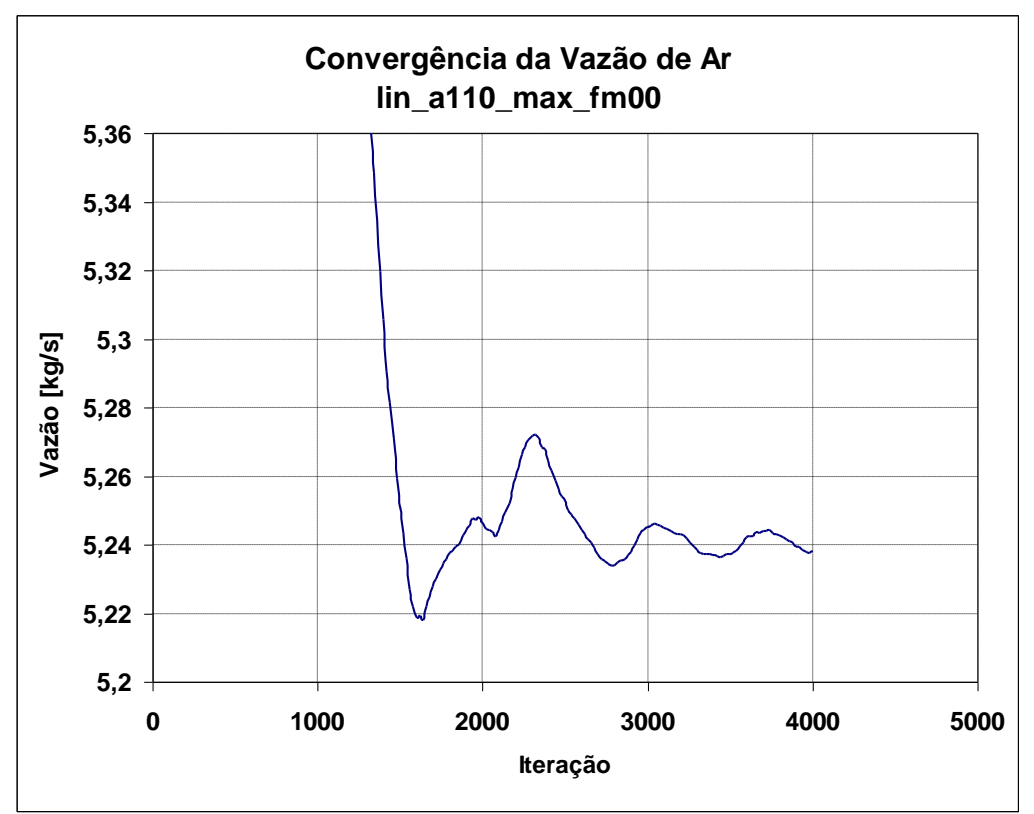

Figura 5.6.11: Convergência da vazão de ar para a configuração com layout em linha, altura das partições de $1,10 \mathrm{~m}$, janelas maxim-ar e velocidade máxima do vento de $2 \mathrm{~m} / \mathrm{s}$. 


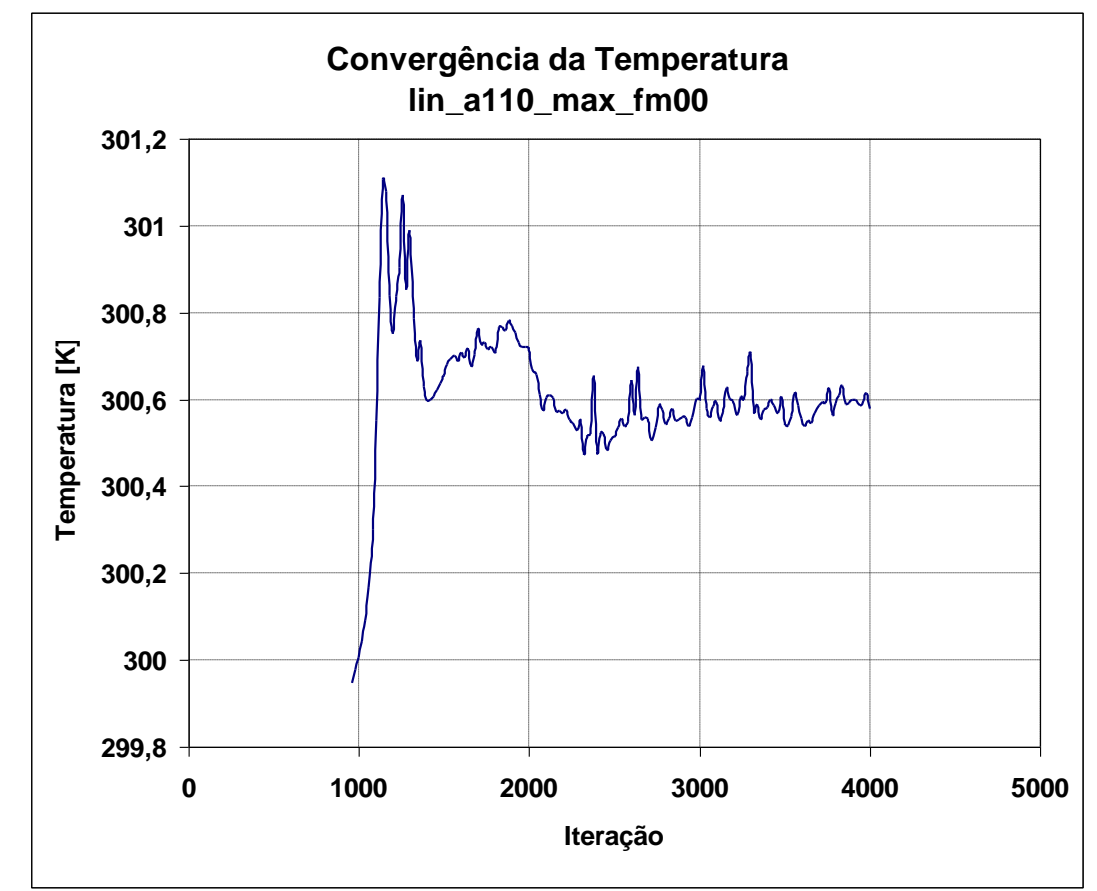

Figura 5.6.12: Convergência da temperatura para a configuração com layout em linha, altura das partições de $1,10 \mathrm{~m}$, janelas maxim-ar e velocidade máxima do vento de $2 \mathrm{~m} / \mathrm{s}$.

\subsection{VARIAÇÃO DE OUTROS ELEMENTOS NA SIMULAÇÃO}

Verificou-se dos resultados apresentados nas seções 5.3 a 5.6 que a configuração que apresentou maior eficiência de ventilação, com tendência de proporcionar menor temperatura do ar, é o escritório com janelas maxim-ar e layout em linha. Como as partições de 0,90m e $1,10 \mathrm{~m}$ de altura apresentaram resultados semelhantes, optou-se por analisar as partições de $1,10 \mathrm{~m}$, por propiciarem maior privacidade aos ocupantes.

Para esta configuração, houve a substituição dos computadores e monitores por computadores portáteis, além de uma redução na potência instalada de iluminação. Os resultados destas modificações nos elementos geradores de carga térmica encontram-se descritos na seção 5.7.1. Simulou-se também esta configuração com cargas térmicas diferentes para uma temperatura do ar exterior $1,5 \mathrm{~K}$ maior, cujos resultados estão descritos na seção 5.7.2. 


\subsubsection{Elementos geradores de carga térmica}

A redução das cargas térmicas do ambiente com layout em linha, partições de 1,10m, janelas maxim-ar e velocidade máxima do vento ao longe de $2 \mathrm{~m} / \mathrm{s}$ proporcionou uma redução na temperatura do ar em todas as situações analisadas, como pode ser visto na tabela 5.7.1. Nesta tabela verifica-se, por exemplo, que o ambiente com redução da densidade de iluminação apresentou redução de $0,3 \mathrm{~K}$ na temperatura do ar.

Tabela 5.7.1: Temperatura média do ar para a variação dos elementos geradores de carga térmica na configuração analisada.

\begin{tabular}{c|c|c|c}
\hline \multicolumn{4}{|c}{ Temperatura média do ar [K] } \\
\hline Carga normal & $\begin{array}{c}\text { Iluminação } \\
\text { reduzida }\end{array}$ & $\begin{array}{c}\text { Computadores } \\
\text { reduzidos }\end{array}$ & $\begin{array}{c}\text { Iluminação + } \\
\text { computadores } \\
\text { reduzidos }\end{array}$ \\
\hline 301,1 & 300,8 & 300,6 & 300,3
\end{tabular}

Já no ambiente com a troca de computadores e monitores por computadores portáteis houve redução de $0,5 \mathrm{~K}$ na temperatura do ar. É interessante verificar da tabela 5.7.1 também que, para as condições analisadas, existiu linearidade na redução da temperatura com a redução da carga térmica do ambiente, com redução total de $0,8 \mathrm{~K}$ quando as duas reduções foram avaliadas simultaneamente.

Considerando a temperatura do ar em cada um dos planos de medição, verifica-se da tabela 5.7.2 que a redução da carga térmica do ambiente resultou em uma redução da temperatura em todos os planos de medição. Praticamente a mesma redução de $0,3 \mathrm{~K}, 0,5 \mathrm{~K}$ e $0,8 \mathrm{~K}$, verificada para a temperatura do ar dos ambientes, repetiu-se para cada um dos planos.

Tabela 5.7.2: Temperatura do ar nos três planos de medição para a variação dos elementos geradores de carga térmica na configuração analisada.

\begin{tabular}{c|c|c|c|c}
\multicolumn{5}{c}{ Temperatura média do ar [K] } \\
$\begin{array}{c}\text { Plano de } \\
\text { medição }\end{array}$ & Carga normal & $\begin{array}{c}\text { Iluminação } \\
\text { reduzida }\end{array}$ & $\begin{array}{c}\text { Computadores } \\
\text { reduzidos }\end{array}$ & $\begin{array}{c}\text { Iluminação + } \\
\text { computadores } \\
\text { reduzidos }\end{array}$ \\
\hline $\mathbf{0 , 1 m}$ & 301,0 & 300,6 & 300,5 & 300,2 \\
$\mathbf{0 , 6 m}$ & 300,8 & 300,6 & 300,3 & 300,1 \\
$\mathbf{1 , 1 m}$ & 301,4 & 301,1 & 300,9 & 300,6
\end{tabular}


$\mathrm{Na}$ análise dos dados de temperatura do ar separados por fileira, apresentados na tabela 5.7.3, verifica-se que com a redução da carga térmica dos ambientes a diminuição da temperatura do ar foi maior nas fileiras 4 a 6, mais longe da entrada de ar no ambiente.

Tabela 5.7.3: Temperatura do ar em cada fileira para a variação dos elementos geradores de carga térmica na configuração analisada.

Temperatura média do ar [K]

\begin{tabular}{c|c|c|c|c}
\hline Fileira & Carga normal & $\begin{array}{c}\text { Iluminação } \\
\text { reduzida }\end{array}$ & $\begin{array}{c}\text { Computadores } \\
\text { reduzidos }\end{array}$ & $\begin{array}{c}\text { Iluminação + } \\
\text { computadores } \\
\text { reduzidos }\end{array}$ \\
\hline $\mathbf{1}$ & 300,6 & 300,4 & 300,3 & 300,1 \\
$\mathbf{2}$ & 300,9 & 300,6 & 300,4 & 300,2 \\
$\mathbf{3}$ & 300,6 & 300,4 & 300,2 & 300,2 \\
$\mathbf{4}$ & 301,6 & 301,1 & 300,9 & 300,6 \\
$\mathbf{5}$ & 301,4 & 301,0 & 300,7 & 300,3 \\
$\mathbf{6}$ & 301,6 & 301,1 & 301,0 & 300,5 \\
\end{tabular}

Em especial, para o caso de maior redução na carga térmica interna, a diminuição da temperatura do ar foi de aproximadamente 1,0K nas fileiras mais próximas da saída do ar. Nas fileiras mais próximas da entrada do ar, a redução média foi de $0,5 \mathrm{~K}$, indicando que houve diferença significativa entre os grupos de fileiras. As figuras 5.7.1 e 5.7.2 apresentam um plano horizontal onde é possível verificar qualitativamente a redução mais significativa da temperatura nas estações de trabalho à jusante.

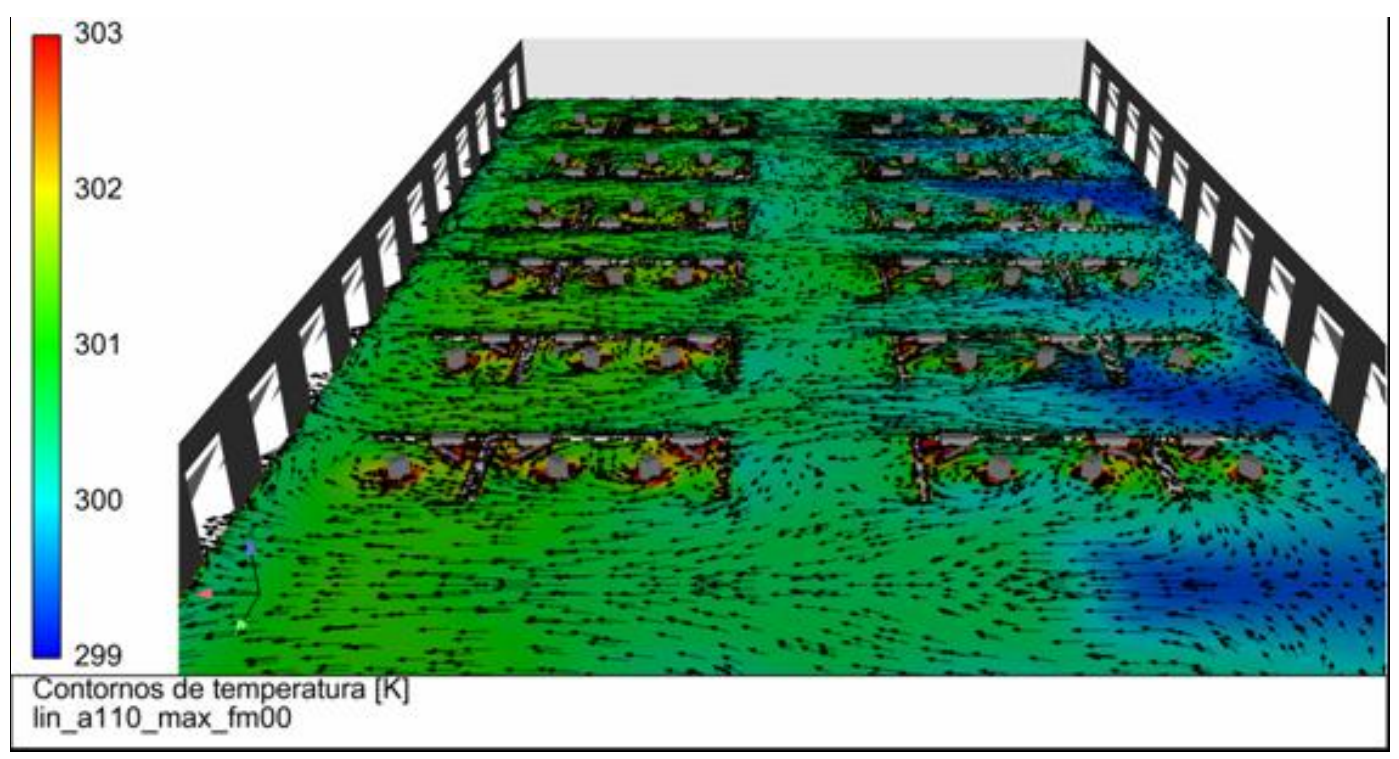

Figura 5.7.1: Plano horizontal $\mathrm{z}=1,10 \mathrm{~m}$ colorido por temperatura com vetores de velocidade para o layout em linha com partições de 1,10m, janelas maxim-ar, velocidade máxima do ar de $2 \mathrm{~m} / \mathrm{s}$ e carga térmica completa. 


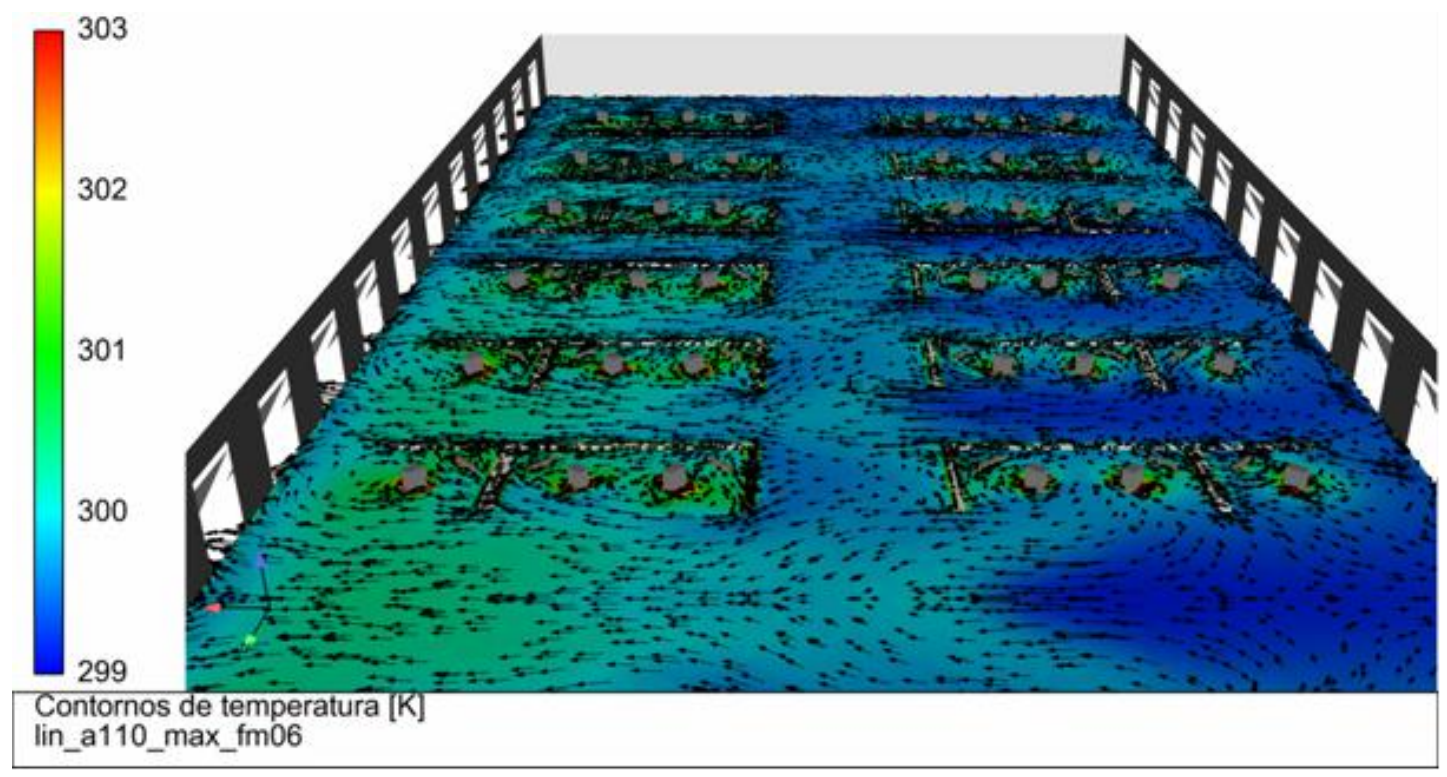

Figura 5.7.2: Plano horizontal $\mathrm{z}=1,10 \mathrm{~m}$ colorido por temperatura com vetores de velocidade para o layout em linha com partições de $1,10 \mathrm{~m}$, janelas maxim-ar, velocidade máxima do ar de $2 \mathrm{~m} / \mathrm{s}$ e carga térmica com maior redução.

Analisando planos verticais, como os das figuras 5.7.3 e 5.7.4, é possível verificar que com a redução da carga térmica houve também um aumento dos vetores de velocidade na parte superior do escritório. Este fluxo maior acabou aumentando o alcance do ar exterior dentro do escritório, o que melhora principalmente as condições nas estações de trabalho localizadas à jusante, como mostrado também na tabela 5.7.3.

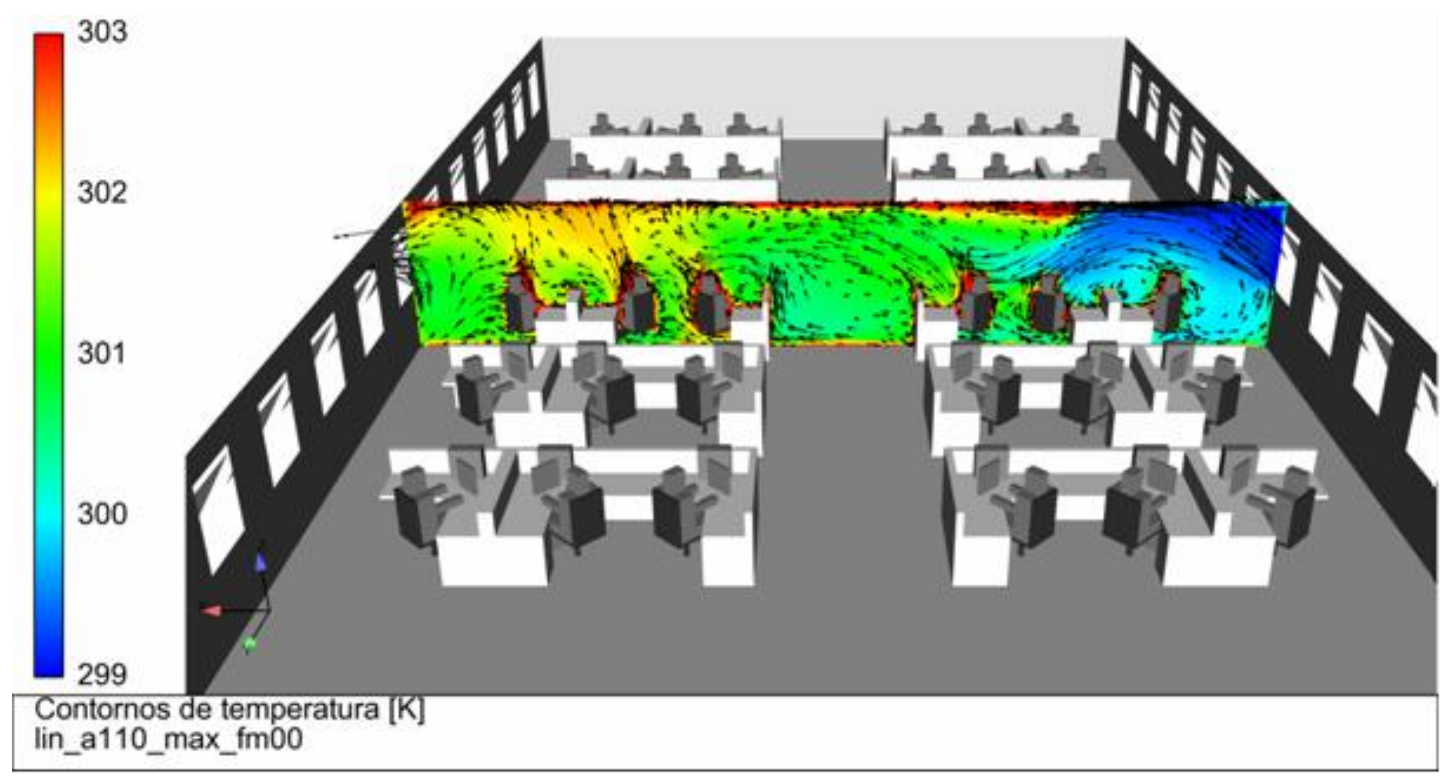

Figura 5.7.3: Plano vertical y = -9,30m colorido por temperatura com vetores de velocidade para o layout em linha com partições de 1,10m, janelas maxim-ar, velocidade máxima do ar de $2 \mathrm{~m} / \mathrm{s}$ e carga térmica completa. 


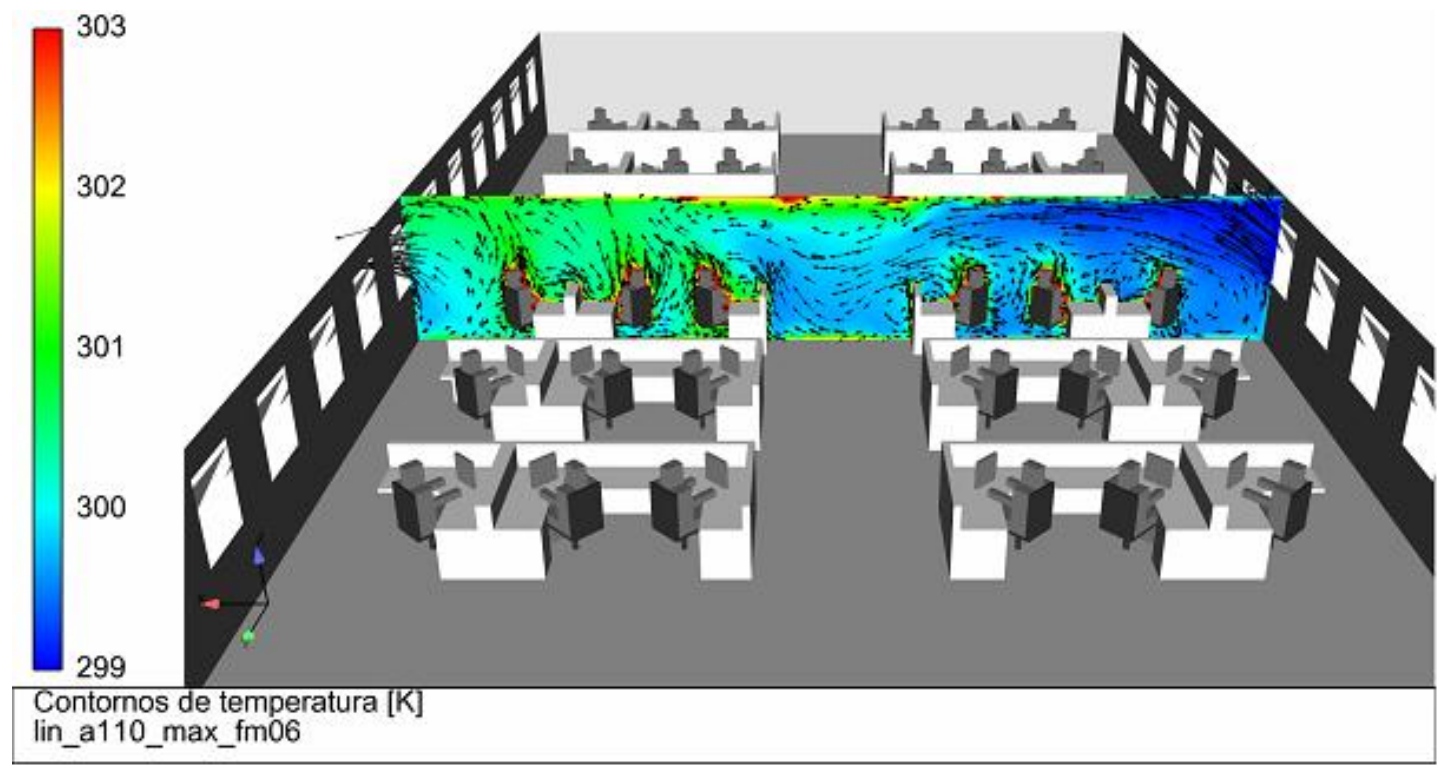

Figura 5.7.4: Plano vertical y = -9,30m colorido por temperatura com vetores de velocidade para o layout em linha com partições de $1,10 \mathrm{~m}$, janelas maxim-ar, velocidade máxima do ar de $2 \mathrm{~m} / \mathrm{s}$ e carga térmica com maior redução.

A quantidade de ar que entra nos ambientes não sofreu influência significativa da redução da carga térmica dos ambientes, embora seja possível verificar que a cada redução houve ligeiro aumento da vazão, como mostra a tabela 5.7.4, com variação máxima de apenas $1,4 \%$.

Tabela 5.7.4: Vazão de ar para a variação dos elementos geradores de carga térmica na configuração analisada.

\begin{tabular}{c|c|c|c}
\multicolumn{4}{|c}{ Vazão de ar [kg/s] } \\
\hline Carga normal & $\begin{array}{c}\text { Iluminação } \\
\text { reduzida }\end{array}$ & $\begin{array}{c}\text { Computadores } \\
\text { reduzidos }\end{array}$ & $\begin{array}{c}\text { Iluminação + } \\
\text { computadores } \\
\text { reduzidos }\end{array}$ \\
\hline 10,48 & 10,59 & 10,61 & 10,63
\end{tabular}

\subsubsection{Temperatura do ar exterior}

No mesmo ambiente analisado na seção 5.7.1, o aumento da temperatura externa para $300,5 \mathrm{~K}$ teve como consequência natural um aumento na temperatura do ar de todas as combinações de elementos geradores de carga térmica, como pode ser visto na tabela 5.7.5. 
Tabela 5.7.5: Temperatura média do ar com temperatura externa aumentada em 1,5K para a variação dos elementos geradores de carga térmica na configuração analisada.

Temperatura média do ar [K]

\begin{tabular}{c|c|c|c}
\hline \multirow{2}{*}{ Carga normal } & $\begin{array}{c}\text { Iluminação } \\
\text { reduzida }\end{array}$ & $\begin{array}{c}\text { Computadores } \\
\text { reduzidos }\end{array}$ & $\begin{array}{c}\text { Iluminação + } \\
\text { computadores } \\
\text { reduzidos }\end{array}$ \\
\hline 302,6 & 302,3 & 302,1 & 301,8
\end{tabular}

Comparando os resultados da tabela 5.7.5 com os da tabela 5.7.1, verifica-se que o aumento de $1,5 \mathrm{~K}$ da temperatura externa causou exatamente o mesmo aumento de temperatura do ar em todos os casos. Desta forma, a mesma redução de temperatura verificada na seção 5.7.1 com a redução dos elementos geradores de carga térmica foi obtida nestes casos.

Considerando a temperatura em cada um dos planos de medição, verifica-se da tabela 5.7.6 que o aumento da temperatura externa teve praticamente os mesmos resultados da temperatura global, com aumento de 1,5K em cada medição. Apenas em dois casos ocorreu um aumento diferente, de 1,6K, o que está dentro da precisão dos resultados.

Tabela 5.7.6: Temperatura do ar nos três planos de medição com temperatura externa aumentada em 1,5K para a variação dos elementos geradores de carga térmica na configuração analisada.

\begin{tabular}{c|c|c|c|c}
\multicolumn{6}{c}{ Temperatura média do ar [K] } \\
$\begin{array}{c}\text { Plano de } \\
\text { medição }\end{array}$ & Carga normal & $\begin{array}{c}\text { Iluminação } \\
\text { reduzida }\end{array}$ & $\begin{array}{c}\text { Computadores } \\
\text { reduzidos }\end{array}$ & $\begin{array}{c}\text { Iluminação + } \\
\text { computadores } \\
\text { reduzidos }\end{array}$ \\
\hline $\mathbf{0 , 1 m}$ & 302,5 & 302,1 & 302,0 & 301,7 \\
$\mathbf{0 , 6 m}$ & 302,3 & 302,1 & 301,9 & 301,6 \\
$\mathbf{1 , 1 m}$ & 303,0 & 302,6 & 302,4 & 302,1
\end{tabular}

$\mathrm{Na}$ análise dos dados de temperatura do ar separados por fileira, apresentados na tabela 5.7.7, verifica-se novamente que o aumento de temperatura em quase todas as fileiras foi de $1,5 \mathrm{~K}$. Apenas na fileira 5, para o caso de substituição dos computadores e monitores por computadores portáteis, a redução foi de $1,6 \mathrm{~K}$ 
Tabela 5.7.7: Temperatura do ar em cada fileira para a variação dos elementos geradores de carga térmica na configuração analisada.

\section{Temperatura média do ar [K]}

\begin{tabular}{c|c|c|c|c}
\hline Fileira & Carga normal & $\begin{array}{c}\text { Iluminação } \\
\text { reduzida }\end{array}$ & $\begin{array}{c}\text { Computadores } \\
\text { reduzidos }\end{array}$ & $\begin{array}{c}\text { Iluminação + } \\
\text { computadores } \\
\text { reduzidos }\end{array}$ \\
\hline $\mathbf{1}$ & 302,1 & 301,9 & 301,8 & 301,7 \\
$\mathbf{2}$ & 302,4 & 302,1 & 301,9 & 301,7 \\
$\mathbf{3}$ & 302,1 & 301,9 & 301,7 & 301,7 \\
$\mathbf{4}$ & 303,1 & 302,7 & 302,4 & 302,1 \\
$\mathbf{5}$ & 302,9 & 302,5 & 302,3 & 301,8 \\
$\mathbf{6}$ & 303,1 & 302,6 & 302,5 & 302,0
\end{tabular}

É interessante verificar nas figuras 5.7.5 e 5.7.6 que o aumento da temperatura do ar externo não causou mudanças significativas no perfil do escoamento no interior do escritório, apenas no campo de temperaturas. Esse mesmo comportamento foi repetido em todos os casos de redução dos elementos geradores de carga térmica, como exemplificado nas figuras 5.7.7 e 5.7.8.

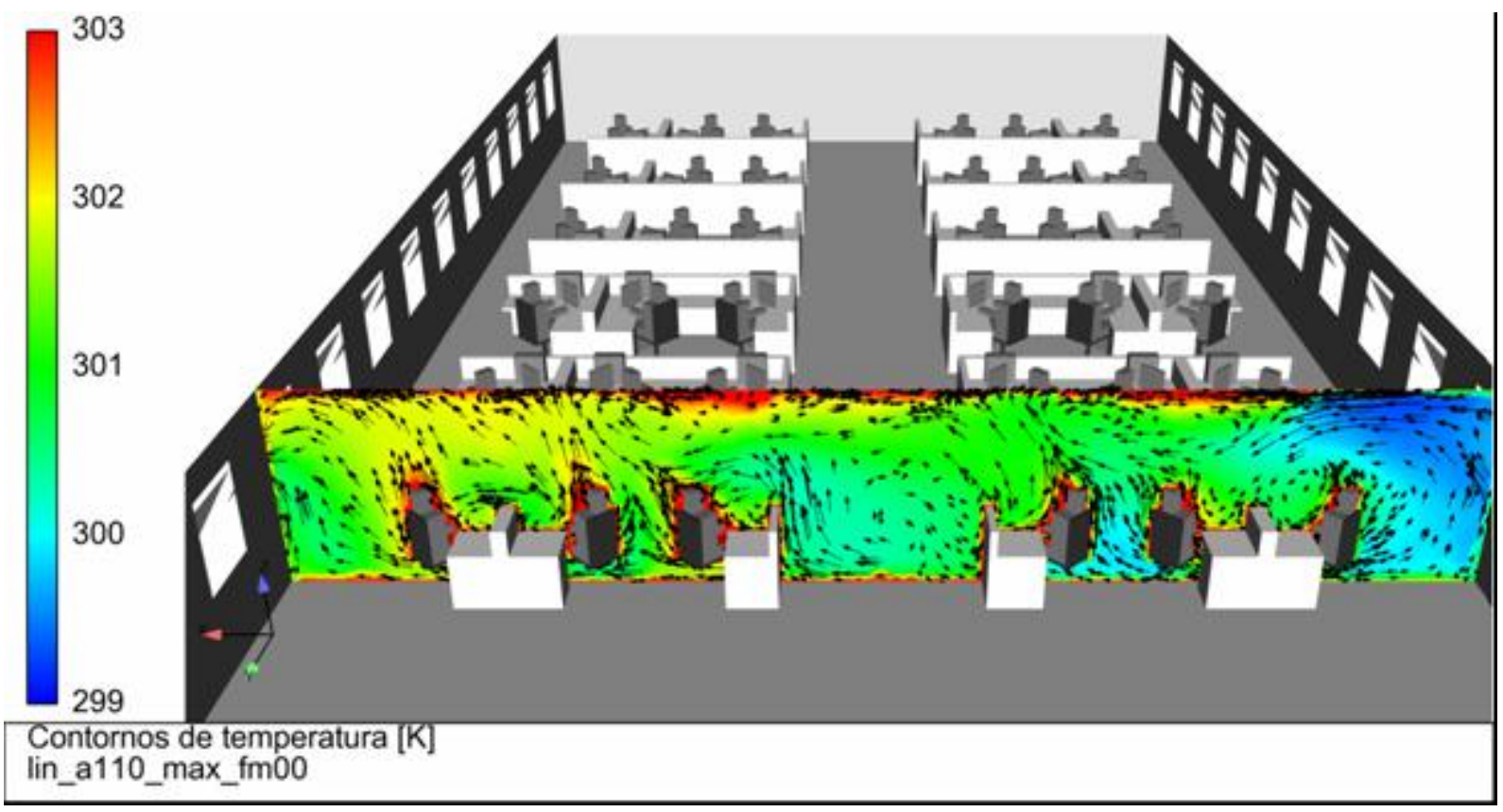

Figura 5.7.5: Plano vertical y $=-2,50 \mathrm{~m}$ colorido por temperatura com vetores de velocidade para o layout $\mathrm{em}$ linha com partições de $1,10 \mathrm{~m}$, janelas maxim-ar, velocidade máxima do ar de $2 \mathrm{~m} / \mathrm{s}$, carga térmica completa e temperatura do ar exterior de $299,0 \mathrm{~K}$. 


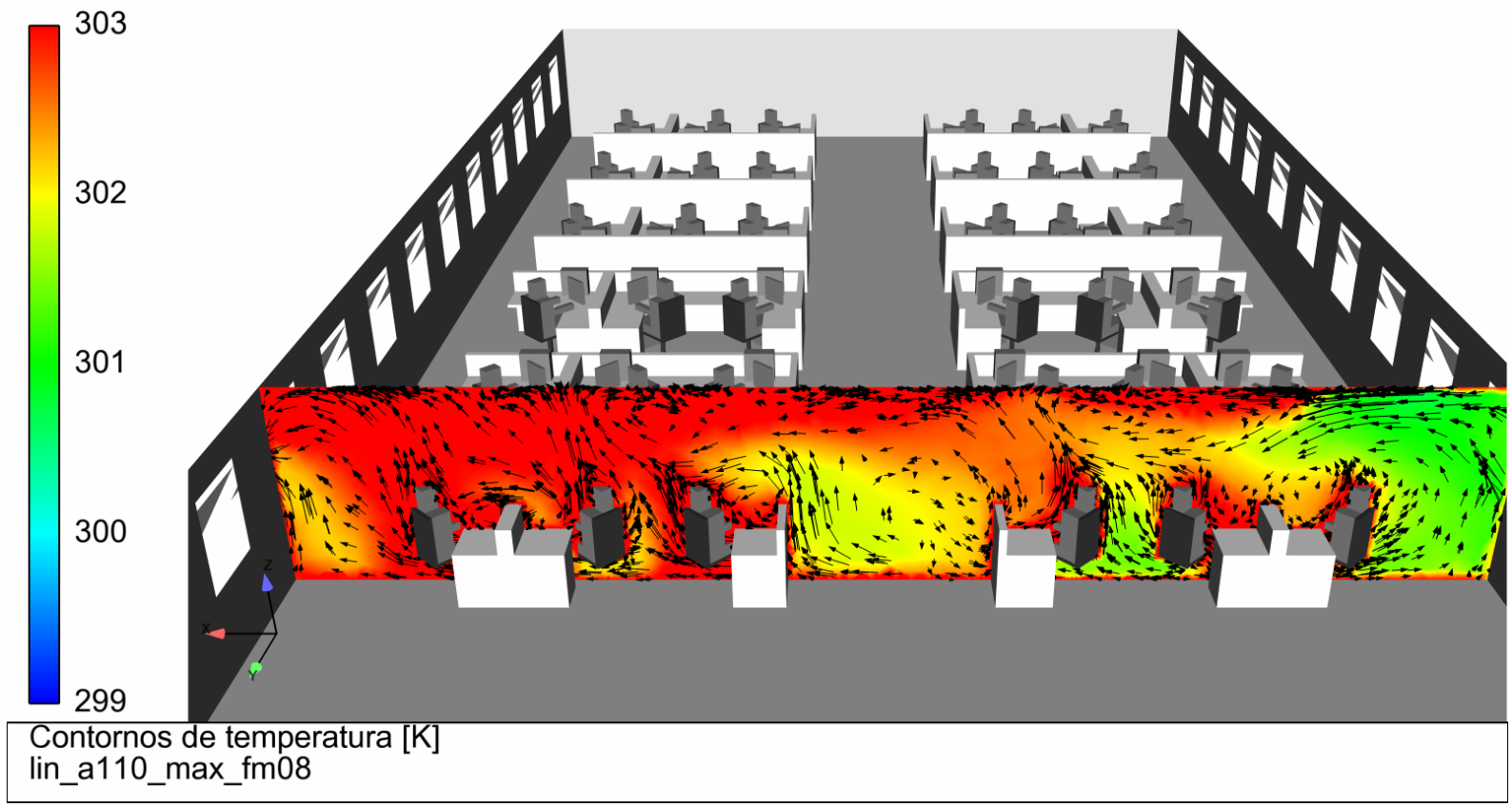

Figura 5.7.6: Plano vertical y $=-2,50 \mathrm{~m}$ colorido por temperatura com vetores de velocidade para o layout $\mathrm{em}$ linha com partições de $1,10 \mathrm{~m}$, janelas maxim-ar, velocidade máxima do ar de $2 \mathrm{~m} / \mathrm{s}$, carga térmica completa e temperatura do ar exterior de $300,5 \mathrm{~K}$.

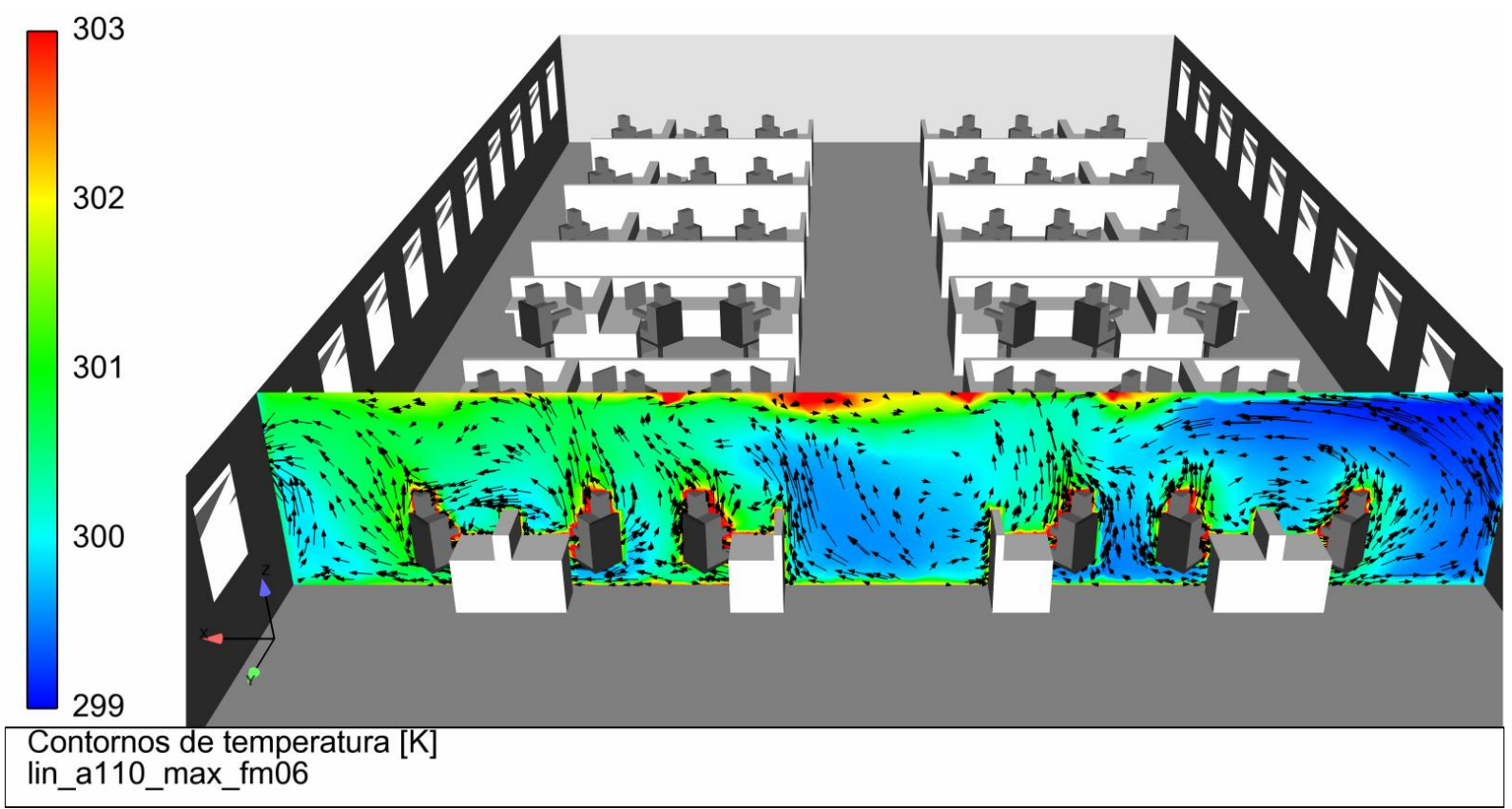

Figura 5.7.7: Plano vertical y $=-2,50 \mathrm{~m}$ colorido por temperatura com vetores de velocidade para o layout $\mathrm{em}$ linha com partições de $1,10 \mathrm{~m}$, janelas maxim-ar, velocidade máxima do ar de $2 \mathrm{~m} / \mathrm{s}$, carga com maior redução e temperatura do ar exterior de $299,0 \mathrm{~K}$. 


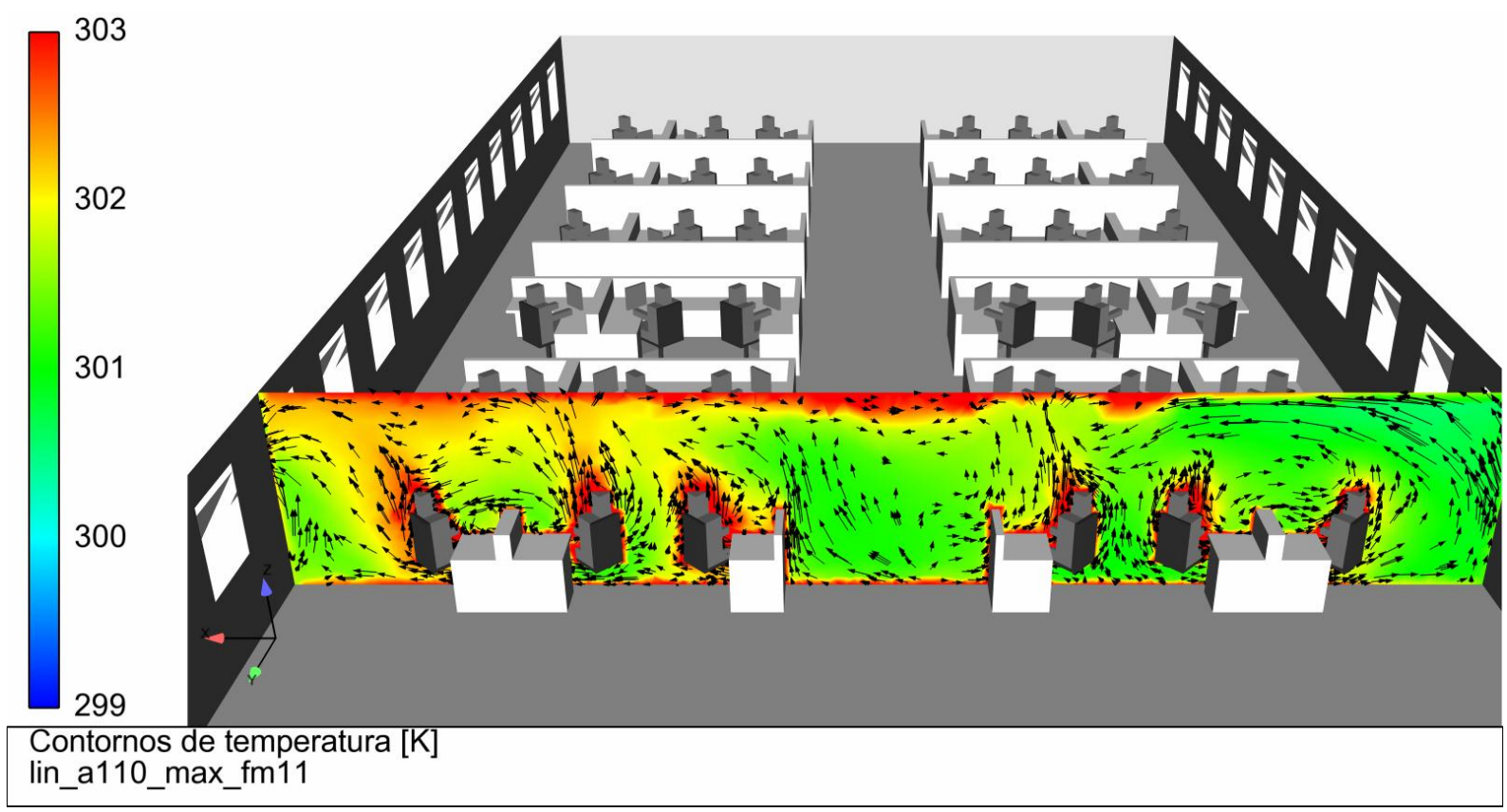

Figura 5.7.8: Plano vertical y = -9,30m colorido por temperatura com vetores de velocidade para o layout em linha com partições de $1,10 \mathrm{~m}$, janelas maxim-ar, velocidade máxima do ar de $2 \mathrm{~m} / \mathrm{s}$ e carga térmica com maior redução.

A quantidade de ar que entra nos ambientes não sofreu influência significativa do aumento da temperatura exterior. Em todos os casos houve uma redução de $0,05 \mathrm{~kg} / \mathrm{s}$ na vazão, como ilustra a tabela 5.7.8. Estas reduções representam uma variação de apenas 0,5\%.

Tabela 5.7.8: Vazão de ar para a variação dos elementos geradores de carga térmica na configuração analisada.

\begin{tabular}{c|c|c|c}
\multicolumn{4}{|c}{ Vazão de ar [kg/s] } \\
\hline Carga normal & $\begin{array}{c}\text { Iluminação } \\
\text { reduzida }\end{array}$ & $\begin{array}{c}\text { Computadores } \\
\text { reduzidos }\end{array}$ & $\begin{array}{c}\text { Iluminação + } \\
\text { computadores } \\
\text { reduzidos }\end{array}$ \\
\hline 10,43 & 10,54 & 10,56 & 10,58
\end{tabular}

\subsection{ANÁLISE DE CONFORTO TÉRMICO}

Como citado na seção 4.6.1, para a análise de conforto térmico dos ambientes simulados foi utilizada a temperatura do ar como sendo a temperatura operativa no ambiente. Da tabela 4.4.2 verifica-se que o mês mais quente do ano é fevereiro, sendo a temperatura média mensal de $23,8^{\circ} \mathrm{C}$, ou $297,0 \mathrm{~K}$. A partir deste valor, da figura 4.6 .1 obtém-se os limites 
superiores de temperatura para prover conforto a $90 \%$ ou $80 \%$ dos ocupantes, $300,9 \mathrm{~K}$ e $302,0 \mathrm{~K}$, respectivamente.

Tendo calculado a temperatura do ar em cada estação de trabalho, comparou-se este valor com o limite superior de conforto para $80 \%$ dos ocupantes, a fim de determinar se este se encontra na região de conforto ou não. Nas tabelas 5.8.1 e 5.8.2 é possível verificar a quantidade de ocupantes em conforto para as análises de mobiliário, geometria das aberturas e velocidade do vento.

Tabela 5.8.1: Percentual de estações de trabalho dentro das condições de conforto para $80 \%$ dos ocupantes para velocidade do ar exterior máxima de $2 \mathrm{~m} / \mathrm{s}$

Quantidade de estações com condições de conforto térmico

\begin{tabular}{c|c|c|c|c|}
\hline \multirow{2}{*}{ Layout } & Geometria das & \multicolumn{3}{|c|}{ Altura das Partições } \\
& Janelas & $\mathbf{0 , 9 0 m}$ & $\mathbf{1 , 1 0 m}$ & $\mathbf{1 , 5 0 m}$ \\
\hline \multirow{2}{*}{ quadrado } & Maxim-ar & $100 \%$ & $97 \%$ & $97 \%$ \\
& De correr vertical & $42 \%$ & $39 \%$ & $33 \%$ \\
\hline \multirow{2}{*}{ linha } & Maxim-ar & $100 \%$ & $100 \%$ & $100 \%$ \\
& De correr vertical & $50 \%$ & $50 \%$ & $44 \%$
\end{tabular}

Tabela 5.8.2: Percentual de estações de trabalho dentro das condições de conforto para $80 \%$ dos ocupantes para velocidade do ar exterior máxima de $4 \mathrm{~m} / \mathrm{s}$.

Quantidade de estações com condições de conforto térmico

\begin{tabular}{c|c|c|c|c|}
\hline \multirow{2}{*}{ Layout } & Geometria das & \multicolumn{3}{|c|}{ Altura das Partições } \\
& Janelas & $\mathbf{0 , 9 0 m}$ & $\mathbf{1 , 1 0 m}$ & $\mathbf{1 , 5 0 m}$ \\
\hline \multirow{2}{*}{ quadrado } & Maxim-ar & $100 \%$ & $100 \%$ & $100 \%$ \\
& De correr vertical & $100 \%$ & $100 \%$ & $100 \%$ \\
\hline \multirow{2}{*}{ linha } & Maxim-ar & $100 \%$ & $100 \%$ & $100 \%$ \\
& De correr vertical & $100 \%$ & $100 \%$ & $100 \%$
\end{tabular}

Percebe-se da tabela 5.8.2 que todos os ocupantes encontram-se em condições de conforto térmico. Caso fosse utilizado o critério mais rigoroso, de $90 \%$, estes valores seriam alterados, como indica a tabela 5.8.3. Esta tabela provê resultados semelhantes aos da tabela 
5.8.1, onde é possível verificar que a geometria das janelas muda significativamente a quantidade de estações de trabalho dentro das condições de conforto.

Tabela 5.8.3: Percentual de estações de trabalho dentro das condições de conforto para 90\% dos ocupantes para velocidade do ar exterior máxima de $4 \mathrm{~m} / \mathrm{s}$.

Quantidade de estações com condições de conforto térmico

\begin{tabular}{c|c|c|c|c|}
\hline \multirow{2}{*}{ Layout } & Geometria das & \multicolumn{3}{|c|}{ Altura das Partições } \\
& Janelas & $\mathbf{0 , 9 0 m}$ & $\mathbf{1 , 1 0 m}$ & $\mathbf{1 , 5 0 m}$ \\
\hline \multirow{3}{*}{ quadrado } & Maxim-ar & $100 \%$ & $100 \%$ & $100 \%$ \\
& De correr vertical & $75 \%$ & $78 \%$ & $61 \%$ \\
\hline \multirow{2}{*}{ linha } & Maxim-ar & $100 \%$ & $100 \%$ & $100 \%$ \\
& De correr vertical & $81 \%$ & $78 \%$ & $78 \%$
\end{tabular}

Outro dado que se obtém das tabelas 5.8.1 e 5.8.3 é que as partições possuem apenas pequena influência sobre as condições de conforto térmico das estações de trabalho. Em geral, quando houve mudança no percentual, ela foi de aproximadamente $3 \%$. Entretanto, alguns casos com partições de $1,50 \mathrm{~m}$ apresentaram o percentual um pouco mais elevado, chegando a uma diferença de até $14 \%$.

Dos resultados apresentados, percebe-se que a configuração que possui piores condições de conforto é a mesma que apresentou os maiores valores de temperatura do ar, o layout quadrado com janelas de correr vertical e partições com 1,50m de altura. Uma análise interessante é comparar as condições de conforto em cada estação de trabalho com a configuração oposta, o layout em linha com janelas maxim-ar e partições com altura de $0,90 \mathrm{~m}$.

Nas figuras 5.8.1 e 5.8.2 é possível ver as estações de trabalho do escritório, onde os ocupantes foram coloridos de acordo com a condição de conforto encontrada: verdes, os que se encontram dentro do limite de $90 \%$ satisfeitos; amarelos, os que se encontram entre os limites de $90 \%$ e $80 \%$ satisfeitos; e vermelho, os que se encontram fora do limite de $80 \%$ satisfeitos. É interessante verificar que em ambos os casos, a partir do segundo grupo de estações de trabalho no sentido do vento, houve mudança para pior nas condições de conforto dos ocupantes. 


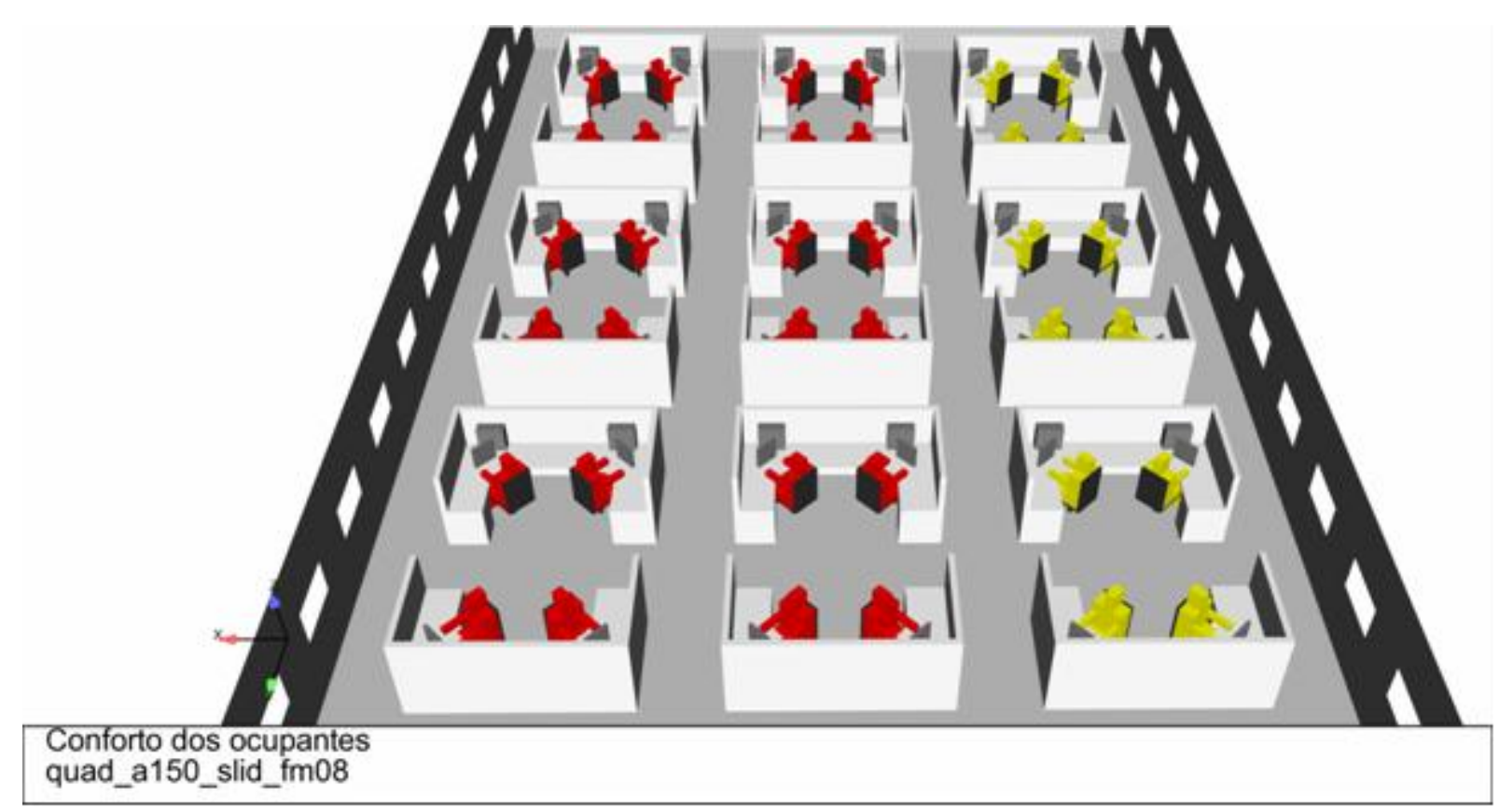

Figura 5.8.1: Ocupantes coloridos identificando condições de conforto térmico para o layout quadrado com partições de $1,50 \mathrm{~m}$, janelas de correr vertical e velocidade máxima do ar de $2 \mathrm{~m} / \mathrm{s}$.

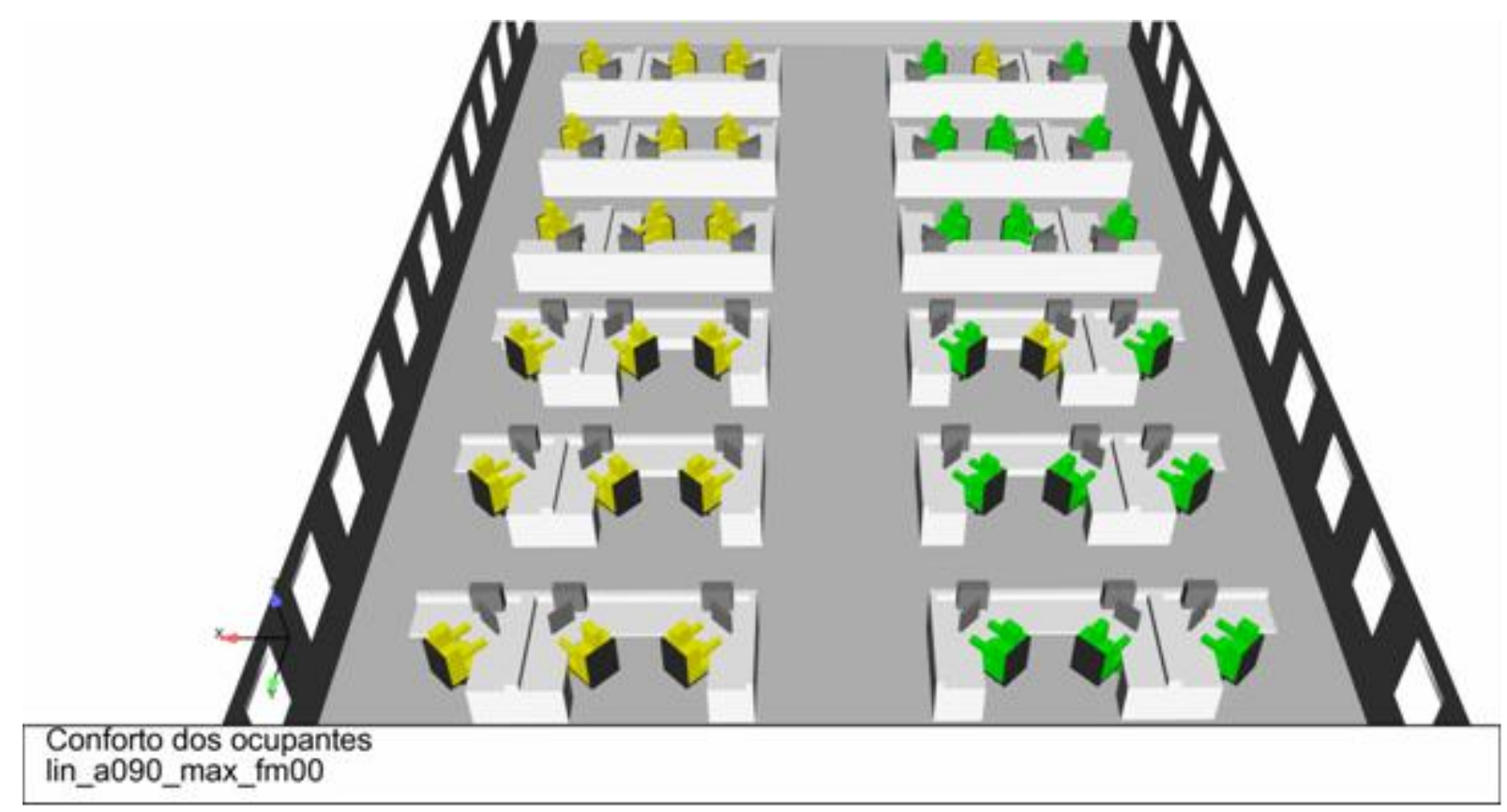

Figura 5.8.2: Ocupantes coloridos identificando condições de conforto térmico para o layout em linha com partições de $0,90 \mathrm{~m}$, janelas maxim-ar e velocidade máxima do ar de $2 \mathrm{~m} / \mathrm{s}$.

No caso escolhido para a análise dos elementos geradores de carga térmica, todos os ocupantes já se encontram dentro da região de conforto do limite de $80 \%$ satisfeitos, de forma que a redução da carga térmica no ambiente não altera estes resultados. Utilizando, no 
entanto, o critério do limite de $90 \%$ satisfeitos, já é possível verificar a existência de diferenças, como mostra a tabela 5.8.4.

Tabela 5.8.4: Estações de trabalho dentro das condições de conforto para $90 \%$ dos ocupantes para a variação dos elementos geradores de carga térmica na configuração analisada com temperatura externa de 299,0K.

\begin{tabular}{c|c|c|c}
\multicolumn{3}{c|}{ Quantidade de estações com condições de conforto térmico } \\
\hline Carga normal & $\begin{array}{c}\text { Iluminação } \\
\text { reduzida }\end{array}$ & $\begin{array}{c}\text { Computadores } \\
\text { reduzidos }\end{array}$ & $\begin{array}{c}\text { Iluminação + } \\
\text { computadores } \\
\text { reduzidos }\end{array}$ \\
\hline $44 \%$ & $58 \%$ & $89 \%$ & $100 \%$
\end{tabular}

Com o aumento de $1,5 \mathrm{~K}$ na temperatura do ar exterior, já foi possível verificar diferenças com o critério do limite de $80 \%$ satisfeitos entre os ambientes com diversas cargas térmicas, como mostra a tabela 5.8.5. Verifica-se que com a maior carga térmica quase não há ocupantes em situação de conforto, enquanto que na situação de menor carga térmica quase todos se encontram em conforto.

Tabela 5.8.5: Estações de trabalho dentro das condições de conforto para 80\% dos ocupantes para a variação dos elementos geradores de carga térmica na configuração analisada com temperatura externa de 300,5K.

\begin{tabular}{c|c|c|c}
\multicolumn{2}{c|}{ Quantidade de estações com condições de conforto térmico } \\
\hline Carga normal & $\begin{array}{c}\text { Iluminação } \\
\text { reduzida }\end{array}$ & $\begin{array}{c}\text { Computadores } \\
\text { reduzidos }\end{array}$ & $\begin{array}{c}\text { Iluminação + } \\
\text { computadores } \\
\text { reduzidos }\end{array}$ \\
\hline $14 \%$ & $36 \%$ & $53 \%$ & $81 \%$
\end{tabular}

Na figura 5.8.3 é possível verificar que os ocupantes com condições de conforto estão nos grupos de estações de trabalho mais próximos da janela de entrada do ar. Para o caso de menor carga térmica, verifica-se da figura 5.8.4 que a maioria os ocupantes fora das condições de conforto estão nos grupos das estações de mais longe da janela de entrada de ar e mais perto do centro do escritório. 


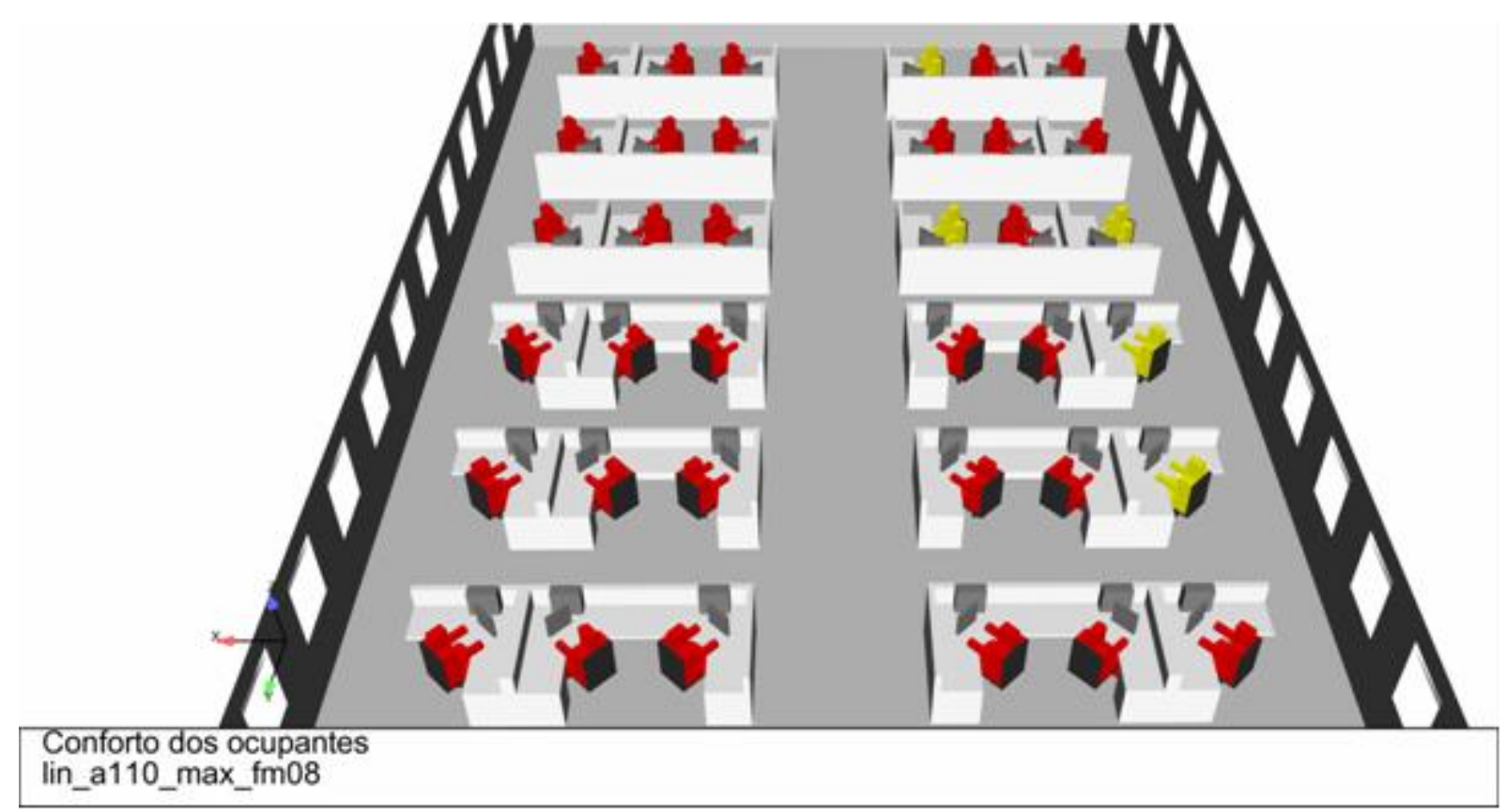

Figura 5.8.3: Ocupantes coloridos identificando condições de conforto térmico para a configuração analisada com carga térmica máxima e temperatura do ar externo de 300,5K.

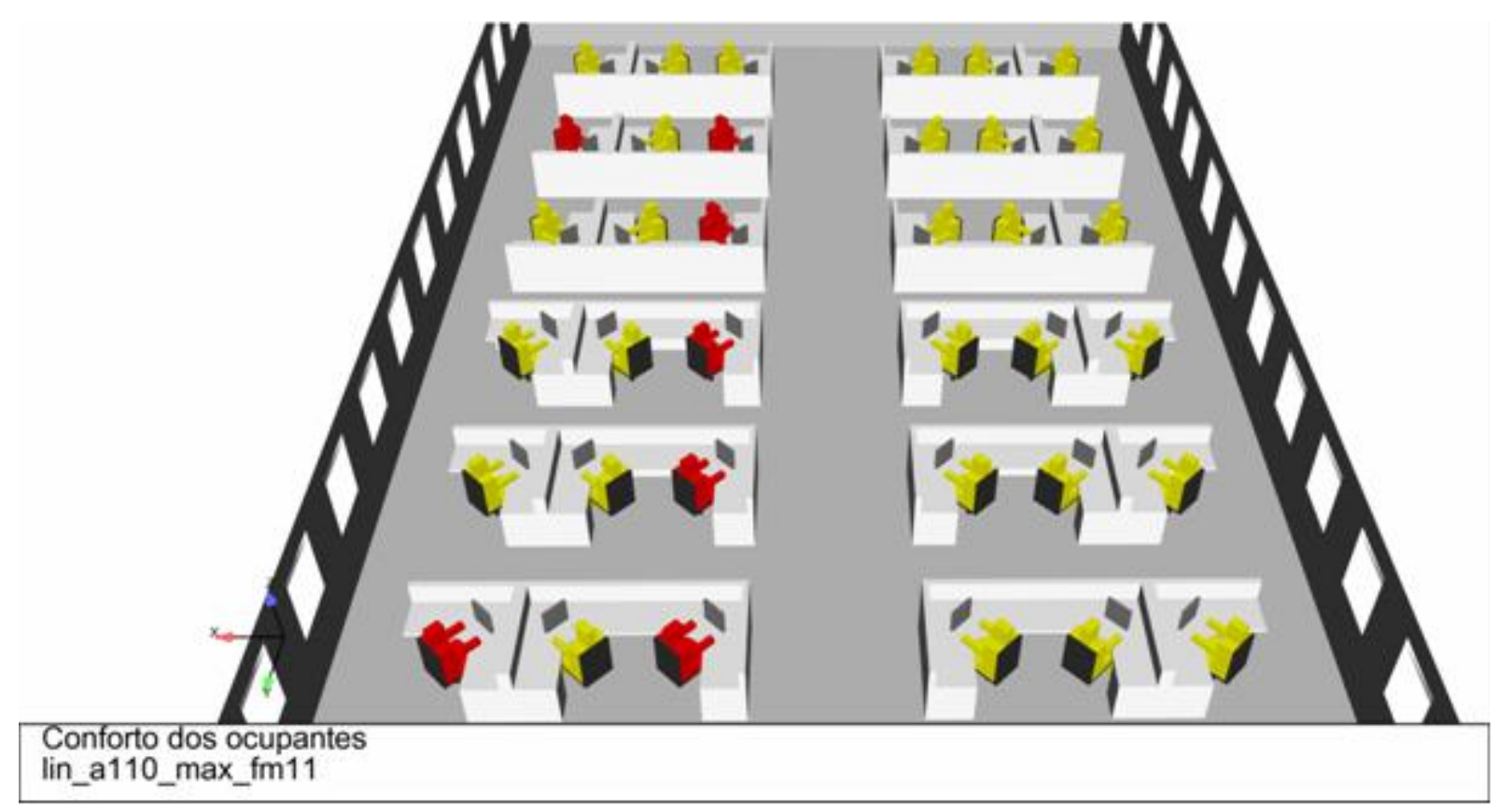

Figura 5.8.4: Ocupantes coloridos identificando condições de conforto térmico para a configuração analisada com carga térmica mínima e temperatura do ar externo de 300,5K. 


\section{CAPÍTULO 6 CONSIDERAÇÕES FINAIS E CONCLUSÕES}

Neste capítulo são apresentadas as considerações finais e conclusões da análise numérica da ventilação natural nos ambientes estudados. Conclusões específicas sobre a influência do mobiliário, aberturas da edificação e velocidade do vento encontram-se em tópicos separados, todos dentro da seção 6.1.

Neste trabalho houve diversas dificuldades enfrentadas até que fosse possível determinar uma metodologia satisfatória para as simulações numéricas, de forma que há também uma seção onde são descritos os principais empecilhos encontrados e qual foi a solução abordada para eles.

Por fim, encontram-se sugestões de trabalhos futuros que podem ser realizados nesta linha de pesquisa. A ventilação natural é um fenômeno abordado há muito tempo por arquitetos e engenheiros, porém ainda há frentes a serem exploradas, especialmente considerando as ferramentas de simulação numérica disponíveis.

\subsection{CONCLUSÕES}

De maneira geral, verifica-se que a ferramenta numérica possui boa capacidade de aplicação em projetos de ventilação natural. A possibilidade de se verificar com maior precisão o fluxo de ar que se distribui no interior do ambiente, assim como sua interação com a fachada da edificação analisada, permite antecipar problemas e procurar por soluções alternativas.

Dentre as configurações analisadas, a que apresentou as mais altas temperaturas do ar e menor vazão de ar foi o layout quadrado com partições de $1,50 \mathrm{~m}$ de altura e janelas de correr vertical. Como contraponto, a configuração que apresentou os melhores resultados foi o layout quadrado com partições de $0,90 \mathrm{~m}$ de altura e janelas maxim-ar.

Em diversos casos as diferenças de temperatura foram pequenas, com apenas alguns décimos de Kelvin, o que não deixa possível tomar por certo que determinada característica seja pior do que a outra. Entretanto, é interessante verificar que, por possuir os piores 
resultados, a configuração com layout quadrado, partições de 1,50m de altura e janelas de correr vertical provavelmente reuniu os piores elementos para a ventilação natural de escritórios, dentre aqueles abordados neste trabalho.

\subsubsection{Influência do mobiliário}

De maneira geral, o aumento da temperatura do ar devido à mudança da altura das partições ou do layout foi pequeno, especialmente em comparação com a mudança da geometria das janelas. Entretanto, na condição mais severa, verificou-se uma influência das divisórias de 1,50m, com diferença de $0,4 \mathrm{~K}$ para as demais alturas de partição.

Desta forma, é possível afirmar que as partições de $1,50 \mathrm{~m}$ podem sim afetar as condições térmicas do ambiente de escritório, além de piorar a iluminação do espaço. Entretanto, considerando a variação de $0,90 \mathrm{~m}$ para $1,10 \mathrm{~m}$, as temperaturas permaneceram praticamente iguais, de forma que para estas alturas de partições não é possível afirmar qualquer tendência de mudança dos resultados.

Uma vez que partições mais altas oferecem um pouco mais de privacidade para os ocupantes, é possível concluir que a altura mais recomendada é a de 1,10m. Uma vantagem desta altura de partição é que as janelas se encontram a 1,10m do piso, de forma que elas não prejudicam a entrada de ar no ambiente.

Nas figuras 5.3.1 e 5.3.2 é possível ver como as partições de $1,50 \mathrm{~m}$ localizadas na primeira estação de trabalho bloqueiam o fluxo de entrada do ar, enquanto que as partições de 0,90m permitem acesso direto ao fluxo de ar dos dois primeiros ocupantes. A figura 6.1.1 apresenta um detalhe da estação de trabalho à montante, onde é possível ver que estas partições não oferecem grande resistência à entrada do ar.

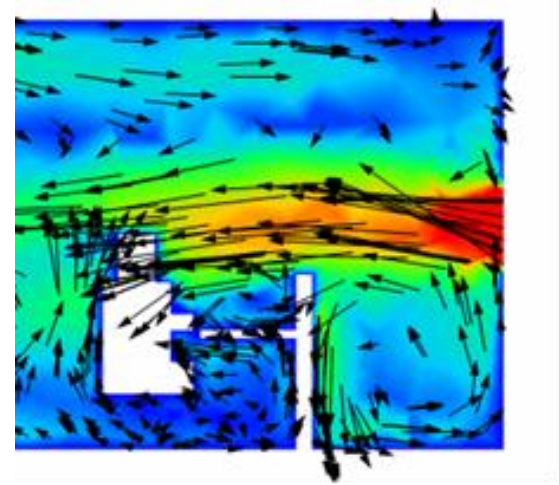

Figura 6.1.1: Detalhe do plano vertical $\mathrm{y}=-12,65 \mathrm{~m}$ colorido por velocidade com os respectivos vetores para o layout quadrado com partições de 1,10m, janelas de correr vertical e velocidade máxima do ar de $2 \mathrm{~m} / \mathrm{s}$. 
Considerando a mudança de layout, os resultados permaneceram praticamente os mesmos, não sendo possível garantir que uma determinada configuração seja melhor do que a outra. Entretanto, considerando o escritório com altura das partições de 1,50m, janelas de correr vertical e velocidades mais baixas do ar, o layout em linha teve uma redução de $0,4 \mathrm{~K}$ na temperatura do ar.

Uma hipótese para o layout em linha ter possibilitado resultados melhores é a de que $33 \%$ dos ocupantes têm acesso direto às janelas. Ainda, os ocupantes centrais possuem apenas uma partição entre eles e as janelas o que, aliado às partições mais baixas, diminui as barreiras para o fluxo de ar e tende a melhorar as temperaturas, como ilustram as figuras 6.1.2 e 6.1.3.

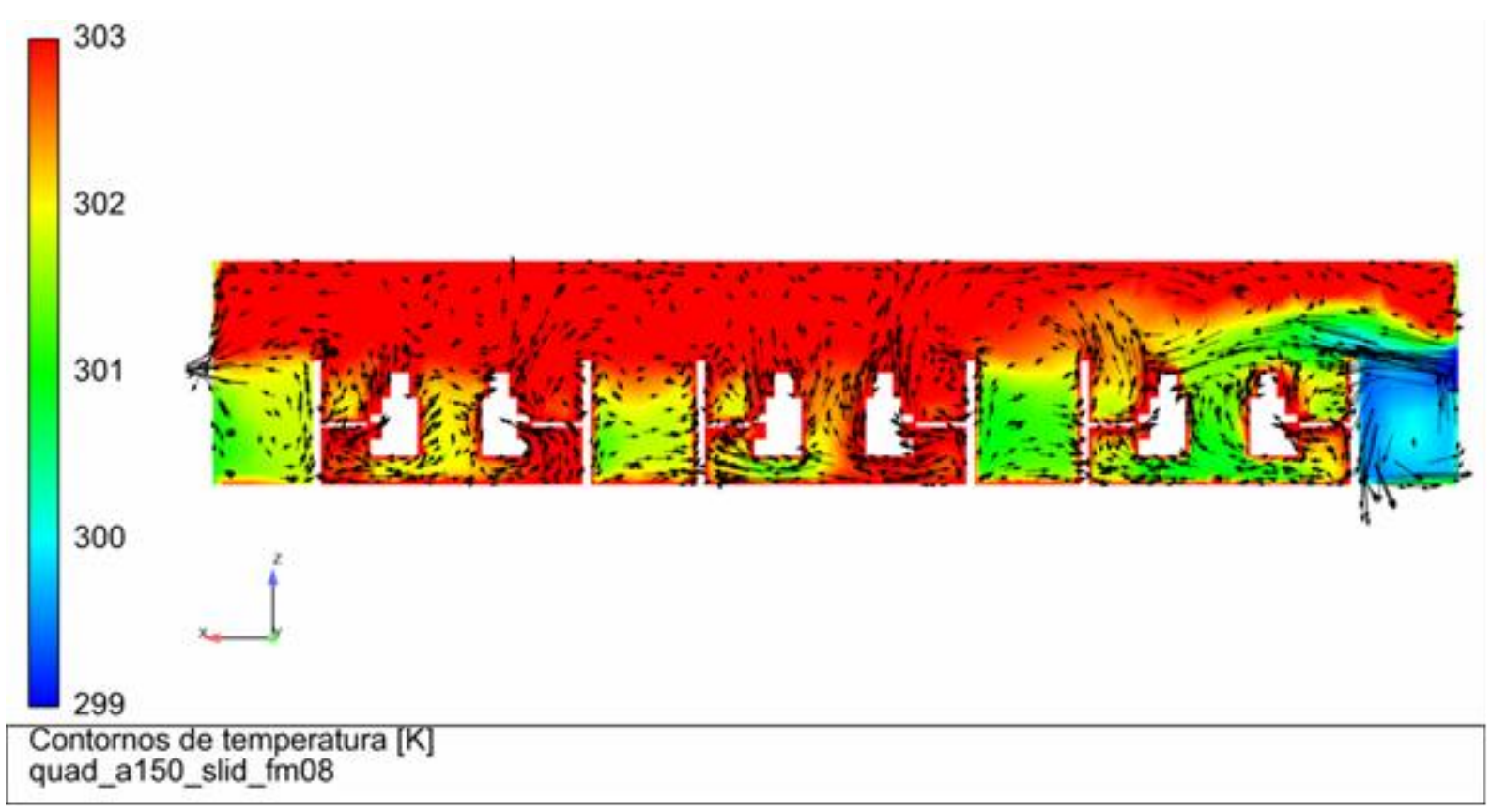

Figura 6.1.2: Plano vertical $\mathrm{y}=-13,20 \mathrm{~m}$ colorido por temperatura com os vetores de velocidade para o layout quadrado com partições de $1,50 \mathrm{~m}$, janelas de correr vertical e velocidade máxima do ar de $2 \mathrm{~m} / \mathrm{s}$.

É interessante verificar que o único caso onde foi possível verificar alguma diferença entre os layouts foi o caso que resultou nos piores valores de temperatura. Talvez simulações com velocidades ainda mais baixas do ar permitam determinar qual destes layouts seria mais adequado para a ventilação natural. 


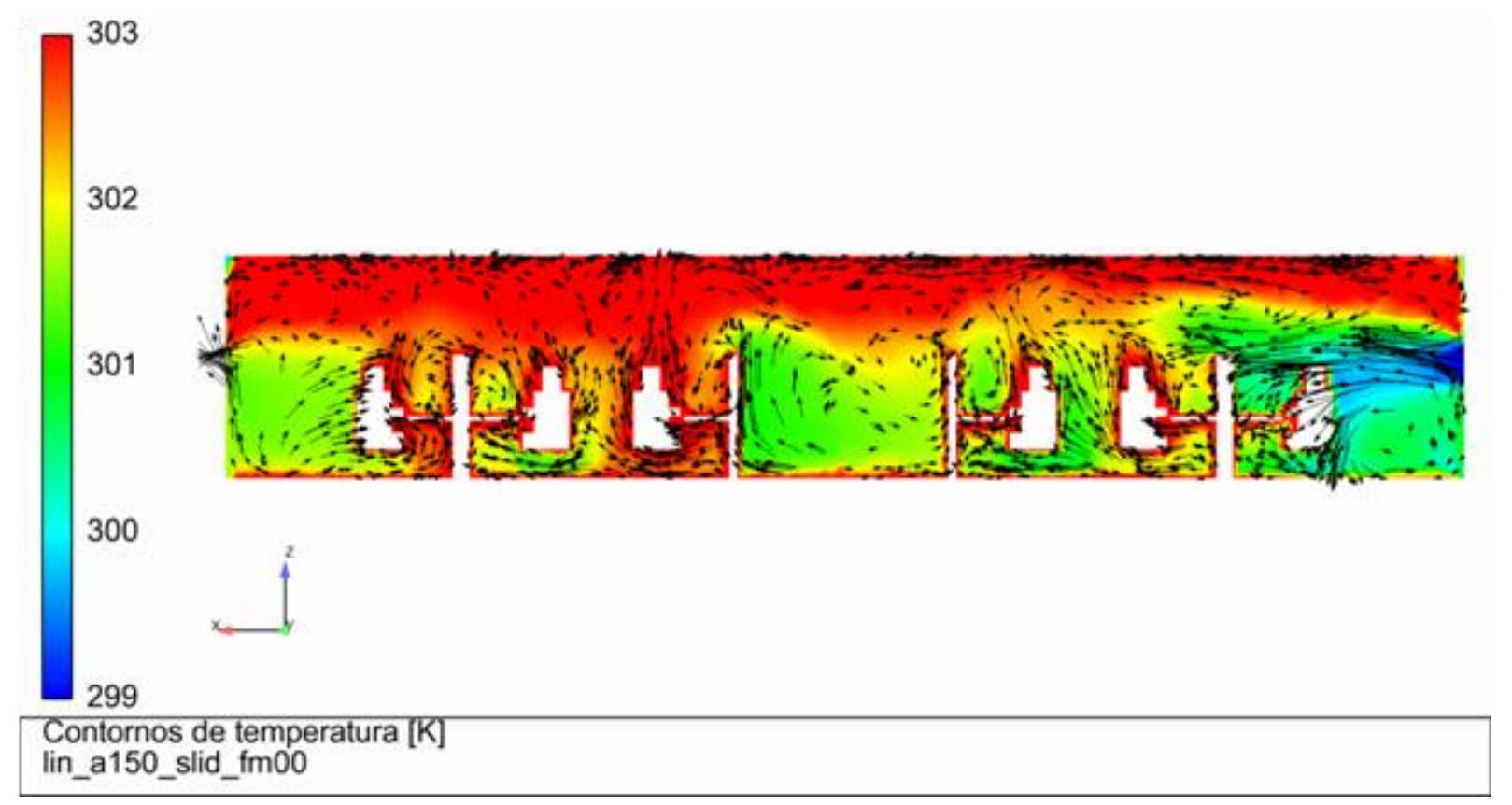

Figura 6.1.3: Plano vertical y = -13,20m colorido por temperatura com os vetores de velocidade para o layout em linha com partições de $1,50 \mathrm{~m}$, janelas de correr vertical e velocidade máxima do ar de $2 \mathrm{~m} / \mathrm{s}$.

Tanto para as mudanças de altura das partições como para a mudança do layout, na configuração com maiores diferenças de temperatura do ar a maior diferença ocorreu no plano das cabeças, região que justamente sofre maior influência das barreiras impostas pelo mobiliário sobre o escoamento de ar.

Destaca-se, contudo, que todas as configurações de mobiliário analisadas já possuem características recomendadas para ambientes ventilados naturalmente, como por exemplo os layouts em estilo aberto, sem paredes ou outras obstruções que ocupem toda a altura do escritório. Ainda, as geometrias simuladas não possuíam estantes ou arquivos, elementos de mobiliário que por conta de sua altura também se recomenda tomar mais cuidado com seu posicionamento em ambientes ventilados naturalmente.

\subsubsection{Influência das aberturas}

A principal conclusão que se obteve da modificação das aberturas é que dentre as geometrias simuladas a maxim-ar apresentou resultados superiores às de correr vertical, sendo preferíveis para o emprego em ambientes de escritórios ventilados naturalmente. Especialmente com velocidades menores do vento, a maxim-ar apresentou resultados significativamente melhores de temperaturas no ambiente. 
Esta diferença de temperaturas é decorrente de dois elementos principais na ventilação de ambientes: a entrada de um volume expressivamente maior de ar externo com janelas maxim-ar; e sua melhor distribuição no ambiente interior. O escoamento mais bem distribuído permitiu que o ar alcançasse até mesmo estações de trabalho localizadas próximas às janelas de saída do ar, aumentado assim a convecção forçada nestas estações de trabalho e reduzindo a temperatura do ar.

As janelas de correr vertical mostraram-se mais sensíveis à mudança da velocidade do vento, pois com velocidade máxima do vento de $2 \mathrm{~m} / \mathrm{s}$ foram observadas mudanças um pouco mais significativas não apenas no campo de temperaturas, mas também sobre como o fluxo de ar distribui-se pelo ambiente ventilado.

Como pode ser observado, com a velocidade máxima do vento de $4 \mathrm{~m} / \mathrm{s}$ o ar tinha potencial suficiente para alcançar grandes distâncias, tornando menor a diferença para os ambientes com janelas maxim-ar. Entretanto, com a velocidade mais baixa, verificou-se que as barreiras impostas pelo mobiliário interno prejudicaram demasiadamente a entrada de ar, tornando o escoamento do ar no escritório menos propício para a obtenção de conforto térmico.

A fim de melhorar o desempenho das janelas de correr vertical, uma primeira medida fundamental seria aumentar a área efetiva de abertura, de maneira a permitir a entrada de um fluxo maior de ar. Com maior quantidade de ar, abre-se a possibilidade de maior remoção de carga térmica, como pode ser observado nas simulações.

Uma segunda medida importante também seria melhorar o posicionamento das janelas na fachada, tendo em vista a distribuição do fluxo de ar no interior do ambiente. Como foi observado para o layout quadrado com partições de $1,50 \mathrm{~m}$, a incidência direta do ar sobre uma partição prejudicou a entrada do ar nos ambientes simulados.

Verificou-se nos resultados das janelas maxim-ar que o fluxo era deslocado para o alto do escritório, junto ao teto, permitindo que o ar alcançasse maiores distâncias. Essa característica, aliada à maior vazão de ar, permitiu que com velocidade máxima do vento de $4 \mathrm{~m} / \mathrm{s}$ as temperaturas continuassem menores. Desta forma, quando houve redução de velocidade do ar, as temperaturas não subiram demasiadamente.

Como pode ser visto no Apêndice A, onde consta um resumo dos principais resultados das simulações, de maneira geral houve um aumento de temperatura da ordem de $1 \mathrm{~K}$ quando se utilizou janelas de correr vertical no lugar das maxim-ar para ventos com velocidade máxima de $2 \mathrm{~m} / \mathrm{s}$. 


\subsubsection{Influência da velocidade do ar}

Já era esperado que a velocidade do vento exercesse uma influência mais significativa sobre as condições térmicas do ambiente, uma vez que esse é o elemento principal da ventilação natural. Entretanto, foi interessante verificar que de acordo com a velocidade do vento escolhida existe a possibilidade de mascarar ou não alguns resultados.

Por exemplo, utilizando a velocidade do ar máxima de $4 \mathrm{~m} / \mathrm{s}$ nos escritórios com layout em linha, a diferença de temperatura ao se trocar a geometria das janelas foi de apenas $0,1 \mathrm{~K}$ com as partições mais baixas, o que poderia levar a crer que nesta configuração de mobiliário a geometria das janelas possuía pouca influência.

Entretanto, ao utilizar a velocidade do vento mais baixa, verificaram-se diferenças de temperaturas de até $1,0 \mathrm{~K}$, o que indica a existência de influência das aberturas. Mesmo em outros cenários, a redução da velocidade do vento amplificou as diferenças, tornando possível avaliar com maior precisão se existe ou não influência e quantificá-la.

Em outras palavras, verificou-se que a utilização de velocidades do vento mais baixas realça a diferença entre os demais elementos sob análise, de forma que em estudos de viabilidade deve ser dada preferência para estas condições mais rigorosas do clima.

Como recomendação de projeto, destaca-se que o potencial de remoção de carga térmica com a convecção forçada mostrou-se bastante superior ao da convecção natural. Desta forma, o primeiro passo para um bom projeto de ventilação natural é tentar maximizar a vazão de ar que entra no ambiente.

Esta otimização pode se dar de diferentes maneiras, utilizando-se plantas mais adequadas para o emprego desta estratégia de ventilação, com um estudo detalhado dos ventos locais para melhorar a orientação da edificação e até mesmo analisar as construções no entorno, que podem reduzir o fluxo de ar incidente na fachada da edificação ou até mesmo aumentá-lo, caso ocorra a formação de um efeito canal.

É interessante observar que, com maior velocidade do vento, o ambiente é ventilado em maiores distâncias. Esta é uma das razões pela qual se afirma que as plantas retangulares estreitas são mais recomendadas para o emprego da ventilação natural.

Por fim, destaca-se também das simulações que a temperatura do ar é significativamente influenciada por pequenas variações da vazão de ar quando a velocidade é baixa. Como pode ser visto nas figuras 5.6.11 e 5.6.12, uma redução de 1,6\% na vazão de ar causou um aumento de temperatura de $0,4 \mathrm{~K}$. Desta forma, é importante frisar que uma boa 
modelagem do ar que entra nos ambientes é muito importante para se obter bons resultados da simulação numérica.

\subsubsection{Influência dos elementos geradores de carga térmica}

A redução dos elementos que geram carga térmica no ambiente causou um decréscimo da temperatura do ar, o que já era esperado. Diminuir a potência instalada de iluminação e substituir os equipamentos convencionais por outros mais econômicos são medidas conhecidas e eficientes na melhoria das condições térmicas ambientais, além de reduzir o consumo de energia de uma edificação.

A diminuição na potência de iluminação significou uma redução absoluta de $3.072 \mathrm{~W}$ instalados no escritório, enquanto que a substituição dos computadores e monitores por computadores portáteis representou uma redução absoluta de $7.920 \mathrm{~W}$. A princípio, a redução nos equipamentos é mais fácil de ser efetuada, já que a iluminação deve sempre prover uma iluminância mínima no plano de trabalho, de acordo com a atividade exercida no ambiente.

Por meio de uma comparação simples, verifica-se que para a redução de $0,1 \mathrm{~K}$ na temperatura dos ambientes seria necessário reduzir em aproximadamente 500W a potência de iluminação instalada e em $800 \mathrm{~W}$ os equipamentos. Desta forma, ressalta-se a importância de um bom projeto de iluminação quando se tem como intenção de projeto utilizar ventilação natural no ambiente, ou mesmo apenas reduzir o consumo de energia de um sistema mecânico de climatização.

É interessante verificar que, com a redução simultânea dos dois elementos geradores de carga térmica, a redução da temperatura do ar foi de $0,8 \mathrm{~K}$. Com o uso das janelas maximar no lugar das de correr vertical, na média, também houve uma redução da temperatura do ar de $0,8 \mathrm{~K}$, de forma a ressaltar o grande potencial de melhoria das condições ambientais com a escolha adequada da geometria das aberturas.

Considerando a carga térmica total dos ambientes, o pior cenário possuía $39,3 \mathrm{~W} / \mathrm{m}^{2}$, enquanto que no caso com menor carga térmica havia 20,0W/m2. CIBSE (2005) recomenda como regra geral que a carga térmica total do ambiente não ultrapasse $40 \mathrm{~W} / \mathrm{m}^{2}$, ou seja, com o acréscimo de uma carga térmica solar o primeiro escritório certamente ultrapassaria este limite, enquanto que outro poderia se encaixar neste perfil. 


\subsubsection{Influência da temperatura do ar}

De início já se sabia que o aumento da temperatura externa causaria também um aumento da temperatura do ar no ambiente de escritório. Contudo, foi interessante verificar que, para os quatro casos de diferentes cargas térmicas internas, o aumento da temperatura exterior foi o mesmo nos diversos planos de medição e fileiras das estações de trabalho.

Desta forma, para ventos de igual ou maior intensidade, é possível supor a existência de certa linearidade na relação entre a temperatura exterior e interior. Como consequência, seria possível então estimar qual a temperatura externa máxima que ainda proveria condições de conforto térmico para os ocupantes.

Ainda, supondo válida esta relação, seria possível afirmar que a redução da temperatura causada pela escolha adequada do mobiliário e da geometria das janelas permitiria o mesmo aumento da temperatura externa, sem comprometer as condições de conforto térmico do ambiente.

Ventos de menor intensidade, contudo, aumentam a parcela de importância da convecção natural na troca de calor entre o ar e os elementos geradores de carga térmica. É possível que em situações de velocidade do vento muita baixa ou ausente esta relação direta entre temperatura externa e interna não seja verificada.

Destaca-se que nas duas temperaturas externas simuladas a redução da liberação de calor dos elementos geradores de carga térmica reduziu na mesma proporção a temperatura do ar no ambiente. Verifica-se, então, que esta estratégia se mantém importante mesmo em situações de temperatura exterior mais elevada.

\subsubsection{Influência sobre as condições de conforto térmico}

O primeiro resultado interessante da análise do conforto térmico é que com a velocidade do vento de $4 \mathrm{~m} / \mathrm{s}$ todas as estações de trabalho de todos os ambientes analisados apresentaram condições de conforto térmico dentro do limite de $80 \%$ de satisfeitos. Este é um indicativo importante de que em projetos de sistemas de ventilação natural deve haver uma preocupação com a orientação e forma da edificação, a fim de maximizar a incidência de ventos sobre as janelas.

Além deste, verificou-se que com a escolha adequada da temperatura externa foi possível verificar o quanto as cargas internas podem influenciar as condições de conforto 
térmico. Como mostrado na tabela 5.8.5, a redução da carga térmica do ambiente foi capaz de mudar um cenário bem desfavorável, com apenas 14\% das estações com condições de conforto, para outro bem mais promissor, com $81 \%$ dos locais com condições adequadas. Desta forma, muito cuidado deve ser dado às cargas térmicas internas de ambientes naturalmente ventilados.

Supondo novamente a relação de linearidade entre a temperatura do ar exterior e a interior, apresentada na seção 6.1.5, seria possível então utilizá-la para estimar inicialmente a temperatura limite de conforto térmico. Esta abordagem foi utilizada para se determinar a temperatura externa de $300,5 \mathrm{~K}$, a fim de que fossem realçadas as diferenças entre os ambientes com cargas térmicas diferentes.

Outro aspecto que deve ser destacado é que nos ambientes com janelas de correr vertical e velocidade máxima do ar de $2 \mathrm{~m} / \mathrm{s}$ foi possível verificar diferenças no percentual de ocupantes em conforto, embora as temperaturas do ar sejam bem próximas. A causa deste fato é que as temperaturas do ar nas estações de trabalho encontram-se em valores muito próximos do limite de temperatura para $80 \%$ de satisfeitos, $302,0 \mathrm{~K}$.

Desta forma, pequenas oscilações de temperatura podem mudar significativamente os resultados de conforto, que são basicamente uma condição binária de "atende" ou "não atende". Esta é uma razão pela qual a análise do conforto térmico deve ser acompanhada pela análise de outras variáveis preferencialmente contínuas, como a temperatura do ar.

Por fim, é interessante ressaltar que em diversos casos simulados foi possível prover boas condições de conforto térmico aos ocupantes. Consequentemente, com os devidos cuidados na implantação da edificação, escolha das aberturas, configuração dos mobiliários e das cargas térmicas internas é possível utilizar sistemas de ventilação natural em ambientes de escritórios com bons resultados.

\subsection{PRINCIPAIS DIFICULDADES ENCONTRADAS NA SIMULAÇÃO}

A principal dificuldade presente no trabalho foi a determinação dos parâmetros numéricos suficientes e/ou necessários para se obter resultados adequados das simulações. Como se trata de um fenômeno complexo, a mudança de diversas configurações do programa computacional faz-se necessária. 
No total, 131 simulações foram realizadas no desenvolvimento do trabalho, desde os primeiros modelos mais simplificados até os trinta e cinco casos de onde foram obtidos os resultados apresentados no capítulo 5. No processo, as seguintes etapas foram necessárias:

a) Criação e aprimoramento das geometrias;

b) Desenvolvimento das malhas;

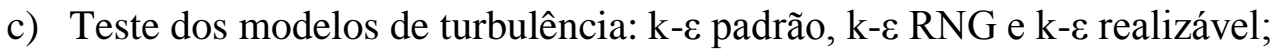

d) Opções do modelo k-E realizável: efeitos totais de empuxo e aquecimento viscoso;

e) Escolha do momento do processo iterativo para trocar o modelo de turbulência;

f) Escolha do momento do processo iterativo para adotar soluções de segunda ordem;

g) Modelos de massa específica do ar: constante, gás-ideal, modelo de Boussinesq, gás ideal incompressível;

h) Modelos de discretização da pressão: padrão, segunda ordem, ponderado pelas forças de campo;

i) Limitação do máximo e mínimo para temperatura;

j) Parâmetros de subrelaxação: quantidade de movimento, energia cinética turbulenta e dissipação da turbulência;

k) Inclusão das lâmpadas nos modelos;

1) Inclusão de modelo de transferência de calor por radiação

m) Escolha do modelo de radiação: ordenadas discretas (DO),

n) Acoplamento ou não da radiação com a equação da energia;

o) Iterações necessárias para se obter convergência das propriedades monitoradas;

p) Testes de independência de malha;

q) Variação da temperatura do ar;

r) Variação da velocidade do ar;

s) Variação da taxa de liberação de calor dos elementos geradores de carga térmica. 


\subsection{SUGESTÕES PARA TRABALHOS FUTUROS}

A primeira sugestão para trabalhos futuros é a utilização de resultados experimentais para se comparar os resultados das simulações numéricas. Apesar de a ferramenta computacional ter boa capacidade comparativa, a comparação com resultados medidos auxilia no processo de calibração dos modelos numéricos. Adotando-se essa calibração, torna-se mais confiável também a capacidade de predição dos resultados, de forma a prover um direcional mais adequado caso seja desejado obter condições operacionais para projeto, por exemplo.

Outra sugestão é a análise mais detalhada da influência da malha empregada sobre os resultados obtidos. Mais especificamente, poderia ser estudada a influência de camadas de prismas sobre as superfícies, ou mesmo incluir mais variáveis no teste de independência de malha, como comprimento médio dos elementos.

Como citado na seção de dificuldades, seria interessante um estudo maior sobre os parâmetros de subrelaxação utilizados. Neste trabalho, com os parâmetros utilizados, era necessário um mínimo de 4000 iterações para se obter boa convergência das variáveis monitoradas. Entretanto, com outros valores destes parâmetros talvez fosse possível obter resultados da mesma qualidade sem exigências computacionais tão severas.

Ainda considerando a parte numérica computacional, uma análise mais rigorosa dos parâmetros do modelo de radiação DO poderia aprimorar os resultados obtidos. Outro aspecto que poderia ser considerado é a inclusão de um modelo de radiação solar no modelo, para capturar mais elementos geradores de carga térmica.

Um aspecto que permaneceu fora do escopo deste trabalho é a influência do entorno sobre as condições de ventilação natural. Como citado anteriormente, a vazão de ar exerce influência significativa sobre o ambiente ventilado, e certamente elementos como direção do vento e construções nas proximidades podem modificar as condições de conforto.

Um elemento geométrico que poderia ser analisado em trabalhos futuros é o emprego de configurações de aberturas mais eficientes para a ventilação natural, que possuem geometrias mais complexas do que as adotadas no trabalho. Exemplos podem ser encontrados na tese de Marcondes (2010).

Por fim, seria interessar a integração da análise numérica de CFD com simulações de condições climáticas de um ano. Estas simulações permitem a análise de uma ampla gama de condições ambientais, e a partir destas poderiam ser determinadas as condições críticas de projeto, que por sua vez poderiam ser simuladas via CFD para melhoria do projeto. 


\section{REFERÊNCIAS}

ABNT - ASSOCIAÇÃO BRASILEIRA DE NORMAS TÉCNICAS. NBR 13964: Móveis para escritório - Divisória tipo painel. Rio de Janeiro, 2003, 07p.

NBR 16401-1: Instalações de ar-condicionado - Sistemas centrais e unitários: Parte 1: Projetos das instalações. Rio de Janeiro, 2008a, 60p.

NBR 16401-2: Instalações de ar-condicionado - Sistemas centrais e unitários: Parte 2: Parâmetros de conforto térmico. Rio de Janeiro, 2008b, 07p.

NBR 16401-3: Instalações de ar-condicionado - Sistemas centrais e unitários: Parte 3: Qualidade do ar interior. Rio de Janeiro, 2008c, 24p.

AHMED, N.A.; WONGPANYATHAWORN, K. Optimising louver location to improve indoor thermal comfort based on natural ventilation. Procedia Engineering. v. 49, p. 169$178,2012$.

AKINS, R.E.; PETERKA, J.A.; CERMAK, J.E. Averaged pressure coefficients for rectangular buildings. Wind Engineering: Proceedings of the Fifth International Conference. v. 7, p. 369-380, 1979.

ALLARD, F. (ed.). Natural Ventilation in Buildings: A Design Handbook. 1st. ed. London: James \& James (Science Publishers) Ltd, 1998.

ALLARD, F.; GHIAUS, C. (ed.). Natural Ventilation in the Urban Environment: Assessment and Design. 1st. ed. London: Earthscan, 2005.

ALLOCA, C.; CHEN, Q.; GLICKSMAN, L. R. Design analysis of single-sided natural ventilation. Energy and Buildings. Oxford, v. 35, p. 785-795, 2003.

ANDRADE, C. M. Avaliação de Desempenho em Edifícios de Escritórios: o ambiente de trabalho como meio para o bem-estar produtivo. 2005. Tese (Doutorado em Arquitetura e Urbanismo) - Faculdade de Arquitetura e Urbanismo, Universidade de São Paulo, São Paulo, 2005.

ANSYS FLUENT. Ansys Fluent Theory Guide: Version 13.0. Canonsburg: Ansys Inc. 2010.

ANSYS TGRID. Ansys TGrid User's Guide: Version 13.0. Canonsburg: Ansys Inc. 2010.

ASHARE - AMERICAN SOCIETY OF HEATING, REFRIGERATING AND AIR CONDITIONING ENGINEERS Inc. ASHRAE Handbook of Fundamentals. Atlanta: ASHRAE, Inc., 2009.

ASHRAE Standard 55-2010: Thermal Environmental Conditions for Human Occupancy. Atlanta: ASHRAE, Inc., 2010. 
ASHRAE Standard 62.1-2007: Ventilation for Acceptable Indoor Air Quality. Atlanta: ASHRAE, Inc., 2007a.

. ASHRAE Standard 90.1-2007: Energy Standard for Buildings Except Low-Rise Residential Buildings. Atlanta: ASHRAE, Inc., 2007b.

AWBI, H. B. Ventilation of Buildings. 2nd. ed. London: Spon Press, 2003.

BADY, M.; KATO, S.; TAKAHASHI, T.; HUANG, H. Experimental investigations of the indoor natural ventilation for different building configurations and incidences. Building and Environment. v. 46, p. 65-74, 2011.

BENEDETTO, G. S. Avaliação da aplicação do modo misto na redução da carga térmica em edifícios de escritórios nas cidades de São Paulo e Rio de Janeiro. 2007. 204 f. Dissertação (Mestrado em Tecnologia da Arquitetura) - Faculdade de Arquitetura e Urbanismo, Universidade de São Paulo, São Paulo, 2007.

BOJIC, M.; YIK, F.; LO, T. Y. Locating air-conditioners and furniture inside residential flats to obtain good thermal comfort. Energy and Buildings. Oxford, v. 34, p. 745-751, 2002.

BOUTET, T. S. Controlling Air Movement: A Manual for Architects and Builders. New York: McGraw-Hill Book Company, 1987.

BRANDÃO, R.; MARCONDES, M. P.; BENEDETTO, G. S.; GONÇALVES, J. C. S.; DUARTE, D. H. S.; RAMOS, J. O. The new research centre of the Brazilian Petroleum Company in Rio de Janeiro, Brazil: The achievements in the thermal performance of airconditioned buildings in the tropics. Energy and Buildings. Oxford, v. 40, p. 1917-1930, 2008.

BRASIL. Ministério das Minas e Energia. Balanço Energético Nacional. Brasília, DF: EPE, 2010. $276 \mathrm{p}$.

BRILL, M.; WIEDEMANN, S. Disproving widespread myths about workplace design. New York: Kimball International, 2001.

BSI - BRITISH STANDARDS INSTITUITION. Code of practice for ventilation principles and designing for natural ventilation: BS 5925, London, 1991.

CFX. User Guide. Version 5. Oxfordshire: AEA Technology, 2003.

CHEN, Q.; JIANG, Z. Significant questions in predicting room air motion. ASHRAE Transactions. Atlanta, v. 98, n. 1, p. 929-939, 1992.

CHEUNG, J. O. P.; LIU, C. -H. CFD simulations of natural ventilation behavior in high-rise buildings in regular and staggered arrangements at various spacings. Energy and Buildings. Oxford, v. 43, p. 1149-1158, 2011.

CIBSE - Chartered Institution of Building Services Engineers. Building control systems: CIBSE Guide H. London: CIBSE, 2000. 
. Energy efficiency in buildings: CIBSE Guide F. London: CIBSE, 2004.

Environmental design: CIBSE Guide A. London: CIBSE, 1999.

. Natural ventilation in non-domestic buildings: CIBSE Applications Manual AM10. London: CIBSE, 2005.

CLEMENTS-CROOME, D. (ed.). Naturally Ventilated Buildings: Buildings for the Senses Economy and Society. 2nd. ed. London: Taylor \& Francis, 2003. 198 p.

COST - European Cooperation in the Field of Scientific and Technical Research. Cost Action 14: Recommendation on the Use of CFD in Predicting Pedestrian Wind Environment. Brussels: COST, 2004.

Cost Action 732: Quality Assurance and Improvement of Microscale Meteorological Models. Bruxelas: COST, 2007.

COSTA, L. C. N. Aproveitamento da Ventilação Natural nas Habitações: um estudo de caso na cidade de Aracaju-SE. 2009. 272 f. Dissertação (Mestrado em Tecnologia da Arquitetura) - Faculdade de Arquitetura e Urbanismo, Universidade de São Paulo, São Paulo, 2009.

CÓSTOLA, D. Ventilação por Ação do Vento no Edifício: Procedimentos para Quantificação. 2006. 214 f. Dissertação (Mestrado em Tecnologia da Arquitetura) Faculdade de Arquitetura e Urbanismo, Universidade de São Paulo, 2006.

CÓSTOLA, D.; BLOCKEN, B.; OHBA, M.; HENSEN, J. L. M. Uncertainty in airflow rate calculations due to the use of surface-averaged pressure coefficients. Energy and Buildings. Oxford, v. 42, p. 881-888, 2010.

DILONARDO, L. F. S. P. Avaliação do Uso de Tecnologias Passivas Visando a Eficiência Energética em Edifícios de Escritórios. 2001. 250 f. Dissertação (Mestrado em Tecnologia da Arquitetura) - Faculdade de Arquitetura e Urbanismo, Universidade de São Paulo, 2001.

DOE. Apresenta dados climáticos para diversas cidades do mundo. Disponível em: <http://apps1.eere.energy.gov/buildings/energyplus/cfm/weather_data.cfm>. Acesso em 25 set. 2011.

ETHERIDGE, D.; SANDBERG, M. Buildings Ventilation: Theory and Measurement. Chichester, West Sussex: John Wiley \& Sons Ltd., 1996.

EVOLA, G.; POPOV, V. Computational analysis of wind driven natural ventilation in buildings. Energy and Buildings. Oxford, v. 38, p. 491-501, 2006.

FADIGAS, E. A. Aula 2 - Recursos eólicos e suas características. Material didático da disciplina de pós-graduação do departamento de Energia e Automação da Escola Politécnica da Universidade de São Paulo PEA 5002. 2010.

FERREIRA, T. A. Avaliação numérica e experimental de um veículo de competição de milhagem. 2011. 205 f. Dissertação (Mestrado em Engenharia Mecânica de Energia e 
Fluidos) - Escola Politécnica, Universidade de São Paulo, 2011.

FERZIGER, J. H.; PERIĆ, M. Computational Methods for Fluid Dynamics. 3rd. ed. Berlin: Springer, 2002.

FIGUEIREDO, C. M. Ventilação Natural em Edifícios de Escritórios na Cidade de São Paulo: Limites e Possibilidades do Ponto de Vista do Conforto Térmico. 2007. 245 f. Dissertação (Mestrado em Tecnologia da Arquitetura) - Faculdade de Arquitetura e Urbanismo, Universidade de São Paulo, São Paulo, 2007.

FRACASTORO, G. V.; PERINO, M. Wind induced air flow through large openings: a numerical analysis. IEA - International Energy Agency. Energy Conservation in Buildings and Community Systems Programme Annex Publications. Annex 35 Report, 1999.

FROTA, A. B.; SCHIFFER, S. R. Manual de conforto térmico. São Paulo: Studio Nobel, 2003.

GIVONI, B. Man, Climate and Architecture. 2nd. ed. London: Applied Science Publishers, 1976.

GRATIA, E.; BRUYÈRE, I.; DE HERDE, A. How to use natural ventilation to cool narrow office buildings. Building and Environment. v. 39, p. 1157-1170, 2004.

HEISELBERG, P.; DAM, H.; SORENSEN, L. C.; NIELSEN, P. V.; SVIDT, K. Characteristics of the Air Flow through Windows. Proceedings of the First International Forum on Natural and Hybrid Ventilation, HybVent Forum 99, 09/1999, Sydney, Australia.

INATOMI, T. A. H. Análise da eficiência energética do sistema de condicionamento de ar com distribuição pelo piso em ambiente de escritório, na cidade de São Paulo, utilizando o modelo computacional Energyplus. 2008. 87 f. Dissertação (Mestrado em Engenharia de Construção Civil e Urbana) - Escola Politécnica, Universidade de São Paulo, 2008.

ISO - INTERNATIONAL ORGANIZATION FOR STANDARDIZATION. ISO 7730: Ergonomics of the Thermal Environment - Analytical Determination and Interpretation of Thermal Comfort using Calculation of the PMV and PPD Indices and Local Thermal Criteria. Geneva, 2005.

JONES, W. P.; LAUNDER, B. E. The Prediction of Laminarization with a Two-Equation Model of Turbulence. International Journal of Heat and Mass Transfer. v. 15, p. 301-314, 1972.

KAWAMOTO, K.; KOOMEY, J. G.; NORDMAN, B.; BROWN, R. E.; PIETTE, M. A.; TING, M.; MEIER, A. K. Electricity Used by Office Equipment and Network Equipment in the U.S.: Detailed Report and Appendices. Berkeley: Energy Analysis Department, University of California, 2001. 46p.

KENDRICK, C.; MARTIN, A.; BOOTH, W. Refurbishment of air-conditioned buildings for natural ventilation. Berkshire: BSRIA, 1998.

LABEEE. Apresenta dados climáticos para diversas cidades do Brasil. Disponível em: 
<http://www.labeee.ufsc.br/downloads/arquivos-climaticos>. Acesso em 25 set. 2011.

LAUNDER, B. E.; SPALDING, D. B. Lectures in Mathematical Models of Turbulence. Academic Press. London, 1972.

LAUNDER, B. E.; SPALDING, D. B. The Numerical Computation of Turbulent Flows. Computer Methods in Applied Mechanics and Engineering. v. 3, p. 269-289, 1974.

LEDUC, J. L. G. M. Procel Edifica: Eficiência energética em edificações - Ações desenvolvidas. In: CONGRESSO BRASILEIRO DE EFICIÊNCIA ENERGÉTICA, 5., 2008, São Paulo. Anais Eletrônicos... São Paulo: ABESCO, 2008. Disponível em: <http://www.metodoeventos.com.br/5eficienciaenergetica/downloads/12-0608/manha/jose_luis_leduc.pdf>. Acesso em: 18 mai 2009.

LI, Y.; DELSANTE, A. Natural ventilation induced by combined wind and thermal forces. Building and Environment. v. 36, p. 59-71, 2001.

LINDDAMENT, M. W. Air Infiltration Calculation Techniques: An Application Guide. 1st. ed. Bracknell: Air Infiltration and Ventilation Centre, 1986.

MALISKA, C. R. Transferência de Calor e Mecânica dos Fluidos Computacional. 2a. ed. Rio de Janeiro: LTC, 2004.

MANWELL, J. F.; MCGOWAN, J. G.; ROGERS, A. L. Wind Energy Explained: Theory, Design and Application. 2nd ed. West Sussex: John Wiley \& Sons Ltd., 2009.

MARCONDES, M. P. Soluções Projetuais de Fachadas para Edifícios de Escritórios com Ventilação Natural em São Paulo. 2010. 261 f. Tese (Doutorado em Tecnologia da Arquitetura) - Faculdade de Arquitetura e Urbanismo, Universidade de São Paulo, São Paulo, 2010.

MARIANA, F. B.; TRIBESS, A. Influência do mobiliário nas condições de conforto térmico em ambientes de escritórios naturalmente ventilados. In: CONGRESSO NACIONAL DE ENGENHARIA MECÂNICA, 7., 2012, São Luís. Anais... São Luís: UEMA, 2012a. 1 CDROM.

Numerical analysis of windows and furniture influence on the airflow in naturally ventilated office. In: BRAZILIAN CONGRESS OF THERMAL SCIENCES AND ENGINEERING, 14., 2012, Rio de Janeiro. Anais... Rio de Janeiro: UFF, 2012b. 1 CDROM.

MOTEZUKI, F. K. Um Estudo Sobre a Simulação Computacional da Ventilação Cruzada em Habitações e sua Aplicação no Projeto Arquitetônico. 2009. 108 f. Dissertação (Mestrado em Engenharia de Construção Civil e Urbana) - Escola Politécnica, Universidade de São Paulo, São Paulo, 2009.

MUNSON, B. R.; YOUNG, D. F.; OKIISHI, T. H. Fundamentos da Mecânica dos Fluidos: Tradução da $4^{a}$ edição americana. 1a. ed. São Paulo: Edgard Blücher, 2004.

PRATA, A. R. Impacto da Altura de Edifícios nas Condições de Ventilação Natural do 
Meio Urbano. 2005. 243 f. Tese (Doutorado em Estruturas Ambientais Urbanas) - Faculdade de Arquitetura e Urbanismo, Universidade de São Paulo, São Paulo, 2005.

PRATA, A. R. Uma Ferramenta Computacional de Avaliação da Ventilação Natural em Projetos Arquitetônicos. 1998. 167 f. Dissertação (Mestrado em Recursos Hídricos e Saneamento) - Faculdade de Engenharia Civil, Arquitetura e Urbanismo, Universidade Estadual de Campinas, Campinas, 1998.

PIRRÓ, L. F. S. O Impacto das Envolventes Verticais no Desempenho Energético de Edifícios de Escritórios. 2005. Tese (Doutorado em Tecnologia da Arquitetura) - Faculdade de Arquitetura e Urbanismo, Universidade de São Paulo, São Paulo, 2005.

POPE, S. B. Turbulent Flows. Cambridge: Cambridge University Press, 2000.

ROETZEL, A.; TSANGRASSOULIS, A.; DIETRICH, U.; BUSCHING, S. A review of occupant control on natural ventilation. Renewable and Sustainable Energy Reviews. v. 14, p. 1001-1013, 2010.

ROULET, C. A. Santé et Qualité de l'environnement dans les Bâtiments. Lausanne, PPUR, 2004.

SANTAMOURIS, M.; ASIMAKOPOULOS, D. Passive cooling of buildings. 1st. ed. London: James \& James, 1996.

SHIH, T.-H.; LIOU, W. W.; SHABBIR, A.; YANG, Z.; ZHU, J. A New k- $\varepsilon$ Eddy-Viscosity Model for High Reynolds Number Turbulent Flows - Model Development and Validation. Computers Fluids. v. 24, n. 3, p. 227-238, 1995.

TENNEKES, H.; LUMLEY, J. L. A First Course in Turbulence. Massachusetts: The MIT Press, 1972.

TECLE, A.; BITSUAMLAK, G.T.; JIRU, T.E. Wind-driven natural ventilation in a low-rise building: A Boundary Layer Wind Tunnel study. Building and Environment. v.59, p. 275$289,2013$.

VERSTEEG, H. K.; MALALASEKERA, W. An Introduction to Computational Fluid Dynamics: The Finite Volume Method. 2nd. ed. Harlow, Essex: Pearson Education Limited, 2007.

WILCOX, D. C. Turbulence Modeling for CFD. 2a. ed. La Cañada: DCW Industries, Inc, 1994.

WILSON, D. J. Flow Patterns over Flat Roofed Buildings and Application to Exhaust Stack Design. ASHRAE Transactions. Atlanta, v. 85, n. 2, p. 284-295, 1979.

WHITE, F. M. Viscous Fluid Flow. 2nd. ed. New York: McGraw-Hill Higher Education, 1991.

YANG, C.; SHI, H.; YANG, X.; ZHAO, B. Research on Flow Resistance Characteristics with Different Window/Door Opening Angles. HVAC\&R Research. London, v. 16, n. 6, p. 813- 
$824,2010$.

YARKE, E. (Ed.) Ventilación natural de edificios: Fundamentos y Métodos de Cálculo para aplicación de Ingenieros y Arquitectos. 1a. ed. Buenos Aires: Nobuko, 2005.

ZHAI, Z. J.; ZHANG, Z.; ZHANG, W.; CHEN, Q. Y. Evaluation of Various Turbulence Models in Predicting Airflow and Turbulence in Enclosed Environments by CFD: Part 1 Summary of Prevalent Turbulence Models. HVAC\&R Research. London, v. 13, n. 6, p. 853870, 2007.

ZHANG, Z.; ZHANG, W.; ZHAI, Z. J.; CHEN, Q. Y. Evaluation of Various Turbulence Models in Predicting Airflow and Turbulence in Enclosed Environments by CFD: Part 2 Comparison with Experimental Data from Literature. HVAC\&R Research. London, v. 13, n. 6, p. 871-886, 2007. 


\section{APÊNDICE A - RESUMO DOS RESULTADOS OBTIDOS}

Como citado anteriormente, é possível obter uma grande quantidade de dados das simulações numéricas de CFD. Abaixo seguem resumos dos principais resultados obtidos das simulações, como vazão de ar que entra no ambiente, temperaturas médias do ar nos ambientes e nos planos de medição $(0,10 \mathrm{~m}, 0,60 \mathrm{~m}$ e $1,10 \mathrm{~m})$ e a estratificação de temperatura do ar. Além desses, também há a quantidade de ocupantes em conforto térmico segundo os critérios da norma ASHRAE 55 (ASHRAE, 2010), seguindo procedimento descrito na seção 4.6.1.

Simulações com layout quadrado, janelas maxim-ar, velocidade máxima do vento de $2 \mathrm{~m} / \mathrm{s}$ e temperatura do ar externo de 299,0K, em ordem crescente das partições:

\begin{tabular}{|l|}
\hline QUAD - 090 - MAX - FM04 \\
\multicolumn{2}{|c|}{ Vazão de Ar [kg/s] } \\
\hline \multicolumn{2}{|c|}{10,69} \\
\hline \multicolumn{2}{|c|}{ Temp Média Ar [K] } \\
\hline \multicolumn{2}{|c|}{301,0} \\
\hline \multicolumn{2}{|c|}{ Estratificação Média Temp [K] } \\
\hline \multicolumn{2}{|c|}{0,5} \\
\hline Temp Med h=0,1/0,6/1,1m [K] \\
\hline 300,9 300,7 301,3 \\
\hline Estações c/ conforto $\mathrm{p} / 80 \%$ \\
\hline \multicolumn{2}{|c|}{$100 \%$} \\
\hline Estações c/ conforto $\mathrm{p} / 90 \%$ \\
\hline \multicolumn{2}{|c|}{$53 \%$} \\
\hline
\end{tabular}

\begin{tabular}{|l|}
\hline QUAD - 110 - MAX - FM30 \\
Vazão de Ar [kg/s] \\
\hline \multicolumn{2}{|c|}{10,63} \\
\hline \multicolumn{2}{|c|}{ Temp Média Ar [K] } \\
\hline \multicolumn{2}{|c|}{301,1} \\
\hline \multicolumn{2}{|c|}{ Estratificação Média Temp [K] } \\
\hline \multicolumn{2}{|c|}{0,5} \\
\hline Temp Med h=0,1/0,6/1,1m [K] \\
\hline 301,0 300,8 301,5 \\
\hline Estações c/ conforto $\mathrm{p} / 80 \%$ \\
\hline \multicolumn{2}{|c|}{$97 \%$} \\
\hline Estações c/ conforto $\mathrm{p} / 90 \%$ \\
\hline \multicolumn{2}{|c|}{$42 \%$} \\
\hline
\end{tabular}

\begin{tabular}{|l|}
\hline QUAD - 150 - MAX - FM15 \\
Vazão de Ar [kg/s] \\
\hline \multicolumn{2}{|c|}{10,38} \\
\hline \multicolumn{2}{|c|}{ Temp Média Ar [K] } \\
\hline \multicolumn{2}{|c|}{301,2} \\
\hline \multicolumn{2}{|c|}{ Estratificação Média Temp [K] } \\
\hline \multicolumn{2}{|c|}{0,6} \\
\hline Temp Med h=0,1/0,6/1,1m [K] \\
\hline 301,1 300,9 301,6 \\
\hline Estações c/ conforto p/ $80 \%$ \\
\hline \multicolumn{2}{|c|}{$97 \%$} \\
\hline Estações c/ conforto $\mathrm{p} / 90 \%$ \\
\hline \multicolumn{2}{|c|}{$31 \%$} \\
\hline
\end{tabular}

Simulações com layout quadrado, janelas de correr vertical, velocidade máxima do vento de $2 \mathrm{~m} / \mathrm{s}$ e temperatura do ar externo de $299,0 \mathrm{~K}$, em ordem crescente das partições:

\begin{tabular}{|c|}
\hline QUAD - 090 - SLID - FM02 \\
Vazão de Ar [kg/s] \\
\hline \multicolumn{2}{|c|}{7,14} \\
\hline \multicolumn{2}{|c|}{302,0} \\
\hline \multicolumn{2}{|c|}{ Temp Média Ar [K] } \\
\hline \multicolumn{2}{|c|}{0,5} \\
\hline Estratificação Média Temp [K] \\
\hline \multicolumn{2}{|c|}{ Temp Med h=0,1/0,6/1,1m [K] } \\
\hline Te1,9 301,8 \\
\hline Estações c/ conforto $\mathrm{p} / 80 \%$ \\
\hline \multicolumn{2}{|c|}{$42 \%$} \\
\hline \multicolumn{2}{|c|}{ Estações c/ conforto $\mathrm{p} / 90 \%$} \\
\hline \multicolumn{2}{|c|}{$0 \%$} \\
\hline
\end{tabular}

\begin{tabular}{|c|c|c|}
\hline \multicolumn{3}{|c|}{ QUAD - 110 - SLID - FM06 } \\
\hline \multicolumn{3}{|c|}{ Vazão de $\operatorname{Ar}[\mathrm{kg} / \mathrm{s}]$} \\
\hline \multicolumn{3}{|c|}{7,25} \\
\hline \multicolumn{3}{|c|}{ Temp Média Ar [K] } \\
\hline \multicolumn{3}{|c|}{302,0} \\
\hline \multicolumn{3}{|c|}{ Estratificação Média Temp [K] } \\
\hline \multicolumn{3}{|c|}{0,6} \\
\hline \multicolumn{3}{|c|}{ Temp Med $\mathrm{h}=0,1 / 0,6 / 1,1 \mathrm{~m}[\mathrm{~K}]$} \\
\hline 301,9 & 301,8 & 302,3 \\
\hline \multicolumn{3}{|c|}{ Estações c/ conforto $\mathrm{p} / 80 \%$} \\
\hline \multicolumn{3}{|c|}{$39 \%$} \\
\hline \multicolumn{3}{|c|}{ Estações c/ conforto p/90\% } \\
\hline & $0 \%$ & \\
\hline
\end{tabular}

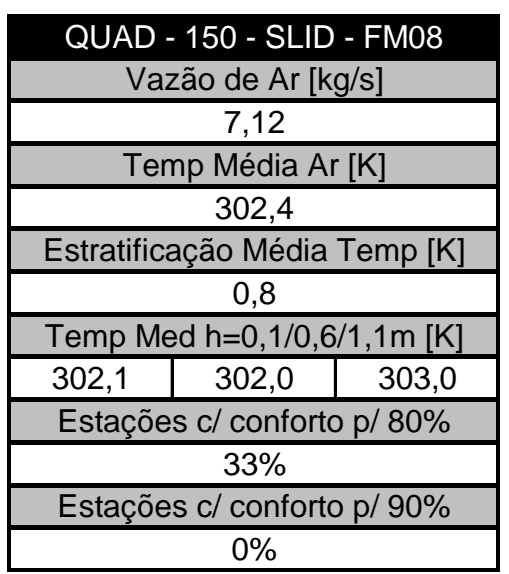


Simulações com layout em linha, janelas maxim-ar, velocidade máxima do vento de $2 \mathrm{~m} / \mathrm{s}$ e temperatura do ar externo de $299,0 \mathrm{~K}$, em ordem crescente das partições:

\begin{tabular}{|l|}
\hline \multicolumn{2}{|c|}{ LIN - 090 - MAX - FM00 } \\
Vazão de Ar [kg/s] \\
\hline \multicolumn{2}{|c|}{10,44} \\
\hline \multicolumn{2}{|c|}{301,1} \\
\hline \multicolumn{2}{|c|}{ Temp Média Ar [K] } \\
\hline \multicolumn{2}{|c|}{ Estratificação Média Temp [K] } \\
\hline \multicolumn{2}{|c|}{0,4} \\
\hline Temp Med h=0,1/0,6/1,1m [K] \\
\hline 301,1 300,9 \\
\hline Estações c/ conforto $\mathrm{p} / 80 \%$ \\
\hline \multicolumn{2}{|c|}{$100 \%$} \\
\hline Estações c/ conforto $\mathrm{p} / 90 \%$ \\
\hline \multicolumn{2}{|c|}{$42 \%$} \\
\hline
\end{tabular}

\begin{tabular}{|c|c|}
\hline \multicolumn{2}{|c|}{ LIN - 110 - MAX - FM00 } \\
\hline \multicolumn{2}{|l|}{10,48} \\
\hline \multicolumn{2}{|c|}{ Temp Média Ar [K] } \\
\hline \multicolumn{2}{|c|}{301,1} \\
\hline \multicolumn{2}{|c|}{ Estratificação Média Temp [K] } \\
\hline \multicolumn{2}{|l|}{0,6} \\
\hline \multicolumn{2}{|c|}{ Temp Med $\mathrm{h}=0,1 / 0,6 / 1,1 \mathrm{~m}[\mathrm{~K}]$} \\
\hline 301,0 & 301,4 \\
\hline \multicolumn{2}{|c|}{ Estações c/ conforto $\mathrm{p} / 80 \%$} \\
\hline \multicolumn{2}{|l|}{$100 \%$} \\
\hline \multicolumn{2}{|c|}{ Estações c/ conforto p/ 90\% } \\
\hline $44 \%$ & \\
\hline
\end{tabular}

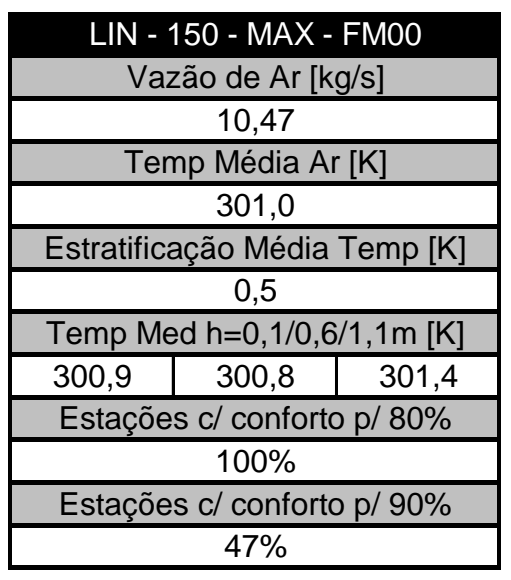

Simulações com layout em linha, janelas de correr vertical, velocidade máxima do vento de $2 \mathrm{~m} / \mathrm{s}$ e temperatura do ar externo de $299,0 \mathrm{~K}$, em ordem crescente das partições:

\begin{tabular}{|l|}
\multicolumn{2}{|c|}{ LIN - 090 - SLID - FM00 } \\
Vazão de Ar [kg/s] \\
\hline \multicolumn{2}{|c|}{7,24} \\
\hline \multicolumn{2}{|c|}{ Temp Média Ar [K] } \\
\hline \multicolumn{2}{|c|}{301,9} \\
\hline \multicolumn{2}{|c|}{ Estratificação Média Temp [K] } \\
\hline \multicolumn{2}{|c|}{0,6} \\
\hline Temp Med h=0,1/0,6/1,1m [K] \\
\hline 301,8 301,7 302,2 \\
\hline Estações c/ conforto $\mathrm{p} / 80 \%$ \\
\hline \multicolumn{2}{|c|}{$50 \%$} \\
\hline Estações c/ conforto $\mathrm{p} / 90 \%$ \\
\hline \multicolumn{2}{|c|}{$11 \%$} \\
\hline
\end{tabular}

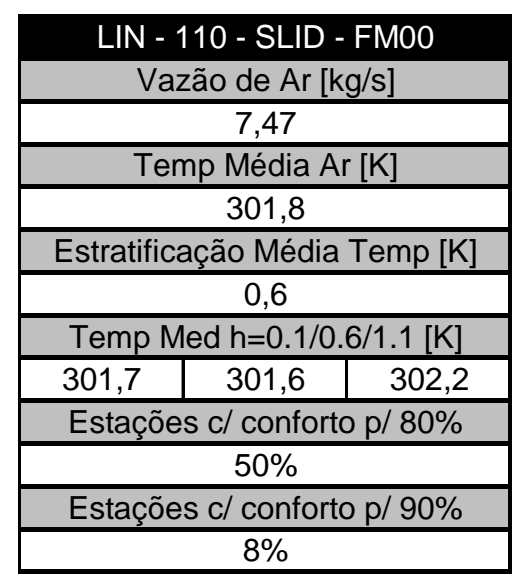

\begin{tabular}{|c|c|c|}
\hline \multicolumn{3}{|c|}{ LIN - 150 - SLID - FM00 } \\
\hline \multicolumn{3}{|c|}{ Vazão de Ar [kg/s] } \\
\hline \multicolumn{3}{|c|}{7,23} \\
\hline \multicolumn{3}{|c|}{ Temp Média Ar [K] } \\
\hline \multicolumn{3}{|c|}{302,0} \\
\hline \multicolumn{3}{|c|}{ Estratificação Média Temp [K] } \\
\hline \multicolumn{3}{|c|}{0,8} \\
\hline \multicolumn{3}{|c|}{ Temp Med $\mathrm{h}=0,1 / 0,6 / 1,1 \mathrm{~m}[\mathrm{~K}]$} \\
\hline 301,8 & 301,7 & 302,4 \\
\hline \multicolumn{3}{|c|}{ Estações c/ conforto p/ $80 \%$} \\
\hline \multicolumn{3}{|c|}{$44 \%$} \\
\hline \multicolumn{3}{|c|}{ Estações c/ conforto p/90\% } \\
\hline \multicolumn{3}{|c|}{$11 \%$} \\
\hline
\end{tabular}

Simulações com layout quadrado, janelas maxim-ar, velocidade máxima do vento de $4 \mathrm{~m} / \mathrm{s}$ e temperatura do ar externo de $299,0 \mathrm{~K}$, em ordem crescente das partições:

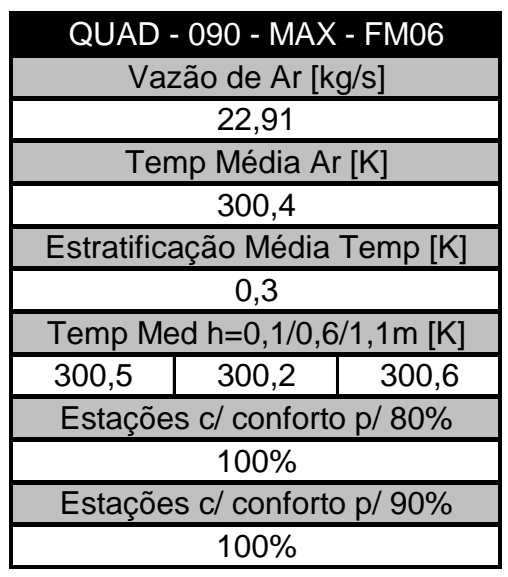

\begin{tabular}{|c|c|c|}
\hline \multicolumn{3}{|c|}{ QUAD - 110 - MAX - FM36 } \\
\hline \multicolumn{3}{|c|}{ Vazão de $\operatorname{Ar}[\mathrm{kg} / \mathrm{s}]$} \\
\hline \multicolumn{3}{|c|}{22,55} \\
\hline \multicolumn{3}{|c|}{ Temp Média Ar [K] } \\
\hline \multicolumn{3}{|c|}{300,4} \\
\hline \multicolumn{3}{|c|}{ Estratificação Média Temp [K] } \\
\hline \multicolumn{3}{|c|}{0,4} \\
\hline \multicolumn{3}{|c|}{ Temp Med $\mathrm{h}=0,1 / 0,6 / 1,1 \mathrm{~m}[\mathrm{~K}]$} \\
\hline 300,4 & 300,2 & 300,6 \\
\hline \multicolumn{3}{|c|}{ Estaç̃es c/ conforto $\mathrm{p} / 80 \%$} \\
\hline \multicolumn{3}{|c|}{$100 \%$} \\
\hline \multicolumn{3}{|c|}{ Estações c/ conforto p/90\% } \\
\hline & $100 \%$ & \\
\hline
\end{tabular}

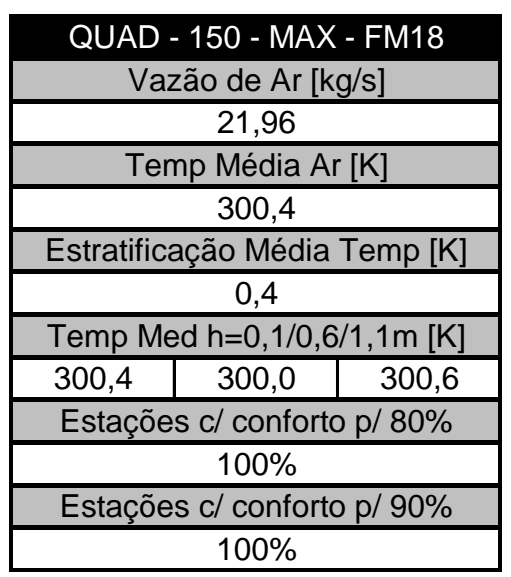


Simulações com layout quadrado, janelas de correr vertical, velocidade máxima do vento de $4 \mathrm{~m} / \mathrm{s}$ e temperatura do ar externo de $299,0 \mathrm{~K}$, em ordem crescente das partições:

\begin{tabular}{|l|}
\hline \multicolumn{2}{|c|}{ QUAD - 090 - SLID - FM04 } \\
\multicolumn{2}{|c|}{ Vazão de Ar [kg/s] } \\
\hline \multicolumn{2}{|c|}{14,34} \\
\hline \multicolumn{2}{|c|}{ Temp Média Ar [K] } \\
\hline \multicolumn{2}{|c|}{300,7} \\
\hline \multicolumn{2}{|c|}{ Estratificação Média Temp [K] } \\
\hline \multicolumn{2}{|c|}{0,4} \\
\hline Temp Med h=0,1/0,6/1,1m [K] \\
\hline 300,7 300,5 300,8 \\
\hline Estações c/ conforto $\mathrm{p} / 80 \%$ \\
\hline \multicolumn{2}{|c|}{$100 \%$} \\
\hline Estações c/ conforto $\mathrm{p} / 90 \%$ \\
\hline \multicolumn{2}{|c|}{$75 \%$} \\
\hline
\end{tabular}

\begin{tabular}{|c|c|}
\hline \multicolumn{2}{|c|}{ QUAD - 110 - SLID - FM08 } \\
\hline \multicolumn{2}{|c|}{ Vazão de $\operatorname{Ar}[\mathrm{kg} / \mathrm{s}]$} \\
\hline \multicolumn{2}{|l|}{14,56} \\
\hline \multicolumn{2}{|c|}{ Temp Média Ar [K] } \\
\hline \multicolumn{2}{|l|}{300,7} \\
\hline \multicolumn{2}{|c|}{ Estratificação Média Temp [K] } \\
\hline \multicolumn{2}{|l|}{0,4} \\
\hline \multicolumn{2}{|c|}{ Temp Med $\mathrm{h}=0,1 / 0,6 / 1,1 \mathrm{~m}[\mathrm{~K}]$} \\
\hline 300,7 & 300,9 \\
\hline \multicolumn{2}{|c|}{ Estações c/ conforto p/ $80 \%$} \\
\hline \multicolumn{2}{|l|}{$100 \%$} \\
\hline \multicolumn{2}{|c|}{ Estações c/ conforto p/90\% } \\
\hline $78 \%$ & \\
\hline
\end{tabular}

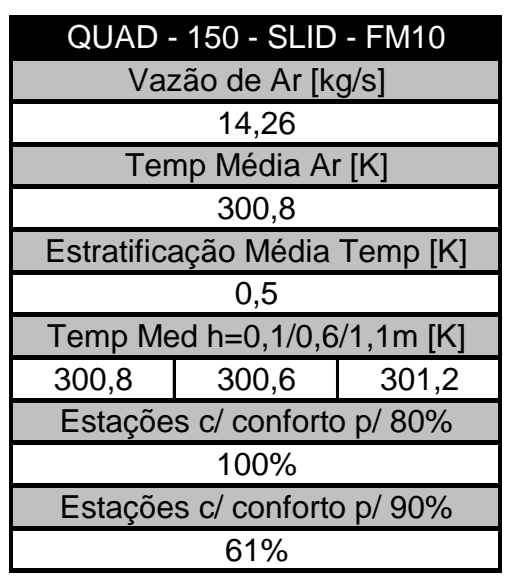

Simulações com layout em linha, janelas maxim-ar, e velocidade máxima do vento de $4 \mathrm{~m} / \mathrm{s}$ e temperatura do ar externo de $299,0 \mathrm{~K}$, em ordem crescente das partições:

\begin{tabular}{|c|c|c|}
\hline \multicolumn{3}{|c|}{ LIN - 090 - MAX - FM03 } \\
\hline \multicolumn{3}{|c|}{ Vazão de $\operatorname{Ar}[\mathrm{kg} / \mathrm{s}]$} \\
\hline \multicolumn{3}{|c|}{22,24} \\
\hline \multicolumn{3}{|c|}{ Temp Média Ar [K] } \\
\hline \multicolumn{3}{|c|}{300,5} \\
\hline \multicolumn{3}{|c|}{ Estratificação Média Temp [K] } \\
\hline \multicolumn{3}{|c|}{0,3} \\
\hline \multicolumn{3}{|c|}{ Temp Med $\mathrm{h}=0,1 / 0,6 / 1,1 \mathrm{~m}[\mathrm{~K}]$} \\
\hline 300,5 & 300,4 & 300,5 \\
\hline \multicolumn{3}{|c|}{ Estações c/ conforto p/ $80 \%$} \\
\hline \multicolumn{3}{|c|}{$100 \%$} \\
\hline \multicolumn{3}{|c|}{ Estações c/ conforto p/90\% } \\
\hline & $100 \%$ & \\
\hline
\end{tabular}

\begin{tabular}{|c|c|c|}
\hline \multicolumn{3}{|c|}{ LIN - 110 - MAX - FM03 } \\
\hline \multicolumn{3}{|c|}{ Vazão de $\mathrm{Ar}[\mathrm{kg} / \mathrm{s}]$} \\
\hline \multicolumn{3}{|c|}{22,46} \\
\hline \multicolumn{3}{|c|}{ Temp Média Ar [K] } \\
\hline \multicolumn{3}{|c|}{300,5} \\
\hline \multicolumn{3}{|c|}{ Estratificação Média Temp [K] } \\
\hline \multicolumn{3}{|c|}{0,4} \\
\hline \multicolumn{3}{|c|}{ Temp Med $\mathrm{h}=0,1 / 0,6 / 1,1 \mathrm{~m}[\mathrm{~K}]$} \\
\hline 300,5 & 300,3 & 300,6 \\
\hline \multicolumn{3}{|c|}{ Estações c/ conforto $\mathrm{p} / 80 \%$} \\
\hline \multicolumn{3}{|c|}{$100 \%$} \\
\hline \multicolumn{3}{|c|}{ Estações c/ conforto p/90\% } \\
\hline & $100 \%$ & \\
\hline
\end{tabular}

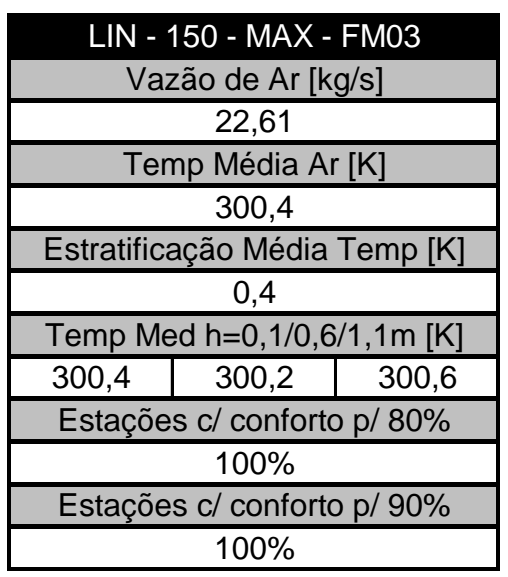

Simulações com layout em linha, janelas de correr vertical, velocidade máxima do vento de $4 \mathrm{~m} / \mathrm{s}$ e temperatura do ar externo de $299,0 \mathrm{~K}$, em ordem crescente das partições:

\begin{tabular}{|c|c|c|}
\hline \multicolumn{3}{|c|}{ LIN - 090 - SLID - FM03 } \\
\hline \multicolumn{3}{|c|}{ Vazão de $\mathrm{Ar}[\mathrm{kg} / \mathrm{s}]$} \\
\hline \multicolumn{3}{|c|}{14,59} \\
\hline \multicolumn{3}{|c|}{ Temp Média Ar [K] } \\
\hline \multicolumn{3}{|c|}{300,6} \\
\hline \multicolumn{3}{|c|}{ Estratificação Média Temp [K] } \\
\hline \multicolumn{3}{|c|}{0,4} \\
\hline \multicolumn{3}{|c|}{ Temp Med $\mathrm{h}=0,1 / 0,6 / 1,1 \mathrm{~m}[\mathrm{~K}]$} \\
\hline 300,7 & 300,4 & 300,7 \\
\hline \multicolumn{3}{|c|}{ Estações c/ conforto p/ $80 \%$} \\
\hline \multicolumn{3}{|c|}{$100 \%$} \\
\hline \multicolumn{3}{|c|}{ Estações c/ conforto $\mathrm{p} / 90 \%$} \\
\hline \multicolumn{3}{|c|}{$81 \%$} \\
\hline
\end{tabular}

\begin{tabular}{|c|c|c|}
\hline \multicolumn{3}{|c|}{ LIN - 110 - SLID - FM03 } \\
\hline \multicolumn{3}{|c|}{ Vazão de $\operatorname{Ar}[\mathrm{kg} / \mathrm{s}]$} \\
\hline \multicolumn{3}{|c|}{15,03} \\
\hline \multicolumn{3}{|c|}{ Temp Média Ar [K] } \\
\hline \multicolumn{3}{|c|}{300,6} \\
\hline \multicolumn{3}{|c|}{ Estratificação Média Temp [K] } \\
\hline \multicolumn{3}{|c|}{0,4} \\
\hline \multicolumn{3}{|c|}{ Temp Med $\mathrm{h}=0,1 / 0,6 / 1,1 \mathrm{~m}[\mathrm{~K}]$} \\
\hline 300,7 & 300,4 & 300,7 \\
\hline \multicolumn{3}{|c|}{ Estações c/ conforto $\mathrm{p} / 80 \%$} \\
\hline \multicolumn{3}{|c|}{$100 \%$} \\
\hline \multicolumn{3}{|c|}{ Estações c/ conforto p/ 90\% } \\
\hline & $78 \%$ & \\
\hline
\end{tabular}

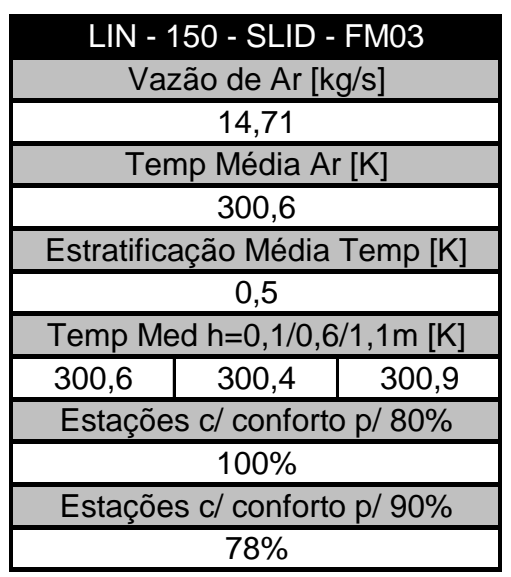


Simulações com layout em linha, janelas maxim-ar, velocidade máxima do vento de $2 \mathrm{~m} / \mathrm{s}$ e temperatura do ar externo de $299,0 \mathrm{~K}$, em ordem decrescente da carga térmica interna:

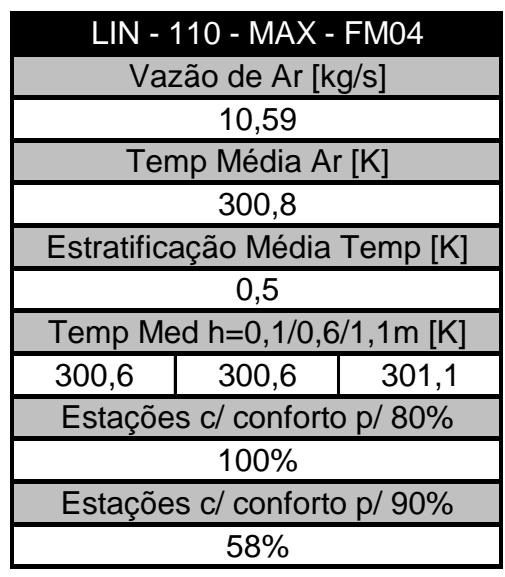

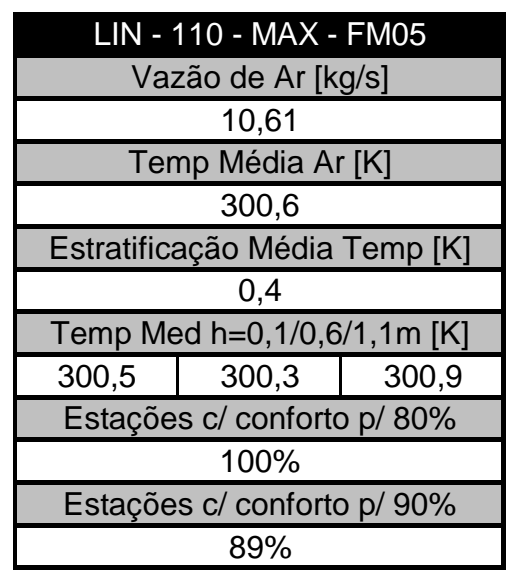

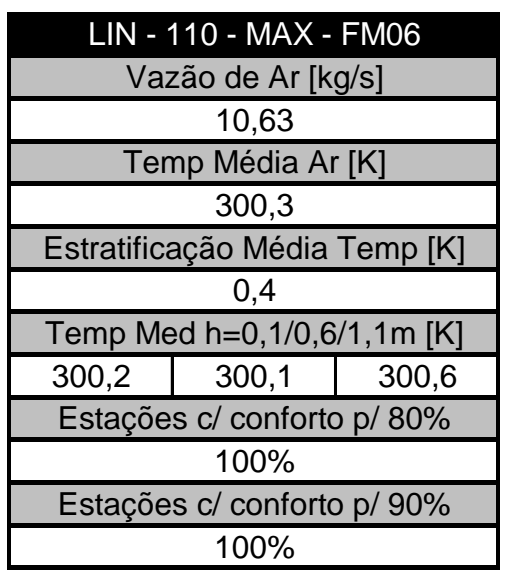

Simulações com layout em linha, janelas maxim-ar, velocidade máxima do vento de $2 \mathrm{~m} / \mathrm{s}$ e temperatura do ar externo de $300,5 \mathrm{~K}$, em ordem decrescente da carga térmica interna:

\begin{tabular}{|c|c|c|}
\hline \multicolumn{3}{|c|}{ LIN - 110 - MAX - FM08 } \\
\hline \multicolumn{3}{|c|}{10,43} \\
\hline \multicolumn{3}{|c|}{ Temp Média Ar [K] } \\
\hline \multicolumn{3}{|c|}{302,6} \\
\hline \multicolumn{3}{|c|}{ Estratificação Média Temp [K] } \\
\hline \multicolumn{3}{|c|}{0,6} \\
\hline \multicolumn{3}{|c|}{ Temp Med $\mathrm{h}=0,1 / 0,6 / 1,1 \mathrm{~m}[\mathrm{~K}]$} \\
\hline 302,5 & 302,3 & 303,0 \\
\hline \multicolumn{3}{|c|}{ Estações c/ conforto p/ $80 \%$} \\
\hline \multicolumn{3}{|c|}{$14 \%$} \\
\hline \multicolumn{3}{|c|}{ Estações c/ conforto p/ 90\% } \\
\hline & $0 \%$ & \\
\hline
\end{tabular}

\begin{tabular}{|c|c|c|}
\hline \multicolumn{3}{|c|}{ LIN - 110 - MAX - FM09 } \\
\hline \multicolumn{3}{|c|}{ Vazão de $\operatorname{Ar}[\mathrm{kg} / \mathrm{s}]$} \\
\hline \multicolumn{3}{|c|}{10,54} \\
\hline \multicolumn{3}{|c|}{ Temp Média Ar [K] } \\
\hline \multicolumn{3}{|c|}{302,3} \\
\hline \multicolumn{3}{|c|}{ Estratificação Média Temp [K] } \\
\hline \multicolumn{3}{|c|}{0,5} \\
\hline \multicolumn{3}{|c|}{ Temp Med $\mathrm{h}=0,1 / 0,6 / 1,1 \mathrm{~m}[\mathrm{~K}]$} \\
\hline 302,1 & 302,1 & 302,6 \\
\hline \multicolumn{3}{|c|}{ Estações c/ conforto $\mathrm{p} / 80 \%$} \\
\hline \multicolumn{3}{|c|}{$36 \%$} \\
\hline \multicolumn{3}{|c|}{ Estações c/ conforto $\mathrm{p} / 90 \%$} \\
\hline \multicolumn{3}{|c|}{$0 \%$} \\
\hline
\end{tabular}

\begin{tabular}{|c|c|c|}
\hline \multicolumn{3}{|c|}{ LIN - 110 - MAX - FM10 } \\
\hline \multicolumn{3}{|c|}{ Vazão de $\mathrm{Ar}[\mathrm{kg} / \mathrm{s}]$} \\
\hline \multicolumn{3}{|c|}{10,56} \\
\hline \multicolumn{3}{|c|}{ Temp Média Ar [K] } \\
\hline \multicolumn{3}{|c|}{302,1} \\
\hline \multicolumn{3}{|c|}{ Estratificação Média Temp [K] } \\
\hline \multicolumn{3}{|c|}{0,4} \\
\hline \multicolumn{3}{|c|}{ Temp Med $\mathrm{h}=0,1 / 0,6 / 1,1 \mathrm{~m}[\mathrm{~K}]$} \\
\hline 302,0 & 301,9 & 302,4 \\
\hline \multicolumn{3}{|c|}{ Estações c/ conforto p/ $80 \%$} \\
\hline \multicolumn{3}{|c|}{$53 \%$} \\
\hline \multicolumn{3}{|c|}{ Estações c/ conforto p/ 90\% } \\
\hline & $0 \%$ & \\
\hline
\end{tabular}

Simulações com layout em linha, janelas maxim-ar, velocidade máxima do vento de $2 \mathrm{~m} / \mathrm{s}$ e temperatura do ar externo de $300,5 \mathrm{~K}$, em ordem decrescente da carga térmica interna (cont.):

\begin{tabular}{|c|c|c|}
\hline \multicolumn{3}{|c|}{ LIN - 110 - MAX - FM11 } \\
\hline \multicolumn{3}{|c|}{10,58} \\
\hline \multicolumn{3}{|c|}{ Temp Média Ar [K] } \\
\hline \multicolumn{3}{|c|}{301,8} \\
\hline \multicolumn{3}{|c|}{ Estratificação Média Temp [K] } \\
\hline \multicolumn{3}{|c|}{0,4} \\
\hline \multicolumn{3}{|c|}{ Temp Med h=0,1/0,6/1,1m [K] } \\
\hline 301,7 & 301,6 & 302,1 \\
\hline \multicolumn{3}{|c|}{ Estações c/ conforto p/ $80 \%$} \\
\hline \multicolumn{3}{|c|}{$81 \%$} \\
\hline \multicolumn{3}{|c|}{ Estações c/ conforto p/90\% } \\
\hline & $0 \%$ & \\
\hline
\end{tabular}




\section{APÊNDICE B - SCRIPT PARA O CÁLCULO DAS SIMULAÇÕES}

Para realizar as análises numéricas foram utilizados scripts no programa ANSYS Fluent, chamados neste programa de journals. Estas linhas de comando realizam mudanças no processo de simulação sem a interferência do usuário, tornando o processo de simulação mais rápido. Como exemplo, segue abaixo o journal utilizado para a simulação do escritório com layout quadrado, janelas de correr vertical, partições com altura de $1,10 \mathrm{~m}$, velocidade máxima do vento ao longe de $2 \mathrm{~m} / \mathrm{s}$ e temperatura do ar externo de $299,0 \mathrm{~K}$.

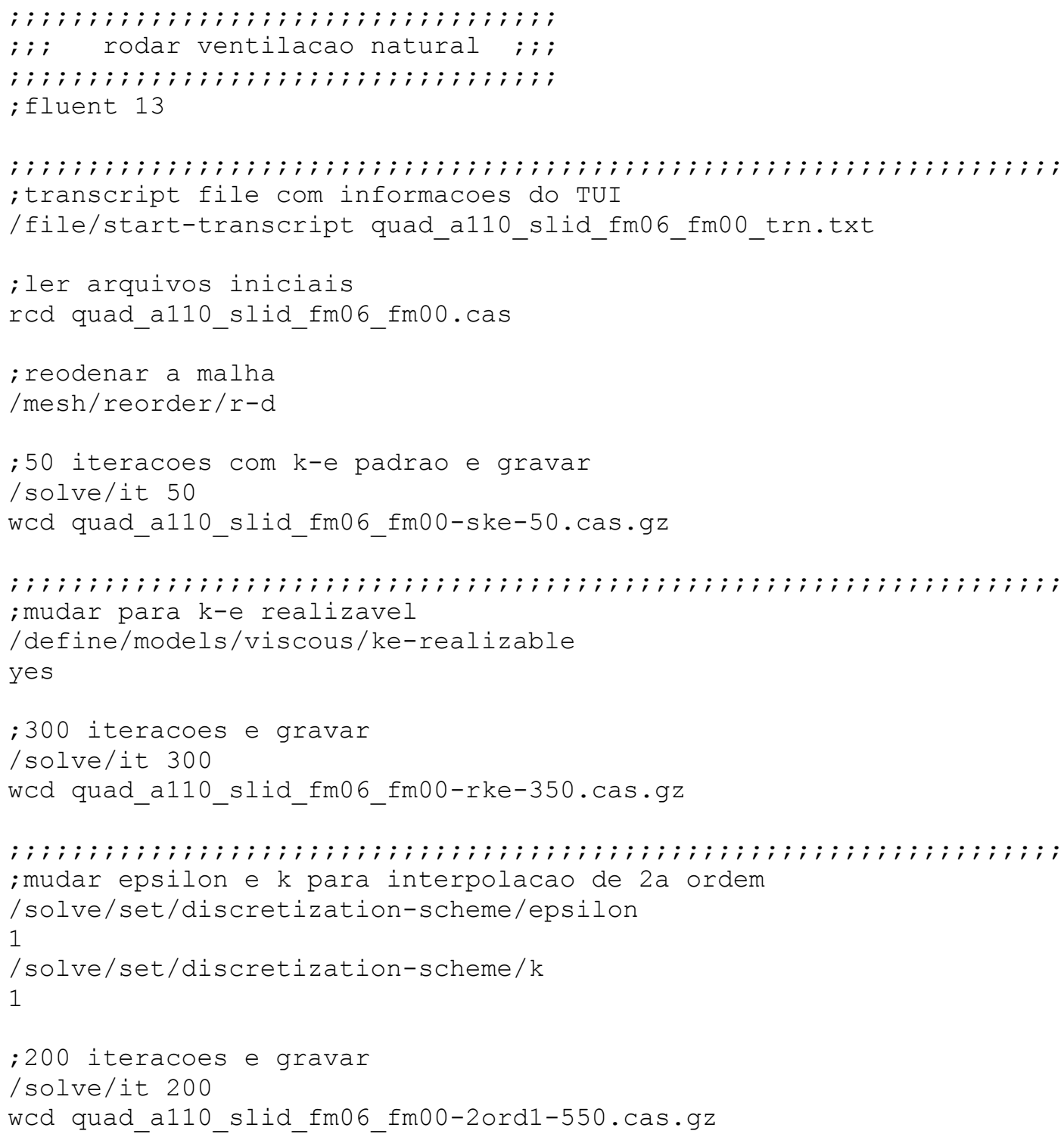




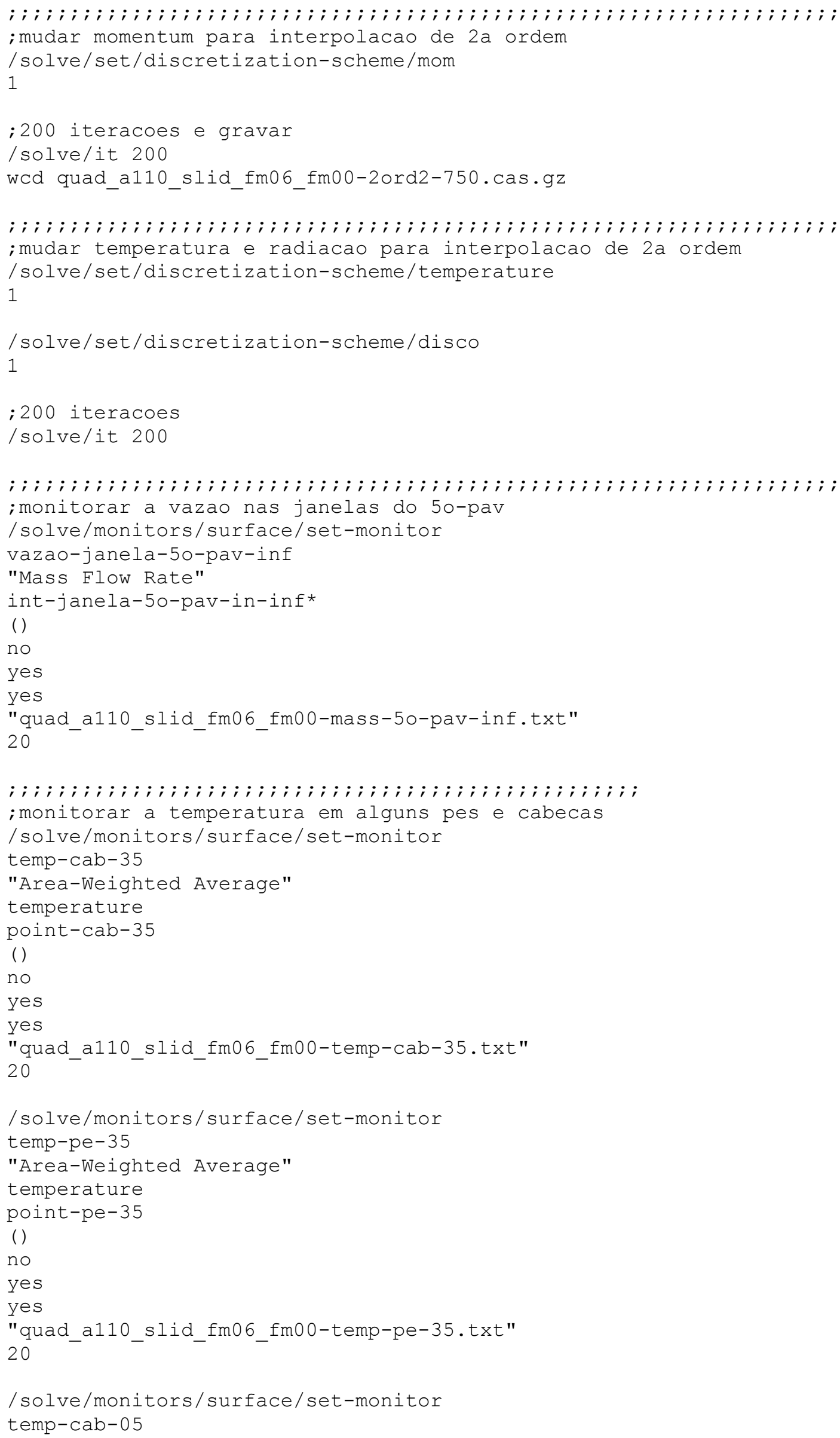


"Area-Weighted Average" temperature point-cab-0 5

()

no

yes

yes

"quad_a110_slid_fm06_fm00-temp-cab-05.txt" 20

/solve/monitors/surface/set-monitor

temp-pe-0 5

"Area-Weighted Average"

temperature

point-pe-0 5

( )

no

yes

yes

"quad_a110_slid_fm06_fm00-temp-pe-05.txt"

20

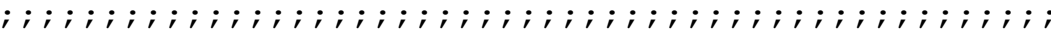

; monitorar a temperatura no ar

/solve/monitors/surface/set-monitor

temp-ar

"Area-Weighted Average"

temperature

point-ar

()

no

yes

yes

"quad_a110_slid_fm06_fm00-temp-ar.txt"

20

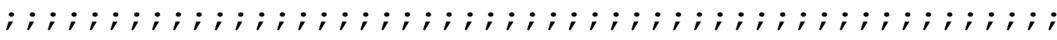

; monitorar a pressao na fachada

/solve/monitors/surface/set-monitor

pressao-fachada

"Area-Weighted Average"

pressure

w-e-fachada-frente

( )

no

yes

yes

"quad_a110_slid_fm06_fm00-pressao-fachada.txt"

20

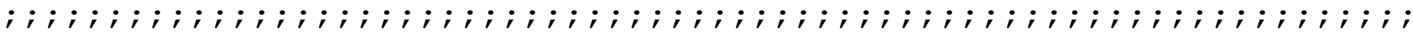
; Gravar arquivo

wcd quad_a110_slid_fm06_fm00-2ord-950.cas.gz

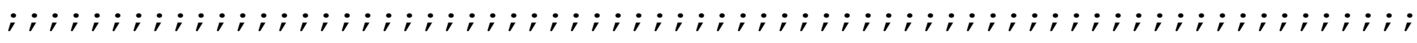
; iteracoes restantes e arquivos intermediarios

/solve/it 550

wd quad_a110_slid_fm06_fm00-2ord-temp-1500.dat.gz

/solve/it $50 \overline{0}$

wd quad_a110_slid_fm06 fm00-2ord-temp-2000.dat.gz

/ solve/it $50 \overline{0}$ 
wd quad_a110_slid_fm06_fm00-2ord-temp-2500.dat.gz

/ solve/īt $50 \overline{0}$

wd quad a110 slid fm06 fm00-2ord-temp-3000.dat.gz

/ solve/it $50 \overline{0}$

wd quad_a110_slid_fm06_fm00-2ord-temp-3500.dat.gz

/solve/it $50 \overline{0}$

wcd quad_a110_slid_fm06_fm00-2ord-temp-4000.cas.gz

; ; ; ; ; ; ; ; ; ; ; ; ; ; ; ; ; ; ; ; ; ; ; ; ; ; ; ; ; ; ; ; ; ; ; ; ; ; ; ; ; ; ; ; ; ; ; ; ;

; exportar temperaturas do ar

/report/surface-integrals

area-weighted-avg

ponto*

()

temperature

yes

"medida-temp-ar_quad_a110_slid_fm06_fm00.txt"

; mostrar o tempo de processamento

/parallel/timer/usage

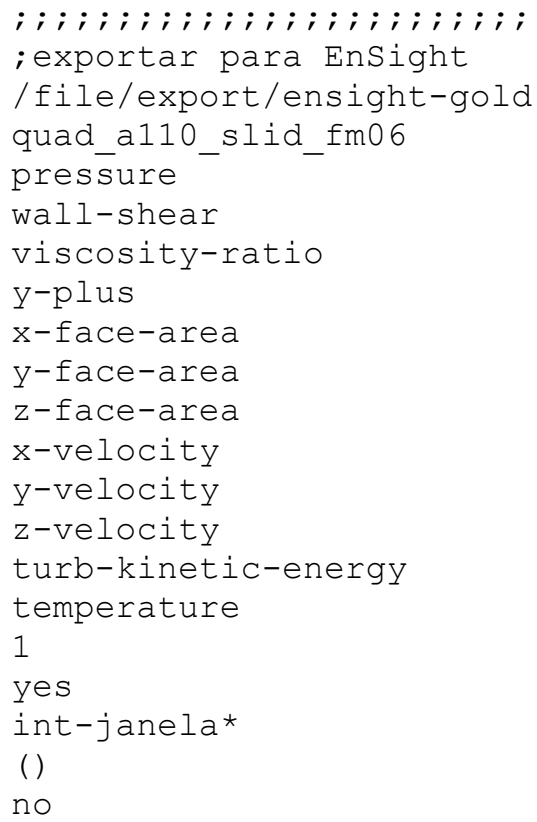

